\title{
IDENTITY CONSTRUCTION ONLINE: IDENTITIES AND IDEOLOGIES IN READER COMMENTS IN ONLINE NEWS FORA
}

KAI LIU

\author{
A thesis \\ submitted to Victoria University of Wellington \\ in fulfilment of the requirements for the degree of \\ Doctor of Philosophy
}

Victoria University of Wellington

Te Herenga Waka

2022 


\begin{abstract}
Kai Liu
Identity construction online: Identities and ideologies in reader comments in news fora, 2022
\end{abstract}

Supervisors:

Dr. Corinne Seals \& Professor Meredith Marra 
To Mum and Dad, with lots of love and gratitude 


\section{Abstract}

\section{IDENTITY CONSTRUCTION ONLINE: IDENTITIES AND IDEOLOGIES IN READER COMMENTS IN ONLINE NEWS FORA

\author{
Kai Liu
}

\section{Thesis Supervisors: Dr. Corinne Seals, Prof. Meredith Marra}

The relationship between language and identity remains a core topic of interest in applied (socio) linguistics. The investigation of identity in the online context, however, remains underexplored despite of a mushrooming of participation by users. Adopting a social constructionist perspective which views identities as dynamic and multiple, this thesis investigates how identities are discursively co-constructed in interaction, with close attention paid to the wider sociocultural Discourses and ideologies that impact on these negotiations. I focus on interactions that take place in online news comment boards, with the goal of identifying how commenters discursively construct and negotiate their identities through their comments, addressing the overarching research question: "How is identity constructed and negotiated through comments discourse in an online communication setting?"

The dataset includes approximately 3,000 comments collected from the reader sections of news articles published on three different online news websites: Stuff in New Zealand, and The Guardian and Mail Online in the UK. The comments are responses to 40 articles, covering topics focusing on same-sex marriage (an explicitly ideologically-loaded topic) and travel (a topic where ideologies are less overt). All comments were collected within a one-week period following the respective news article's appearance. This data set allows me to capture the most immediate 
responses from readers and provides naturally-occurring interactional data to investigate identity construction.

In line with the social constructionist stance I view identity as emergent and negotiated within discourse, as a discursive and socially situated phenomenon that is interactionally achieved with other interactants. Through in-depth qualitative discourse analysis supported by thematic coding, the findings demonstrate the interrelationship between commenters' ideologies and identity construction in online interaction. Interactional Sociolinguistics (IS) with its principled inclusion of both micro and macro considerations is applied to ensure rigour in the discourse analysis and I employ positionality (Bucholtz \& Hall, 2005) and Intertextuality (Bakhtin, 1981) to productively narrow the analytic focus.

The analysis indicates that salient identities for commenters hinge on constructs of nationality (which in turn interacts with ethnicity) and gender (and relatedly sexuality). This resonates with the concept of intersectionality (Crenshaw, 1989), at the core of which is the recognition that macro aspects of identity (e.g. race, sexual orientation, etc.) are overlap and interact with each other in multiple ways. In addition, the findings suggest that these identities are often 'triggered' by the positioning of self and other, including the present interlocutor(s) and other characters involved in the interaction, as represented by specific ideologies. In reaching these conclusions I highlight the contextual intricacies of the asynchronous, text-based online environment where traditional contextualisation cues such as gesture, intonation, eye contact, etc are not available. In their stead I demonstrate the omnipresence of ideologies through the lens of the 'ideal reader' (Fairclough, 2001). The study thereby draws attention to the affordances of investigating ideologies when exploring identity and emphasises the need for a deeper reflection on the connections between language, identity, and ideology in the online context. 


\section{Acknowledgments}

Over the course of past few years, I have been through a devastating intimate relationship and have lost someone I once loved so much. This causes both physical and mental problems, and as a result, I've been suffering from depression throughout my PhD candidature. I submerged myself in this study at this period of high intensity pressure. Indeed, I have come a long way and endured great hardships to complete this thesis. As much as it may feel like a long and lonely road, a thesis is not a solitary endeavour. I hereby take this opportunity to thank those people who have helped me through this incredibly bumpy but fulfilling journey.

First and foremost, I am greatly indebted to my wonderful supervisors, Dr. Corinne Seals and Prof. Meredith Marra. The completion of this thesis owes much to their wisdom and firm assurance that it remained a doable as well as a valuable project when I feel lost. Thanks to Corinne, for the unceasing support, guidance, and inspiration over the past years. Thanks for your keen eye on matters big and small, your always-direct counsel helped me solve various academic inquiries. Thanks to Meredith, for saving me from the predicament when I needed most, and for your constant feedback. Thanks for making time when there was essentially none, I truly appreciate the countless hours you have dedicated to shaping my analyses and strengthening my writing. I have enjoyed my many (weekly) meetings and discussion with you. Meredith is such an asset as a supervisor, not only in what she has achieved in terms of academic achievement, but also in her unwavering commitment to supporting students and making time for everyone despite her many roles and responsibilities. Thank you both for the passionate debates, intellectual challenges, and perfectly timed words of encouragement when I was at the lowest of times.

A special thanks to Prof. Janet Holmes, whose feedback on some chapters has been extremely valuable and somehow made me feel secured and confident in terms of the writing. This thesis would not be what it is without the unwavering support, encouragement, and advice from them 
along the way. You are all academic inspirations. I would also like to thank Erica Schouten (from VUW Students' Association), for her generous help, support and caring in my most difficult situation.

I would also like to express my deepest appreciation to my parents, siblings, and friends in China for their love and encouragement. The various forms of support you have provided have been greatly appreciated. To my parents, whose faith in the power of knowledge/education inspired me to pursue this path. To Minhui, for providing much needed help with formatting. Thanks to Emma and Jonathan for your emotional support over the years.

A doctorate, while enriching, is said to be a practice of isolation. This might be true, but one of the best parts of this thesis journey has been meeting new, lifelong friends. I thank my officemates (VZ 401) and friends at LALS for accompanying me through the ups and downs along the way. Special mention to Lingli and Dr. Paweena Jaruteerapan, whose support, friendship and understanding have been invaluable.

Lastly, I would like to thank the entire staff of the School of Linguistics and Applied Language Studies for their help. I highly appreciate the generous help and support from Meredith Marra (as the Head of School, 2016-2020). A project of this magnitude is impossible without its finical support. My thanks therefore go to Victoria University of Wellington for the three years' Doctoral Scholarship. 


\section{Table of Contents}

Chapter 1 Introduction ............................................................................................1

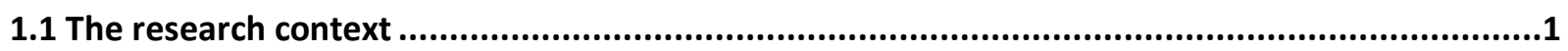

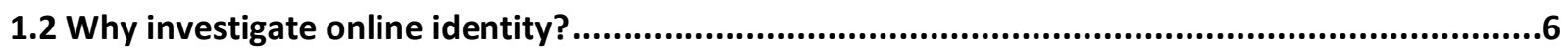

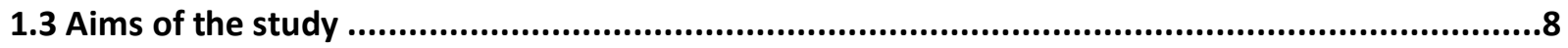

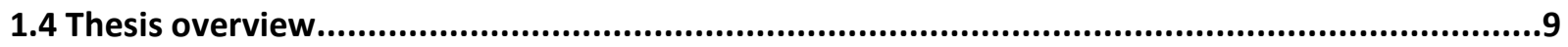

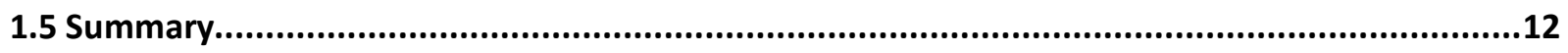

Chapter 2 Theoretical background ................................................................ 13

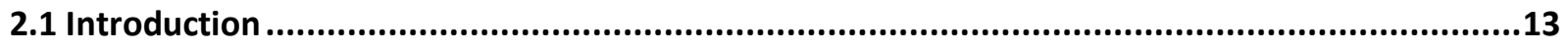

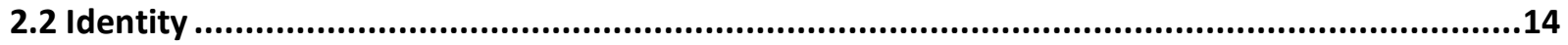

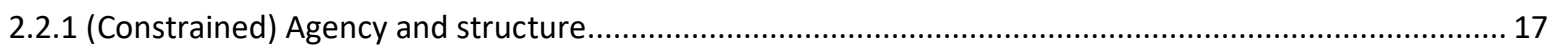

2.2.2 Identity as a negotiation: Social constructionism and poststructuralism .............................................. 20



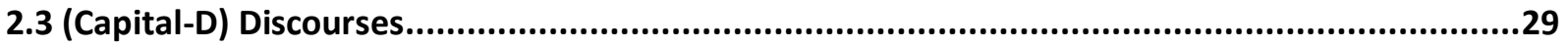

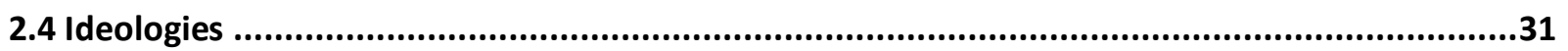

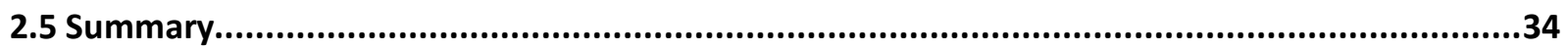

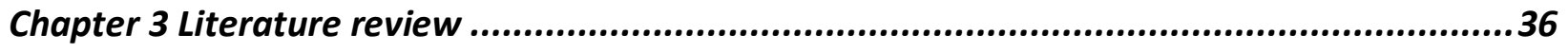

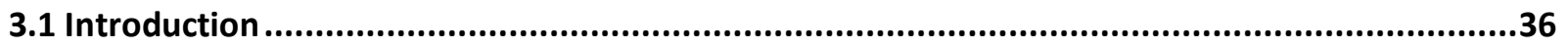

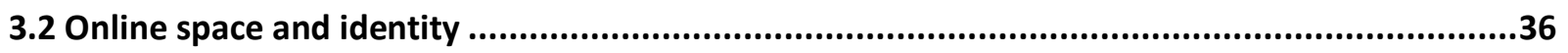

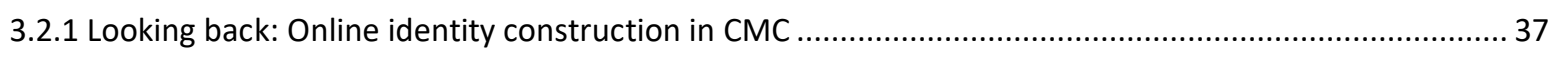

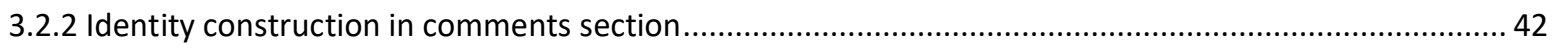

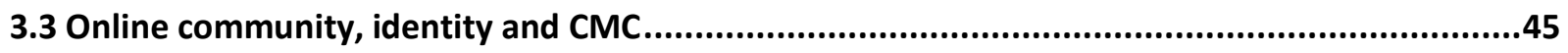

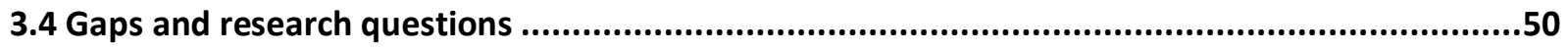

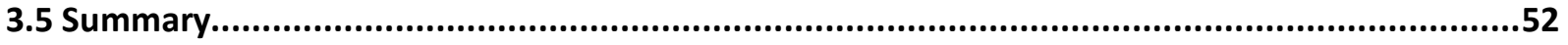

Chapter 4 Methodology ...............................................................................5

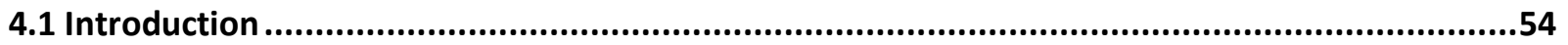




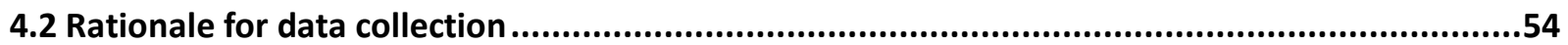

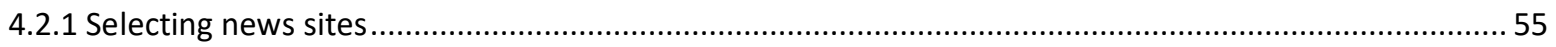

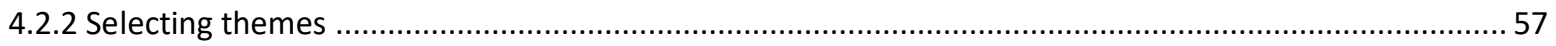

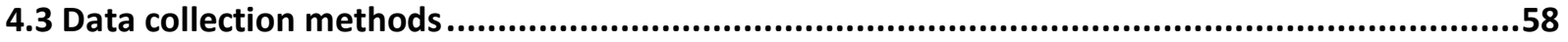

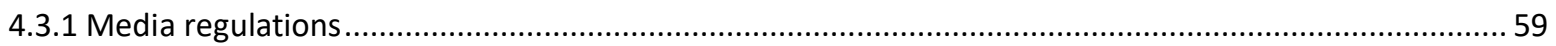

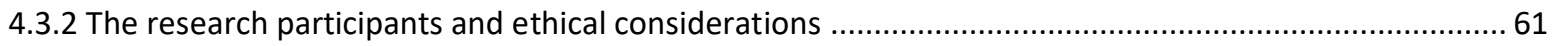

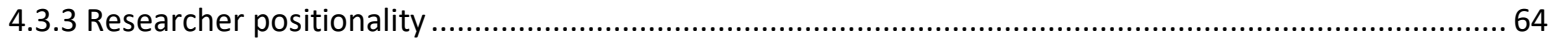

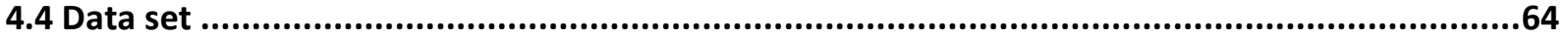

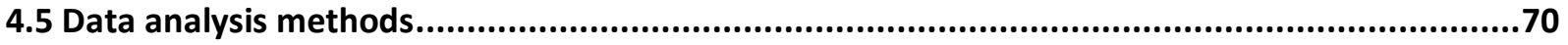

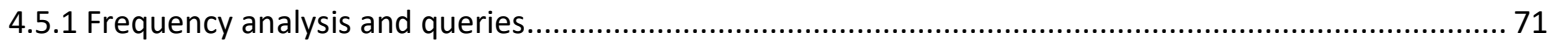

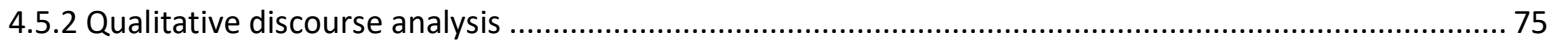

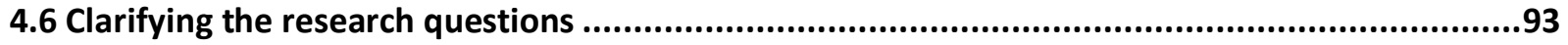

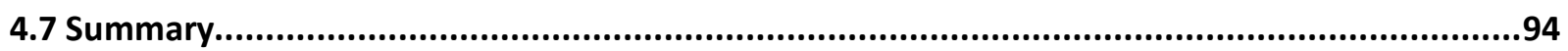

Chapter 5 Analysis of theme 1: Same-sex marriage ................................................95

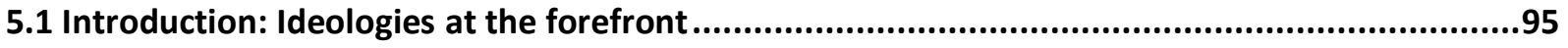

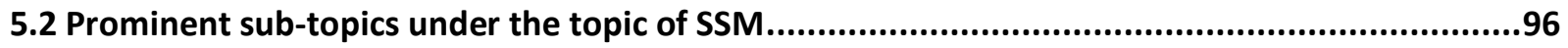

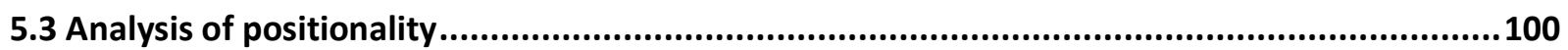

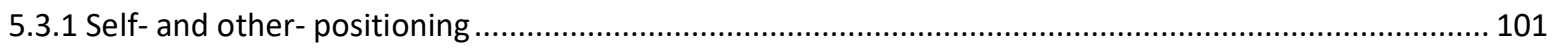

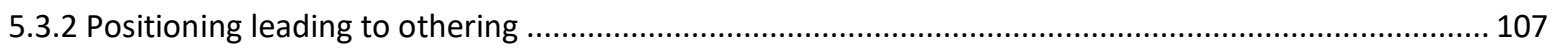

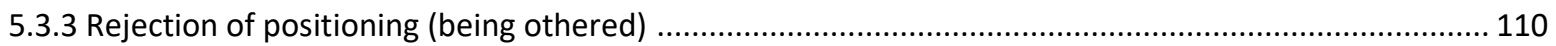

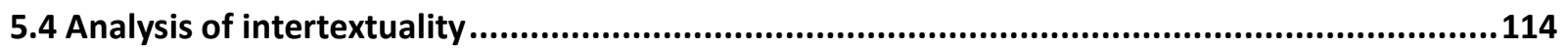

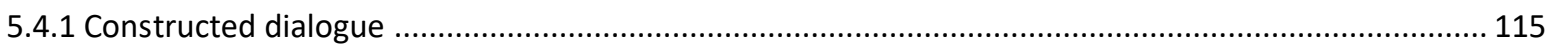

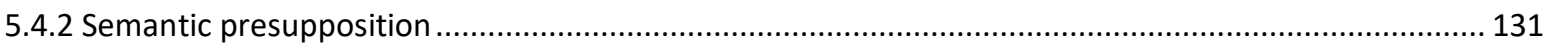

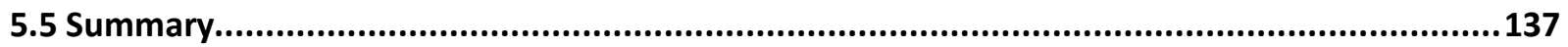

Chapter 6 Analysis of theme 2: Travel ........................................................... 140

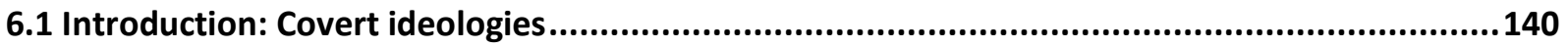

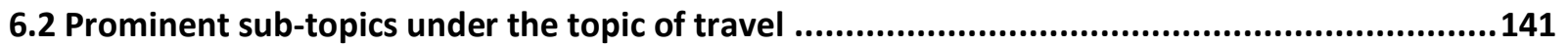

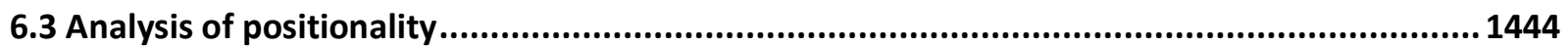

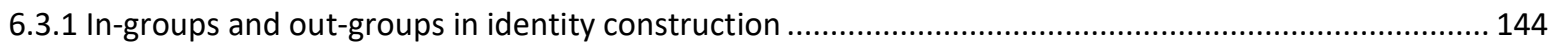




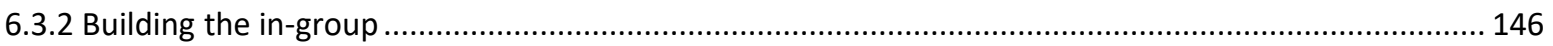

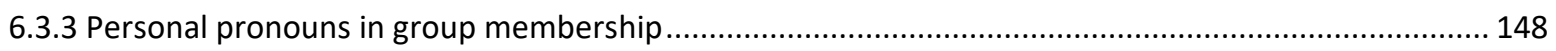

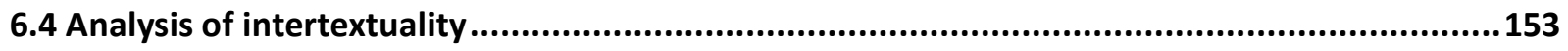

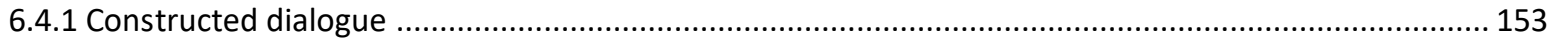

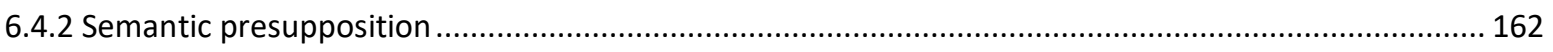

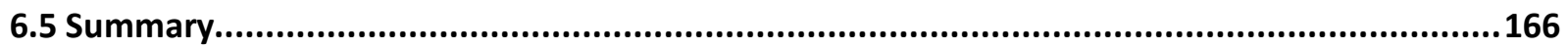

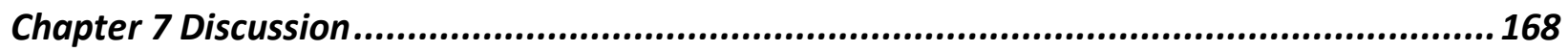

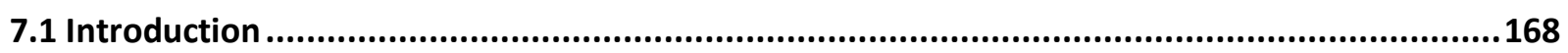

7.2 Indexicality in investigating online identity ......................................................................171

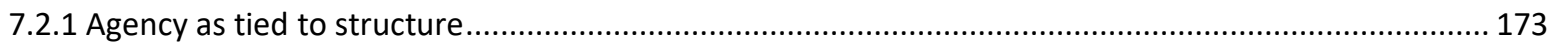

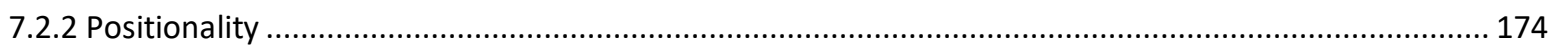

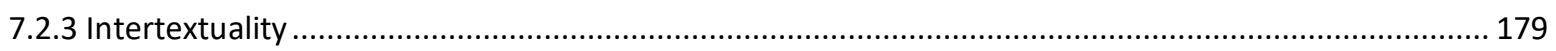

7.3 How can positionality and intertextuality inform each other? ............................................182

7.4 The ideal reader, ideologies, and online identity construction .........................................187

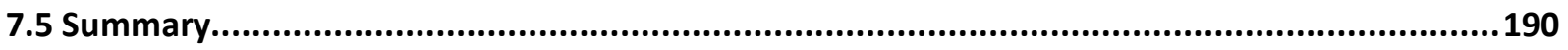

Chapter 8 Conclusion ............................................................................. 191

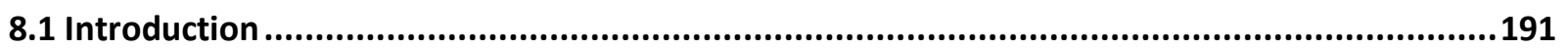

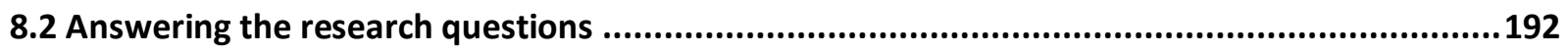

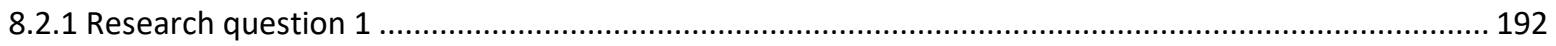

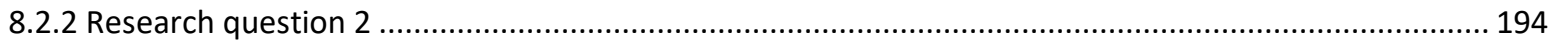

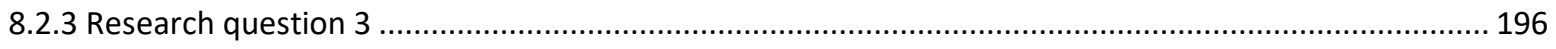

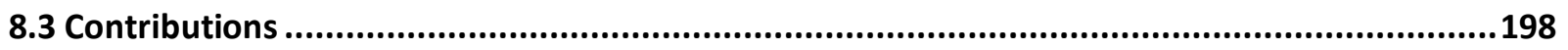

8.3.1 Methodological contributions (and overcoming challenges) ........................................................ 198

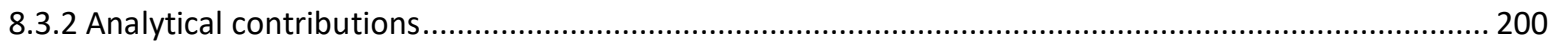

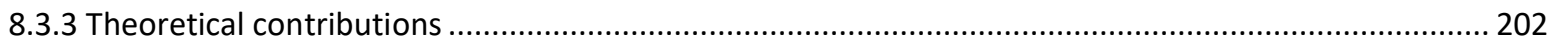

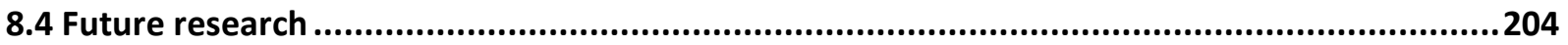

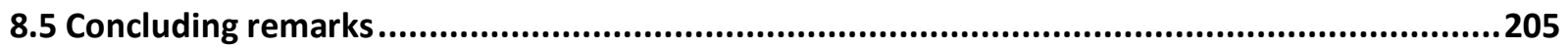

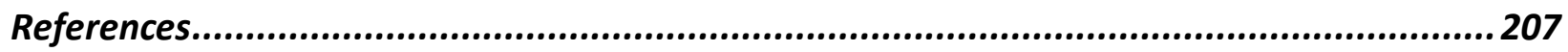




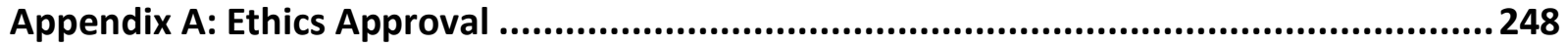

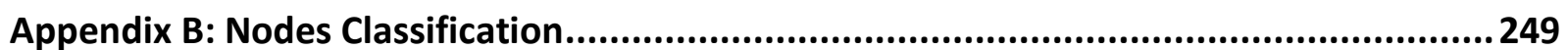

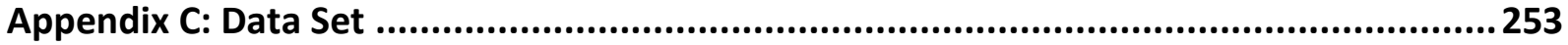




\section{List of Tables}

Table 4.1 Information about Stuff news source ...........................................................66

Table 4.2 Information about The Guardian news source ................................................67

Table 4.3 Information about Mail Online news source .....................................................68

Table 5.1 Number of Comments on each sub-topic (in the parent nodes) coded in three news

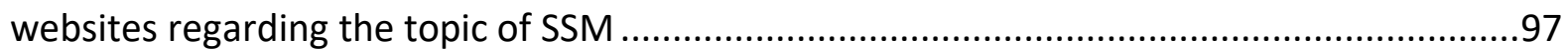

Table 5.2 Percentage of the top four sub-topics discussed in three news websites regarding the

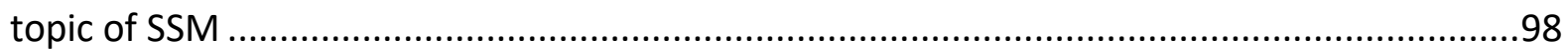

Table 5.3 Distribution of quotation in three news websites on the topic of SSM ...............120 Table 6.1 Number of comments on each sub-topic (in the parent nodes) coded in three news websites regarding the topic of Travel .......................................................................142 Table 6.2 Percentage of the top five sub-topics discussed in three news websites regarding the topic of Travel 142

Table 6.3 Distribution of quotation in three news websites on the topic of Travel .155 


\section{List of Figures}

Figure 4.1 Examples of nodes classification and integration (topic of same-sex marriage) ...73

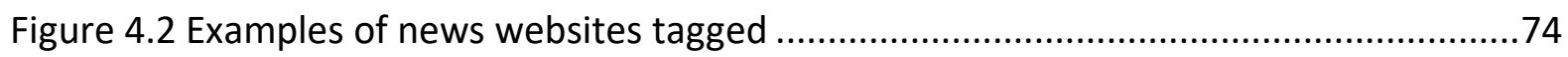

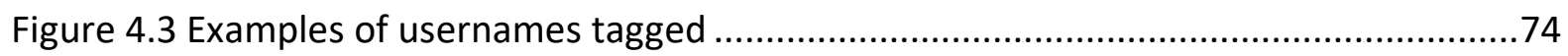

Figure 5.1 Quotations used by participants in three news websites regarding the topic of SSM .119

Figure 6.1 Quotations used by participants in three news websites regarding the topic of Travel .154 


\section{Chapter 1}

\section{Introduction}

\subsection{The research context}

The way we communicate and engage with one another has changed tremendously as a result of technological advancements. New forms of social involvement from online users have emerged thanks to the escalation of more affordable communication devices, social media and online connectivity (Darvin, 2016). Among these various forms of participation, online commenting offers an opportunity for people to communicate with others (Domingo et al., 2008) within and across communities. In particular, comment sections attached to news articles have thrived in the past decade or two (Reich, 2011; Singer, 2009) as a chance for readers to be active contributes to the interpretation of news and information.

My own experience of participating in online commenting (interaction) made me realise that in this online context (i.e. a relatively anonymous environment), people are provided with a greater possibility to have multiple identities. In contrast to face-to-face communication, online commenting often takes place between people who are not familiar with each other; they are connected through the Internet partly because of the same interest, that is, sharing and exchanging opinions and information with other online users. This anonymity allows online users to present themselves differently by enacting various types of identities during interaction.

Furthermore, the regular contextualisation cues (Gumperz, 1982) which play a part in interaction are mostly absent in this written online context (see Chapters 5, 6 and 7). Therefore, how online users create new forms of language use and contextualisation cues to help them better construct their identities online, deserves more attention from linguistic researchers and discourse analysts, as it places emphasis on the use of written language in the online context (see discussion later in this section). 
It is safe to say that participating in online commenting is now a ubiquitous phenomenon in the Web 2.0 world. In traditional mass media, before the online comment function, free public expression of opinion was, in the main, something of myth: "the only ways to exercise this right were through letters to the editor or phone calls to radio and television, although these were usually pre-filtered by the corresponding media companies" (Rueda, 2012, p. 91). In this respect, communication in traditional mass media differs from others kinds of communication in the sense that it is largely receptive due to spatial and temporal disjunctions, and sometimes appropriately labelled one-sided (Ellison \& Vitak, 2015). In other words, "recipients of media messages are not so much partners in a reciprocal process of communicative exchange but rather participants in a structured process of symbolic transmission" (Thompson, 1995, p. 25). As a result, members of the audience often have no chance to provide feedback directly to the media outlet, or, to express opposing views. Yet this form of one-way communication has come to be challenged, initially through forums such as comment sections, and latterly through social networking sites. Comment sections now bring people together in a way that defies space, time and physicality (Ellison \& Vitak, 2015).

In a well-known 1921 essay marking the centenary of the Manchester Guardian, the editor, C. P. Scott, argued that the "primary office" of a newspaper is accurate news reporting: in his own words, "comment is free, but facts are sacred". Given that newspapers have the power to strengthen certain representations of reality and to disregard others, the emergence of the online comments function means news is no longer a "product" with a one-size fits all mentality, but a "process" involving a collaboration with readers/viewers (Ellison \& Vitak, 2015). Comment sections provide readers from diverse walks of life with access to a forum of their own. In this space, they can raise arguments and express opinions, opening up the opportunity for interactive engagement between readers with a wider range of opinions than features in news articles themselves (Ruiz et al., 2011). Investigating online readers' comments thus allows the previously un-highlighted views of minority groups and individuals in news commentary to be heard and recognised, to some extent (Santana, 2011), which "makes the ordinary visible to others" (Oulasvirta et al., 2010, p. 238). 
Focusing on the comments section of online news websites, in this thesis I will be investigating the navigation of identity through a discourse analysis of commenters' online interaction. This investigation thus contributes to the existing body of literature on language and identity as well as to CMC studies.

While comment sections are now common among online news websites, newspapers were once cautious to include them (Wallsten \& Tarsi, 2016). In 1988, as one of the first newspapers to provide an online commenting function, The Rocky Mountain News was regarded as pioneering in the history of newspapers (Chen \& Pain, 2017). Due to the increasing popularity of the Internet as well as the fast development of web technologies, online commenting was welcomed by readers. At the end of $21^{\text {st }}$ century, comments sections were regularly added to online news websites. According to Chen and Pain (2017), the number of popular online news sites featuring comments sections increased by 42\% within two years (between 2007 and 2008). Yet, because of the anonymity provided by those online news sites, countless commenters behaved inappropriately and harassed other interactants, including ad-hominem attacks, profanity, and other abusive behaviors (e.g. engaging in hate speech) (Coe et al., 2014). Consequently, in 2010, some online publications, such as The American Journalism Review, said that anonymous comments sections should be removed. Following this, other online news websites (e.g. Reuters) either made comments under a regulatory purview (also known as gated comments sections) or alternatively turned off the commenting function. Before posting a comment in gated comments sections, users must provide the news sites with certain identifying details. Most online news websites currently ask participants to provide personal data, for example a confirmed IP address or at least a username, before posting. In so doing, all comments fall under the moderation processes of the specific website. The target online news websites in this study (i.e. Stuff, The Guardian and Mail Online) all offer gated comments; Users can log in and post comments only under a username that identifies (parts of) the user's information. By saying identifying the participants, it does not mean that participants' demographic information such as age, gender, location and so on will be identified. It only means that the username presents one specific participant who joined online commenting. For example, if a participant posts a comment under 
the username 'ThisGuy' (this is an actual username from the data), it is presumed that this commenter is a male participant. However, considering the anonymity of online commenting, this might not be the case; we need to recognise that usernames do not necessarily accurately reflect who the users are, but under hegemonic norms (in this case guy indexing male), it is what many readers would assume. For ease of explanation, I will use 'he' to identify this participant in analysis. The personal information provided by the commenter will not be shown and only the comments will be used for analysis in this study. ${ }^{1}$ Being a relatively young medium of online interaction, as compared to newspapers, TV or radio, interactional norms in online news comment sections are still emerging. Individuals and groups may rely on specific discursive strategies to present themselves, realised by constructing and negotiating their identities and coconstructing interactional norms. All of these factors thus make comment sections an intriguing site of research for language use in identity construction.

Darvin (2016, p. 523) argues that technological advances have had far-reaching impacts on our social lives, and this is particularly true when it comes to language use and how we interpret our identities in the cyberworld. The popularity of social media encourages varied user-generated content through different forms of computer-mediated communication (CMC), which contributes to a better understanding of how individuals discursively construct and negotiate identities online. According to Thurlow et al. (2004, p. 83), the notion of CMC broadly refers to "communication that takes place between human beings via the instrumentality of computers." Computer-mediated discourse analysis (CMDA) is a term used to describe linguistic study that focuses on the CMC context (Herring, 2004). Rather than looking at the actual behaviour of online users and the communicative purposes behind these behaviours, previous CMC research placed emphasis on the classification of online interactional types, which gave priority to the technical provisions of these spaces (See Locher \& Mondada, 2014, for a full account of what linguistics have studied in the field of "new media"). Crystal (2001) observed that studies had begun to focus on understanding CMC data as a range of new settings for language activity rather than as a "new" and different (kind of) language. Similarly some twenty years ago, Herring

\footnotetext{
${ }^{1}$ The comment policy of each news website will be explained in detail in Chapter 4 (see section 4.3.1).
} 
(2001) observed that "most CMC currently in use is text-based, that is, messages are typed on a computer keyboard and read as text on a computer screen" (p. 612). While Herring's understanding of message and Crystal's claims, are probably still true, the introduction and development of audio-visual services such as YouTube in the 2000's, and Instagram and Snapchat in the 2010's, to just name a few, has broadened the spectrum of CMC. In addition, recent technical development has allowed users to embed videos, GIFs, emoticons, emojis and similar into written interactions, further enriching formerly text-only interactions. This discussion suggests that CMC is not a homogenous form of communication. Rather, it has developed along with the diversification of technology and communication channels, from originally only Internet Relay Chat (IRC) to email, blogs, web-forums and many more platforms today. (Readers are referred to e.g. Androutsopoulos (2006), Herring (2001, 2005, 2013) who offer systemic overviews of $\mathrm{CMC}$ research). Through networked telecommunication systems, $\mathrm{CMC}$ has the ability to create, exchange and gather information, including anything that conveys a message. These messages in turn contribute to our construction of identity online.

As a type of $\mathrm{CMC}$, interactions that take place in comment sections remains as before, i.e. they are "constituted primarily_in most cases, exclusively—by visually presented language" (Herring, 2001, p. 612). In other words, unlike face-to-face interactions, interlocutors are not physically visible to each other; physical features such as age, gender, and way of dressing, which help to shape identity, are absent in this particular online space. Interactions mainly take place through typed text. In contrast to spoken discourse, identity investigation in comment sections largely relies on the commenters' use of written language, which simultaneously allows them in this space to actively construct their preferred identities by employing diverse linguistic strategies and a chance to edit and deliberately craft their words which then become a lasting record (Redeker, 1984; Sindoni, 2013). By saying that, I am not ignoring other factors (e.g. emoticons, punctuations, etc., which occur in this data set) that contribute to one's identity formation. Rather, I intend to stress the importance of paying close attention to language use in written communication, especially when contextualisation cues such as intonation, body gesture, eye contact and so forth are missing in this technical constrained (i.e. text-based mainly) online 
space. Online comments as a new feature of written communication offer users various affordances, which to date remain underexplored in terms of language and identity.

\subsection{Why investigate online identity?}

In lay terms, identity is often conceived of as singular and unchanging, lasting a lifetime with only relatively minor changes (Marwick, 2013). This understanding of identity is akin to Sandy Stone's description of the individual as a "body unit grounded in a self" (1996, p. 85), describing the self as a distinctive and constant character. This point of view, however, has been challenged by many scholars as it contrasts with the experience of how we construct and negotiate our identities (different theories of identity will be further discussed in Chapter 2). The idea that identity is not a fixed entity, but rather an ongoing construction (e.g. Bamberg et al., 2011; Bucholtz \& Hall, 2005; Darvin \& Norton, 2015; Holmes \& Marra, 2017) is appealing to me as an identity researcher in the field of linguistics. Every individual is an active contributor to the complex process of identity construction, for both themselves and others with whom they interact. An aspect of this negotiation includes (first) physical impressions which serve as identity labels that might lead to specific interaction patterns, for example, questioning of expertise in professional contexts (e.g. women as builders in the workplace of building sites; cf. Baxter \& Wallace, 2009). To observe identity construction and negotiation in an environment without those initial labels, namely online comment sections, represents a fascinating opportunity where interactants on the one hand rely on written language alone but where they are free on the other hand to choose more freely than in their real life encounters.

According to the sociologist Erving Goffman (1990), individuals usually present themselves differentially depending on the context (which circumstances they are faced with) and the audience (who they are engaging with) (cited in Marwick, 2013, p. 356). Sitting within this line of thinking, when referring to the notion of online identity, De Ruyter and Conroy (2002) accordingly applied this notion to the CMC context and defined it as "the dynamic configuration of the defining characteristics of a person in online space that makes the person feel they have their own character and are different from other people" (p. 510). Based on this definition, De 
Ruyter and Conroy (2002) suggest that identity does not include all parts of a person's personality, but only those that they (or others) perceive as the best representation of them (see e.g. Flanagan, 1991). Satchell et al., (2006) argue that investigating the online identity is crucial for us to understand how individuals engage with one another in online spaces. Given the context-dependent nature of identity, some scholars (e.g. Calvert, 1999; Turkle, 1997) claim that people's online identity can even displace and deny the "real world" offline. As more and more identity theorists view identity as flexible and multiple, the dominant position is that identity is discursively (co)constructed between interlocutors and continuously developed through social interactions (e.g. Butler, 1990; Giddens, 1991; Darvin \& Nortin, 2015; De Fina, 2011; Holmes et al., 2011; Holmes \& Stubbe, 2015; Norton, 2013). The concept of 'a multiple self' (e.g. Lester, 2010; McConnell, 2011; Pears, 1985) explains that people's identity performance varies depending on context: "multiplicity is an inherent property of identity rather than somehow dishonest or false" (Baym, 2010; cited in Marwick, p. 356).

Due to the booming popularity of Web 2.0 technologies in recent decades, individuals are able to present themselves and construct their identities online without meeting each other. This corresponds to the foundational assumption that people can present multiple identities (or personalities) with and without sharing those identity indicators, that is, macro facets of identity such as gender and class (among many other categories) are social constructs (Turkle, 2011). From this perspective, the way individuals perceive their identities may be substantially challenged by the developments of new technologies, especially about online identity and its construction, since the text-based online context allows people to make full use of language devoid of certain visual social cues as a medium to express themselves to others. Following this, some researchers (e.g. Marwick, 2013) have posited that this "disembodied" communication has the potential to eliminate discrimination against people based on social categories (e.g. their gender, race, sexuality, etc.) because users can choose what to reveal, what to hide and when to lie during online interaction. It is plausible that this is a way of reducing the effects of discrimination in interaction. However, I recognise that language provides online users with opportunities to actively construct preferred identities. While discrimination is one kind of 
discourse, commenters are inevitably exposed to new norms, various ideologies and Discourses ${ }^{2}$ in the interaction, which impact on their negotiations of online identity. The term 'online identity' implies that differences exist between how people present themselves online and offline (cf. Georgalou, 2016). As an analyst, we should be aware of those factors (e.g. different platforms, technology constraints) that enable different types of self-presentation and further contribute to influencing people's identity construction and negotiations in online contexts, which become something to be "worked on" (Perkel, 2008).

Additionally, to the best of my knowledge, although identity has been the focus within many research fields, explorations situated in online interaction settings still remain scarce, particularly those focusing on how people discursively construct and negotiate their identities through interaction in a particular online space (but see for example, Blitvich, 2018, Santana, 2014); where studies have been conducted, most focus on social networking sites in a Western context (these studies will be mentioned in Chapter 3; see section 3.2.1). This phenomenon not only triggers my interest in exploring identity construction online, but also draws my attention to this particular online space where identity construction relies more on the use of written discursive strategies rather than other audio-visual features (e.g. profile pictures, videos, etc.).

\subsection{Aims of the study}

The present study has three primary aims. Given it mainly focuses on the broad context of online commenting, my first, and main, aim of the present study is to investigate how commenters discursively construct and negotiate their identities in interaction in a text-based online communication setting. In order to achieve this objective, my second aim involves exploring how ideologies and Discourses manifested in the comments impact on commenters' identity construction and negotiation in terms of different topics and news websites. Finally, as the present study focuses on positionality (Bucholtz and Hall, 2005) and intertextuality (Bakhtin,

\footnotetext{
2 In this thesis, I follow the orthographic distinction made by James Paul Gee $(1990,2015)$ whereby capital 'D' Discourses are sociocultural, institutionalised ways of understanding things (e.g. political Discourse or third wave feminist Discourse), while discourse with a small ' $d$ ' is everyday (often mundane) talk.
} 
1981) to access commenters' ideologies and identity construction, the third aim is to evaluate how these two analytical foci inform each other and contribute to the examination of online identity.

This study thus contributes to the existing body of research on the construction of identity and interaction by exploring a text-based online commenting context, which has not been extensively examined before, through the lens of discourse analysis. This investigation is exploratory in nature and I begin by establishing an overarching research question before examining the complex process of identity construction and negotiation that will be addressed as the thesis continues. The thesis aims to explore the following overarching research question: How is identity constructed and negotiated through comments discourse in an online communication setting? This larger goal comprises three-sub questions, which are motivated by discussions around the theoretical approach and literature; these research sub-questions are introduced in Section 4.6.

\subsection{Thesis overview}

This thesis is divided into eight chapters, with the first providing a rationale and overview of the study's main aims. Chapter 2 outlines the theoretical frameworks adopted in this study. It begins with a discussion which foregrounds identity as fluid, dynamic and negotiated within interactions. I then provide a brief review of pertinent identity-focused literature with an eye towards how a constructionist understanding of identity can be applied in my analysis, and in particular the notion of discursive agency as foundational to the formulation of identity. Specifically, I examine discursive social constructionist approaches to identity as operationalised through Interactional Sociolinguistics methods. The approaches, which overlap significantly, scaffold my own research, emphasising the interconnected relationship between the individual and the social, and the emergent properties of identity. I follow this with a discussion of sociolinguistic concepts which have strong analytical purchase in my study, namely, intersubjectivity (e.g. Bucholtz \& Hall, 2005) and indexicality (Eckert, 2008; Ochs, 1992; Silverstein, 2003). Through an exploration of these concepts, I consider how identity 
construction can be accessed in interactional data. This discussion indicates the close relationship between ideological social discourses (i.e. Capital-D Discourses, see Gee (2015)) and the distribution of social power, both of which can impact on the enactment of online identities in practice.

Having established the rationale for conducting this study and providing theoretical background that illuminates how I treat and access the key concept of identity, Chapter 3 offers a review of relevant literature. It provides an overview of how identity has been explored in online spaces and the comment sections of news articles in particular. This points to the research gaps that the present study aims to fulfill. At the end of this chapter, I offer more detailed research questions to justify the methodology of the study.

Chapter 4 operationalises the aims of the study by providing a detailed account of the methodology employed. This chapter first briefly states the reasons for choosing the target online news websites and topics. Then, it describes the data collection methods (including ethical concerns) and provides a detailed description of the data sources. This is followed by the methods of data analysis, in which I discuss the value of using Interactional Sociolinguistic as a methodological framework to examine identity in a text-based online commenting context. The discourse analytical foci (i.e. positionality and intertextuality) utilised in this study are elucidated, aiming to explain how these two analytical concepts contribute to the data analysis. Finally, I revisit my research questions by narrowing down my focus of each for analytical purposes.

These first four chapters serve as a platform for the analysis chapters which follow. These later chapters instantiate many of the theoretical and analytical commitments detailed in the preceding chapters and it is at this point that theory meets practice and where interactions take centre stage. This thesis has two analysis chapters: Chapter 5 and 6 . In these chapters I shift the focus from the macro-level of social context to the micro analysis of various identities navigation 'on the ground'. In Chapters 5 and 6, I focus on two different themes drawing upon positionality and intertextuality as two main approaches to access identity. That is, same-sex marriage 
(Chapter 5) and travel (Chapter 6) are the topics investigated in order to explore how commenters construct and negotiate their online identities during their interactions.

In Chapter 5, I start with the theme of same-sex marriage as the ideological differences embedded in this topic are more explicit in comparison with the theme of travel. Specifically, I first look at the prominent sub-topics discussed by commenters, which provides preliminary indications in terms of the ideologies they index as being more salient in the data set. This investigation allows me to see the overall trends that I should focus on, demonstrating the way in which my analysis is systematically motivated. In the remainder of this chapter, analyses of positionality and intertextuality aim to explore the salient identity categories across the data. Throughout this chapter, I show how attention to ideologies and numerous Discourses are crucial in accounting for ways in which diverse (imagined) identities are negotiated in interaction. Following the same progression, Chapter 6 shifts the focus to the theme of travel, in which I explore how covert ideologies are embodied in interaction and further play a role in negotiating identities. The ideology focus of this thesis provides a valuable lens for us to better understand the complexity of identity construction in online interaction. For example, by unpacking the dominant ideologies, such as heteronormativity and white supremacy in two topics, we are able to see how various positionings (e.g. in opposition to marriage equality) and the enactment of particular social identities (e.g. heterosexual identity) are impacted by relevant ideologies manifested in the discourse. In addition, this focus draws our attention to the ubiquitous nature of ideology. That is, ideologies are always embedded in discourse regardless of whether they manifest in explicit or implicit ways.

In Chapter 5 and 6, I describe how particularly salient identities for commenters hinge on constructs of, for example, nationality (which interacts with ethnicity), gender, and sexuality, and how commenters' intersectional experiences play an important role in the particular shape these negotiations take. I show how a focus on the ideological realm can reveal the workings of ingrained phenomena, and how various ideologies and language permeate the specific Discourses and norms which frame the identity negotiations of interlocutors in an online 
interactional context. These chapters also begin to investigate the role of agency within these structural constraints. In sum, these two analysis chapters do the 'heavy lifting' in terms of the problematisation of identity, and open up space for a discussion of how these concepts interrelate and add depth to interactional analyses.

The discussion chapter, Chapter 7 brings together the key findings emerging from the analysis as well as reflecting on the value of the particular methods used to access identity in this study. I acknowledge the complexity of identity construction in online interaction and draw on the concept of indexicality to describe this complexity. I then discuss core findings emerging from the analyses of positionality and intertextuality by revisiting some important examples in this research data. Through this, I show the affordances of combining these two analytic concepts. This allows me to see the role of ideologies, for example, how the specific themes affect how commenters present ideologies and how these ideologies impact on their identity construction in interaction. In addition, this chapter also weaves together key theoretical constructs which emerged as germane to the understanding of identity construction and negotiation, and acknowledges the connections between micro and macro aspects in moving towards a cohesive whole.

Finally, Chapter 8 concludes the study with a consideration of the theoretical, methodological, and analytical contributions of this research, as well as the implications. Suggestions for future research are also presented, particularly for researchers who might be interested in investigating identity construction in different CMC settings.

\subsection{Summary}

This thesis explores how commenters discursively construct and negotiate their online identities in a text-based online commenting setting, which provides a rich source of data to better understand identity and language use. After introducing the rationale and main aims of the present study, in the next chapter I will present my own theoretical stance for how I explore identity in this anonymous online space. 


\section{Chapter 2}

\section{Theoretical background}

\subsection{Introduction}

Over the past few decades, researchers in applied (socio)linguistics, sociology, and anthropology (amongst other disciplines) have directed significant attention towards the study of identity.

Within this research, the online space as a contextual setting for identity enactment has attracted interest from a large number of scholars (e.g. Page, 2013, 2018; Thurlow \& Mroczek, 2011; Vásquez, 2019; Zappavigna, 2012). Analysis of how online users construct their identities in the "comments section" of news media has seen a growing number of studies in particular (see e.g. Blitvich, 2018; Rohling \& Rucinski, 2017; Weizman \& Dori-Hacohen, 2017). In order to explore commenters' construction of their various identities, this chapter reviews relevant literature and outlines the theoretical stance this study takes on identity construction.

At this point, it is worth noting that the aspects of identity formation that will be explored in this review are traditionally associated with a number of sometimes competing theories in the field of sociolinguistics. Independently of the theories from which scholars have appropriated these crucial concepts in language and identity research, I acknowledge the significance of the concepts for their prominent role in the processes of identity construction, recognising that they are valuable resources for the discursive formation and negotiation of identities. I aim to bring together relevant concepts in a way that makes sense of their underlying theoretical compatibilities.

By introducing the concept of identity as analysed in linguistics, this chapter foregrounds a social constructionist approach. I focus in particular on the interrelationship between personal agency and social structure in language and identity research as well as discussions of D/discourse and 
ideologies as the wider societal context in which identity construction takes place. This chapter ends with the overarching research question that the present study aims to explore.

\subsection{Identity}

As for all contexts, constructing and negotiating identities online is a complex interactional process. To address this complexity, the theoretical framework used in this study explicitly foregrounds the discursive nature of identity. In this study, I engage with identity through a broadly constructionist lens, taking a discursive approach to explore identity construction. Recognising language as a primary site for the dialectic construction of identity allows for emphasis to be placed on how individuals and the social world are mutually constitutive (Greenbank, 2020). In other words, language is central to the way that we construct our identities and our social worlds.

Prior to discussing the inherent connection between language and identity, it is important to understand the term 'identity' from a range of viewpoints. Conceptualisations of identity are complex and the term itself has been explored across a wide spectrum of disciplines, for instance, language learning and teaching (e.g. Cook, 2008; Norton, 2000, 2010), sociolinguistics (e.g. Bucholtz \& Hall, 2005; De Fina, 2015; De Fina \& Tseng, 2017), psychology (e.g. Burke, 2009; Cote \& Levine, 2014), and sociology (e.g. Bandyopadhyay, 2010; Tracy \& Robles, 2013). While early research often makes use of macro social categories in a more essentialised, fixed way (e.g. first wave Variationist Sociolinguistics, see e.g. Labov, 1972), interactional conceptualisations foreground identities as multiple, fluid and dynamic sociocultural phenomena that emerge from and are negotiated within interaction (Bamberg, De Fina, \& Schiffrin, 2011; Bucholtz \& Hall, 2005; De Fina, Schiffrin, \& Bamberg, 2006). Heeding this conceptualisation, my understanding of

identity recognises the evolution from identity being seen as "a stable structure located primarily in the individual psyche or in fixed social categories" (Bucholtz \& Hall, 2005, p. 586) to being viewed as dynamic and multi-faceted (Block, 2006, 2007a; Hua, 2017). 
Work in (socio)linguistics and applied linguistics has continued to build on these revolutionary ideas by emphasising identity as a process with its locus in social interaction (De Fina, 2011, p. 267). In her work of investigating the employable identity of refugees in the New Zealand context, Greenbank (2020, p. 16) provides a productive summary of early identity research in the field of sociolinguistics. She describes studies of language variation (e.g. Coupland, 1980; Labov, 1972) as viewing identity as a variable (along with social context) that influences how speakers adjust their speaking styles according to context (see also De Fina, 2012, p. 2). However, as scholars such as Coupland et al. (1988) and Giles et al. (1991) remind us, speakers are not the only contributors to the enactment of identity. More recently, sociolinguistic researchers (both third wave variationists and discursive scholars) have focused on how speakers use diverse linguistic strategies to index distinct identities in interaction (e.g. Bucholtz \& Hall, 2005; De Fina, 2012; De Fina et al., 2006). Greenbank (2020, p. 16) goes on to argue that, rather than assuming the types of positions and identities speakers will take and how these positions will be negotiated (see e.g. Bucholtz \& Hall, 2005; De Fina, 2012; De Fina et al., 2006; Holmes, Marra, \& Vine, 2011), current studies of language and identity explore the ways in which identity is constructed and negotiated through interactions have grown exponentially. Recognising these developments and this trajectory, I align with Bucholtz and Hall's (2005) definition of identity, embracing its goal to be deliberately broad and open-ended: "Identity is the social positioning of self and other within social and institutional constraints" (p. 586).

Bucholtz and Hall (2005) summarised the wide array of research on the analysis of identity as produced in linguistic interaction in their influential framework. Specifically, they put forward five guiding principles of sociocultural linguistic identity, reflecting on the applicability of a variety of approaches to the study of language and interaction. The first principle addresses the key notion of emergence, indicating that identity is an emergent product of interaction, constructed not separately but in collaboration with all other interlocutors in that encounter. Rather than a ready-made source for linguistic or semiotic practices, identities should thereby be viewed as social processes (Bucholtz \& Hall, 2005, p. 588). This principle acknowledges the importance of one's sense of self, yet emphasises the important role of discourse as a conduit 
for these self-conceptions to enter the social world and gain meaning, aligning with notions of 'doing' and 'performing' identities (2005, p. 588; see Butler, 1990). The concept of emergence, however, does not preclude the possibility that identity work in any interaction is influenced by 'structure', for instance, ideology and the linguistic system (2005, p. 588). Furthermore, positions adopted by individuals as well as the events referenced in the discourse can shape the construction of their particular identities. This context-bound and multi-levelled nature of identity is described as positionality (principle 2) in Bucholtz and Hall's (2005) framework.

While the first two principles recognise the ontological feature of identity, the third principle, indexicality, deals with "the ways in which linguistic forms are used to construct identity positions" (2005, p. 594). Indexicality, Bucholtz and Hall (2005) note, "relies heavily on ideological structures, for associations between language and identity are rooted in cultural beliefs and values - that is, ideologies - about the sorts of speakers who (can or should) produce particular sorts of language" (p. 594). When indexicality is applied to language, it is related to the function of linguistic cues through which (different) facets of the social context are invoked (De Fina et al., 2006, p. 4; also see Woodhams, 2015, 2019). This "indexicality" refers to a process that connects language to certain contexts. Identity work in interaction, according to Bucholtz and Hall (2005, p. 594), is indexical in a variety of ways, including explicit labelling, footings, or ideologically related verbal structures. As an example, the discourse marker oh might be used in reported speech to index a negatively evaluative positioning towards the individual or the event being discussed (Trester, 2009) (See section 2.2.3 for a more extensive discussion of indexicality). However, understanding the local meanings of indexicalities requires access to the addressee and speaker's socio-cultural knowledge in order to understand the indexicality as interpreted and intended respectively. In this regard, any language feature can be interpreted in a variety of ways. The last two principles of relationality and partialness encapsulate this phenomenon.

The fourth principle calls attention to identity as a relational phenomenon. In this description, Bucholtz and Hall argue that "identities are never autonomous or independent but always acquire social meaning in relation to other available identity positions and other social actors" ( $p$. 
598). The principle of relationality brings the idea of emergence to the locus of interaction, underscoring that "identities are intersubjectively constructed through several, often overlapping, complementary relations, including similarity/difference, genuineness/artifice, and authority/delegitimacy" (p. 598). This relies upon the idea that identity is intersubjective.

The last principle, partialness, explains the fragmentary and dynamic composition of identity. The practice of recognising one's positionality in discourse suggests that identity will always be

produced through "contextually situated" yet "ideologically informed configurations of self and other" (Bucholtz \& Hall, p. 605). Thus, "even seemingly coherent displays of identity, such as those that pose as deliberate and intentional, are reliant on both interactional and ideological constraints for their articulation" (ibid). Following Bucholtz and Hall, I argue that this principle in particular helps resolve the question of agency's role in identity formation, as discussed in the next section.

\subsection{1 (Constrained) Agency and structure}

Because the concept of agency remains elusive and contested across the social sciences, the relationship between personal agency and social structure in language and identity research requires careful consideration (Block, 2013). As Burr (2003) posits, "we are born into a world where the conceptual frameworks and categories used by people in our culture already exist" ( $p$. 7), that is, our everyday encounters are accordingly socio-culturally situated (Greenbank, 2020, p. 22), or put differently, the formation of social identities does not take place in a vacuum (see e.g. Marra \& Angouri, 2011). With this in mind, social actors then become 'agents' of their own identity construction (see Bucholtz \& Hall, 2010; Korsgaard, 2009). This concept has been extensively developed as one of the pillars of sociolinguistic theories such as performativity theory in gender studies (see Bulter, 1990; King, 2011; Pennycook, 2004 for a comprehensive review of performativity theory). A social constructionist conception of identity prioritises the social actor as an agent who manages the construction of their own identity by making decisions on, for example, linguistic choice (see 'language use as an act of identity' in Pennycook, 2004). This self-regulated process helps social actors accomplish a preferred orientation of the self by 
displaying certain positionings (see Davies \& Harré, 1990; also see Chapter 4; cf. 'positionality principle' in Bucholtz \& Hall, 2005); individuals do not perform agency in isolation from the social structures that further shape decisions to either embrace or refuse particular discursive stances in interaction (Greenbank, 2020, p. 19).

This discussion recognises the importance of commenters' agency in their construction of identity; through negotiation, commenters are continually adopting and/or abandoning different facets of their emerging identities. According to Bamberg (2005), agency is "central to the study of self, identity, and personhood... the human subject creates itself; it is based on consciousness and free will, capable of making decisions, and agentively engaged in both world-and selfmaking" (p. 10). With respect to the present study, when the commenters have convenient and free access to a virtual world through their opinions and positionings which are outwardly reflected by their discursive choices, these interlocutors are then able to exercise their agency to actively construct their preferred identities in this context.

The interplay of agency and structure is a regular focus of academic debates. Influential theorist Ahearn (2001) argues that agency is an accomplishment of social action. In line with this, current researchers, particularly within sociolinguistics, view language itself is an act of agency (Duranti, 2004, p. 451). In a similar vein, Bucholtz and Hall (2005, p. 606) note that "sociocultural linguists are generally not concerned with calibrating the degree of autonomy or intentionality in any given act; rather, agency is more productively viewed as the accomplishment of social action". In other words, agency is the result of discursive action framed by social-cultural settings, although not always intentional. Drawing upon these views, we can understand identity as a form of "social action that agency can accomplish" (Bucholtz \& Hall, 2010, p. 26). This understanding indicates that agency may be the result of individual action, but it also can be "distributed among several actors and hence intersubjective" (Bucholtz \& Hall, 2005, p. 606).

Bucholtz and Hall (2005) go further to deal with structure and its relationship to agency by arguing that 
One the one hand, it is only through discursive interaction that large-scale social structures come into being; on the other hand, even the most mundane of everyday conversations are impinged upon by ideological and material constructs that produce relations of power. Thus both structure and agency are intertwined as components of micro as well as macro articulations of identity. (Bucholtz \& Hall, 2005, p. 607).

The dialectical nature of structure and agency is significant because it tackles the complexity of individual actions and the ways in which larger power structures, including social and institutional powers, constrains them. Instead of structures pre-existing talk, it is argued that structures are negotiated between people during the interaction. As for my approach to identity, I conceptualise agency as dynamic and co-constructed in interaction (cf. Ahearn, 2001): agency is embedded in the taking up of discursive positions which contribute to the enactment of specific identities.

As discussed, when we attempt to exercise agency during interactions, it is not only constituted by, but also subject to, a number of structural constraints. As a result, we are never completely free to act. In the online context, commenters as "social actors" of online interaction are then "neither free agents nor completely socially determined products" (Ahearn, 2001, p. 120). Importantly, the connection between identity and agency provides rich insight for better understanding this process. I see identity as produced by "contextually situated and ideologically informed" perceptions of oneself and others (Bucholtz \& Hall, 2005, p. 605). As such, social and ideological forces always confine any identity performance. I embrace VanderStouwe's (2016) definition of constrained agency as: "The agentive manipulation of and negotiation around constraints, whether self-imposed or external, that limit the capacity of a subject or group of subjects to act" (2016, p. 14).

In the construction of social identities, I therefore adopt an understanding of constrained agency that shifts the focus away from the individual's capacity for action and toward a focus on commenters as social agents operating in varied sociocultural contexts (VanderStouwe, 2016). 
Thus, examining agency helps to reveal the constructed nature of commenters' knowledge, which determines power relations amongst those who are engaged in this social interaction.

\subsubsection{Identity as a negotiation: Social constructionism and poststructuralism}

A large number of current studies on language and identity are situated within social constructionism or poststructuralism (e.g. Bucholtz \& Hall, 2005; Menard-Warwick, 2005, 2009, 2014; Norton, 2000, 2013; Norton \& Morgan, 2013; Zimman, 2014); here I focus on how these two approaches or theories contribute to the understanding of identity construction and negotiation in linguistic interaction, thereby explaining my own location within this field.

Discursive identity has been conceptualised in a variety of ways. De Fina $(2012$, p. 3) observes, however, that these conceptualisations "have, in one way or another, all been influenced by social constructionism." For example, Bucholtz and Hall's identity principles are firmly rooted in the social constructionist paradigm; identity is described as an emerging consequence of the interaction that is created by all participants rather than a pre-existing condition (see e.g. Marra \& Angouri, 2011, p. 5). Based on the work of phenomenologist such as Berger \& Luckmann (1967), social constructionism sees the individual-social world relationship as mutual constitutive. In addition, constructionism emphasises the social dimension of knowledge development (Lazzaro-Salazar, 2017), thus challenging the 'common-sense knowledge'. This idea has significant implications for the ways in which we understand the relations between 'truth' and the production of knowledge, as it takes a critical stance in relation to unquestioned knowledge about the social world. Social constructionism views "reality and knowledge as socially constituted -that is - contingent on historical, cultural, political and economic contexts" (Seals, 2019, p. 19). That is, instead of relying on static meanings, social constructionism maintains that meanings are culturally and historically situated, (re)created anew in interaction (Holmes, 2007). Through this stance, the individual and the social world are mutually constitutive and hence the social world is "in fact constituted through human action and interaction and is not independent of it", as De Fina $(2012$, p. 1) argues. 
The role of language is emphasised; language is seen as a social activity in the construction of 'truths' (Khoja-Moolji, 2014). In social constructionism, language is thus more than just a way of connecting people. People "exist" in language (Galbin, 2014, p. 84); the world is talked into being. Identity is understood as a process of social interaction, rather than as something that solely exists in and belong to the individual (De Fina, 2003, 2012). In other words, identity categories vary throughout time and are reliant on the context. For example, even within one place and time, what it means to be 'a professional' differs from what it means in another (Crenshaw, 1989; Davis, 2008; see discussion in Seals, 2019, p. 19). With all this in mind, social constructionists frame identity as a social process, constructed and negotiated by creating different meanings, using language (among other resources) as a medium. Analysis focuses on how people (re)create identity constructs (Seals, 2019, p. 19).

A wide range of social constructionist research has been conducted across a variety of fields examining identity as a dynamic socio-cultural phenomenon that is co-constructed and negotiated within discourse. Many linguists follow this approach, focusing on how things are negotiated in the data, and how these further relate to identities indexically (e.g. Marra \& Angouri, 2011; Bamberg et al., 2011; Ochs, 1993). Taking the field of workplace discourse analysis as an example, where this approach is particularly popular, rather than merely asking the participants how they enact (or do) leadership, instantiations will often emerge in the data (e.g. Holmes \& Marra, 2002, 2017; Holmes et al., 2011; Vine, Holmes, Marra, Pfeifer, \& Jackson, 2008). As observed by Janet Holmes (2007, p. 54), "sociolinguists who adopt a social constructionist approach simply do not accept that categories need to be observably and explicitly salient for participants in order to be considered relevant in their analyses". ${ }^{3}$ Her observation on how to approach identities speaks directly to my aims of avoiding any a priori (or assigned) identity categories in this thesis.

\footnotetext{
${ }^{3}$ Although this claim works for social constructionism more generally, at this point, Holmes is specifically addressing issues of categories as raised by conversation analysis (CA).
} 
While social constructionism dominates research in sociolinguistics, interestingly within applied linguistics, analysts have typically aligned more closely with poststructuralism, focusing on specific issues, such as heritage language and language acquisition and maintenance (e.g. Norton, 2000, 2001, 2013; Seals, 2017a, 2017b). Poststructuralism pays close attention to how power (of individuals as well as the society) plays a role in understanding how identities are enacted, performed and negotiated (Seals, 2019, p. 20). As Norton (2013, p. 45) explains, "it is through language that a person negotiates a sense of self within and across different sites and different points in time, and it is through language that that person gains access to - or is denied access to - powerful social networks that give learners the opportunity to speak". Locating identity as a social and cultural phenomenon underscores the significance of taking these social and cultural differences into account while investigating identity. As a result, numerous research studies have been conducted in multicultural contexts focusing on identity construction and negotiation in particular (Duff, 2015; Meadows, 2009; Pavlenko \& Blackledge, 2003). With respect to the present study, commenters certainly face challenges in terms of how they perceive themselves and other interlocutors, considering that they come from different backgrounds. This directly impacts on how commenters view their relationship with the (imagined) online community as well as the online world. These challenges reflect "identity struggle" (e.g. Armour, 2004; Holmes \& Marra, 2017). Constructing and negotiating identity in the hybrid context of CMC is inextricably related to socially constructed demographic categories, such as age, race, nationality, gender, sexuality and so on. Identity is not simply conditioned by social interactions and social structures, but it is also simultaneously constitutive of the social environment.

Furthermore, poststructuralist ideas of identity draw upon several key concepts in the social sciences, including, for example, subjectivity, positioning, performativity and intersectionality. Subjectivity is related to agency (see section 2.2.1), in that both terms consider how much power a person has, how much this power is constrained, and what can be done within those constrains. Norton (2013, p. 4) illuminates the connection between identity and subjectivity: "A person's identity must always be understood in relational terms: one is often the subject of a set 
of relationships (i.e. in a position of power) or subject to relationships (i.e. in a position of reduced power)". Norton's explanation of subjectivity then further associates it with the notion of positioning (Davies \& Harré, 1990; see Chapter 4). According to Menard-Warwick (2009, p. 38), positioning is about interactions involving speakers claiming identities (reflexive positioning), and at the same time assigning identities to their interlocutors (interactive positioning), a process which is dynamic and constantly (re)negotiated. This idea of constant negotiation leads us to treat identities as emergent and intersubjective phenomena, a perspective which aligns with the poststructural emphasis on discursive construction.

In addition to subjectivity and positioning, a poststructuralist view of identity also considers how identity is performed. Drawing upon Butler's (1990) ideas that all identities are performative, I also argue later in this thesis that no identity category (including gender, ethnicity, nationality, etc.) exists on its own; rather, people do them in order to bring them into existence. Butler's concept of performativity sees identity, and particularly gender, as discursively produced and as such, performativity coheres well with the idea of co-construction, the heart of the negotiation of identity. For this reason, what it means to be a woman, or to be a 'Kiwi' is an ongoing process, depending on the immediate context (while also echoing prior experiences). In addition, the process includes ways of 'doing' and ways of 'being' that occur within larger societal contexts and draw upon the Discourses (Gee, 1990) (Capital-D Discourses will be further discussed later; see section 2.3.1) of those larger contexts. In the process of 'doing' identities, an individual may highlight a particular aspect of their identity, but all aspects of identity are always present.

Because each aspect of identity influences every other aspect, there is an acknowledgment of the overlapping identities within a specific social category. This resonates with the social constructionist argument that identity is not singular and unique, described as intersectionality (Crenshaw, 1989). This concept was first developed by Black legal theorist Kimberlé Crenshaw (1989) and served as Black feminists' critique to the assumed homogeneous concept of 'women' that reflected the viewpoint of white middle-class women. Intersectionality emphasises that macro aspects of identity (e.g. gender, age, etc.) are intertwined with each other. These facets 
(among many other categories) interact with one another to impact on how the category 'woman' is understood and negotiated (Crenshaw, 1989; Davis, 2008). For example, although women may have gender in common, experiences of being an African American woman are not the same as experiences of being an Asian woman; nor are the experiences of lesbian women the same as experiences of straight women. No two people experience life in the same way (Seals, 2019). Therefore, as Norton (2013, p. 11) explains, identity categories are not seen as " 'variables' but rather as sets of relationships that are socially and historically constructed within particular relations of power". The concept of intersectionality thus affords a useful conceptualisation of identity. This lens assumes that our own conceptions of self are the product of multiple and intersecting systems of social classification, highlighting the relevance of the concept of intersectionality in this study.

While the ideas underlying both social constructionism and poststructuralism are similar, poststructuralist ideas of identity focus more on the power relations involved in enabling and constraining the co-construction of reality (Seals, 2019, p. 21). For this reason, as discussed earlier, poststructuralism is more popular in the studies of critical education, such as language learning and teaching (see e.g. Norton, 2000, 2013; Seals, 2017a, 2017b). The dividing line between social constructionism and poststructuralism is often hard to draw, despite these theoretical claims. ${ }^{4}$ My own approach includes the critical perspective prioritised in poststructuralism and the affordances of related concepts, but relies more explicitly on social constructionism as applied through the discursive approach of Intersectional Sociolinguistics (see Holmes et al., 2011).

Interactional Sociolinguistics (IS) is well established in sociolinguistics (Vine, Holmes, Marra, Pfeifer \& Jackson, 2008, p. 344), and explores discourse in its broader sociocultural context, bringing forward the analyst's knowledge and familiarity of the community and its norms to explain what is going on in interaction (Gordon, 2011; Holmes, 2008; Schiffrin, 1996; Vine et al.,

\footnotetext{
${ }^{4} \mathrm{~A}$ full discussion of differences between social constructionism and poststructuralism is well beyond the scope of this study. The reader is referred to, e.g. Seals (2019).
} 
2008). As an interpretative approach, IS is well suited to exploring social interactions. This framework takes the position that "language as it is used in social interaction is constitutive of social relationships" (Trudgill, 2003, p. 65). As such, IS focuses on the ways in which language is used by speakers to achieve relational goals. Moreover, IS takes into account the socio-cultural environment and applies this understanding of context to the analysis of micro linguistic features (Holmes, 2013). Given that contextual information is an important aspect of interpretation (Gumperz, 1982), IS enriches explanations of participants' expectations and knowledge in an interaction (Gordon, 2011; Holmes, 2013). This conception of the role of language in interaction makes IS a suitable methodological framework for the study of commenters' online identity construction through actual language use (see section 4.5.2 for a full discussion of IS). These ideas thus are in line with discursive approaches to identity as they all place emphasis on actual language use in specific contexts.

\subsubsection{Discursive approaches to identity}

Discursive approaches to identity have emphasised the role of language in the emergence of identities as they are revealed in interaction, showing both the ways in which meaning is negotiated and how these are impacted by wider social Discourses. Discursive approaches thus add valuable linguistic scaffolding to interactional understandings of identity construction. With regard to the present study, how commenters adopt language to construct and negotiate their identities in communicative action will be explored to highlight the fact that identity does not pre-exist language (Marra \& Angouri, 2011, p. 1). Just as Cameron (2006) points out, "[...] people are who they are because of (among other things) the way they talk" (p. 49). This does not mean that commenters do not constantly perform identities through language, but rather that commenters constitute the identities they are orienting to through language. It is in the performance that commenters make the difference.

Discursive approaches to identity attempt to make their relationship with social constructionism more explicit than poststructural treatments (Bamberg et al., 2011; De Fina, 2011; Holmes et al., 2011; see discussion in section 2.2.2). This not only highlights the dynamic nature of meaning- 
making in identity construction, but also emphasises the linguistic choices made by interlocutors in interaction. Interactional data (i.e. comments discourse in this context) is therefore privileged for the insights it provides. Previous research which adopts a discursive approach to investigate identity (understood as plural) nonetheless pays close attention to social identities. For example, leadership (e.g. Holmes et al., 2011; Holmes et al., 2016; Holmes \& Marra, 2004; Vine et al., 2008), ethnicity (e.g. De Fina, 2007; Holmes et al., 2011), and gender identities (e.g. Holmes,

2006; McDowell, Lazzaro-Salazar, \& Marra, 2020). Some may argue that the studies mentioned above appear to be contradictory in terms of the poststructural and social constructionist rejection of establishing categories in advance. As a result, it is worth mentioning that those identity categories are chosen as an overarching research focus at the beginning ('strategic essentialism', Boyne, 1990, p. 170; see e.g. Holmes, 2007; McElhinny, 1996), but their analytical prominence depends on how specific categories of identity emerge in the data being analysed.

In what follows, I will discuss some key concepts that are closely related to identity construction within the focus on identity negotiation, which are salient in my research data.

\section{Intersubjectivity}

Intersubjectivity is a central tenet of constructionist approaches to identity. This concept also links to the concepts of co-construction and negotiation. Taylor $(1989$, p. 36) points out that "one cannot be a self on one's own." This statement is widely echoed in discursive approaches. Duff's (2015) definition of identity provides a good explanation of this interconnectedness, as her view on identity goes beyond the level of the individual by incorporating the dual nature of identity co-construction. Specifically, Duff explores identity in globalised contexts and draws on Block (2007a) and Norton (2013) to define identity as:

How people see or imagine themselves, how they relate to the social world, and how they are seen and positioned by others in their various social, cultural, and linguistic settings, and thus their sense of belonging to and legitimacy within particular social groups near and far (Duff, 2015, p. 61). 
Additionally, drawing upon understandings of queer, feminist and sociolinguistic theories, Mary Bucholtz and Kira Hall (2004, p. 469) argue that research on identity "is most productive when the concept is understood as the outcome of intersubjectively negotiated practices and ideologies". Following this line of thinking, identities then always require negotiation. This idea calls forth Bakhtin's theory of dialogism (this point will be discussed in detail in Chapter 4) in which the self becomes a subject only through participating in dialogue. This point also relates to Bucholtz and Hall's (2005) discussion of the principles of identity and notions of emergence and relationality as two of five overarching principles summarizing identity research (see section 2.2).

\section{Indexicality}

The indexicality principle is, as mentioned earlier, the third principle in Bucholtz and Hall's seminal summary of the field (2005) and importantly, it is the first step in exploring how identity is achieved as intersubjective and emergent.

Within (applied) sociolinguistics, indexicality refers to the social meaning (as opposed to denotational meaning) that a (linguistic) form carries in a certain context (Silverstein, 1976). Ochs (1992, p. 335) defines indexicality as "a property of speech through which cultural contexts such as social identities (e.g. gender) and social activities (e.g. a gossip session) are constituted by particular stances and acts." That is, speakers often use a linguistic feature as an index of a social identity (e.g. gender identity). An index then can be defined as any feature (linguistic or otherwise) whose meaning is dependent on its interactional contextc. In this regard, indexes serve as valuable contextualisation cues (e.g. Gumperz, 1982, 2001) in understanding the meanings embodied in interactions. Moreover, Ochs (1992) distinguishes between 'direct' indexicalities, which are "associations between stances [e.g. toughness] or social activities [e.g. jokes] and a particular linguistic form [e.g. swearing]" (as discussed in Meyerhoff, 2013, p. 267), and 'indirect' indexicalities which connect a certain stance (e.g. casual solidarity by using 'dude') with a social group (e.g. white masculinity) (see Kiesling, 2004). In this sense, indexicality is used to show how social forms contribute to the construction of social identity. The distinction between direct and indirect indexicality is in turn extremely valuable in accessing identity in 
interaction. In more recent years, indexicality has been expanded upon by scholars (e.g. Yoder \& Johnstone, 2018) to include not only linguistic signs (e.g. sociolinguistic style), but also other non-linguistic features (e.g. colours, punctuation marks, etc; e.g. Nofal, 2020). In this study, I focus mainly on linguistic indexes, though at times the indexical features of non-linguistic signs, such as punctuation marks and other semiotics, are also part of the focus of my analysis.

In an attempt to organise various indexicalities, Silverstein (2003) refers to indexical orders as chains of meanings that are associated with a linguistic form. These indexical orders are based on cultural realisations (ideological or stereotypical) that associate a form with group membership, that can be extended to associate this form with a stereotypical property of this group, and then associate the same form with some other association of that property, and so on (Eckert \& McConnell-Ginet, 2013). Indexical orders reveal the connections with ideologies, which resonate with Bucholtz and Hall's $(2005$, p. 594) claim that ideological structures play a leading part in indexicality. Indexicality in the first order, for example, is where the relationship between language and identity is obvious and does not require a great deal of inferential work on the behalf of the interlocutor. For instance, if a man mentioned his husband in conversation, he can be seen to be indexing in the first order his identity as a gay man, as the relationship between the linguistic form and the social identity is direct. However, indexing an identity (e.g. the identity of gay man) relies more heavily on shared knowledge of what it means to be a gay in a particular sociocultural setting. This shared knowledge helps us understand how the speaker "does" social identities. As linguistic features may well index multiple identities and meanings, the notion of the indexical field (Eckert, 2008) which draws upon and extends Silverstein's indexical orders (2003), points to a set of potential meanings connected to the speaker/hearer's ideology that helps (re)produce social meanings. Eckert argues that any index has "a constellation of ideologically-related meanings, any one of which can be activated" (2008, p. 453) in situated usages. Eckert (2008) provides examples of using the 'hypo-hyperarticulation' of (ING) and /t/ release to demonstrate the fluid nature of indexical fields, explaining that Silverstein's first indexical order indexes "membership in a population", while the second indexical order is a result of the continual interpretation of the form in context which signals that 
"speakers position themselves with respect to the elements of character selected out for internal use" (p. 463). Another illustration of an indexical field is provided by Holmes et al. (2011). They show how particular linguistic and discursive features are indirectly associated with ethnicity and leadership (as components of social meaning) through stance-taking in interaction. Therefore, indexicality also includes stance-taking, which is "the display of evaluative, affective and epistemic orientation in discourse" (Bucholtz \& Hall, 2005I p. 595) that can come to be associated with particular social categories (Eckert \& McConnell-Ginet, 2013; Ochs, 1992). By conceiving of identity as formulated through multiple indexical layers, we can assemble a richer idea of intersubjectivity as found in interaction. The concepts of direct and indirect indexicality, indexical order, and the indexical field all reinforce the analytical importance of close attention to context. As a way to access the emergence of identities for commenters in online interaction, the concept of indexicality therefore holds analytical promise in investigating online identity construction.

Serving as a summary of the discussion, Bucholtz and Hall (2005) argue for the analytical value of treating identity as "a relational and sociocultural phenomenon that emerges and circulates in local discourse contexts of interaction rather than as a stable structure located primarily in the individual psyche or in the fixed social categories" (pp. 585-586). As such, interactional views of identity reflect the overall underpinnings of the present thesis. That is, identities are intersubjective in that they are constructed within specific interactions with other interlocutors (as intersectional; see Crenshaw, 1989), and also within wider sociocultural Discourses which shape subjectivity and identities (Blackledge \& Pavlenko, 2001; Block, 2007b; Weedon, 1997). As mentioned earlier, wider societal narratives (or Discourses) have an impact on identity negotiation. Here I shift my focus to the role of $D /$ discourses to emphasise their importance in conceptualising identity.

\section{3 (Capital-D) Discourses}

There is a discussion around what exactly is meant by the term "discourse", including the ways in which it is applied and is investigated in research (Cameron, 2001). Different disciplines offer 
diverse definitions. Kayi-Aydar (2019, p. 28) argues that the most widely accepted meaning is "language in use." Many researchers (e.g. Fairclough, 2001; Gee, 2015) posit that solely focusing on language is insufficient as "language use conceived of as socially determined" (Fairclough, 2001, p. 8). Gee (2015) notes that people do not develop language but acquire it from other people. This view similarly relates to the concept of intertextuality (Bakhtin, 1981), emphasising that our language is interconnected with the language of others because every word we say is influenced by prior discursive practices (see discussion in section 4.5.2). Sharing prior knowledge and conventions for language use enables us to communicate with and to understand each other better (see discussion of Interactional Sociolinguistics provided in Chapter 4). Within these conventions, we are then able to invent new ways of saying things, but the premise is that these conventions must be shared with others (Gee, 2015). This points to the distinction drawn by James Paul Gee $(1990,2015)$ between two concepts: discourse (with a little "d") and Discourse (with a Big "D"). The following explains the important difference.

Discourses with a small 'd' are instantiated through everyday talk (see e.g. Marra, 2012), referring to conversations or "connected stretches of language that make sense" (Gee, 1990, 2015). The data excerpts from online interaction, such as participants' arguments or stories in response to a particular topic are examples of discourse. 'Big-D' Discourses refers to, in Gee's (1990, p. 3) own words, "ways of being, interacting, valuing, thinking, believing, speaking, and often reading and writing, that are accepted as instantiations of particular identities (or 'types of people') by specific groups." That is to say, in Capital-D Discourses, the world is constructed; our sense of who we are is also part of Discourses (Bamberg, 2014, p. 133). Bamberg (2005) argues that a Discourse is "pre-existent sociocultural form of interpretation" (p. 287). This is similar to Gee's (1990) argument that Capital-D Discourse is part of an "identity kit", functioning as an introduction to explain how to assume specific social roles (p. 142). In other words, aligning with or indexing Discourses is a way to demonstrate (diverse) group memberships in society, or to perform a specific social identity (Gee, 2015). For example, by aligning with Discourses of heteronormativity, people are indexing their social identities as heterosexual people in the interaction (see discussion in Chapter 5). 
Based on the above discussion on the distinction between the two concepts (i.e. little-d discourse and Capital-D Discourse), it is easy to see how these two definitions work together in identity construction; in order to demonstrate the latter sense of Discourse, interactants do so through little-d discourse (i.e. everyday language use); everyday language use, conversely, is always socially situated, outlining the significance of the circulation of Discourses. The two types of discourse are mutually implicated in the process of identity construction and negotiation, and these connections will be foregrounded in my analyses. Given that people who live in the same society often share mutual understanding of Discourses, Discourses can be used as resources to perform specific identities in the course of interaction (Kiesling, 2006, p. 265). The range of Discourses are used by people in society by conventions, for example, the Discourse of Masculinism, the Discourse of (enacting being a) New Zealander ( i.e. Kiwi identity; see e.g. Holmes \& Marra, 2011, 2017; Marra \& Holmes, 2008), the Discourse of Tourism (this will be further discussed in the analysis chapter regarding the topic of Travel; see Chapter 6), the Discourse of Heteronormativity (this will also be illustrated through the analysis of same sex marriage legalisation; see Chapter 5), and so forth. In the following section, I turn my focus to a further layer of abstraction, namely ideology, which I argue scaffolds both senses of D/discourse.

\subsection{Ideologies}

Scholars from numerous fields make use of the concept of ideology. Given the complexities of this concept and the disciplinary differences, it can be understood in diverse ways. In light of this, Woolard (1998) offers a succinct but convincing answer from the perspective of linguistic approaches. She underlines the close relationship between language and ideology arguing that in language studies, as Goffman (1972) puts it, analysts must examine ideology in a systematic way rather than arbitrarily negating its presence. This underlines the close relationship between language and ideology. In this section, I am not going to rehearse the varied definitions of ideology; ${ }^{5}$ rather, as I mentioned earlier, I will explore how this term can be used analytically so as to investigate identity by connecting it with $\mathrm{D} /$ discourse.

\footnotetext{
${ }^{5}$ Readers are referred to Woolard (1998). A full discussion of ideology, including its emergence, dimensions of commonality and variation in its use, is provided.
} 
Despite a certain definitional elusiveness (see Gee, 2015), scholars agree that ideology is closely linked to inhabitable positions of power (e.g. social, political, and economic power) (Schieffelin et al., 1998). Within this line of thinking, ideology is viewed as "ideas, discourse, or signifying practices in the service of the struggle to acquire or maintain power" (Woolard, 1998, p. 7). Within sociolinguistics, the idea that ideology always has impact on people's formation of cultural beliefs and exercise of power relations is commonly accepted (Bucholtz, 2003, p. 379). As Bucholtz and Hall (2003) point out, sociolinguistic researchers (e.g. Fishman, 1968; Gumperz, 1964; Labov, 1966) use terms such as 'attitudes' or 'stereotypes' to describe sociocultural practices of language and its users (see discussion provided in Agheyisi \& Fishman, 1970). As a social phenomenon, the issue of power thus becomes a central focus in the concept of ideology, attracting considerable attention within a field that focuses on the ways in which the interpretation of language relies on socio-political contexts (Blommaert, 1999; Kroskrity, 2000a, 2000b; Schieffelin et al., 1998). For some (e.g. V. I. Lenin; cited in Schieffelin et al., 1998), ideology is seen as a tool of any protagonist in the contestation of power. It follows that "power can be 'ours' as well as 'theirs', subaltern as well as dominant" (Woolard, 1998, p. 7). Nonetheless, in the most restrictive formulations of this connection, ideology is always a practice of dominant social groups, as it is "essentially linked to the process of sustaining asymmetrical relations of power - to maintaining domination... by disguising, legitimating, or distorting those relations" (Thompson, 1984, p. 4).

People acquire ideologies through language and then in turn the ideologies learnt in the process influence what people say and how they say it. Ideologies can change because "all systems have a historical validity, and are necessary" (Gramsci, 1971, p. 138). Changes in ideologies are reflected in the nature of language. Simultaneously, change in language also shapes changes in ideologies. While ideologies are not the same everywhere and they change over time (see Darvin \& Norton, 2015), many ideologies are also shared. Therefore, it is important to understand how ideologies function through language and how the dialectical relationship between language and society is mediated by ideologies. As De Costa (2010) suggests, while the use of constructs, such as 'cultural models', 'subjectivity', or 'positioning' in the linguistic research field reflect 
researchers' interest in applying a critical lens towards investigating ideology, a more comprehensive approach that explicitly calls for the examination of ideology in socio-cultural and socio-political contexts is still needed. Saying this does not mean that the existing approaches are not appropriate for the examination of ideologies. Rather, a great number of studies have proposed many frameworks for researchers to choose from that are often used in the literature.

For the purpose of this study, I find value in Julia Menard-Warwick's (2014) work, whose definition of ideology builds on the work of van Dijk (1998), Fairclough (1992), and Bakhtin (1986). That is, ideology is referred to as "beliefs and perceptions linked to power relations between social groups -which may or may not be expressed explicitly as discourses, but often become apparent in taken-for granted practice" (p. 2). The link between ideology and Big-D Discourses (Gee, 1990) is especially pertinent for the current study where the online communication context is characterised by hybridity, mobility and connectedness, all of which impact on the existence of large-scale ideologies among participants from different backgrounds. To recall the notion of Big-D discourse, a Discourse captures how individuals enact and recognise socially and historically significant identities through well-integrated combinations of language, interactions, beliefs and values. The investigation of Big-D Discourses therefore can be used to identify, for example, one's membership in a given group or socially significant identity. In addition, because people often understand Discourses in the same way, these Discourses are utilized to perform specific identities in interaction. Therefore, there is analytical potential in unveiling the processes by which ideologies form part of commenters' identity construction and negotiation and ways in which these are given voice through $\mathrm{D} /$ discourse. This corresponds to Gee's (1990, p. 145) statement that "it is not individuals who speak and act, but rather that historically and socially defined Discourses speak to each other through individuals." Although Gee's argument highlights the ways in which Discourses come into being by recognising their close relationship to various socio-historical circumstances, and their underlying structural constraints on little-d discourse, I argue that in the course of interaction people exercise agency either by showing alliance with or distancing themselves from particular Discourses. 
The discussion has brought together the concepts that I see as crucial for a nuanced investigation of identity in online interaction context. In light of this study's exploratory nature and to avoid assigning identities at the outset (despite the likelihood of certain identities coming to the fore in this study, for example, sexuality), I frame my investigation with the overarching research question that guides this study as follows:

"How is identity constructed and negotiated through comments discourse in an online communication setting?"

The literature review in the next chapter enables me to refine this overarching research question.

\subsection{Summary}

This chapter has explored, and brought together, many aspects of identity which frame the approach I consider to be foundational in my study. I first provided an overview of how identity is understood through different viewpoints, showing how understandings have shifted from ideas of fixed and essentialised notions of identity to social constructionist conceptualisations of identities as socially embedded and discursively constructed. This discussion led to a consideration of the relationship between agency and identity as of ongoing importance in language and identity research. Drawing on the relevant literature, I then investigated how the social constructionist approach has been used primarily to investigate identity in sociolinguistics, alongside a comparison with the poststructuralist approach more often used in applied linguistics. I build on this by looking at discursive approaches to identity. In emphasising the discursive element of identities, I clarified key concepts in interaction, such as intersubjectivity and indexicality, then explaining the dual meanings of D/discourse and connecting these to ideologies, both of which are important layers in identity construction. These discussions underscore the significance of investigating identity construction in interactional data. 
The theoretical issues that have been discussed in this chapter have typically been applied to face-to-face interactions rather than to the more recent context of online space, and specifically the online comment boards which are the focus in this study. In the next chapter, I provide a summary of literature in the online spaces in particular to motivate my research and to identify the research gap I address. 


\section{Chapter 3}

\section{Literature review}

\subsection{Introduction}

As discussed in Chapter 2, my theoretical stance foregrounds identity as a sociocultural phenomenon that is multiple, fluid and dynamic and emerges from and is negotiated within interaction (Bamberg, 2011a, 2011b; Bucholtz \& Hall, 2005; Darvin \& Norton, 2015; De Fina, 2003). Having established this social constructionist lens, this chapter shifts the focus from the theoretical underpinnings to a synthesis of the literature of most relevance to my research. Namely, I pay attention to previous studies in the context of computer-mediated communication $(\mathrm{CMC})$, focusing on the medium that this thesis deals with-text-based online commenting -in particular. I identify the research gaps in online identity research that this study intends to address and the literature that motivates the research questions that guide this study.

\subsection{Online space and identity}

Investigations of identity have grown exponentially in the social sciences and have become a major focus in communication studies and linguistics (Bamberg et al., 2007; also see section 2.2). Expanding the focus from traditional face-to-face communication settings, online spaces are increasingly seen as valuable sites for the examination of identity construction. Social networking sites, also understood as a type of "networked publics" (boyd, 2014, p. 39), have gained particular popularity for the ways in which they allow online users to negotiate mutual norms and values as collective identities (Facer, 2011). Whether on social networking sites or other online fora, the role of language in online identity construction has seen an explosion of literature (e.g. Page, 2018, 2013; Vásquez, 2019; Zappavigna, 2012, 2014; Zhao et al., 2008). One of the goals of this research is to recognise the affordances of the online environment which allows users to portray different selves online (Turkle, 2011) and potentially in contrast to their 
offline identities. The many dimensions of identities, including the potential for multiple online identities, influence people's perceptions and developments in self-presentation (e.g. De Fina, 2015; De Fina \& Tseng, 2017; Hua, 2017). This is especially true as we enter the Web 2.0 era,

where face-to-face communication is seen to be morphing into a range of forms; online identity has become a core focus of CMC studies (Yuan, 2018). Dobrowsky $(2012$, p. 93) observes that in the digital world, individuals "always think of questions, for example, what do I think? what do I do? What do I feel?" These questions only make sense when we consider the circumstances of the actual situation because the individual's construction of meaning is dependent on these circumstances. Identity can only be constituted according to the actual circumstances of the situation. Thus, the individual's construction of identity varies according to the situational contexts. Traditional socialisation spaces such as school, family, and other societal institutions have evolved into a plethora of on and offline spaces where people can interact with one another (Yuan, 2018). Online social networks, such as social media sites (e.g. discussion forums, microblogs, Facebook, Twitter, Instagram, LinkedIn, Tiktok, etc.) have provided space for interaction where individuals can engage in self-presentation and thus construct their identities through interactions.

\subsubsection{Looking back: Online identity construction in CMC}

One of the traditional ways to investigate identity has been to use large social categories such as ethnicity, gender, sexuality, and class (albeit more recently with a realisation of the strategic essentialism these labels represent). A great deal of previous research conducted into online identities makes use of these categories, ranging from professional and personal identity (Kasperiuniene \& Zydziunaite, 2019; Papacharissi, 2009; Zhao et al., 2008), through national identity (Yadlin-Segal, 2017), ethnic and religious identity (e.g. Duderija, 2007; Greenfield et al., 2006; Marotta, 2011; Parker \& Song, 2009), to gender and sexual identity (e.g. Bond, 2020; Rosenmann \& Safir, 2006; Szulc \& Dhoest, 2013), to name a few. Among these studies, it is notable that a majority have been conducted using social networking sites (SNS), such as Facebook or Twitter (see more e.g. Bolander \& Locher, 2010, 2015; boyd, 2008; Durante, 2011; Gilpin, 2011; Papacharissi, 2009; Zappavigna, 2011, 2012, 2014). 
Boyd is regarded as a pioneer researcher in the field of CMC studies, with a particular research interest in SNS (e.g. teenagers and Twitter). She claims that distinctions between private and public are hard to maintain in SNS because it is impossible to establish a unique social environment when these places have no physical, social, or temporal limits (boyd, 2008, p. 34). This lack of boundaries remains a focal point for social media studies. For example, applying a lens of trust and privacy, Durante (2011) investigated how people construct their personal online identities and found that the extensive use of technology may be seen as a threat to the stability of our identities. Following these concerns CMC studies involving identity are typically dominated by social-psychological approaches and tend to focus on how anonymity influences individuals' identity construction (Androutsopoulos, 2006). In a similar vein, Danet (1998) speculates that interactions that take place online allow people to enact personas that are distinct from their 'real-life' identities. Many other scholars, such as Chandler (2000), Miller and Arnold $(2003,2009)$ also note that post-modern identities can be constructed and negotiated through a bricolage of word and image online. In other words, in the setting of CMC, online users enjoy a wide range of resources to "interactively create identifiable personalities for themselves" (Baym, 1998, p. 56), including the choice of usernames online, use of profiles, use of specific language choices, and an assumed group role that they can take up (e.g. Baym, 1998, 2000; Kersten \& Lotze, 2020; Liu, 2007; Perkel, 2008; Shafie et al., 2012). However, these resources require further investigation, especially in terms of micro-linguistic and interactional details. This suggests a need for more nuanced methods of approaching online identities, placing emphasis on the use of language in the process of identity construction in online interaction.

Focusing specifically on linguistic research, scholars such as Zhao et al., (2008) have argued that the identities generated on platforms like Facebook are not the same as those created in anonymous online contexts. Facebook users are likely to prioritise their collective and consumer identities over personal narratives; they perform identities implicitly not explicitly: "they show rather than tell" (p. 1816). This finding is akin to research by Bolander and Locher's (2010) which claims that while attempting to update their status and personal profiles, Swiss Facebook users who have offline interactions with other participants are more likely to use implicit rather than 
explicit identification assertions. Others propose a distinction between the online and offline self (Cinnirella \& Green, 2007; Clark, 1998; cf. Georgalou, 2016). In comparison to the supposedly 'real' self in everyday face-to-face communication, online users are seen to be given more freedom to perform their identities. As a result, online identities are argued to be "constructed out of a void at the host's will" (Yuan, 2018, p. 45). However, we must be cautious about theorising online and offline identities as independent entities. As Weber and Mitchell (2008) point out the construction of online identities is tied to physical bodies; interacting within these online spaces is simply a new way of enacting "embodied" identities (for more information on early theories of "embodiment", see e.g. Bucholtz \& Hall, 2016; Butler, 1990; Grosz, 1994).

\begin{abstract}
"Although we may forget our bodies when cruising in cyberspace, all our actions are taken through them. Indeed, if there is anything that gives a sense of performance and stability to the flux of identity processes, it is the body, which even as it changes in appearance, remains at the heart of identity. While theorists may ignore the role of actual bodies in both individual and collective identities (they seem to prefer theoretical ones), people must certainly understand that identity is always embodied. For example, by posting photos of themselves which they have taken, often deliberately posed (eg, à la Hillary Duff) [they] are examining, modifying, dressing, adorning, and putting their bodies out there" (Weber \& Mitchell, 2008, p. 42).
\end{abstract}

The discussion implies that the construction of online identity be perceived as "work-in-progress, and an evolving active construction that constantly sheds bits and adds bits, changing through dialectical interactions with the digital and nondigital world, involving physical, psychological, social, and cultural agents" (Weber \& Mitchell, 2008, p. 43). Identity whether online or face-toface is "something we do, rather than simply something we are" (Buckingham, 2008). In addition to exploring online identity from the perspective of identity categories, many studies focus on the formation of online identity and its impact on users' online engagement (e.g. boyd et al., 2004; Millen \& Patterson, 2003; Turkle, 1997). In boyd et al. (2004), the authors note that in $\mathrm{CMC}$, identity is established through the addition of software-enabled techniques, scuh as the use of emoticons to expressing personal feelings (which, in contrast to the traditional textual 
tools, allows users to present themselves visually; even if they may not be used by all). Yet, the available emoticons are limited and may not adequately represent one's feeling, potentially constraining online identity construction. Moreover, customizing online user profile pictures is another option to express oneself (Vasalou et al., 2007), which reflects an individuation of personalities to represent themselves and the communities they belong to. This influence on establishing an online identity was also examined by Walker (2000), who explores how online identity impacts the appearance and content of users' homepage (Yahoo!). Millen and Patterson (2003), on the other hand, investiagte the impact of online identity on polciy-making for a community netwrok. Findings from this research imply that there are many factors that contribute to building one's online identity, and those elements, in turn, influence the construction of that dentity.

More recent work on discourse and identity in $\mathrm{CMC}$ has been conducted from the perspective of (applied) sociolinguistic and/or discourse analysis (Barton \& Lee, 2013; Page, 2013, 2018; Thurlow \& Mroczek, 2011; Vásquez, 2019; Weizman \& Dori-Hacohen, 2017; West, 2013; Zappavigna, 2012). These studies mainly can be categorised into three foci, namely (1) the narrative aspect; (2) applying systemic functional linguistics (SFL) as a discourse approach to accessing identity; and (3) focusing on specific linguistic strategies (e.g. facework, politeness, humour, etc.). Each of these aspects will be illustrated by the following instantiations. West (2013) presents a sociolinguistic analysis of users' storytelling in Facebook communities. She argues that Facebook users prefer to tell small stories (see Bamberg, 2004) when updating status online. "Tellings that can be [...] about very recent ('this morning', 'last night') or still unfolding events" (West, 2013, p. 2). Importantly, these small stories allow Facebook users to enact multiple versions of self in a given context. This is in line with findings from Page (2013), who argues that updates function as small stories in online interaction; users are more likely to tell these small stories when an event occurs, and it is through the tellings of the event that users' various identities are constructed. Page (2018) demonstrates how shared stories are used to construct online users' identities via four different interactional contexts (i.e. Facebook, Twitter, YouTube and Wikipedia). Through the analysis of narratives in social media, she claims that 
shared stories are ideologically loaded and thereby contribute to a gathering or separating of audiences into groups. This distinction however largely depends on how vague the narratives are. That is, the more ambiguous the story, the more likely it is that the audience will disagree. To navigate the multimodal nature of online narratives, Page proposes a new approach called 'Mediated Narrative Analysis', allowing discourse analysts to better decipher the underlying meaning embedded in online discourse (see e.g. Liu, 2019). Being recognised as an important site for the exploration of identity in discourse, narratives provide analysts with additional insights into how people use extended discourse to construct identity online.

Theoretically and methodologically guided by SFL and Corpus Linguistics, Zappavigna (2011, 2012, 2014) explores how people use Twitter to construct identities and form communities with other participants who share common values. The author describes identities as following two different patterns, namely, patterns of bonds (which focus on social relations enacted by participants during the interaction) and values (which focus on meanings being negotiated in interaction) (emphasis added). Guided by this particular approach, Zappavigna's work reflects her (as well as other researchers who adopt SFL in their study) theoretical stance, which demonstrates a different way of approaching and analysing identity in the online context. By contrast, my research adopts a social constructionist stance to foreground identity as multiple and dynamic, emerging from and negotiated within interaction (see discussion in Chapter 2).

Particularly relevant to the present study, West and Trester (2013) (as cited in Tannen \& Trester, 2013) combine a focus on intertextuality with an interactional sociolinguistics approach to investigate the complexity of the multimodal interactions of new media (e.g. Facebook), especially when extra intertextual knowledge from users is required in interaction because physical cues are lacking. From the perspective of facework (see Goffman, 1955), the authors conclude that interactions on Facebook play a role in recognising users' construction of positive face. Furthermore, the findings of this study indicate that while members of this community share some common norms, users may react differently to exactly what constitutes facethreatening acts (FTAs) given that members come from diverse socio-cultural backgrounds. This 
important study by West and Trester successfully ties the notion of face to intertextual features in online discourse, providing a new perspective on identity in social media for future research. As a complement to this facework perspective, Vásque (2019) explores how individuals engage in creative forms of online self-expression and identity construction by focusing on the use of discourse strategy of humour in three different social media platforms (i.e. Twitter, Tumblr, and Amazon). Her research into the use of creative humour in online spaces recognises the importance of humour as part of online engagement to enact the functions of building solidarity between participants and conveying "serious" messages to one another (see e.g. Dynel \& Poppi, 2018). The literature mentioned above is only a part of many studies focusing on language and identity in CMC contexts. This review of relevant literature not only acknowledges the usefulness offered by previous research when investigate identity online, but also emphasises my own way of exploring identity, that is, I take a social constructionist approach to identity.

This discussion around language and online identity in CMC literature indicates that most extant research pays close attention to the non-anonymous environment of social media (e.g. Facebook, Twitter), where people make full use of the media to interact with others with whom they often retain offline interactions at school, home and work (Ellison et al., 2007). In contrast to this, the following section explores identity work in a more anonymous context, that is, comment boards.

\subsubsection{Identity construction in comments section}

Online space has mutated into a variety of platforms - many of which have thrived in recent decades. One of these spaces, the online comments section following news articles serves as a host to modern-day public discourse (see discussion in Chapter 1). Comment sections are dedicated to the opinions and reactions of readers who are invited to respond to the issues reported in a particular news article. In contrast to the traditional section of 'letters to the editor' that formed the "symbolic participatory spaces" (Reich, 2011, p. 99) of print newspapers, the online space provides voice to all who have access and who are willing to engage in public discussion. In this sense, the comment section is the modern-day 'lobby' of news organizations 
and provides a space for public discussion online. These discussions are regarded as part of “participatory journalism” by some researchers (e.g. Chung, 2008; Manosevitch \& Walker, 2009). However, instead of a physical newspaper and a cup of coffee, that might have been offered in earlier times, readers are now offered a username.

Reader comments, seen as a key mode of online participation (Weber, 2014), have empowered readers to express themselves in ways not previously seen. The fast-growing needs of online participation have also meant that the comment sections have become established places for public discussion; online news articles that evoke strong emotions garner hundreds, or at times thousands, of comments within a short period of time. As Reich (2011, p. 89) summarizes: "online items without comments are becoming rare and starting to look awkward, even suspicious". As a result, reader comments are pervasive among most of the online mainstream newspapers (Santana, 2011; Weber, 2014). In turn they have begun to attract attention from researchers in various fields.

A number of research studies on reader comments have been undertaken, with a focus on participatory journalism, in which comments constitute one of the multiple types of online engagement (Weber, 2014). Recent studies have centered on the appraisal of user participation by journalists (e.g. Frischlich et al., 2019; Nielsen, 2012), the investigation of participatory elements on news sites (e.g. Kammer, 2020; Reich, 2011), and the strategies harnessed by users to manage user-generated content (e.g. Boyd, 2018). Other studies have placed emphasis on the content of comments (e.g. Diakopoulos \& Naaman, 2011; Douai \& Nofal, 2012; McCluskey \& Hmielowski, 2011; Santana, 2015) and the impact of content on other participants' opinions (e.g. Lee \& Jang, 2010; Yang, 2008). Given that the technology allows a certain degree of anonymity, attention has also been paid to an investigation of the impact of anonymous commentary on reader participation and the quality of comments. Many researchers claim that the 'anonymity' offered by online platforms gives rise to uncivil reader comments which are detrimental to online discussions (Borah, 2014; Santana, 2014; Ziegele et al., 2014). Santana (2014) suggests that the anonymity contributes to readers' uncivil expressions, not only resulting in moral 
indignation but also contributing detrimentally to readers' open-mindedness. In other words, when incivility is reflected in the discourse, people seem to become more adamant about their views when it comes to accepting new opinions, halting further discussion (Santana, 2014, p. 21). From the opposite viewpoint, Barber et al., (1997) comment that respect between readers can contributes to the development of different opinions as well as a relatively free expression environment. A number of researchers claim that anonymous comments should be moderated or even abandoned, aiming to make progress towards a more civilized and vibrant environment of online interaction. However, scholars from the opposite camp believe that anonymity granted by online news websites still exercises some positive influence on online interaction. Within this line of inquiry, Rosenberry (2011) claims that regardless of the increasing occurrence of linguistic incivility, anonymous comments can promote freer and livelier conversations. Similarly, Nielsen (2012, p. 89) argues that anonymous online reader comments open opportunities and controversy, leading to a more passionate discussion. This debate continues. Examinations on perspectives of civility and anonymity of comments discourse are not my primary focus in this study, but these considerations are an important component to my research.

More closely aligned with my chosen data context, in recent years, there have been a number of investigations of the construction of different types of identities (e.g. professional, ethnic identity, etc.) within comments discourse (e.g. Blitvich, 2018; Prantl, 2016; Rohling \& Rucinski, 2017; Rosino \& Hughey, 2017). Blitvich (2018) examines the construction of a Latino identity through conflict discourse. She collected comments posted on a CNN discussion board following a documentary in which Soledad O'Brian was a correspondent. O’Brian asked “what did you think about Latino in America?". The analysis revealed that many Latino participants were offended, claiming that CNN had depicted the community negatively because of its deliberate focus on undocumented Latinos. The study looks at the close relationship between transnational identities and globalisation, arguing that conflict talk functions as "an ideologically-loaded, indirect index" in identity formation (Blitvich, 2018, p. 120; see also Kiesling, 2013). As another relevant example, Prantl (2016) focuses on a culture blog (i.e. tomandlorenzo.com) to investigate how participants communicate with one another and work on their identities in this online 
space. Findings show that participants primarily made use of indexicality to place themselves in a social environment independent from the local community. This study supports earlier findings that identity is made up of overlapping aspects which are impacted by interactive media. While online identity continues to receive considerable attention from researchers, the investigation of discursive practices in online commenting on news topics, has not been examined on a large scale, and there remains scope for further investigation. My study thus contributes to this field by investigating how commenters discursively construct and negotiate their identities through online interaction.

During online interaction, commenters inevitably share personal values, interest, knowledge and societal understandings with other interlocutor(s). The online space thus provides commenters with potential to construct their membership of communities just as in the offline world. As a result, the concept of 'online community' is worth consideration.

\subsection{Online community, identity and CMC}

Community and identity are key concepts in the theorising of CMC in media studies (Androutsopoulos, 2006; cf. Jones, 1998; Preece et al., 2003; Smith \& Kollock, 1999). However, an online community (or 'virtual community') is a contested term, and researchers have difficulty in reaching a general and universally accepted definition (G. Z. Liu, 1999, p. 2). Despite definitional differences, the concept of an online community has become increasingly relevant in Internet research (e.g. Hercheui, 2011; King, 2019; Preece \& Maloney-Krichmar, 2005).

Rheingold's (1993) somewhat clumsy definition of online communities as "social aggregations that emerge from the Net when enough people carry on [...] public discussions long enough, with sufficient human feelings, to form webs of personal relationships in cyberspace" (p. 5) has not only been influential for understandings within the field but also points to community characteristics such as fluidity and indeterminacy. In response to this definition, some have critically argued that features that describe and define communities in the sociological sense, such as "physical proximity, stable membership, long-term commitment, and social 
accountability" (Androutsopoulos, 2006, p. 422) are lacking in CMC, and that online communities cannot exist (e.g. Androutsopoulos, 2006; Jones, 1995, 1998). Others, however, refute these critiques, emphasizing that online communities must be investigated as "communities of some sort" (Androutsopoulos, 2006, p. 422) in their own right, as "their 'social morphology [...] is hard to classify and their longevity difficult to predict" (Appadurai, 1996, p. 195; cited in Androutsopoulos, 2006, p. 422). Similarly, Castells (2000, p. 389) argues that online communities "do not follow the same patterns of communication and interaction as physical communities do. But they are not 'unreal', they work in a different plane of reality" (cf. Angouri, 2016). As seen, arguments around the definition of online community generally include a pragmatic concern that the term itself has been overextended to the point of becoming meaningless; every online group appears to be spontaneously classified as a 'community' (Herring, 2004). In addition to this, Herring (2004, p. 343) voices a "philosophical skepticism that a virtual community can exist at all, given the fluid membership, reduced social accountability, and lack of shared geographical space that characterize most groups on the Internet."

Defining what constitutes an online community remains a challenge. Current definitions in CMC studies range from the open definition - for example, "a group of people who interact in a virtual environment" (Preece et al., 2003, p. 1023) - to a list of specific conditions. Herring's (2004) framework for computer-mediated discourse analysis, in which she proposed a definition that falls into the latter category, seems a good starting point. In reviewing the pre-existing notions of what constitutes communities, Herring (2008) makes use of criteria proposed by Rheingold (1993) which aim to highlight the main characteristics of an online community:

(i) existence of a common interest (in this context, common interest could be, for example, being engaged in online interaction in response to a specific news topic);

(ii) persistence of interactions;

(iii) "emotional attachment" among users or a sense of community (p. 921). 
The second criterion addressed above-persistence of interactions, is not necessarily a core feature of the online communities I investigate. The comments section is an open-access platform and social media users have flexibility to share knowledge and negotiate values with other potential interlocutors across multiple online contexts (boyd, 2012). Nevertheless, despite a lack of consistent involvement and stable membership in most online communities, aligning with particular values (and contrasting with others in recognition of that shared position), remains a vital way of examining users' online behaviour. As Herring (2008) claims, such discourse behaviours can act as indicators of the development of the online community.

Although Herring's multi-faceted lens has provided some useful guidance, it does not provide categories with which to distinguish different types of communities. Findings of previous CMC research are congruent with the many conceptualisations of community that circulate within sociolinguistics. For example, application of the notion of speech communities (Patrick, 2001; Rampton, 1998) underlines how virtual communities are perpetuated through "frequent engagement, a shared communicative history and a common rule-guided usage" (Höflich, 1997, p. 507); Similarly the concept of the 'imagined community' (as originally coined by Anderson (1983) referring to nationhood as an abstract construct that only exists in our imagination) has been widely used in (applied) sociolinguistics, notably in Bonny Norton's work. Norton extends the term beyond the construct of nation to include any "desired community that offers possibilities for an enhanced range of identity options in the future" (2010, p. 355). This aligns with the notion of 'ideal reader' who is also imagined (see Fairclough, 2001; also see discussion in Chapters 5 and 6) and is gaining theoretical weight among Internet researchers (e.g. Karim, 2003; Lee \& Wong, 2003). Similarly the popular 'community of practice' (CofP) (Holmes \& Meyerhoff, 1999; Lave \& Wenger, 1991) is commonly used to describe groups that maintain a mix of online and offline interaction (see e.g. Bolander \& Locher, 2020). As a result, the application of CofP to online communities in sociolinguistics has been comparatively uncontroversial (King, 2019, p. 132). This model is particularly useful for approaches (e.g. Lehtonen, 2017; Newon, 2016) where blended online and offline interaction are the focus (Androutsopoulos, 2006), but it can also be valid when examining groups that are entirely 
digitally bounded (Bolander \& Locher, 2015; Kytölä, 2013, 2017; Kytölä \& Westinen, 2015; Newon, 2011, 2016). For example, in Newon's (2011) study of a guild in the game World of Warcraft, she contends that in the case of World of Warcraft, the guild, or at least a certain portion of its members, function as a community of practice. This is evidenced in overt discussion of community membership roles during gameplay, which she equates with core and peripheral membership. While in the study of League of Legends, Newon (2016) finds that players and community managers co-construct a 'sense of community', a concept that she theorises robustly, through game players' online as well as offline linguistic interactions.

Samu Kytölä's examination of online Finnish football discussion groups also focuses on online community of practices (the form of an asynchronous web forum, Futisforums; see e.g. Kytölä, 2013, 2014, 2017; Kytölä \& Westinen, 2015). This study demonstrates how a given community of practice can function while being completely bounded by online space (while still recognising that many communities of practice blend the online and offline). The author shows that this specific online community of practice is framed by diverse kinds of multilingualism (Kytölä, 2013). Furthermore, this multilingualism involves other shared practices such as making use of 'media quotes' from elsewhere in the internet and specific styles of discourse that function as 'affiliation, identification, disidentification, joking and making fun, mockery, and (socio)linguistic performance' (Kytölä, 2014, p. 82). Importantly, Kytölä (2013, p. 34) makes the astute observation that "one person's community of practice can be another person's affinity space (see Gee, 2005b)" . Based on this argument, King (2019, p. 132) points out that "there are other participants who are not part of any of the communities of practice in the constellation, and might not even desire to be; their participation is likely oriented not so much to belonging but to content." This implies that Gee's affinity space does not require the same kind of interaction of the group members but recognises the potential of a community. King (2019) goes a step further and critiques that the online CofP model has been applied too liberally, which does not match the definitional characteristics. Instead, people are imagining a shared sense of self and shared values amongst the group. King's (2019) observation thus draws our attention to the recognition 
of the space as an affinity space (Gee, 2005b), which is frequently referenced in current online research.

In the absence of a well-developed community of practice, or in the absence of a desire to engage with the notion of membership (see earlier discussion acknowledged by Kytölä, 2013), Gee's (2005b) model of affinity space provides another way to theorise the coming together of people online and avoids 'community' notions of membership and belonging, arguing that these elements are often not present online (Gee, 2005a, 2005b). Thus, the focus with the affinity space is not on a sense of belonging but mainly on a common interest, or on content (King, 2019, 135). In other words, the model of affinity space recognises that due to common interests or activities, people are attracted and gathered online to communicate with others. Participants may interpret this as a type of community practices with shared norms, but at a technical level analysts are more hesitant. In recent years, the concept has been applied by language researchers, opening up research areas into a wider variety of online experiences involving different people that do not necessarily qualify as communities of practice, leading to some interesting findings. For example, in a study of Christian heavy metal music fans on YouTube, the group of people under the analysts' lens is not seen to qualify as a community of practice, and so the interaction space is labelled as an 'interest-based affinity space' (Leppänen et al., 2012). In this study, the authors have shown us how users post video montages of their favourite Christian heavy metal music, combining it with a series of images that get recontextualised as part of the user's own message (e.g. a pentagram). Even though the findings provide a useful example of entextualisation online, King (2019, p. 136) argues that readers are not told about any effects that might be created by it reportedly being an affinity space instead of some other type of social space.

Based on the discussion, I contend that the online community likely influences interaction, but that not all online groups constitute online communities. In this context, the comment sections can be viewed as comprising affinity spaces, in which online news websites allow for active participation and especially knowledge exchange and shared values. As a result, distinct group 
roles may be enacted, and a sense of shared group identity among the interlocutors may also develop (see e.g. Kouper, 2010; Stommel, 2008). My analysis aligns with the notion of an affinity space and will recognise the impact of a potential community (i.e. imagined communities) on interaction (See Chapter 5 and 6 for detailed discussion).

Having provided a review of relevant literature on identity construction in online interactional settings, the following section addresses the gaps and research questions that this study aims to address through the investigation of commenters' online identity constructions.

\subsection{Gaps and research questions}

First, while online space is a rich and developed/developing context for research across various disciplines, there is a dearth of, or relatively limited, linguistic research concerning anonymous online users' language use and identity construction. As discussed, a great number of studies have been conducted in the area of social networking sites (e.g. Facebook, Twitter, Instagram, television programmes, blogs, etc.), particularly in a Western context (see discussion in section 3.2.1). By focusing on a different interactional environment, namely reader comments, the present study draws attention to anonymous comment boards. Comment boards as social sites deserve their own attention in the digital age, as they afford the expression of opinions and sentiment about public events potentially by anyone. This allows individuals and groups formerly excluded from public opinion building to have a voice alongside mainstream media. Given the significance of social media and of microblogging opportunities (e.g. Twitter) in shaping public discourse, this study also makes an important contribution to this area by highlighting interaction within the online public space. Additionally, how anonymous online users communicate with others and "make the ordinary visible to others" (Oulasvirta et al., 2010, p. 238) in online comment boards through the lens of identity construction and negotiation contributes to the widening of access for marginalized individuals.

Second, although the exploration of identity has gained momentum, there seems to be a gap in the literature when it comes to how ideologies affect and shape people's discursive choices 
within identity negotiations in response to online news reporting. As discussed in Chapter 2, identity sits within wider Discourses and ideologies and it is interesting that in $\mathrm{CMC}$ literature this level has not been extensively investigated. While the concept of community has been discussed in the earlier section, for example, what different forms of communities represent in terms of sharing values, and how they might represent ideologies remains under-theorised; in addition, the idea of layering of ideologies, that is, a community space might be embedded within other communities that have ideologies is also important. All of these considerations make ideology a vital concept in exploring identity. In this regard, the triad of 'ideology, linguistic interaction and online identity construction', chosen as the focus of this study attempts to bridge the research gap.

By reviewing relevant literature on identity construction in online spaces in particular, this chapter identifies gaps in CMC linguistic research. The work mentioned in this chapter is foundational for understanding the interactional context of online communication. I address these gaps by offering a discourse analysis of commenters' online interaction using an Interactional Sociolinguistic framework for contextualising the data. By adopting an IS approach to analyse how commenters discursively construct and negotiate their identities within the context of societal Discourses and ideologies, I will contribute to the under-researched area of identity construction in the online context. This study thus contributes to the existing body of literature on language and identity construction and will be guided by the following sub questions:

RQ1: How does context impact on commenters' identity construction?

RQ2: How do commenters make use of discursive strategies to negotiate their identities online?

RQ3: How do commenters draw upon wider societal ideologies to shape their interactions and identity negotiations? 
From a social constructionist stance, to investigate these three sub-research questions I aim to emphasise the discursively constructed nature of identity, that is, identity is a co-construction and negotiation between participants. This approach "frames communication as a process that is instrumental in the creation of our social worlds, rather than simply an activity that we do within them" (Holmes, et al., 2011, p. 21).

\subsection{Summary}

Online spaces as sites of social interaction have received attention from researchers in different fields. Over the past few decades, studies focusing on these spaces have increased exponentially and alongside those studies, language and identity has become a major concern of (applied) sociolinguistics. Importantly, linguistic studies conceptualize the key concept of identity as socially embedded and discursively constructed. This chapter examined interactions and identity in online spaces. It began with an overview of relevant literature focusing on studies of online identity construction, aiming to identify research gaps. As a result, I argue that research focusing on how online users discursively construct and negotiate identities in online comment boards has not been extensively examined. In this sense, this study highlights the uniqueness of news commenting in today's media landscape in that news commenting remains mostly textual, despite the affordances of current technological developments to post photos, videos, etc., which makes this data of particular interest to linguists.

This chapter also discusses the feasibility of the concept of a virtual community in identity research. With the wide popularization and use of online communication and social networking, users have multiple options for representing themselves. These online spaces therefore are crucial considerations when examining identity as complex and fluid, embedded in group norms. Darvin (2016, p.536) notes that "in the digital world, online users are able to perform different identities through creative assembly, aligning themselves with different communities and imagining other identities." As technology has inspired us to think more about language's role in online identity construction, nuanced approaches which enable researchers to better capture 
the flexible nature of text-based online communication are then needed in linguistic research (Darvin, 2016, p. 537; also see discussion in Bolander \& Locher, 2020).

The next chapter outlines my methodological approach and operationalizes the theoretical underpinnings (Chapter 2) and this chapter's literature review of online identity construction. 


\section{Chapter 4}

\section{Methodology}

\subsection{Introduction}

As discussed in Chapter 2, this study adopts a social constructionist perspective to the discursive enquiry of how commenters construct their online identities in comment boards. In line with this stance, I place emphasis on the importance of collecting authentic data and address calls for a methodological design that allows for comprehensive understanding of how the data is (co)constructed in different levels of context(s). To enact the social constructionist perspective, an interactional sociolinguistic approach to discourse analysis offers opportunities for future examination because it allows for the navigation between macro level of analysis (e.g. the sociocultural context) and the micro level where commenters' linguistic choices are reflected discursively and where commenters (as social actors) enact, perform, and negotiate their identities in social interaction.

This chapter elaborates on the design of the methodology used in this thesis. I first outline the rationale behind selecting the specific news sites and themes. I then discuss the research design, providing a detailed description of the data collection process and data sources as well as the approach I take to data analysis. I revisit the research questions towards the end of the chapter.

\subsection{Rationale for data collection}

The data chosen for examination in this thesis comprises readers' comments selected from specific online news websites in New Zealand (Stuff) and the UK (The Guardian and Mail Online). Before explaining the research methods further, it is important to provide a rationale for why these three specific news sites were chosen from a great number of potential online news websites, as well as the two focus themes around which my analysis is organised. 


\subsubsection{Selecting news sites}

Previous scholars have chosen data sets of various sizes, ranging from more than one thousand collected items to tens of thousands (cf. e.g. Blitvich, 2018; Boyd, 2018; Diakopoulos \& Naaman, 2011; Santana, 2011; Weber, 2014), yet rarely have they justified why that size was appropriate. The choices of sources in the data set and the number of items in each source are important issues for any researcher to consider. In the case of my research, I chose Stuff in New Zealand, The Guardian and Mail Online in the UK context for the following reasons.

First, print and digital media in New Zealand is dominated by two foreign-owned companies (Rosenberg, 2008). At the time of this research, Fairfax New Zealand, an Australian controlled company owned a variety of daily and community newspapers, such as The Dominion Post, The Press and Stuff. Initially these three newspapers were considered as they have wide circulation in New Zealand. It became apparent, however, that the news articles derived from other Fairfaxowned online news websites were almost all duplicates of those found on Stuff; Stuff hosted the websites for Fairfax's New Zealand newspapers and served as a web portal to other Fairfax websites. In addition, I was surprised to find that readers did not take such an active part in other news websites controlled by Fairfax (where they provide readers with comments section) in comparison with the audience of Stuff (Nielsen, 2018; Rafeeq \& Jiang, 2020; Stuff, 2016). Stuff s primary competitor, the New Zealand Herald, was not included in this study because it does not provide readers access to post comments ${ }^{6}$, even though it has the largest readership in New Zealand (ABC, 2018; Gibbons, 2014; NZHerald, 2020; NZME, 2020; Salahshour, 2017). I therefore limited my data collection to Stuff in the context of New Zealand online news websites. As the largest online news source in New Zealand, Stuff brings readers timely news and information, which in turn triggers users' interest in online discussion (Rafeeq \& Jiang, 2020). This source provided my collection of comments for further analysis.

\footnotetext{
${ }^{6}$ It is notable that New Zealand Herald in fact now include comments for some of its content, a practice it began in 2020. This commenting function did not begin until after my data collection was completed.
} 
Given Seib's claim that "audiences are rapidly shifting from almost exclusively local, to communities of interest that transcend geographic and political boundaries", international online news websites are a leading alternative for readers to fulfill their needs for international journalism that is more 'global' in terms of content and approach; "distance may turn out to be meaningless in the era of cyber communication" (2001, p. 100). In this respect, 'distance' is no longer a barrier for people to share and exchange information because technology eliminates this communication obstacle. In other words, online news websites have helped to open up national and local newspapers to a worldwide audience (see e.g. Boyd, 2018; Herring, 2013; Landert \& Jucker, 2011), providing readers with opportunities to participate in online commenting on international news websites (where/when the content of news articles interest them). Following this logic, I decided to focus on international news websites to supplement my local, New Zealand focus, websites where the media environment is similar but not exactly the same as New Zealand. British publications were chosen as a viable example. This allowed me to explore how different newspapers influence commenters' contributions. Furthermore, as the study aims to frame an analysis of two different media environments, The Guardian and Mail Online were selected because of their clear political orientation, namely left-wing and right-wing, respectively (see Islentyeva, 2019; Jonsson, 2014). In contrast, Stuff is more moderate compared to the above two strongly ideological websites; in New Zealand, newspapers have no clear-cut categorization (Maydell, 2010, p. 67). The Guardian and Mail Online were also chosen to represent the UK context because of their genre and history. The two newspapers are often referred to as 'broadsheet' (The Guardian) and 'tabloid' (Mail Online) news sources. Specifically, The Guardian, is known as more "serious" reflecting the highbrow stereotype of broadsheets, and is associated with a more relatively liberal and affluent readership compared with Mail Online (e.g. Cushion et al., 2018; Kaposi, 2019). Accordingly, the tone and, to some extent, content of the specific newspaper reflects these primary demographics in terms of education and class. This selection therefore allows for analysis of a variety of identity formations along a scale of political orientation. 
Second, I only chose news websites that are open access - that is, available to anyone with an Internet connection without subscription requirements or other barriers to access the reader comment sections. However, a minimal site registration requirement (e.g. to register with a username or a pseudonym, email address, social networking account, etc.) is still in place in order to post a comment. Using only free access sites ensures that the present study focuses on the most accessible online space. Using aggregated data from the online space aimed to address an ethical approach to using online data with assumed consent (Maydell, 2010). Therefore, some of the largest online news websites in the world, for example, the NYtimes.com and WashingtonPost.com were ruled out as they have monthly article limits without a paid subscription and thus are not truly open access.

Finally, the news sources selected in this study all enjoy a high level of page views (regionally and internationally) so as to provide a warrant for collecting comments (Nelison, 2018; Duffy \& Rowden, 2005; Pavlik, 2013; Rafeeq \& Jiang, 2020). It is worth mentioning that in the UK context, according to the traffic figures from comScore $(2012,2015)$, Mail Online is now the most visited English-language news website in the world, followed by The Guardian. The large readership highlights the importance of these newspapers and hence their selection as the sources of data for this study.

\subsubsection{Selecting themes}

These online news sites present a wide range of topics, including 'burning issues' that receive the most responses from the public. In this study, I focused on news articles in relation to two different themes, namely, same-sex marriage and travel. Same-sex marriage was chosen as a controversial topic that has been continuously debated by the public in the past decades. As a result, it has drawn particular attention in studies focusing on media discourse (Gibson, 2018; Hemmatian et al., 2019; Paterson \& Coffey-Glover, 2018). Importantly, while discussing this topic, ideologies embodied in the discourse are generally explicit (specifically ideologies of

\footnotetext{
${ }^{7}$ comscore is a media measurement and analytics company based in the United States that provide marketing data and analytics to companies and organizations.
} 
heterosexism). To contrast with this, the ideologies embedded in the topic of travel, my second theme, are more covert or hidden. Travel has also attracted considerable interest from scholars (e.g. Azariah, 2016; Jaworski \& Thurlow, 2009; Thurlow \& Jaworski, 2006, 2011), adding a body of literature from which I can draw in my analysis, active for a different purpose. In this way, I hoped to find out how different topics relate to commenters' online identity construction (addressing one of the sub-research questions in this study).

After providing the rationale for choosing specific news sites and topics, the following section details the methods of data collection used in the present study.

\subsection{Data collection methods}

The size of a data set is primarily determined by the research methods as well as the aims of the study (Given, 2008). As mentioned earlier, previous studies have rarely provided the rationale for choosing specific data sizes while collecting data. As a result, there is no practical reference significance for my study in terms of deciding the data size. Based on my own observation and experience of online commenting, I collected a total number of forty articles from the target online news websites, as I felt confident that the selected forty articles would have enough comments for my further analysis (see Prantl, 2016, who also used a similar number of articles as the data set). In my case, I recognised the repetition of these themes which arguably represent "theoretical saturation" (see Bowen, 2008; Charmaz, 2006; Guest et al., 2006; cf. Woodhams, 2015). Because Stuff is the only news source in New Zealand context, I selected ten articles about same-sex marriage and another ten on travel, while reducing to five articles on each topic from Mail Online and The Guardian in the UK, respectively. This decision provided an even number of articles selected from two contexts. The articles were retrieved by entering keywords into the search engine, such as same-sex marriage, gay marriage, and by searching for relevant articles in the "Travel" section of each news website. 
In terms of the time frame, after contacting the editors of these online news websites for further clarification on how long a news articles is available for readers to read and comment online ${ }^{8}$, I decided to focus on the 12-month period prior to starting data collection (June 2017) when most of the news articles were still available for reading and comments remained accessible. In addition, the comments were collected within a one-week period following each news article's appearance. This is primarily because the comments posted during this period of time can be considered to be the most immediate and fresh responses from readers (cf. Prantl, 2016). ${ }^{9}$ If an entire comment was off topic, for example spamming and advertisements, these were excluded from data analysis. Some initial articles were not used for data analysis as they did not receive any comments even though they were produced within the timeframe. As a result, some news articles that slightly exceeded the initial timeframe were included based on the number of comments they attracted.

All the news articles I collected for data analysis in this study were produced from March 2016 to August 2017. The total number of comments which were collected and analysed is 2,874 (1026 from Stuff, 960 from The Guardian and 888 from Mail Online). The lower number of comments collected from Stuff reflects a numerically limited readership compared to the other two news websites. Another important contributing factor concerns the regulations laid down by the websites, which to some extent imposed restrictions on commenters' participation. More detailed information will be given in the following section.

\subsubsection{Media regulations}

Comment boards related to their respective news articles welcome interaction from readers. However, readers also need to abide by terms and conditions in their online behaviour. In this study, the target online news sources share some common policies. For example, readers are all invited to participate in online commenting to discuss issues and share views. However, due to

\footnotetext{
8 This is personal communication, i.e. on the $12^{\text {th }}$ April 2017, I wrote emails to the editors as their contact details are provided online.

${ }^{9}$ Based on my own observation of online commenting as well as the personal communication from the editors, i.e. I wrote emails to the editors to ask about this on the $27^{\text {th }}$ April 2017).
} 
the anonymity offered by the online platforms, linguistic impoliteness (e.g. profanity, ad hominem attacks, and so on) has been widespread (Coe et al., 2014). In response to this phenomenon, online news websites encourage robust debate and criticism, provided it is civil. In principle, online news websites accept no liability in respect of any comments posted online and the moderators reserve the right to reject or remove comments drawing on its publication policy ${ }^{10}$. Comment sections are thus moderated online discussions. Using real names rather than pseudonyms is preferred best practice, but it is not compulsory. Within this data set, according to my observations, most of the commenters use pseudonyms. Online readers' comments are also "typically arranged in reverse chronological order, rather than adopting journalistic criteria like relevance, and items are published as they are posted" (Domingo \& Heinonen, 2008, p. 5).

Another vital issue concerns word limitations. Specifically, Stuff limits each post to 200 words approximately, while Mail Online maximally allows readers to post 1,000 words within one comment and The Guardian has no word limits at all. This is employed, according to the editors of online news websites (personal communication, $20^{\text {th }}$ April, 2017), to help alleviate the strain on resources required to moderate comments and keep readers' comments relevant to the topics being discussed. The editors believe that the specific word limit criterion is enough for a contributor to express a reasoned opinion. Because of this difference, in this research data, the length of comments is generally longer in The Guardian in comparison with the other two news sources.

Additionally, if there is a comment posted by others which a user thinks should not be approved, they can "flag" or "report" it (screenshots from the target online news websites show the relevant icons: $\sim$ Report , which will resubmit it to the editor for review. Comments are deleted by the moderators if they deviate from the comment policy of the news website. Commenters can also use 'like', 'dislike', 'thumbs up' and 'thumbs down' icons (as shown by the

\footnotetext{
10 For more detailed terms and conditions of online news websites, see https://www.stuff.co.nz/aboutstuff/100908393/stuffs-terms-and-conditions; https://www.theguardian.com/community-standards; https://www.dailymail.co.uk/home/article-1388145/House-Rules.html. I provide these URLs for reference to help readers get a general understanding of how comments are moderated.
} 
following screenshots from the target online news websites

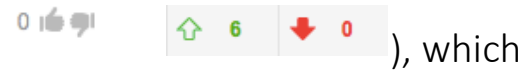
are provided by news websites for users to react to and rate others' comments. Regarded as prompt invitations (Larsson, 2018), these semiotic resources have become another pivotal way for commenters to get an indication on whether other participants agree or disagree with a certain point of view. In this sense, comments that are dis/liked could also be viewed as including a means of multimodal feedback while analysing comments discourse in online communication (Eranti \& Lonkila, 2015; Larsson, 2018). All of these issues were considered while analysing the data.

\subsubsection{The research participants and ethical considerations}

This research is about how readers use discursive choices to construct and negotiate their identities in online interaction, focusing on the online comment boards following news articles in New Zealand (Stuff) and the UK (The Guardian and Mail Online). As a result, the research participants are comprised of readers who participate in online commenting. Given the anonymity provided by the target online platforms, commenters' personal information, such as age, gender, ethnicity and so on, cannot be obtained. In this study therefore, only their posted comments were collected and used for data analysis. Even though the research dataset was composed of anonymous comments, which are entirely open-access and free to view, ethical consideration still needs to be addressed, given that comments are made by human beings (Bolander \& Locher, 2013)

When conducting computer-mediated discourse analysis (CMDA), it is easy to forget that humans are involved. This is mainly because there are no necessarily direct interactions between the researcher and participants during data collection. Since the earliest research on language use in CMD in the early 1990s, the ethics surrounding CMC data have undergone a change from questions of accessibility to questions of privacy (Bolander \& Locher, 2013). In the first wave of CMDA, the question of accessibility and group size determined how sensitive the data was considered to be. If the interactions took place in an environment to which no login was required, or to which a large group had access, the data then would not be considered to be 
sensitive. By contrast, data that was addressed to a specific recipient or smaller groups, for example private blogs and emails, were considered more delicate.

While this simplistic standard is still useful, it is no longer sufficient for future research. In more recent years, the notion of what constitutes private versus public interactions have evolved away from purely access related concerns towards acknowledging content-related considerations as well (Bolander \& Locher, 2013). The distinction of what defines private and public is consequently more comprehensive than if mere accessibility were considered. As Landert and Jucker (2011) write:

We are confronted with media texts that combine private and public aspects on various levels. They may be public in the sense that they are within the public space and can be read by a large and anonymous audience, while at the same time discussing topics which we think of as 'private' and using language which is associated with informal and private conversations (p. 1423).

Accessing such data includes deciding whether consent should be given (or not) by each person whose online materials has been observed, so as to protect their right to autonomy. There are a number of questions that a researcher might ask, for instance, whether or not the data come from a site that is publicly available. If the data is publicly available, the participants may or may not orient to that site as a public context for interaction, and the subject matter may be "sensitive" in some way. According to Bolander and Locher (2013), theoretically, there are four different types of data based on the criteria about. Namely, closed access and sensitive content (private-private); public in both access and content (public-public); public in access, but sensitive in content (public-private); and lastly, closed access yet unproblematic content (private-public). In terms of this study, I categorise the data as "public-public" since the dataset was selected from publicly available sites, where the interactions were clearly oriented to a public audience rather than a private audience of known intimates. In this case, the participants' online identity carefully preserves their anonymity in ways that make it difficult to contact them. On these 
grounds, I did not seek consent from every individual whose words were part of the datasets complied for the analysis.

Comments are shown in the comment box together with usernames and a profile picture (users can choose to upload a profile picture or not; some profile pictures are readers' apparently real facial pictures that may identify who they are while most readers do not include one or use a fake image). In consideration of commenters' privacy, in this present study, all users' profile pictures are blocked and only their screen names (i.e. the pseudonyms that they used to register an account) are shown. In this way, commenters' privacy and their personal information (if they have presented it) are protected and no identifying information was kept (cf. Kerry, 2019). The following screenshot illustrates the format when a commenter posts a comment on the website of Mail Online.

1: now then, Loughborough, $+13-7$ Is this not the same story and photos that you printed last year?

(*Note: "+13" means that this comment receives 13 'likes', while "-7" represents 7 'dislikes' from other commenters.)

As shown, the username (i.e. now then ${ }^{11}$ ) is followed by geographical information (i.e. Loughborough), which tells the current location they are based in. However, this kind of information could not be obtained from The Guardian and Stuff. As the present study primarily focuses on the discursive features of online commenters, this information thus will not be used for analysis.

To conclude, in this study, all the participants are anonymous readers who "self-select" to participate in online commenting in the target online news websites. A continual (re)assessment of the raw data's ethical implications has aimed to ensure the integrity of the present study. This is especially relevant as participants who contributed to the present study's data could not be

\footnotetext{
${ }^{11}$ All commenters' user names are marked in bold in the analysis.
} 
contacted to give consent. A human ethics application (\# 24563) was approved by the Human Ethics Committee, Victoria University of Wellington on May 9 ${ }^{\text {th }}, 2017$.

\subsubsection{Researcher positionality}

In Chapter 1, I commented on my own experience with online commenting (see discussion in Chapter 1). In order to examine this complex process of identity construction without interference, I myself, as the researcher, did not participate in the online commenting I was analysing. I did not engage in posting and replying to other readers' comments in order to encourage further conversations and more opinions being expressed. Importantly, this positioning is in line with other studies which deal with online comments data (e.g. Blitvich, 2018; Rohling \& Rucinski, 2017) and aims to exclude the possibility of guiding readers to create comments that best fit the research purpose, i.e. what the researcher expects to see in the data and hence can selectively interpret to confirm their own preconceptions. At the same time, my practical knowledge and the insights gained from my own experience helped me to interpret the data.

After providing the rationale for data collection and showing the process of how I collect the data, information about the current data set is outlined in the following section.

\subsection{Data set}

As mentioned earlier, the present study focuses on both domestic and international online news websites to collect data. This includes Stuff (www.stuff.co.nz ) in New Zealand; Mail Online (www.dailymail.co.uk) and The Guardian (www.theguardian.com/uk-news) in the UK.

After the forty news articles had been collected (and I had read through all the articles), I categorised each topic into three sub-categories. On the basis of their contents, I divided the topic of same-sex marriage into personal stories, politics-related issues and social-related issues. With respect to the topic of travel, I classified the articles into airlines, destinations and travel tips, respectively. Through the subdivision of each topic, I was able to ascertain greater 
understanding of how the media present same-sex marriage and travel in a broad sense. More detailed information, including names of the articles, numbers of comments that each article has received, and their publication date and so forth are presented in the following three tables. 
Table 4.1 Information about Stuff news source

\begin{tabular}{|c|c|c|c|c|c|c|}
\hline $\begin{array}{l}\text { newspaper } \\
\text { sources }\end{array}$ & news topic & sub category & article name & $\begin{array}{l}\text { numbers of } \\
\text { comments }\end{array}$ & $\begin{array}{l}\text { publication } \\
\text { date }\end{array}$ & $\begin{array}{l}\text { originally } \\
\text { from }\end{array}$ \\
\hline \multirow{20}{*}{ Stuff } & \multirow{10}{*}{$\begin{array}{l}\text { same-sex } \\
\text { marriage }\end{array}$} & \multirow{3}{*}{$\begin{array}{l}\text { politics- } \\
\text { related }\end{array}$} & $\begin{array}{l}\text { Australia's referendum on gay } \\
\text { marriage killed off by Senate }\end{array}$ & 50 & $\begin{array}{l}\text { November } \\
8,2016\end{array}$ & $\begin{array}{l}\text { Sydney } \\
\text { Morning } \\
\text { Herald }\end{array}$ \\
\hline & & & $\begin{array}{l}\text { Australian Govt Backs Away From } \\
\text { Gay Marriage Vote This Year }\end{array}$ & 23 & $\begin{array}{l}\text { March 6, } \\
2016\end{array}$ & Reuters \\
\hline & & & $\begin{array}{l}\text { Australia's same-sex marriage } \\
\text { vote in doubt }\end{array}$ & 79 & $\begin{array}{l}\text { August 21, } \\
2016\end{array}$ & $\begin{array}{l}\text { Australian } \\
\text { Associated } \\
\text { Press }\end{array}$ \\
\hline & & \multirow{4}{*}{$\begin{array}{l}\text { personal } \\
\text { stories }\end{array}$} & $\begin{array}{l}\text { Same-sex couples flocking to } \\
\text { New Zealand to tie the knot }\end{array}$ & 21 & $\begin{array}{l}\text { August 14, } \\
2016\end{array}$ & $\begin{array}{l}\text { Sydney } \\
\text { Morning } \\
\text { Hrald }\end{array}$ \\
\hline & & & $\begin{array}{l}\text { Aussie Couple Elope To NZ Years } \\
\text { After Gay Marriage Was Banned }\end{array}$ & 11 & May 2, 2016 & $\begin{array}{l}\text { dailylife.com. } \\
\text { au }\end{array}$ \\
\hline & & & $\begin{array}{l}\text { I got same-sex married and now I } \\
\text { can't get divorced }\end{array}$ & 82 & $\begin{array}{l}\text { August 21, } \\
2016\end{array}$ & $\begin{array}{l}\text { Australian } \\
\text { Associated } \\
\text { Press }\end{array}$ \\
\hline & & & $\begin{array}{l}\text { Sudbury in Kapiti hosts first } \\
\text { same-sex wedding }\end{array}$ & 276 & $\begin{array}{l}\text { March 21, } \\
2017\end{array}$ & stuff \\
\hline & & \multirow{3}{*}{ social-related } & $\begin{array}{l}\text { Anglican Church delays decision } \\
\text { on same sex weedings for }\end{array}$ & 12 & $\begin{array}{l}\text { May 13, } \\
2016\end{array}$ & stuff \\
\hline & & & $\begin{array}{l}\text { Meghan Trainor hits out after } \\
\text { being used in Australia anti- } \\
\text { marriage equality ad }\end{array}$ & 40 & $\begin{array}{l}\text { August 25, } \\
2017\end{array}$ & $\begin{array}{l}\text { Sydney } \\
\text { Morning } \\
\text { Herald }\end{array}$ \\
\hline & & & $\begin{array}{l}\text { The hypocrisy of Maried at First } \\
\text { Sight Australia }\end{array}$ & 64 & $\begin{array}{l}\text { April 20, } \\
2017\end{array}$ & stuff \\
\hline & \multirow{10}{*}{ travel } & \multirow{5}{*}{ airlines } & $\begin{array}{l}\text { The secret button on plane seats } \\
\text { - does it really give you more } \\
\text { room? }\end{array}$ & 37 & $\begin{array}{l}\text { July 10, } \\
2017\end{array}$ & Stuff \\
\hline & & & $\begin{array}{l}\text { Doctor dragged off United } \\
\text { Airlines flight speaks for the first } \\
\text { time }\end{array}$ & 38 & July 8, 2017 & Stuff \\
\hline & & & $\begin{array}{l}\text { United accidentally gave a } \\
\text { toddler's seat away - and made } \\
\text { his mum hold him }\end{array}$ & 24 & July 6, 2017 & $\begin{array}{l}\text { The } \\
\text { Washington } \\
\text { Post }\end{array}$ \\
\hline & & & $\begin{array}{l}\text { In-flight abuse leaves anxious } \\
\text { plus-sized model heartbroken }\end{array}$ & 62 & July 3, 2017 & Stuff \\
\hline & & & $\begin{array}{l}\text { Fighting fog delays at our } \\
\text { airports: what is the answer? }\end{array}$ & 20 & July 8, 2017 & Stuff \\
\hline & & \multirow[b]{2}{*}{ destinations } & $\begin{array}{l}\text { Three in four elephants that } \\
\text { entertain tourists in Asia live in } \\
\text { cruel conditions, study shows }\end{array}$ & 12 & $\begin{array}{l}\text { July 10, } \\
2017\end{array}$ & Stuff \\
\hline & & & $\begin{array}{l}\text { Travel blogger names New } \\
\text { Plymouth his favourite, but } \\
\text { infrastructure investment } \\
\text { needed }\end{array}$ & 36 & $\begin{array}{l}\text { March 30, } \\
2017\end{array}$ & Stuff \\
\hline & & \multirow{3}{*}{ travel tips } & $\begin{array}{l}\text { All the single ladies... aren't } \\
\text { welcome at this Indian hotel }\end{array}$ & 42 & $\begin{array}{l}\text { June 29, } \\
2017\end{array}$ & Stuff \\
\hline & & & $\begin{array}{l}\text { UK visa woes leave Kiwis in limbo } \\
\text { and out of pocket }\end{array}$ & 78 & July 3, 2017 & Stuff \\
\hline & & & $\begin{array}{l}\text { Money belt, iron and zip-off } \\
\text { pants: } 10 \text { useless travel items } \\
\text { you don't need to pack }\end{array}$ & 29 & July 7, 2017 & $\begin{array}{l}\text { traveller.com. } \\
\text { au }\end{array}$ \\
\hline
\end{tabular}


Table 4.2 Information about The Guardian news source

\begin{tabular}{|c|c|c|c|c|c|c|}
\hline $\begin{array}{l}\text { newspaper } \\
\text { sources }\end{array}$ & news topic & sub category & article name & $\begin{array}{l}\text { numbers } \\
\text { of } \\
\text { comments }\end{array}$ & $\begin{array}{l}\text { publication } \\
\text { date }\end{array}$ & $\begin{array}{l}\text { originally } \\
\text { from }\end{array}$ \\
\hline \multirow{11}{*}{$\begin{array}{l}\text { The } \\
\text { Guardian }\end{array}$} & \multirow{5}{*}{$\begin{array}{l}\text { same-sex } \\
\text { marriage }\end{array}$} & \multirow{3}{*}{$\begin{array}{l}\text { politics- } \\
\text { related }\end{array}$} & $\begin{array}{l}\text { At long last, Germany's } \\
\text { bells are ringing for same- } \\
\text { sex marriage }\end{array}$ & 147 & June 30, 2017 & $\begin{array}{l}\text { The } \\
\text { Guardian }\end{array}$ \\
\hline & & & $\begin{array}{l}\text { Warren Entsch shoots } \\
\text { down Dutton's postal } \\
\text { plebiscite on marriage } \\
\text { equality }\end{array}$ & 789 & July 24, 2017 & $\begin{array}{l}\text { The } \\
\text { Guardian }\end{array}$ \\
\hline & & & $\begin{array}{l}\text { A marriage equality } \\
\text { plebiscite is not inevitable } \\
\text { anymore. We have the } \\
\text { numbers for a free vote }\end{array}$ & 151 & July 5, 2016 & $\begin{array}{l}\text { The } \\
\text { Guardian }\end{array}$ \\
\hline & & $\begin{array}{l}\text { personal } \\
\text { stories }\end{array}$ & $\begin{array}{l}\text { King's College removes } \\
\text { photo of ex-archbishop } \\
\text { opposed to gay marriage }\end{array}$ & 553 & $\begin{array}{l}\text { December 21, } \\
2016\end{array}$ & $\begin{array}{l}\text { The } \\
\text { Guardian }\end{array}$ \\
\hline & & social-related & $\begin{array}{l}\text { religious faith is no } \\
\text { obstacle for marriage } \\
\text { equality }\end{array}$ & 262 & $\begin{array}{l}\text { November 18, } \\
2016\end{array}$ & $\begin{array}{l}\text { The } \\
\text { Guardian }\end{array}$ \\
\hline & & & & & & \\
\hline & \multirow{5}{*}{ travel } & airlines & $\begin{array}{l}\text { United Airlines CEO calls } \\
\text { passenger's removal a } \\
\text { 'mistake of epic } \\
\text { proportions' }\end{array}$ & 529 & May 2, 2017 & $\begin{array}{l}\text { The } \\
\text { Guardian }\end{array}$ \\
\hline & & \multirow{3}{*}{ destinations } & $\begin{array}{l}\text { Whitby: why it's love at } \\
\text { first bite for foodies }\end{array}$ & 197 & July 10, 2017 & $\begin{array}{l}\text { The } \\
\text { Guardian }\end{array}$ \\
\hline & & & $\begin{array}{l}\text { Glamping in central France: } \\
\text { a rural retreat that's } \\
\text { packed with creature } \\
\text { comforts }\end{array}$ & 60 & July 9, 2017 & $\begin{array}{l}\text { The } \\
\text { Guardian }\end{array}$ \\
\hline & & & $\begin{array}{l}\text { Europe's hidden coasts: } \\
\text { Costa Maresme, Spain }\end{array}$ & 118 & May 20, 2017 & $\begin{array}{l}\text { The } \\
\text { Guardian }\end{array}$ \\
\hline & & travel tips & $\begin{array}{l}\text { How to travel the world } \\
\text { with no money - by people } \\
\text { who have done it }\end{array}$ & 1109 & $\begin{array}{l}\text { January 2, } \\
2017\end{array}$ & $\begin{array}{l}\text { The } \\
\text { Guardian }\end{array}$ \\
\hline
\end{tabular}


Table 4.3 Information about Mail Online news source

\begin{tabular}{|c|c|c|c|c|c|c|}
\hline $\begin{array}{l}\text { newspaper } \\
\text { sources }\end{array}$ & news topic & sub category & article name & $\begin{array}{l}\text { numbers of } \\
\text { comments }\end{array}$ & $\begin{array}{l}\text { publication } \\
\text { date }\end{array}$ & originally from \\
\hline \multirow{3}{*}{ Mail Online } & \multirow{5}{*}{$\begin{array}{l}\text { same-sex } \\
\text { marriage }\end{array}$} & \multirow[t]{2}{*}{ politics-related } & $\begin{array}{l}\text { Little men with soft backbones and no } \\
\text { soul': Furious Peta Credlin unleashes on } \\
\text { her former Liberal Party colleagues as } \\
\text { gay marriage debate splits the } \\
\text { government }\end{array}$ & 94 & $\begin{array}{l}\text { June 27, } \\
2017\end{array}$ & $\begin{array}{l}\text { Daily Mail } \\
\text { Australia }\end{array}$ \\
\hline & & & $\begin{array}{l}\text { Angela Merkel votes AGAINST legalising } \\
\text { gay marriage but is defeated as } \\
\text { Germany passes new same-sex wedding } \\
\text { law }\end{array}$ & 113 & July 1, 2017 & Mail Online \\
\hline & & $\begin{array}{l}\text { personal } \\
\text { stories }\end{array}$ & $\begin{array}{l}\text { Woman, 28, and her pregnant bride, } 31 \text {, } \\
\text { become first same-sex Australian couple } \\
\text { to get 'married' in new 'legally-binding } \\
\text { unity' }\end{array}$ & 51 & July 7, 2017 & $\begin{array}{l}\text { Daily Mail } \\
\text { Australia }\end{array}$ \\
\hline \multirow{8}{*}{ Mail Online } & & & $\begin{array}{l}\text { Devout Christian, 67, who shoved a } \\
\text { lemon meringue pie into Qantas CEO } \\
\text { Alan Joyce's face in protest of same-sex } \\
\text { marriage pleads GUILTY to assault }\end{array}$ & 82 & July 7, 2017 & $\begin{array}{l}\text { Daily Mail } \\
\text { Australia }\end{array}$ \\
\hline & & social-related & $\begin{array}{l}\text { Lesbian conspiracies and transgender } \\
\text { 'devil children': How tennis legends } \\
\text { Martina Navratilova and Margaret Court } \\
\text { went to war over 'racist and } \\
\text { homophobic' insults sparked by two } \\
\text { female players having a baby together }\end{array}$ & 61 & June 3, 2017 & Mail Online \\
\hline & \multirow{6}{*}{ travel } & \multirow{3}{*}{ airlines } & $\begin{array}{l}\text { Chaos for thousands of British tourists as } \\
\text { they face two-hour delays at Majorca } \\
\text { airport caused by a shortage of Spanish } \\
\text { police officers }\end{array}$ & 112 & July 12, 2017 & $\begin{array}{l}\text { Daily Mail } \\
\text { Australia }\end{array}$ \\
\hline & & & $\begin{array}{l}\text { Say farewell to your in-flight tipple! } \\
\text { Spain's party islands demand alcohol } \\
\text { ban on planes and even AIRPORTS to } \\
\text { tackle 'anti-social' tourism }\end{array}$ & 132 & July 13, 2017 & Mail Online \\
\hline & & & $\begin{array}{l}\text { Welcome to hell': Furious British tourists } \\
\text { endure severe delays at Majorca airport } \\
\text { as police warn of MORE chaos this } \\
\text { weekend }\end{array}$ & 281 & July 15, 2017 & Mail Online \\
\hline & & & & & & \\
\hline & & destinations & $\begin{array}{l}\text { Smiling for the camera seconds before } \\
\text { dream holiday ends in tragedy: } \\
\text { Australian tourist, } 70 \text {, plunges } 100 \mathrm{ft} \text { to } \\
\text { his death while parasailing in Thailand }\end{array}$ & 238 & July 13, 2017 & $\begin{array}{r}\text { Daily Mail } \\
\text { Australia }\end{array}$ \\
\hline & & travel tips & $\begin{array}{l}\text { EXCLUSIVE: The tricks than mean anyone } \\
\text { can travel upper class - professional } \\
\text { flight hacker reveals how he tours the } \\
\text { world like royalty (without earning } \\
\text { points or using a credit card) }\end{array}$ & 690 & July 25, 2017 & Mail Online \\
\hline
\end{tabular}


I initially somewhat optimistically determined that all the comments (including replies to the previous comments) would be collected and analysed. However, from observing participants' engagement with online commenting, it became clear that the number of comments that each article received differs, largely depending on the popularity of the news article as well as the readership of the specific news site. Considering the high volume of comments for some of the articles (sometimes in the thousands), I realised that it was necessary to limit the number of comments collected from each article. In order to ascertain the appropriate size of data collection, I began with one hundred comments to see what kind of data that produced. And I then compared to other data sizes and found that was appropriate and managable for a thesis. Following other scholars (e.g. Boyd, 2018; Chen \& Pain, 2017; Santana, 2011), I collected and analysed all the comments of that news article if the number was less than the proposed standard, i.e. one hundred comments. If the number of comments was over one hundred, I used the first one hundred comments (I collected the oldest comments as they were arranged chronologically) from each article as a threshold for the data. In this way, my initial intention was to collect approximately 4,000 comments from 40 articles in total as a manageable dataset. The actual number amounts to 2,874 comments, as shown by the above three tables. By comparing with the data size of other studies dealing with online comments (e.g. Blitvich, 2018; Santana, 2011; Weber, 2014), I believe that the final data size of the present study is manageable and provides sufficient data for later data analysis.

In addition, because many articles are syndicated or reproduced from other sources, the original sources of the news articles have been identified. As evident in the above tables, The Guardian only uses news articles produced by themselves. Stuff and Mail Online, however, pull articles from other news websites. For example, Mail Online borrowed 5 articles (5 out of 10) from Mail Online Australia, and Stuff pulls some of their news articles from the Sydney Morning Herald, The Washington Post, the Australian Associated Press, and so on. The rationale for pointing out this difference is, from the readers' perspective, that they are going to a specific site to get their news. In this study, all the commenters go to the specific target news site to read news and further participate in online commenting, but the articles they respond to are sometimes drawn 
from other groups sometimes (e.g. the Australian media). This kind of selection shows that news websites are inherently intertextual as they pull news articles from other regions (Seals, 2012). The main reason for the newspapers to do this is because they identify specific articles as a matter of interest for their own readerships (cf. Riffe et al., 2018; also see e.g. replies from the editors regarding why they borrow news arctiles from other news sources). Although the current research focuses on the UK and New Zealand context, the Australian context is also significant because of the relevance of that context to the readerships of those sites, i.e. Stuff recycled news articles focusing on the legalisation of same-sex marriage in Australia from Australian newspapers as the editors assume that their readers, mostly New Zealanders, would be interested in this.

Having acknowledged the imbalance where Mail Online and Stuff pull news from other news sites while The Guardian does not, it is important to mention the current legal status of same-sex marriage in different contexts. To be specific, during the period of data collection and analysis of this study, same-sex marriage was legal in both New Zealand and the UK (in each case from 2013), while it was illegal in the Australian context.

\subsection{Data analysis methods}

In this study, the main method of analysis is qualitative discourse analysis, narrowed to an analytical focus on positionality (Bucholtz \& Hall, 2005) and intertextuality (Bakhtin, 1981; Fairclough, 1992; Tannen, 2007) to examine how commenters discursively construct and negotiate their identity in online interaction. This analysis is combined with a frequency analysis of the sub-topics (the theme of same-sex marriage and travel) discussed by participants for the purposes of warranting, as well as the specific linguistic strategies (i.e. constructed dialogue; this examination is in line with the practices of previous research focusing on intertextaulity, as will be discussed in section 4.5.2) used by commenters in different news websites. Each is detailed further below. 


\subsubsection{Frequency analysis and queries}

Under the themes of same-sex marriage and travel, I analysed the content of each comment and then coded the sub-topics further. The reason for doing this is not to pay attention to the significantly statistic differences, but to guide my qualitative analysis. For example, according to the results of this thematic coding, commenters talked about religious beliefs most under the category of same-sex marriage, whilst they were more willing to share personal experiences when discussing travel issues (detailed information about the dominant sub-topics will be discussed in Chapter 5 and 6). This demonstrates that my analysis is not a result of cherry picking, a common accusation aimed at qualitative research, but instead systematic, with the frequency analysis of sub-topics as the initial tool used for sorting the data and allowing me to see the prominent issues that I should focus on. During my analysis, I also investigated the distribution of constructed dialogue (see section 4.5.2) employed by commenters as a more micro level discourse feature to allow access to the intricacies of the discourse. Together, the frequency analysis of constructed dialogue alongside the distributional investigation of subtopics discussed by commenters, informed a deeper understanding of how participants discursively construct and negotiate their ideologies and identities.

\section{Process of running queries}

After all the data had been coded, I ran queries through the NVivo11 software I used for coding. If we see coding nodes as a process of splitting up and decontextualising the sources, then, the process of running different queries could be considered as the recontextualisation and bringing together of the data into different patterns of understanding and deeper insight (Bengtsson, 2016). Queries enabled me to probe my data, so as to find patterns and pursue the connections between the topics (same-sex marriage and travel), the people (commenters) and places (news

websites) and so on in this study. To be more specific, running queries allowed me to investigate how the discursive resources (especially my chosen micro focus on constructed dialogue) were differently employed by commenters in the three target online news websites as well as in regard to the two topics of same-sex marriage and travel. The dominating trends of variable cross-occurrence that emerged from query running not only provided me with the overarching 
patterns of language use, but also a closer look at how linguistic strategies were utilized by commenters to construct and negotiate their identities.

I created different types of nodes when I was coding the data. A node is a collection of references about a specific topic (e.g. person, place, etc.) or other area of interest (Bazeley, 2007). With respect to the present study, I created nodes such as constructed dialogue, and labelled the sub-topics being discussed by commenters. Once all the data had been analysed, I re-examined my analysis and integrated similar nodes on the basis of their topics. For example, with respect to the topic of same-sex marriage, some commenters compared gay marriage in different countries, such as Germany, Australia and New Zealand (e.g. the user HHeLibe commented: "Congratulations to the Germans, joining the band of developed nations which have moved into the $21^{\text {st }}$ century. That just leaves us here in Australia. Sigh"; Maxypaddy wrote, "I'm shocked to hear that gay marriage has only just been made legal in Germany"). As shown, commenters were discussing the legalisation of gay marriage. Yet, these discussions were simultaneously showing the status of same-sex marriage in Germany and Australia. Therefore, those nodes were integrated into one parent-node named "status of gay marriage across the world".

Following the same method, other nodes were also re-categorised. For instance, under the parent-node of "rights", three child-nodes were identified, including human rights (e.g. Trains, "once again Australia continues to become embarrassment when it comes to human rights"), marriage rights (e.g. Djc92, “...gay people have the same marriage rights as the rest of us...") and civil rights (e.g. JayJay13, "why should you be granted a veto over other people's civil rights? what possible business is it of yours if other people wish to marry each other?"). As the sample comments extracted from the data illustrate, each commenter's focus was different although they were all talking about rights-related issues. Using JayJay13's comment as an example, the user was not just emphasising the importance of gay people's civil rights. They have signalled their explicit position towards same-sex marriage at the same time. That is, marrying someone is not "your" (referring to someone who does not support the legalisation of same-sex marriage as 
they do) business. Thus, two sub-topics are discussed under the topic of 'rights' in this example. Accordingly, this type of comment that embeds more than one topic was cross-coded.

Importantly, I categorised free nodes on the basis of how the commenters were talking about a certain issue, rather than their opinions on the issue. For example, the node classified as 'bigotry', in fact, was not about the commenter who made this comment casting themselves as a bigot. Instead, it was classified into the category of 'bigotry' because the wording has to do with different reasons why people are not in favour of same-sex marriage, such as religious conflicts (e.g. Notveryanonymous wrote: "good to see she's following the Christian teachings of tolerance and loving thy neighbour. Bigoted old bat"). From the above example posted on Mail Online by Notveryanonymous, we can postulate that what they were trying to convey is not simply defining Margaret Court (a tennis player) as a bigot, but to voice that her stance on gay marriage is bigotry because of her personal religious beliefs. From this perspective, we can interpret the contribution as a sarcastic comment that satirizes Christianity and the stance on the same-sex marriage. In order to demonstrate how I classified these nodes and further interpreted them into parent-nodes, an example has been given as follows. See Figure 4.1 below.

Figure 4.1 Examples of nodes classification and integration (topic of same-sex marriage)

\section{Nodes classification}

\begin{tabular}{|c|c|c|c|}
\hline \multicolumn{4}{|c|}{ Topic of same-sex marriage } \\
\hline No. & parent node & child node & sub-child-node \\
\hline \multirow{3}{*}{1} & \multirow{3}{*}{$\begin{array}{l}\text { the legalisation of gay } \\
\text { marriage }\end{array}$} & \multirow[b]{2}{*}{$\begin{array}{l}\text { status of gay marriage across the } \\
\text { world }\end{array}$} & $\begin{array}{l}\text { marriage in } \\
\text { Germany }\end{array}$ \\
\hline & & & $\begin{array}{c}\text { marriage in New } \\
\text { Zealand \& } \\
\text { Australia }\end{array}$ \\
\hline & & $\begin{array}{c}\text { influence of the legalisation gay } \\
\text { marriage }\end{array}$ & step back \\
\hline \multirow{4}{*}{2} & \multirow{4}{*}{ politics-related issues } & comments about politicians & \\
\hline & & conscience vote & \\
\hline & & plebiscite & \\
\hline & & democracy & \\
\hline \multirow{4}{*}{3} & \multirow{4}{*}{ rights } & human rights & \\
\hline & & marriage rights & $\begin{array}{c}\text { marriage rights' } \\
\text { availability }\end{array}$ \\
\hline & & civil rights & \\
\hline & & constitutional rights & \\
\hline
\end{tabular}


In order to give a full demonstration of the nodes classification, I offer two tables (i.e. the classifying nodes on the topic of same-sex marriage and the classifying nodes on the topic of travel) that detail how nodes were classified and integrated according to the topics discussed by commenters in the forty articles that constitutes the current dataset. See Appendices (Appendix B: Nodes classification).

In total, I categorised 10 parent-nodes regarding the topic of same-sex marriage and 21 parentnodes for the topic of travel. Notably, some of the parent-nodes were further classified into more detailed child-nodes and sub-child-nodes if further divisions of topic were triggered. The integration of classified nodes thus provided me with a clear picture of how individuals talk about same-sex marriage and travel in a systematic way. Additionally, some case-nodes were also created, namely usernames of commenters (all the comments made by the same commenter were tagged) and news websites (all the comments posted on the same news website were tagged based on the same topic). See Figures 4.2 and 4.3.

Figure 4.2 Examples of news websites tagged

\begin{tabular}{|c|c|c|c|c|c|c|c|}
\hline Name & $\wedge$ & Sources & Referen.... & Created On & Created By & Modified On & Modified By \\
\hline (†) Mail Online & & 5 & 5 & $24 / 05 / 2018,10: 5 \ldots$ & LIU & $24 / 05 / 2018,10: 5 \ldots$ & LIU \\
\hline$\Theta$ stuff & & 10 & 10 & 24/05/2018, 10:5... & LIU & $24 / 05 / 2018,11: 0 \ldots$ & LIU \\
\hline (†) The Guardian & & 5 & 5 & 24/05/2018, 10:5... & LIU & $30 / 05 / 2018,11: 1 \ldots$ & LIU \\
\hline
\end{tabular}

Figure 4.3 Examples of usernames tagged

\begin{tabular}{|c|c|c|c|c|c|c|c|}
\hline Name & $\hat{\imath}$ & Sources & Referen... & Created On & Created By & Modified On & Modified By \\
\hline$\Theta$ Annony Mouse & & 1 & 1 & $22 / 05 / 2018,3: 55 \ldots$ & LIU & $22 / 05 / 2018,3: 56 \ldots$ & LIU \\
\hline$\oplus$ anon & & 1 & 1 & $22 / 05 / 2018,3: 09 \ldots$ & LIU & $22 / 05 / 2018,3: 10 \ldots$ & LIU \\
\hline$\oplus$ ApegotFire & & 3 & 10 & $22 / 05 / 2018,1: 41 \ldots$ & LIU & $22 / 05 / 2018,4: 58 \ldots$ & LIU \\
\hline$\Theta$ Apple pie & & 1 & 3 & 22/05/2018. 1:41... & LIU & $22 / 05 / 2018.1: 41 \ldots$ & LIU \\
\hline
\end{tabular}

These figures show how news websites and usernames of commenters were tagged. Figure 4.3 shows that some participants do not just comment on one news article. Rather, they comment on different news articles, as seen in the information of 'sources' and 'references'. In this case, in 
Figure 4.2, 'sources' refers to the number of articles that makes up the dataset (i.e. how many news articles I collected from each news website), and the icon 'references' explains how many news articles I coded and analysed. In terms of Figure 4.3, the category of 'sources' specifically reports the number of articles that a participant comments on. The column 'references' refers to how many times their comments were coded (e.g. the commenter 'ApegotFire' contributed 10 comments on the topic of same-sex marriage in 3 different news articles; it is assumed that the same person is using the same username). This information shows the (relatively) stable membership and regular interaction within this specific online space. ${ }^{12}$ Once the nodes were classified, I ran queries related to my research questions. In particular, I initiated two queries as follows:

1) Which of the sub-topics are discussed most by commenters on the topic of same-sex marriage and travel?

2) How is constructed dialogue employed by commenters on different topics in the three different news websites?

By running these queries, trends emerged that informed the qualitative analysis, offering me a better understanding about how commenters discursively construct and negotiate their identities in online interaction.

\subsubsection{Qualitative discourse analysis}

The frequency analysis described helped me recognize emergent trends from within the data. I then surveyed the coded instances to find representative comments to explain those trends. Once these representative comments were extracted, I conducted qualitative discourse analysis on the data. Qualitative discourse analysis seeks to examine the interactional (and not merely informational) meanings and interpretations that arise in and are created through discourse,

\footnotetext{
12 Recall the debate on the existence of a virtual community as discussed in Chapter 3 and which will be discussed further in the analysis chapters.
} 
including interpersonal, social, political, ideological and other meanings (Seals, 2013, p. 59). In other words, employing qualitative discourse analysis to analyse the readers' comments allows me to take a closer look at what and how ideas were expressed, what could have been said instead, and how what was said was responded to, by whom and so forth, among a great number of considerations (Gee, 2005c; Schiffrin et al., 2001). My choice of analytic approach is Interactional Sociolinguistics (to inform my constructionist stance).

\section{Interactional Sociolinguistics as a methodological framework}

Interactional Sociolinguistics as an approach to discourse analysis emerged out of Gumperz's earlier work on the ethnography of communication (Gumperz \& Hymes, 1972). It builds on assumptions from several disciplines notably sociology, ethnomethodology, linguistics, pragmatics, and anthropology (Gumperz, 1982, 2005; Schiffrin, 1996). As discussed earlier in this thesis (see section 2.2.2), as a fundamentally interpretative and qualitative approach to discourse analysis, IS focuses on how meaning is created in talk in daily communication (Vine et al., 2008) and specifically explores how people manage social identities as they interact. Gumperz drew on the work of sociologist Erving Goffman (1967, 1981, 1989), placing emphasis on the contextual nature of language in a variety of social interactions (Goffman, 1981; Schiffrin, 1996). IS is, in other words, an approach which studies actual language use in specific contexts (see Holmes et al., 2011; Marra, 2012a, 2012b; Schiffrin, 1996 for overviews).

Gumperz and Cook-Gumperz (2008) define IS as "an approach to discourse analysis that has its origin in the search for replicable methods of qualitative analysis that account for our ability to interpret what participants intend to convey in everyday communicative practice" (p. 215). Because interlocutors are unable to say everything they mean explicitly when they communicate, IS posits that they have to rely on the words that are used as well as background knowledge in order to appreciate what is meant and "to discover what others assumed the relevant context was for producing their words in" (Jaspers, 2011, p. 135). Using miscommunication as an example, Jaspers (2011) argues that when people are asked to clarify exactly what they meant, they can easily become upset because the logical inferences are 
assumed. Jaspers uses a well-rehearsed example to explain this phenomenon: A tells his colleague B that he had a flat tire on his way to work; colleague B replies: "what do you mean, you had a flat tire?" (cited in Jaspers 2011, p. 135; for more examples, see Garfinkel, 1963, pp. 221-222). In this case it is argued that, $A$ is surprised by this response from colleague $B$ because he believes that there is no need for further explanation (that is, having a flat tire is something that B should have been able to interpret). We expect our interlocutors to draw upon shared knowledge to interpret the full meaning of our utterances and leave space for this. IS takes the view that talk is incomplete and that speakers expect "one another to be aware of the social world that extends beyond the actual setting and of the norms for the use of words that apply there" (Jaspers, 2011, p. 135). In other words, IS takes the position that because conversations are incomplete, interlocutors have to draw on extra communicative knowledge to understand each other, that is, what the present speaker attempts to express and how this is relative to the conversational context. Gumperz's view was instrumental in laying the explanatory groundwork for understanding miscommunication between interlocutors from different backgrounds, I argue that his view regarding the propensity for this communication as the norm is highly prescient and relevant to my data, not least because of the hybrid nature of online communication. Gumperz argues that as people are socialised into the practices of different speech communities, they come to accrue a set of conversational presuppositions which guide inferential practices (Heller, 2013, p. 192). These practices, however, differ across cultures, and communities of practice within these (a more current conceptual framework used in sociolinguistics; see e.g. Eckert \& McConnell-Ginet, 2013; Holmes \& Meyerhoff, 1999; Marra \& Holmes, 2007; Wenger, 1998; also see discusion in section 3.3), placing the analytic focus on understanding the dynamic norms of the specific community being investigated. Therefore, an IS approach to discourse emphasises much more than surface forms.

In terms of my data, contextualisation cues (Gumperz, 1982, 2005) are valuable in that they provide clues to "determine what meaning the speaker intends to convey", as well as "planning appropriate responses, and managing their expectations of what is next to come" (Gumperz, 2005, p. 219; Rampton, 2017, p. 3). This, in the focus on wider social contexts, clearly links to 
Bakhtin's $(1981,1992)$ notion of intertextuality (also see Seals, 2019) in that both our utterances and inferences are anchored in established practices as well as feeding forward into future deployments. In practical terms, contextualisation cues can be accessed through a variety of linguistic components, including content, code-switching, and prosody as well as fine grained linguistic detail such as discourse markers and pronoun use (see Holmes et al., 2011). Speakers use contextualisation cues to display "different aspects of self and other" (Schiffrin, 1996, p. 318) in order to indicate "not only what they mean to say, but also what speech activity they are engaged in" (Tannen, 1992, p. 10).

In sum, IS tries to "describe how meaningful contexts are implied via talk, how and if these are picked up by relevant others, and how the production and reception of talk influences subsequent interaction" (Jaspers, 2011, p. 135). In other words, IS focuses on how people make communicative meaning 'in the now' while simultaneously acknowledging the crucial interconnectedness with sociocultural and sociohistorical contexts, and paying attention to the power relations within these.

\section{Doing Interactional Sociolinguistics in a CMC context}

As discussed earlier in Chapter 2, identity construction does not take place in a social, cultural, or historical vacuum (see e.g. Greenbank, 2020; Marra \& Angouri, 2011). Aligning with this, IS views language as a crucial resource that can be creatively harnessed to construct social structures rather than simply reflecting them (Jaspers, 2011). Recalling the example from Garfinkel described above, we observe that interaction can be streamlined through the shared knowledge (i.e. knowing what a flat tire is) and by the identities (i.e. being a knowledgeable colleague) of the interlocutor. The implicit meanings must be recognised by interlocutors so as to understand the full meaning. Consequently, words and utterances can be said to have an indexical function (a concept used by Garfinkel's ethnomethodology; also see discussion in 2.2.3); the interpretation of the talk is dependent on the indexical meanings that each word carries with it (Bailey, 2008, p. 2317; Jaspers, 2011). Within this line of thinking, the present study principally adopts the notion of intertextuality to examine how commenters interact with each other and extend the 
communicative act, as will be discussed in Chapter 5 and 6 where it is used to operationalise (and focus) my analysis. IS therefore approaches discourse "through the worm's eye, not the bird's" (Rampton, 2001, p. 84). As explained by Jaspers (2011), rather than focusing on public texts (e.g. news reporting), IS pays close attention to small-scale interaction. By maintaining such a focus, IS is able to provide a more nuanced understanding of larger social processes and to show how in fact many larger interactions depend upon small ones (Jaspers, 2011, p. 142). In this sense, IS helps us to gain a better understanding of larger social evolutions as it "is very useful for its micro-and macro-contextually situated insights into interaction" (Seals, 2021, p. 231).

Although IS has most typically been applied to face-to-face communication settings, this discourse context has gradually lost the importance it once had due to the fact that "a substantial and increasing portion of everyday life is spent not in the physical copresence of others but in virtual spaces" (Cetina, 2009, p. 63). Goffman (1989) explains that the technology of his time promotes the "interaction order" (Goffman, 1983), a term he used to describe the realm of face-to-face interactions, arguing that telephone conversations (the technology of non face-to-face spoken interaction of the time) "are essentially 'a departure from the norm' (Goffman, 1964), a 'marginal' way to interact socially (Goffman, 1971, p. 70), and provide an inferior version of 'the primordial real thing'" (Goffman, 1983; Goffman, 1989; cited in Bullingham \& Vasconcelos, 2013, p. 102). This reasoning would suggest that online interaction is not as rich as physical interaction due to a lack of observable clues (Bullingham \& Vasconcelos, 2013). The relevance of Goffman's interaction order has been debated in the intervening years, especially whether the argument about inferior status still holds theoretical weight for nonphysical online contexts, particularly considering the spread of computer-mediated communication for social interaction and the role of macro-societal power in modern society.

Cetina (2009) points out the need to update Goffman's theory to account for changes in modern society, such as asynchronous communication (e.g. leaving a text message for someone to read later) and human communication with computers (e.g. buying movie tickets from an automated 
kiosk) (Seals, 2021). Goffman's work, according to Arundale (2010), should be updated to reflect current technological developments and relevant studies. Yet other researchers have argued that while it is not applicable in every case, the interaction order proposed by Goffman continues to explain much of what takes place in our current communication practices. For example, Bullingham and Vasconcelos (2013) recognise the usefulness of Goffman's interaction order in exploring identity formation and interaction in various online contexts, including interaction in message boards and blogs. Other scholars, such as Miller (1995), also believe that online interaction is just another form that expands Goffman's theoretical framework of interaction order.

With respect to the present study, advanced Web 2.0 technology includes the multimedia features of online news websites, such as photos, videos, 'dislike/like', 'flag/report' buttons and links to the commenter's personal profiles. All of these enable online users to display a variety of markers which index their identities during the interaction (Hodkinson \& Lincoln, 2008), bringing "richness" to their online communication. In this respect, the functions inherent to the context contribute to people's online interaction and identity construction. Drawing on this point of view, Jenkins (2010) points out that the gulf between face-to-face and computer-mediated communication has been bridged as a result of technological advancements that have triggered various new means of performing identities online. Similarly, Laughey's (2007) study endorses Goffman's theories as being applicable to CMC environments. Adopting Goffman's account of the presentation of self, Miller and Arnold (2009) have gone so far as to argue that offline identity construction are "back-region preparation" (p. 54) for online encounters.

In the present study I see the value of Goffman's theories (especially in the way that they provide an underpinning to the Gumperz approach) and follow other scholars who adopt an IS approach to analyse comments discourse, aiming to explore how commenters construct identities in an online world through the use of their linguistic choices while interacting with other interlocutors. From a social constructionist perspective, an IS approach allows the analyst to consider both micro-level discursive choices and macro-level social structures that influence 
online users' identity performance, underscoring the dynamic negotiation of identity

(Greenbank, 2020; Marra \& Angouri, 2011). Rather than seeing identity as a static entity, it is a process of co-construction and negotiation between interlocutors of that specific interaction (recall the discussion provided in Chapter 2).

\section{Analytic focus}

As discussed in Chapter 2, then, the overarching philosophical stance that the present study takes is social constructionism, and interactional sociolinguistics informs how I enact the social constructionist stance; it allows the analyses to consider both the micro level of discourse features and the macro level components of context. I then narrow down my analytical focus to positionality (Bucholtz \& Hall, 2005) and intertextuality (Bakhtin, 1981) to explore the ways in which readers of online news use diverse linguistic devices to construct their ideologies and identities in the setting of online interaction.

\section{Positionality}

As discussed in Chapter 2, this study draws heavily on ideas summarized in Bucholtz and Hall's sociocultural linguistic identity framework. According to them, identity is described as "the social positioning of self and other" (Bucholtz \& Hall, 2995, p. 586) through which the relational, emergent, negotiated and co-constructed nature of identity is highlighted (see e.g. Bamberg, De Fina, \& Schiffrin, 2011; Bucholtz \& Hall, 2005; Greenbank, 2020; Lønsmann, 2016; also see discussion in section 2.2). In this view identity does not belong to any singular person but rather it is a discursive co-construction between interlocutors, emerging from the interaction (Bucholtz \& Hall, p. 587). Following Bucholtz and Hall (2005), I therefore view commenters' positioning and identity enactment as a process of co-construction and negotiation between interlocutors, whereby commenters position themselves and others while at the same time being positioned by these others. My analysis begins at the micro-level, with close attention paid to positionality.

Within the positionality principle, Bucholtz and Hall broaden the traditional range of identity by presenting a creative model of identity. This model is made up of three levels, including "macro- 
level demographic categories (e.g. gender and age), local, ethnographically specific cultural positions (e.g. manager or warehouse worker), and temporary, interactionally specific stances and participant roles (e.g. interviewer and interviewee)" (Bucholta \& Hall, 2005, p. 592; cited in Lønsmann, 2016, pp. 17-18). Within this principle, Bucholtz and Hall incorporate macro-level trends, such as studied in variationist sociolinguistics, local identity categories, such as those found in ethnographic observations, and micro-level identity work, such as those captured by close discourse analysis. Rather than arguing that one of these levels of identity work is most properly called "identity", Bucholtz and Hall demonstrate that multiple levels can be found in a single discourse. They claim that, for doing linguistic analysis, "it is not a matter of choosing one dimension of identity over others, but of considering multiple facets in order to achieve a more complete understanding of how identity works" (2005, p. 593).

In other words, by taking up different assumed roles (e.g. listener), relevant identities of interlocutors are enacted during the interaction. These temporary roles and interactional positions in turn "contribute to the formation of subjectivity and intersubjectivity in discourse" (Bucholtz \& Hall, p. 591). Focusing on a group of 17-year-old Californian girls who share similar access to linguistic resources (because they all come from European American middle-class families and go to the same high school), Bucholtz and Hall (2005) demonstrate how different levels of identity emerge in interaction through the use of quotative forms. Interviews conducted with these participants indicate that the creative usage of linguistic markers allow them to portray themselves as various types of teenagers and symbolise their memberships of that group. For example, by using quotative markers such as "say", "go" and "be like", one girl aims to "perform quotative functions" (Bucholtz \& Hall, p. 592). In addition, another two girls adopt a more recent emerged quotative marker of "be all"13 to "index their youth identity" (p. 593). Consequently, local interactional identities are enacted by using these different levels of quotative markers, that is, that the former girl representing the nerdy group is considered not

\footnotetext{
13 Readers are referred to, for example, Blyth et al., 1990; Dailey-O'Cain, 2000; Waksler, 2001, for a full discussion on the functionality of these quotative markers.
} 
interested in pursuing trendiness, while the latter girl representing the popular group seems to be more fashionable.

In order to capture practical evidence regarding positioning taking and identity construction in interaction, I draw on positioning theory (Davies \& Harré, 1990) as a salient tool in my analysis. Like identity, Davies and Harré (1990) also see positioning as a process of discursive interaction between participants (Lønsmann, 2016, p. 18). The concept of positioning then draws our attention to appreciate identity as intersubjective and as something that is in flux. In Davies and Harré's theory, there are two different types of positioning, namely interactive positioning and reflective positioning (p. 4). ${ }^{14}$ Specifically, the term reflective positioning is used for the claiming of identities by the individuals; while interactive positioning describes the circumstances where identities are assigned to them by other interlocutors in the course of interaction (Davies \& Harré, 1990, p. 4; Menard-Warwick, 2009, p. 38). In this study, I make use of these concepts and tools that Davies and Harré offer, which give me access to the micro-features that contribute to the positionality. Building on this distinction, my analysis pays attention to how commenters position themselves and others (including relevant subjects being evaluated) at all levels of identity during the interaction, as well as the ways in which these positions are negotiated and contested (Lønsmann, 2016, p. 17). Analysing positioning thus offers "the close inspection of how speakers describe people and their action in one way rather than another and, by doing so, perform discursive actions that result in acts of identity" (Bamberg et al., 2011, p. 182).

In addition to the relationships between the speaker and the talk, self and other, positionality also includes relationships to "the dominant ideologies, widespread social practices and underlying structures drawn together as Discourse" (De Fina, Schiffrin, \& Bamberg, 2006, p. 7). This statement again expands positioning analysis to include big-D Discourses (Gee, 1990, 2015) as central to the construction of identity (see section 2.3.1). Bamberg (2004b, p. 225) notes that positioning analysis allows "differentiation of how speakers work up a position as complicit

\footnotetext{
${ }^{14}$ A full discussion of positioning theory is well beyond the scope of this study. The reader is referred to e.g. Davies \& Harré, 1990; Van Langenghove \& Harré, 1999.
} 
with...or countering dominant [D]iscourses" and illustrates how speakers "position themselves in relation to the $[D]$ iscoures by which they are positioned." ${ }^{15}$ Focusing on both self and other positioning, positioning analysis reveals how interactional data is produced during interaction. In addition, it highlights the close relationship to an emergent identity, being negotiated in a different setting (i.e. online interaction is different from traditional face-to-face communication), and recounted through discourse.

Drawing on IS resources, positioning analysis allows me to investigate how identity is coconstructed and negotiated between interlocutors in interaction. At the same time, this analysis emphasises the impacts of ideologies on identity construction by illustrating the relationship between (little-d) discourse and (Capital-D) Discourses, and between agency and larger social structures (Greenbank, 2020).

\section{Intertextuality}

Hodges (2015) argues that "social actors do not formulate utterances in a vacuum, nor do individual 'speech events' (Hymes, 1974) take place in isolation from one another" (p. 42). Rather, when people interact, they inevitably imbue their discourse with other texts that help constitute meaning. This principle speaks directly to the ideas of Russian philosopher and literary theorist Mikhail Bakhtin, who developed an intertextual (or the more closely translated term 'translinguistic') approach to the analysis of texts. Fairclough (1992) makes use of Bakhtin (1986) to demonstrate how speakers formulate a text by making use of other texts:

"Bakhtin points to the relative neglect of the communicative functions of language within linguistics, and more specifically to the neglect of ways in which texts and utterances are shaped by prior texts that they are 'responding' to, and by subsequent texts that they 'anticipate'." (p. 101).

\footnotetext{
${ }^{15}$ In this quotation, I embrace Gee's $(1990,2015)$ distinction between little-d discourse and capital-D Discourse and hence, I capitalised Discourse here (also see discussion in Chapter 2).
} 
Putting it another way, for Bakhtin, all texts, both spoken and written, are dialogic, responding to prior (previously produced) and anticipating future (still to be produced) texts. This point of view is corroborated by Seals (2012), who argues that "in all discourse, no language is solely authored by the person speaking at the time. It has been influenced by past discourse and is thus connected to other people" (p. 233). This feature of discourse is referred to as "intertextuality", a term originally coined by Kristeva in the late 1960s, who introduced the Bakhtinian idea and translated Bakhtin's work into English to western audiences (see Kristeva, 1986). The term is not always credited to Bakhtin, it is the Bakhtin Circle (comprising Bakhtin and his colleagues) where the origins lie. Their claim is that "all language use is filled with dialogic overtones" (Bakhtin, 1986, p. 102). This dialogic approach recognises the multiplicities of voices (see Seals, 2019) and emphasises that the "internal dialogism of the word that permeates all forms of speech, including forms externally structured as monologues" (Bakhtin, 1986, p. 279).

This idea presupposes that even monologues exist in a world of pre-existing talk (Hodges, 2015, p. 43) and as a result, "language is not a neutral medium that passes freely and easily into the private property of the speaker's intentions; it is populated-over populated-with the intentions of others" (Bakhtin, 1992, p. 294). In this regard, intertextuality is theorised as carrying "two voices" in conversation: that is, past and anticipated (Bakhtin, 1986; cited in Wertsch, 1993, p. 53) which emphasises the responsive and dialogic nature of discourse. Elsewhere, Fairclough (1992, p. 104) uses the terms of French discourse analysts Authier-Révuz (1982) and Maingueneau (1987), namely 'manifest' as opposed to 'constitutive' intertextuality. Specifically, in manifest intertextuality, other texts are explicitly present and recognisable by readers, stereotypically marked by features such as quotation markers to indicate the overlapping use of prior discourse. 'Constitutive intertextuality' as the complement refers to the "confluence of discourse conventions that contribute to text production" (p. 45). Analysts do not focus on the product of discourse practice alone and so Fairclough argues for the term interdiscursivity for the intertextual phenomenon (1992, p. 104) to reserve the term intertextuality as “a broad label for all phenomena" (Hodges, 2015, p. 45). 
Given the fact that the meaning embedded in discourse is not always directly conveyed from writers to readers, Kristeva (1980) argues that "the notion of intertextuality replaces that of intersubjectivity" (p. 66). In the usage of intertextuality, Kristeva divides it into two axes, that is, horizontal (subject-addressee) and vertical (text-context), capturing the "three dimensions of textual space" (p. 65) as "writing subject, addressee, and the exterior texts" (p. 66). These two axes have shared codes and every text relies on prior codes or intertexts. Her argument is that instead of focusing their attention on the 'structure' of the text, readers should look at the structuration of how the text comes into being. For Kristeva (1980), horizontal intertextuality refers to the space between writer and reader, which is associated with the relationship between subject and addressee-so that in written texts "the word in the text belongs to both writing subject and addressee" (p. 66); while the vertical intertextuality "deals with the orientation of a written text to the broader literary and cultural context in which it is embedded" (ibid; also see Hodges, 2015, p. 45). In other words, the vertical axis focuses on how texts create meaning (by reader or writer) in relation to other texts. From the Bakhtinian perspective, these two types of intertextuality comprise the dialogical links that connect the author and the readers of the text (Bakhtin, 1986). As a further extension in her most important essay The Bounded Text (pp. 36-63), Kristeva aims to establishing how a text is constructed from previously existing discourse (p. 36). According to Allen (2011, p. 35), "texts are made up of what is at times styled 'the cultural (or social) text', all the different discourses, ways of speaking and saying, institutionally sanctioned structures and systems which make up what we call culture." In this sense, every single text "is not an individual, isolated object, but, rather, a compilation of cultural textuality." (Allen, 2011, p. 35). Therefore, the individual text and the cultural text are inextricably linked to each other.

The discussion by Kristeva outlined above is a substantial reinterpretation of the Bakhtinian notion of "dialogue", establishing relationships between the writer, reader, and society. The distinction is that Kristeva's theory focuses on more abstract notion of, for example, "text, textuality, and their relation to ideological structures" (Allen, 2011, p. 35). Despite this distinction, both Bakhtin and Kristeva posit that texts are not isolated objects but rather they act 
as entities that closely relates to larger socio-cultural textuality where they are created. Accordingly, all texts contain ideological structures expressed through discourse (Allen, 2011). This insistence implies that, as Allen writes,

“For Kristeva, the intertextual dimensions of a text cannot be studied as mere 'sources' or 'influences' stemming from what has traditionally has been styled 'background' or 'context' (Kristeva, 1980, pp. 36-37). [...] the text is a practice and a productivity, its intertextual status represents its structuration of words and utterances that existed before, will go on after the moment of utterance, and so are, in Bakhtin's terms, 'doublevoiced'. (p. 35).

'Double-voicing' is a crucial complement to the Bakhtinian notion of dialogism. Allen (2011, p. 22) observes that other terms, for example, 'heteroglossia', 'double-voiced discourse' and 'hybridization' have also begun to emerge in literature. From the Bakhtinian perspective, language use is substantially a social phenomenon since "our speech, namely, all our utterances, is filled with others' words, varying degrees of 'otherness' or varying degrees of 'our-own-ness', varying degrees of awareness and detachment" (Bakhtin, 1986, p. 89; emphasis added). Intertextuality thus is an analysis of how different elements in society influence the production of language interconnected in various social contexts.

With respect to the present study, unlike face-to-face communication, online commenting offers online news readers interactive options in a 'one-to-many' way, largely realised by making responses to previous comments made by other interlocutors. Readers make use of this opportunity to convey, for example, their ideologies and stances to others. As Bakhtin (1986, p. 338) contends, "people talk most of all about what others talk about - they transmit, recall, weigh and pass judgment on other people's words, opinions, assertions, information". The concept of intertextuality which sets up relations between different 'voices', hence, provides researchers with valuable insights about the relationship between discourse and interaction (in contrast to single speech events). As Bauman (2005) contends, intertextuality "gives us a vantage 
point on social formations larger than those of the immediate interaction order, and it gives us ways of thinking of power and authority in discourse-based terms larger than those that are immediately and locally produced in the bounded speech event (interactional power)" (p. 146).

So far, the notion of intertextuality has been conceptualised in this thesis by drawing on the work of key scholars in the space. I now turn to examples chosen from my data to illustrate how I operationalise this abstract concept in the analysis. As discussed earlier, one of the most recognisable features of intertextuality can be seen in the employment of quotations (regardless of whether they are direct or indirect quotations). For example, in response to the rejection of legalising gay marriage in Australia, one of the commenters directly quotes someone, saying, “@WilliamMoon, 'our civilisation is dying', where is this fact stated?..." (see section 5.4.1, Excerpt 5.6 for further discussion). In this example, the intertextual aspect is manifested by overtly drawing upon the presence of other texts. By quoting an other's words directly, the commenter simultaneously addresses their own concerns (i.e. where is this fact stated?), indicating that they are anticipating an explanation from the prior interlocutor with whom they are engaged. This example shows how commenters can, in some cases, easily make access to the shared previous texts.

When examining intertextuality, people also need to rely on their external world knowledge (e.g. ideological understandings, the perceptions and actions of the society they live in, etc.) when the addressee does not immediately and overtly share all necessary background information in the present message. The following example extracted from the same-sex marriage data shows how commenters use intertextuality to better understand what is going on during the interaction. Leerdam comments on that rejecting the same-sex marriage bill in Australia is an act of "making its indigenous people sit in the back of bus" (lines 3-4; see more discussion in Except 5.3). This particular expression is later picked up by Rectinol, who rephrases it and says, "they don't let them get on the bus-hence anger" (line 17, Excerpt 5.3). This intertextual echo of previous discourse, however, requires some background knowledge to grasp the interwovenness of meaning embedded in the discourse. Specifically, when people describe someone/something as 
'back of the bus', it can be seen as being related to Rosa Park (an African-American activist in the civil rights movement), indexing that someone is being oppressed and/or disregarded. In this conversation, through the employment of metaphor, both commenters are drawing on the intertextual knowledge of forcing someone to the 'back of bus'. This functions to convey a message to an ideal reader who understands the reference as well as expecting that reader to extrapolate that the LGBTQ community is being placed in a position of lack of agency/power. An intertextual lens shows how our utterances are both based on established practices and can be used in future deployments.

The establishment of intertextuality offers an appropriate method to explore a variety of discourses. In this study, I will follow Seals' (2012) notion of intertextuality, defining it as "the joining together of ideas through texts in communication, while simultaneously reacting to and reflecting primed prior texts and anticipating unrealized future texts" (p. 233). To conduct the intertextual analysis in this study at a practical level, I follow Seals's (2012) work by paying close attention to the intertextuality of constructed dialogue (Tannen, 2010), particularly focusing on the effects of types of quotations (whether direct or indirect; see e.g. Clark \& Gerrig, 1990; Sclafani, 2008) used by commenters. In addition, I am also interested in how semantic presupposition makes use of commenters' ideologies through intertextuality (Porter, 1986; Seals, 2012). Each perspective will be discussed in the following section.

\section{Constructed Dialogue}

According to Tannen (1989), examining quotations, labelled as 'constructed dialogue', is an effective way to analyse intertextuality in discourse. Rather than constantly coming up with ideas anew, Tannen argues that utterances are established based on prior discourse. From this point of view, as Kristeva (1980, p. 36) puts it, a text is a "permutation of texts, an intertextuality in the space of a given text, in which several utterances, taken from other texts, intersect and neutralize one another." As an echo of this view, many scholars have focused on constructed dialogue in media discourse largely because of its inherently intertextual nature. That is, writers in the media have to show ideological stances or emphasise their opinions through the use of 
quotation no matter whether it is directly quoted or paraphrased. For example, Thetela (2001) and Sclafani (2008) successfully applied an intertextual analysis to news discourse through the lens of constructed dialogue. For this reason, in this study, I am following Sclafani and Thetela's method to analysing the intertextual nature of constructed dialogue.

In online commenting, commenters are encouraged to engage in conversations with other interlocutors to share and exchange opinions. This kind of interaction often makes use of direct and indirect quotations from other commenters' statements. Direct quotation ${ }^{16}$ is a repetition of the established discourse (Bauman \& Briggs, 1990). Through the use of quotation, the writer enables themself to position the quoted author in a particular position. The quotation used in interaction then becomes a means of showing the writer's own ideological stance (Seals, 2012). In this regard, the examination of the constructed dialogue allows us to see how commenters use different types of quotation to position themselves and others who they are responding to. This contributes to unpacking the ideologies behind the use of the specific quotations and further helps us examine commenters' online identity construction.

\section{Semantic Presupposition}

It is crucial to consider more than just the explicit and literal information to understand the text. Importantly, in some genres there can be a substantial portion of text that requires some effort to decipher the meanings it contains which can be concealed or implicit (Harmash et al., 2020). In line with this thinking, in my analysis attention has been paid to the nature of presupposition in discourse, or the presupposed meanings and connotations that are expected to be brought to bear on interpretations by the addressees. It is important to distinguish what kinds of presuppositions are being identified, however. While some linguists are interested in sematic presupposition, others are interested in pragmatic presupposition (cf. Kempson, 1975; BurtonRoberts, 1989; Gazdar, 1979). This difference in focus had led to a terminological and theoretical

\footnotetext{
16 When the words used in the writing are exactly the same as the original source, it is regarded as a direct quotation. When anything someone said is referenced to in an indirect quotation, the meaning rather than the exact words is referred to. Detailed clarification between direct and indirect quotation (i.e. how I code constructed dialogue in this study) will be discussed in the analysis chapter when this discourse feature emerges from the data.
} 
distinction when discussing presupposition. For the purposes of this study, I here attempt to distinguish between these in order to highlight how I apply semantic presupposition to my analysis.

Discussions around presupposition touch on a theory of meaning that underpins and extends much beyond linguistic form. According to Oualif (2017), pragmatic presupposition focuses on the speaker, the context of the utterances, and the "knowledge" shared by the interactants. Stalanker (1974), for example, claims that pragmatic presupposition is what the speaker considers to be the common ground of the interlocutors in a conversation. Put differently, it concerns understandings of the logic behind how we get from an expressed utterance to the interpretation of that expression by paying close attention to implicature and inferencing in the text of the discourse. In contrast to this, semantic presupposition deals with the relationship between sentences (Oualif, 2017). It is much more connected to the idea of the 'ideal reader' (Fairclough, 2001; see discussion in section 5.4), focusing on what source of intertextual knowledge is needed in order to be able to make sense as an ideal reader of that meaning. That is, semantic presupposition is more interested in the cognitive process involved in the interaction, while pragmatic presupposition is more interested with the social meaning. Semantic presupposition is about what meaning is primed in discourse and how the meaning is received by people to get a certain understanding of these ideas.

In this study, instead of purely looking at the intended or inferred meaning of a text, in my analysis I consider how the semantic meaning is interpreted intertextually by the participants of a conversation. For example, within the topic of travel, I discuss how commenters draw on wider societal ideologies (e.g. 'bar girls' in Thailand; young wife and old white men) and harness semantic presupposition (e.g. "I'd investigate the wife", "how long was he married and how big is his life insurance") to allow them to speak to their ideal readers.

Combining discourse analysis with semantic models affords a deeper understanding of how discourse makes use of ideologies to speak to the audience via intertextuality (Seals, 2012). At 
the same time, the effects of presupposition on intertextual understanding should also be taken into consideration. As Porter (1986, p. 34) insists: "examining texts 'intertextually' means looking for 'traces', the bits and pieces of Text which writers or speakers borrow and sew together to create new discourse." Drawing on this statement, it seems that presupposition has pointed to the relationship between discourse and semantics in intertextuality. Porter supports this view by going on to say, "presupposition refers to assumptions a text makes about its referent, its readers, and its context - to portions of the text which are read, but which are not explicitly 'there'" (Porter, 1986, p. 35). Accordingly, analysing semantic presupposition in comment discourse helps to reveal commenters' expressed ideologies and hidden meanings beyond the text itself.

As discussed, semantics is closely related to ideologies in discourse. van Dijk explains that:

Ideologies organize specific group attitudes; these attitudes may be used in the formation of personal opinions as represented in models; and these personal opinions may finally be expressed in text and talk... Because models represent what people know and think about an event or situation, they essentially control the 'content', or semantics, of discourse. (van Dijk, 1998, p. 27)

Van Dijk goes on to explore the relationship between ideologies and a semantic model of discourse by claiming that

[i]n many respects a text is merely the tip of the iceberg of what is mentally represented in models. And conversely, due to the construction of a model and the application of knowledge and attitudes in this construction, people usually understand much more of a text than it actually expresses. (1998, p. 28)

To sum up, the intertextual analysis conducted in this study investigates the ways in which multiple voices (e.g. multiple types of ideologies, multiple points of view, and multiple things to 
say) are transformed and reused to create something new. The ways that the comments discourse is recognised involves specific ideological and socio-political positions that have implications for the identities of their advocates. Studying how commenters draw upon, recognise, and transform different discourses in an interaction will provide insights into the processes of ideological and 'reality' construction.

\subsection{Clarifying the research questions}

As discussed in Chapter 2 and 3, under the overarching research question, there are three refined sub-questions:

RQ1: How does context impact on commenters' identity construction?

RQ2: How do commenters make use of discursive strategies to negotiate their identities online?

RQ3: How do commenters draw upon wider societal ideologies to shape their interactions and identity negotiations?

To operationalise these research questions, I narrow down my focus of each for analytical purposes. First, instead of broadly focusing on the online context (i.e. online interactions that take place in comment boards), I focus on the chosen topics that are represented in the news sources in particular. Thus, RQ1 investigates how topic impacts on commenters'identity construction. Second, to operationalise RQ2, through the lens of positionality and intertextuality (see discussion in this chapter), I aim to investigate how commenters make use of positionality and intertextuality to negotiate their identities online. Last, RQ3 recognises the important role that ideology plays in this study to explore how ideologies (whether explicit or implicit) shape commenters' interactions and identity negotiations. 


\subsection{Summary}

To investigate (online) identity, the employment of an IS framework highlights the discursively emergent nature of identity in interaction. It not only focuses on the micro level of discursive choices but also considers the important effects of wider social structures that influence discourse. This IS approach to analysis therefore provides a fruitful tool to answer this study's overarching research question - How is identity constructed and negotiated through comments discourse in an online communication setting? - into more detailed questions that explore micro level identity negotiation.

Throughout this chapter, I have provided the rationale for data collection (including reasons for choosing news sites and topics), a description of methods of data collection and analysis, as well as the analytical focus of this study. It is worth noting that the data used in this study is entirely open to view and is collected from free-access online news websites located in New Zealand and the UK. The data was imported to the qualitative data analysis software NVivo11 where data was reviewed and coded into relevant nodes. After that, in-depth discourse analysis was carried out resulting in the findings presented in the following chapters. Importantly, I clarify the research questions to provide justification of how I am going to analyse my data. In the analysis chapters to follow (Chapter 5 and 6), I will show how these methodological and analytical decisions play out, bringing an empirical focus to the fore. 


\section{Chapter 5}

\section{Analysis of theme 1: Same-sex marriage}

\subsection{Introduction: Ideologies at the forefront}

While public support for same-sex marriage (SSM) has increased dramatically in recent years, there remain ongoing dissenting voices in society. As a result, the theme of same-sex marriage continues to generate intense debates, including in the comments section on online news site. It is through these debates that a wide range of ideologies are indexed, recognised and further negotiated. In emphasising the discursive elements of identities, I explore the dual role of $\mathrm{D} /$ discourse, connecting these to ideologies while examining how commenters construct and negotiate identities. The context of online commenting, understood here as an interactional process through which social actors construct their identity, provides a rich environment for this kind of negotiation. In this chapter, I analyse the topic of same-sex marriage as the first focus for analysis, arguing the choice of this theme to explore discussions when ideological differences are made explicit because of the topic's widely recognised controversial nature. I primarily focus on how ideologies are explicitly embodied in interactions, and I then take a step further to examine the construction and negotiation of commenters' identities in online interaction.

Importantly, I draw upon positionality and intertextuality as two useful and interdependent approaches to access identity. From an identity perspective, I examine self- and otherpositioning (the current participants and/or other related topics and interlocutors mentioned in the interaction), including how interlocutors discursively accept or reject specific positions (Bamberg, 2011a; De Fina, 2003). This analysis enables me to investigate how commenters' positions are impacted by the capital-D Discourses which are widely shared in society so as to see how these Discourses are reflected in little-d discourse (Gee, 1990, 2005c). While analysis of positionality provides rich data for identity investigation, it simultaneously points to the nuance that is needed for the intertextual analysis in my data. Given the dialogical nature of comments 
discourse, the concept of intertextuality affords extra insights to investigate how the interaction comes into being, thus contributing to a systematic analysis of identity enactment and negotiation. I begin the chapter with a brief review of sub-topics being discussed by commenters, outlining the overall trend for how the theme of same-sex marriage is discussed in the present data set.

\subsection{Prominent sub-topics under the topic of SSM}

Identification of sub-topics is useful because it provides a preliminary indication as to those themes, and in turn the ideologies they index, which are most salient in the dataset. The result of this thematic coding offers a productive starting point, as a great number of individual comments are aggregated and can then be divided into broad categories based on the subtopics discussed by commenters (cf. Aker et al., 2016; Madden et al., 2013). In this section, I begin by presenting the results of Query 1 (i.e. which of the sub-topics are discussed most by commenters on the topic of same-sex marriage; see section 4.5.1) before moving to the in-depth qualitative discourse analysis. By doing so, I parallel the established procedures for corpusassisted informed discourse analysis, providing me with a means of seeing significance in the data set (P. Baker, 2010; P. Baker \& Levon, 2015). By running the query (i.e. Query 1) through the analytic software Nvivo11, the top four sub-topics that emerged are found in Table 5.1 (as highlighted in red in the table). 
Table 5.1 Number of Comments on each sub-topic (in the parent nodes) coded in three news websites regarding the topic of SSM

\begin{tabular}{|l|c|c|c|c|}
\hline sub topics & A: Stuff & B: Mail Online & C: The Guardian & Total \\
\hline $\begin{array}{l}\text { 1: attitudes towards same-sex } \\
\text { marriage }\end{array}$ & 41 & 30 & 26 & 97 \\
\hline 2: culture & 1 & 0 & 2 & 3 \\
\hline 3: gay wedding tourism & 4 & 0 & 0 & 4 \\
\hline 4: legalisation of same-sex marriage & 80 & 14 & 22 & 116 \\
\hline 5: marriage equality & 29 & 5 & 22 & 56 \\
\hline 6: morality & 6 & 1 & 2 & 9 \\
\hline 7: mind your own business & 9 & 6 & 3 & 18 \\
\hline 8: politics-related issues & 29 & 52 & 93 & 174 \\
\hline 9: religion & 42 & 32 & 53 & 127 \\
\hline 10: rights & 22 & 2 & 15 & 39 \\
\hline
\end{tabular}

As shown in the table, the most prominent sub-topics discussed by the participants are those relating to politics, religion, the legalisation of same-sex marriage and attitudes towards samesex marriage. The top-four topics are clearly interrelated. Specifically, when commenters talk about, for instance, politicians, democracy, and votes (e.g. plebiscite), these comments are coded as political-related issues; when their discussion focuses more on the status of marriage equality and the influence of legalising same-sex marriage, their comments are categorised as the legalisation of same-sex marriage. In terms of attitudes towards same-sex marriage, I primarily focus on commenters' expression of their personal feelings towards SSM, for example, whether they support marriage equality or not; the node of religion specifically deals with commenter's religious beliefs. This thematic coding needs to be treated with caution because of the issues around cross-coding, yet it is useful as indicative of the overall trends, providing me with the prominent issues that I should focus on my qualitative analysis (see section 4.5.1).

After explaining how I decided on these sub-topics and how these categories are distinct from each other, I explore these differences in detail in each readership. For comparison purpose, based on table 5.1, the percentage of the top four sub-topics discussed by commenters in each news website is presented in the following table. See Table 5.2. 
Table 5.2 Percentage of the top four sub-topics discussed in three news websites regarding the topic of SSM

\begin{tabular}{lcccccc}
\hline & \multicolumn{2}{c}{$\begin{array}{c}\text { Stuff } \\
\text { Total: } 482\end{array}$} & \multicolumn{2}{c}{$\begin{array}{c}\text { The Guardian } \\
\text { Total: } 500\end{array}$} & \multicolumn{2}{c}{$\begin{array}{c}\text { Mail Online } \\
\text { Total: } 388\end{array}$} \\
\cline { 2 - 7 } & $\begin{array}{c}\text { No. of } \\
\text { references } \\
\text { coded }\end{array}$ & $\begin{array}{c}\text { Percentage } \\
\%\end{array}$ & $\begin{array}{c}\text { No. of } \\
\text { references } \\
\text { coded }\end{array}$ & $\begin{array}{c}\text { Percentage } \\
\%\end{array}$ & $\begin{array}{c}\text { No. of } \\
\text { references } \\
\text { coded }\end{array}$ & $\begin{array}{c}\text { Percentage } \\
\%\end{array}$ \\
\hline $\begin{array}{l}\text { Politics- } \\
\text { related } \\
\text { issues }\end{array}$ & 29 & $6.0 \%$ & 93 & $18.6 \%$ & 52 & $13.4 \%$ \\
\hline $\begin{array}{l}\text { Religion } \\
\text { legalization } \\
\text { of SSM }\end{array}$ & 42 & $8.7 \%$ & 53 & $10.6 \%$ & 32 & $8.2 \%$ \\
\hline $\begin{array}{l}\text { Attitudes } \\
\text { towards }\end{array}$ & 41 & $16.6 \%$ & 22 & $4.4 \%$ & 14 & $3.6 \%$ \\
SSM & $8.5 \%$ & 26 & $5.2 \%$ & 30 & $7.7 \%$ \\
\hline
\end{tabular}

As seen from table 5.2, in The Guardian, the top three sub-topics discussed by commenters in order of frequency are: political-related issues (93 times), religion (53 times), and attitudes toward gay and same-sex marriage (26 times). This order and relative frequency also appears in Mail Online (e.g. political-related issues have been coded 52 times, religion and attitudes toward gay and same-sex marriage have been coded 32 and 30 times, respectively). However, the top three sub-topics discussed by participants are slightly different in Stuff. The Stuff readership comments directly on the legalisation of same-sex marriage most (80 times), following by religion (42 times) and attitudes toward gay and same-sex marriage (41 times). These differences remain even when considering the uneven totals of comments analysed for each website. As explained in section 4.4 (i.e. data set), regarding the topic of same-sex marriage, the Stuff data set comprises 482 comments; while The Guardian and Mail Online involve 500 and 388, respectively.

It can be seen that the topic of political-related issues takes up $18.6 \%$ and $13.4 \%$ in The Guardian and Mail Online, respectively; while the topic of the legalisation of same-sex marriage is discussed most by commenters of Stuff, making up $16.6 \%$ of comments. Additionally, within the top four sub-topics discussed by commenters, the topics of 'politics-related issues' and 'the 
legalisation of SSM' are not mutually exclusive, resulting in some being cross-coded. I surmise that the difference can mainly be explained by the fact that I was collecting the data about the same time that Australians were having a debate on legalising same-sex marriage. It thus represents a significant regional issue for New Zealand. In terms of the UK context, commenters focus more on the political personalities involved in the same-sex marriage issue, which appears to align with the interest of their readership at the time. This shows the importance of considering the local context and events of note at any given time that research is being conducted. ${ }^{17}$

With respect to the UK context, the highly frequent discussion about politics-related issues reflects readerships' interest in discussing politics in both Mail Online and The Guardian as well as article writers' preference of focusing on the political perspective while reporting same-sex marriage (Binderkrantz et al., 2017; Gavin, 2018). It is worth mentioning that Germany's samesex marriage bill was passed during the period of my data collection, resulting in many news articles reporting this event. While this is similar to the New Zealand context of Australis's samesex marriage legalisation debate, there is an important additional component in the UK context of personality politics (Gavin, 2018). That is, some articles devoted considerable space to informing their readers that the chancellor of Germany (Angela Merkel) voted against gay marriage, which in turn produced a lot of comments surrounding on politicians' votes and attitudes towards legalising gay marriage. In fact, the article itself influences the content of comments as it shows the news writer's positioning of the media sources along a political spectrum. This, to some extent, explains why politics-related issues emerge as the top sub-topic discussed by participants in the UK context. The focus on political issues could also be evidenced from the news articles' titles. For example, “Angela Merkel votes AGAINST legalizing gay marriage but is defeated as Germany passes new same-sex wedding law" - Mail Online; "Warren Entsch shoots down Dutton's postal plebiscite on marriage equality" - The Guardian, and so on.

\footnotetext{
17 See the Discourse Historical Approach proposed by Ruth Wodak (e.g. Reisigl, 2017; Reisigl \& Wodak, 2016) in which the argument is made for understanding the discourse in its historical context.
} 
This offers one plausible explanation for the dominance of the sub-topic of politics-related issues.

In addition to these two sub-topics, the topic of 'religion' also plays an important part in their discussion (see Table 5.2). More specifically, the topic of religion equates to $8.7 \%$ of the topics in Stuff; while it accounts for $10.6 \%$ and $8.2 \%$ in The Guardian and Mail Online, respectively. This point is evidenced in the qualitative analysis, showing that commenters' religious beliefs are indexed within presentation of their attitudes towards same-sex marriage, further influencing their positioning and identity construction and negotiations. I now turn my attention to qualitative perspective to explore how commenters construct their online identities through the lens of positionality and intertextuality.

\subsection{Analysis of positionality}

As discussed in Chapter 2 and 4, drawing on the extensive literature from sociolinguistics, Bucholtz and Hall (2005) synthesize current approaches to analysing identity. As one of these principles as argued in the previous chapter, the concept of 'positionality' is valuable for describing the dynamic nature of identity constriuction in interaction. I hereby reintroduce this concept in brief (see section 4.5.2), as it emerges in the data and plays a role in constructing and negotiating commenters' online identities.

Positionality is theorised as multidimensional, dynamic and emergent, and investigated in terms of how it is negotiated in interactions between interlocutors. In other words, the traditional assumption that social behaviour is only confined by macro level identity categories (e.g. gender, age, etc.) is challenged by the principle of positionality. By contrast, Bucholtz and Hall (2005) posit that participants make use of local identity categories in their encounters. Importantly, during interaction, these identity categories are often captured by various positionings (cf. Davies \& Harré, 1990). Within my focus on positionality, Davies and Harré's (1990) concept of positioning offers practical tools to look at the ways in which interlocutors discursively position themselves and others. These identity positions offer extra intended information, including their 
attitudes and stances towards specific issues. From this perspective, positioning of selves within the interaction points to the identities being constructed by the participants: "Positioning aims at a description of the discursive practice by which people position self and others in talk-ininteraction so as to assign locally relevant identities" (Lucius-Hoene \& Deppermann, 2000, p. 210). This view echoes Bucholtz and Hall's positionality principle; the way a person positions $\mathrm{him} /$ herself and the way a person is positioned by others matters for how information is understood.

The lens of positionality allows us to ascertain how interlocutors see each other in terms of the writer/speaker's understandings of the events being discussed. When commenters are ideologically positioning themselves and others, and being positioned by others in interactions, they use the respective positions to understand and then make conclusions about what other commenters are saying in connection to their own points of view and "ideological 'truths' "(Seals, 2012, p. 232). The principle of positionality, therefore, leaves space for analyses of identity from small to large scale, using close discourse analysis to investigate micro-level identities. Following Bucholtz and Hall (2005) as well as drawing on Davies and Harré (1990), the present study looks at the myriad positionings taken by commenters, suggesting a way to operationalize how identities are constructed in individual discourse texts such as online interaction.

My research data provides a bridge from these theoretical considerations to practice. Examining commenters' identity practices in online interaction sheds light on the many ways in which the wide range of ideologies and Discourses contribute to their identity work, adding valuable nuance to existing online identity findings.

\subsubsection{Self- and other- positioning}

In this section, I begin to illustrate how various positionings (e.g. self- and other-positioning) contribute to constructing and negotiating identities during online interaction through some specific interactional examples extracted from the dataset. Articles about the passing of the 
Marriage (same-sex couples) Act by the German parliament and the rejection of the marriage bill by the Australian parliament prompted heated discussion among commenters. Through the analysis of positionality, I explore how commenters react to diametrically opposed voting results of a similar event so as to enact and further negotiate their identities.

Excerpt 5.1: [At long last, Germany's bells are ringing for same-sex marriage; The Guardian] ${ }^{18}$

1 HHeLibe: $\quad$ Congratulations to the Germans, joining the brand of developed

2

3

4 ID0268416 $>{ }^{19} \mathrm{HHeLibe:}$ 5 JonnyCK > HHeLibe:

6

7

8

9 Ursus Rexxx > JonnyCK

10

11

12

13

14

15

16

17

18

19 nations which have moved into the $21^{\text {st }}$ century. That just leaves us here in Australia. Sigh

Don't worry, it will come...

Good message to be sending, but shameful that Merkel voted against. She's a real cynic-bring the vote forward because it'll be popular, but vote against to maintain credibility with her part.

I feel so sad that she voted against...shame on you Chancellor Merkel! I've come to expect this sort of moronic prejudice from my country's so called president, "Humpty Trumpty"; (so, nicknamed for his never, to exist, wall!), but...l expect $\mathrm{MUCH}$ MORE from other...more, 'coherent', world leaders! As a 'straight', (hetero), male U.S. voter-citizen...' profound embarrassment' CONTINUES to be the most 'family friendly' expression I can think of...to describe my reaction to racism, sexism, and homophobia...Aka, 3 words, applied to different social segments... which are synonyms for these pernicious, anti-social behaviors!!

\footnotetext{
18 News article and news source are provided in brackets. The name of the news source is italicized for identification.

19 I use this notation to indicate who replies to whose comment in a conversation. For example, in this context, it shows that commenter ID0268416 replies to HHeLibe.
} 
20 ScottMcG > JonnyCK

21 SUMSITUP > ScottMcG

22

23

24 ID9397281 > JonnyCK:

25

26

27

28

29

30

31

32
Sad that a scientist would put her religion before logic.

She is against gay marriage, but wants to flood Germany and the great German people with M's and continue to weaken its strong family of people. Germany, get her out ASAP, please! I agree with the good message, and the fact it's disappointing that Merkel voted against it. However, I can't help but think that, having a politician say "this is my personal opinion, but let's put it out to vote, respect both view points, and go with the majority" is a very grown-up thing to do. Humans have their own personal beliefs. Merkel is not a millennial. She grew up as a pastor's daughter in the former Eastern Block. I can forgive her for having this view, as long as she's happy to go with the majority wants.

Excerpt 5.1 is extracted from The Guardian, a representative conversation that took place after the German parliament approved the same-sex marriage bill. This excerpt exemplifies identity as dynamic and constantly evolving (Marra \& Angouri, 2021). At the beginning of this conversation, HHelibe's statement (lines 1-3) positions the commenter as an advocate of marriage equality by comparing the status of same-sex marriage between Germany and Australia. In line 3, the written representation of a spoken feature (i.e. sigh ) reinforces their disappointment regarding the issue of legalising gay marriage in their own country. Notably, their national identity emerges from the strategic use of personal pronouns (Brown \& Gilman, 1960; cf. ÍñigoMora, 2004), that is, they employ the first-person plural pronoun (i.e. "leaves us here in Australia"; line 3) to reveal that they are an Australian. The interlocutor, ID0268416 shows their affiliation to HHelibe by expressing their positive feeling towards legalising same-sex marriage (line 4), as they write, "don't worry, it will come..." This statement thus implicitly put themselves in the same camp as HHeLibe. Similar self-positioning could also be found in JonnyCK's reply to the original comment, as he acknowledges that it is a "good message to be sending" (line 5). Furthermore, introduced by but, JonnyCK continues to pass judgment based on the fact that 
Merkel voted against same-sex marriage and describes it as 'shameful' (line 5), thus making a contrast between himself and Merkel so as to drive home his disalignment with her. In so doing, Merkel is then positioned as a "cynic" (line 6). The use of 'cynic' indexes that Merkel is strategically making use of public opinions in her favour in a negative way. This interactive positioning therefore has distanced JonnyCK himself from Merkel and accordingly the positioning has put himself in the opposite camp to Merkel.

Similarly, in lines 9 through 20, Ursus Rexxx and ScottMcG also explicitly position themselves on JonnyCK's side by claiming that Merkel's decision made them feel 'sad' (line 9, 20). Interestingly, in these two comments Merkel is referred to as a 'Chancellor' (line 9) and a 'scientist' (line 20), respectively. In this context, by using labels to refer to people (see e.g. Cervantes \& Callanan, 1998; Golash-Boza, 2010; Martin et al., 1996; Rucker et al., 2019), they are drawing upon the Discourses surrounding the identities of Chancellor (e.g. an identity of authority) and scientist (e.g. detached and logical), suggesting that she (Merkel) should know better. That is, Merkel is not aligning with those identities they would expect of her. The use of labels therefore contributes to successfully distancing themselves from Merkel. It is noteworthy that through Ursus Rexxx's narrative, he has also explicitly indexed his national and sexual identities. That is, "my country's so-called president 'Humpty-Trumpty"' ('so-called' suggesting that the status of President is undeserved); "As a straight male U.S. voter-citizen" (line 11, 14). The underlined elements illustrate strategies adopted by commenters to enact their identity during the interaction, namely indexicality, one of the 5 key principles of identity proposed by Bucholtz and Hall (2005; also see Ochs, 1992; Silverstein, 1976; in this study see sections 2.2 and 2.2.3). According to Bucholtz and Hall (2005), indexicality is the creation of links between discourse and social meanings. It is the first step in exploring how identity is achieved as intersubjective and emergent (Bucholtz \& Hall, 2005). That is, speakers often use a linguistic feature as an index of a social identity (e.g. gender identity). An index then can be defined as any feature (verbal or otherwise) whose meaning is dependent on its interactional context (Ochs, 1992; Silverstein, 1976, 2003). 
Ochs's (1992) theorising suggests that most linguistic indexing is indirect. The language-identity relationship itself is commonly mediated through more direct indices, such as acts, activities, and positionings, and these connections are anchored in broader cultural ideologies. As a result, they are susceptible to transformation (see Silverstein, 1976). In order to understand the relativities of various indexicalities, Silverstein (2003) uses indexical orders to describe chains of meaning correlated with linguistic forms. Drawing upon cultural realisations, indexical orders disclose connections with ideologies (see discussion in section 2.2.3). In this context, Ursus Rexxx's national identity is indexed through the use of first-personal pronoun (i.e. 'my') and by mentioning Trump's name (as they are sharing the societal understanding of the current president of America with the interlocutors). In addition, the national identity of American is syntactically connected to the signalling of his sexual identity, perhaps suggesting that a 'straight male' is somehow a legitimate US voter-citizen. By mentioning these categories (i.e. a straight male US voter citizen), Ursus Rexxx is drawing on intertextual knowledge and indexing the historical ideologies of each category. That is, who has been and who has not been allowed to speak. When he specifically positions himself as a US voter citizen, he could also be seen as claiming certain rights because his is a status that historically would allow him to dominate the conversation. In addition, the commenter draws upon this as a way to position himself in a place of power. All of these would allow the potential readers to (incorrectly I argue) assume that Ursus Rexxx is a Trump supporter. Indexing these ideologies allows Ursus Rexxx to access what his interlocutors might assume about him and to simultaneously challenge their assumptions by not matching them (i.e. even I support same-sex marriage, so what is wrong with the rest of you?). Realised through indexicality, speakers' local identities in this interaction are enacted and performed.

The strategy of indexing identity categories is a regular feature of the current data, both explicitly and implicitly (e.g. "As I am not German”, "I am straight but I’ve always supported marriage equality"; many more examples will be given in the remainder of this chapter and Chapter 6 as well). Commenters index their diverse identities by mentioning the relevance of certain aspects of their identities in either an overt or covert manner. Bucholtz and Hall (2005) 
note that "indexicality relies heavily on ideological structures, for associations between language and identity are rooted in cultural beliefs and values" (p. 594). Therefore, indexicality supports the emergence of who they are on the one hand, and contribute to reveal the ideological meaning reflected in their comments on the other in online interactions. So far, commenters in the data presented draw upon minority Discourses (referring to a sexual minority; e.g. LGBTQ rights, marriage rights; see Kidner, 2015) to position themselves as advocates of marriage equality around a common opposition to Angela Merkel, which in turn has portrayed an unfriendly image of Merkel to LGBTQ community and a hypocritical political identity. However, these similarities are disguising for the moment sharp differences in identity construction between Ursus Rexxx (pro-immigrant) and SUMSITUP, who is performing an anti-immigrant (and racist) identity (despite at a surface level both discussing SSM). This other-positioning that places Merkel as opposite to the interlocutors within this example, is challenged and negotiated at the end of the conversation. In lines 24 through 32, ID9397281 begins to defend Merkel by explaining why she would vote against same-sex marriage, such as her changing environment and religious beliefs. The previous positioning (i.e. opposed to the legalisation of same-sex marriage) that is assigned to Merkel by other interlocutors therefore has been reassigned.

The excerpt illustrates how interlocutors discursively position selves and others in an interaction, showing that the process of positioning is dynamic as well. Identity emerges within the interaction by taking up a temporary assumed role (e.g. advocates of marriage equality in this example) and orientations assumed by commenters (cf. the positionality principle in Bucholtz and Hall's (2005) framework for identity analysis). The development of subjectivity and intersubjectivity in conversation is enacted by these interactional positions, which help commenters construct and negotiate specific identities in an interaction.

Social actors use "language displays of oneself" (Howie \& Peters, 1996, p. 53) to locate themselves and others in discursive activities and these positionings reflect their ideologies and emotions among other embedded cultural meanings (Hatoss, 2012, p. 50). Building on a general finding that individuals sometimes are positioned in a way that they do not want, this then leads 
them to experience a kind of positioning, particularly 'othering', that influences their national, cultural or ethnic identity construction. Othering is the construction and identification of the self or in-group and the other or out-group in mutual (cf. Hatoss, 2012; Jaworski \& Coupland, 2005; also see discussion in Chapter 3). The following excerpt below presents an example of othering.

\subsubsection{Positioning leading to othering}

Like the legalisation of same-sex marriage in Germany, the rejection of the Marriage (same-sex couples) Act in Australia attracted a great deal of attention from news writers, triggering a heated discussion among commenters. In Excerpt 5.2 below, there are instances where interlocutors are positioned and othered through specific discourse strategies.

Excerpt 5.2: [Australia's same-sex marriage vote in doubt; Stuff]

1 Chromelayer

2

3 Baranta > Chromelayer

4

5

6

7

8 JonnyCK > Baranta

9 Baranta > JonnyCK

10

11

12

13 Chromelayer > Baranta

14

15 @all, legalising SSM is not something we should be

proud of. Get real people. I'm happy it's rejected.

Yeah! if gays and lesbians want to institutionalize their relationship, fine-but use a different word for that.

Oh you know, they can't even steal a trademark, a

figment in time and space in its significance, compared

to the persistence and common understanding of marriage.

Fucking weird reason to deny people rights mate.

Not more weird that demanding the right to re- interpret

the meaning of a word with a universally defined content.

they can use the word, but have no right to make me accept it.

Should we let them abuse and exploit the definition marriage? The legalisation of gay marriage is totally a bad joke, as today's German's voting has clearly shown. 
In line 1, Chromelayer explicitly reveals their own positioning on the issue of legalising same-sex marriage. That is, they position themselves as an opponent of marriage equality by acknowledging that they are happy with its rejection (line 2). By inviting the reader to share this disalignment (e.g. Fairclough, 2001; Janks, 1997; Oteiza, 2003) with the legalisation of same-sex marriage through the use of the collective pronoun 'we' (cf. Íñigo-Mora, 2004), they have positioned the reader as a critic and in opposition to those countries which have already legalised gay marriage. In response to this positioning, the subsequent interlocutor, Baranta directly shows their alignment with Chromelayer, as they say, "Yeah" (line 3). This individual word therefore has positioned Baranta at the same side as Chromelayer. Importantly, the discursive strategy of othering is used through the expression of "gays and lesbians" (line 3) as well as through the multiple uses of the third person pronouns (i.e. 'their 'they') in line 3 and 5, respectively. In fact, as Thurlow (2001, p. 32) observes, in British schools, the use of word 'gay' is commonly seen as a homophobic abuse, yet "this is ironically the very word that many young homosexual people will more than likely be choosing to use to describe themselves." 'Gay' thus can be used for both explicit self-identification and othering. In this example, it is clear that the expression of "gays and lesbians" helps Baranta distance themselves from LGBTQ communities and set a distinct boundary between heterosexual and homosexual. Using a collective identification facilitates this othering (Abizadeh, 2005; Triandafyllidou \& Wodak, 2003; Wodak \& Boukala, 2015). This echoes Coupland's (2010) finding that "othering is the process of representing an individual or a social group to render them distant, alien or deviant" and that it "raises issues about group boundaries". As a result, their sexual identity as a heterosexual person spontaneously emerges from the reply to Chromelayer.

Baranta reassigns and emphasises this positioning as opposition to marriage equality to themself when they employ the discourse markers (Schiffrin, 1987), that is, "oh" and "you know" (see e.g. Fuller, 2003; Jucker \& Smith, 1998; Östman, 1981; Stubbe \& Holmes, 1995; Trester, 2009) to align with Chromelayer as their interlocutor. In this context, considering the conversational tone and the attitudinal meaning, the use of the reception marker oh conveys information about the speaker's evaluation of gay people (cf. Fuller, 2003), suggesting a sense of contempt for the 
LGBTQ community, which implicitly reveals their ideologies of heterosexism. It is possible that Baranta is also drawing on their shared ideologies of the traditional institution of marriage with Chromelayer as well as other heterosexual people (or those who hold their view) through "you know" as a device to create the sense of a commonality across all readers. Therefore, Baranta positions both themself and Chromeplayer as active participants in politics and as conservative in their political orientations by showing their alignment with Australian parliament's rejection of marriage equality. This particular discourse strategy is used again by Baranta and Chromeplayer while JonnyCK tries to challenge their narrow understanding of marriage (line 8). Interestingly, in line 8, Baranta is referred to as 'mate' when JonnyCK tries to retort upon Baranta's positioning. 'Mate', here, is not used for showing politeness (see e.g. Holmes \& Stubbe, 2015) or affiliation, but to position Baranta as an Other in a sarcastic way. This kind of othering is achieved by using a term of intimacy. By adopting the macro affiliation, JonnyCK is persuading Baranta as well as indexing affiliation where there is no affiliation. Thus, the address term mate in this specific context arguably functions as a condescending strategy (cf. the use of mate in Australian English, see e.g. Rendle-Short, 2009; Wilkes, 1993). In line 11, this time, Baranta switches from thirdperson pronoun (i.e 'they') to first-person pronoun (i.e. 'me'), reinforcing their straight identity while simultaneously creating a sense of 'othering'. In so doing, they firmly position themselves in opposition to the LGBTQ community and thus Discourses of minority (e.g. marriage rights for sexual minority; see discussion in section 5.3.1).

Chromeplayer makes strategic use of the rhetorical question tag (lines 13-14) and the firstperson pronoun (i.e. 'we') to persuade other readers to take the same positioning as they take. Here the question leads the reader to an "unavoidable" answer. The text operates under the assumption that the reader will inevitably supply, "No, of course, 'we' should not let homosexual abuse and exploit the definition of marriage". Therefore, within this interaction, the proposition at issue is "common-sensical" (Seals, 2012), that agreement can be taken for granted. That is, the legalisation of same-sex marriage is a threat to traditional marriage as well as to heterosexuality. This interpretation is confirmed in lines 14 through 15, as Chromeplayer sees marriage equality as unacceptable, referencing Germany's legalisation of same-sex marriage. It is 
noteworthy that the use of 'we' in line 13 is completely different from the one in line 1.

Specifically, in line 1, 'we' refers to all human begins in general; while in line 13, 'we' is used to achieve the discursive 'othering' which specifically excludes LGBTQ group; that is, ' $w e^{\prime}=$ 'I' + my group (i.e. the heterosexual community). ${ }^{20}$ They make a distinction between ' $w e^{\prime}$ and 'them', illustrating Bucholtz and Hall's (2005) relationality principle (see section 2.2), to give saliency to their heterosexual identity. I therefore argue that the positioning is strengthened by the strategic use of personal pronouns in this context which leads to 'othering'. The analyses show the commenter embracing Discourses of homophobia (firmly tethered to the ideology of heteronormativity; see Dawson, 2019). In this research data, sexual identity accordingly becomes one of the most salient tools of othering.

\subsubsection{Rejection of positioning (being othered)}

When considering positioning, we need to recognise the influence of power relations between interlocutors. This means rejection, resistance and negotiations are sometimes impossible or challenging (Blackledge \& Pavlenko, 2001). Excerpt 5.3 is an example. The excerpt is part of a conversation in response to the failure of legalising same-sex marriage in Australia.

Excerpt 5.3 [A marriage equality plebiscite is not inevitable anymore. We have the numbers for a free vote; The Guardian]

\section{Leerdam}

2

3

4

5

6 Kitkat70 > Leerdam

7
Australia is the last developed country to have equal marriage, you know, even Taiwan, NZ and Argentina have equal marriage. Does Australia still make its indigenous peoples sit in the back of the bus? The rest of the Western world is confused.

I would worry about my own backyard if I were you. We will finally get there one day.

\footnotetext{
${ }^{20}$ Readers are referred to Íñigo-Mora (2004) where the different types of first-person pronoun, 'we', have been identified.
} 


\section{Rectinol > Leerdam}

18

19

20

21

22 Positivepower $>$ Rectinol

23

24 Kitkat70

25

26

27 they don't let them get on the bus- hence the anger. All desperately counting their beans. As I am not Australian, luckily I don't have to be outraged, as my country's Constitution evolves the term 'marriage' from a union between a man and a woman to same-sex couples. Who said no? Australia is the most backward country I've lived in. Equal rights to peope should take priority. @Positivepower@Leerdam @Rectinol. According to the Pew Research Centre and some latest surveys, over 70\% of Australians now support marriage equality and the trend is up. Australia is a great country!

Leerdam initiates the conversation and positions Australia as an inferior developing country in terms of marriage equality by comparing its status quo to other similar countries. Through the use of the discourse marker you know (cf. Bell, 2000; Stubbe \& Holmes, 1995) they align with other readers as their potential interlocutors with, thus positioning themselves in opposition to Discourses of heteronormativity. The rhetorical question in lines 3 through 4 is sarcastic (see sarcasm use in online interaction, e.g. Das \& Clark, 2018; Kunneman et al., 2015; Pickering et al., 2018), alluding (via an analogy to race) to the fact that people in Australia do not have equal marriage. Sarcasm, however, requires shared knowledge between the speaker and audience (Bamman \& Smith, 2015). In this context, the audience recognises the illegal situation of samesex marriage in Australia. I therefore interpret this as a sarcasm and argue that sarcasm is a profoundly contextual phenomenon. In response to this positioning, Kitkat70 chides the commenter to mind their own business (line 6) and positions the commenter as an outsider through the collective first-person pronoun we (i.e. we will finally get there one day). At an interactional level, Kitkat70 has directly indexed their national identity as well as their confidence with the legalisation of gay marriage in Australia. In other words, being an Australian, Kitkat70 is rejecting the specific position that Leerdam has previously assigned to Australia (as well as them). However, it seems that their attempt to resist this interactive positioning is not that 
successful, as Rectinol then contributes to the interaction seemingly with the intention of aggravating Leerdam's insistence. The statement in line 17, on the one hand, shows Rectinol's affiliation to Leerdam; on the other hand, it also denies their ethical integrity in terms of equal marriage. By referencing the illegal status of same-sex marriage in Australia, Rectinol has coconstructed their identity using a strategy Schiffrin (1993) calls 'speaking for another'. The statement "they don't let them get on the bus" is a rephrasing borrowed from Leerdam (line 4). This phenomenon shows the dialogical nature of comments discourse, and underscores the importance of intertexual analysis during interaction. This point will be argued later, where I bring in the analysis of intertextuality to futher explore identity construction.

Additionally, in this comment, Rectional uses exclusionary third-person pronouns (i.e. they, them, their; lines 17-18) to distance themselves from Australia, which implicitly contributes to a disclosure of their national identity (i.e. that they are not Australian). This performance of identity work is then confirmed with a direct rejection by using not in line 18 (i.e. "I'm not Australian"). Nonetheless, they continue referring sarcastically to Australians. That is, "all desperately counting their beans" (line 17-18). This expression intertextually suggests "bean counters"; it seemingly implies that Australians are inappropriately focused on the budget implications of a public discussion around passing the same-sex marrige bill; the commenter is challenging the idea about not wasting money to get answers we knew anyway. Therefore, through the intertextual reference, Rectinol once again stresses their national identity. The tension between Australian and non-Australian participants esclates when the fourth interlocutor joins in the conversation. In line 22, Positvepower employes a rhetorcial question to fully align themselves with Leerdam and Rectinol, demonstrating how those three interlocutors from the same positioning initiate an interactional team (Gordon, 2003; Kangasharju, 1996; Lerner, 1993) against Kitkat70. From this perspective, I therefore interpret Kitkat70 as being intentionally 'othered' in this context.

The final reply from Kitkat70 sounds to be another attempt at resistance to the continuation of positioning them as an 'Other' (Hatoss, 2012). In lines 24 through 27, Kitkat70 introduces 
external voices into the conversation (e.g. Pew Research Centre and some latest surveys). These external voices draw upon what Bourdieu (1986) calls symbolic capital. Specifically, Bourdieu defines several types of symbolic capital, with the two most relevant here being embodied symbolic capital and institutionalized symbolic capital. Embodied capital can be represented in discourse by the sharing of one's personal experience and opinions. Institutional capital can be understood as knowledge which is based in and backed up by an established institution. In this extract, through the employment of institutional capital (Kitkat70 specifically addresses that the source (line 25) is Pew Research Centre), Kitkat70 positions themselves as more persuasive (e.g. Meadows, 2009; Seals, 2011). In so doing, they are expecting that many people (including the interlocutors in this conversation) feel the same way, that is, people typically feel that using institutional symbolic capital will be more persuasive than using embodied symbolic capital (Seals, 2011). The use of symbolic capital in discourse thus points to its relationship with positioning, which has been investigated by others. For example, Meadows (2009) conducted a study to examine how capital is negotiated in face-to-face interaction and how that negotiation relates to identity practices. Seals (2011) focuses on small discussion group of five graduate students (three women and two men) also argues that how something is said without altering the content of the discourse creates a difference in what is remembered by both women and men. Crucially, these studies have shown that the way that a person positions themselves within an interaction determines the type of symbolic capital that the person's interlocutors will accept from them, and the type of symbolic capital people draw upon matters for persuasiveness of argumentation.

The excerpt shows that despite the inequity in power relations between Kitkat70 and the other three interlocutors, Kitkat70 shows resistance and reluctance towards the overemphasis on the illegal status of same-sex marriage in Australia (arguably as well as their Australian identity).

Kitkat70's reluctance towards what they feel as 'othering' is evident in the argument during the interaction. The negotiation of Kitkat70's stance in relation to Australia being positioned as an inferior nation (and thus othered in their views) takes the forms of avoidance and contestation. Like their responses in Excerpt 5.3, they remind others to 'mind their own business' to avoid 
further debate and use institutionalized symbolic capital to increase the authority of their contestation. Although the process of othering is often based on, for example, negative stereotypes (MacNaughton et al., 2009), Kitkat70's rejection of being positioned as an inferior nation might derive from their understanding of the attempts to connect them with Discourses of minority (Kidner, 2015). That is, they do support marriage equality, although it is not yet legalised.

In addition to the important role that positioning analysis plays in interaction while examining identity, the use of constructed dialogue as shown in Excerpt 5.3 reveals the dialogic nature of their interactions. Semantic presuppositions employed by participants also carry the wider societal ideologies that connect commenters' identity negotiation. In this sense, I identify the nuance needed for conducting an intertextual analysis in this study. For example, in Excerpt 5.3, a closer look at what statement is quoted from other interlocutors, how the statement is quoted (in a direct or indirect way), why it is quoted and such, largely depend on commenters' interactional purposes. This kind of investigation provides me with a more comprehensive perspective to explore online identity construction. I therefore introduce the analysis of intertextuality into the present study, beginning with the examination of constructed dialogue as a prominent manifestation of intertextuality.

\subsection{Analysis of intertextuality}

The idea of many voices is paramount to Bakhtin's theories of discourse, reflected in the Englishtranslation of his terms - dialogism, heteroglossia, double-voicing, and intertextuality. Multiple voices encapsulate the idea that the language we use and the identities we construct are never 'new' but reflective of an engagement with 'past voices' and 'authoritative discourses' (Bakhtin, 1992). The Bakhtinian notion of intertextuality (Menard-Warwick, 2009, 2014; Seals, 2019) offers a promising middle ground between structure and agency in identity (co)construction (see section 2.5), in that everything we say can be seen to build on, alter, and contribute to unending chains of meaning. With a focus on wider social contexts, this reminds us that both our utterances and inferences are anchored in established practise as well as feeding forward into 
future deployments. As such, intertextuality offers an important lens for examining identity construction in online interaction.

A focus on the intertextual features embodied in interactions complements the analysis of positioning and supports a deeper understanding of how different discourse strategies contribute to commenters' online identity construction. The most mundane and overt manifestation of intertextuality is quotation (Porter, 1986), yet intertextuality animates all discourse and goes well beyond this. As mentioned in chapter 4, my analysis follows Tannen (2010), Sclafani (2008) and Seals (2012), which combines a method for investigating elements of discourse to flesh out the analysis. In particular I have selected constructed dialogue and the use of semantic presupposition (following Thetela, 2001) to understand who the writer is targeting, and how they are speaking to the 'ideal reader' (a concept used by Fairclough, 2001). Fairclough (2001) defines the ideal reader as someone "with particular intertextual experiences" (p. 52) who "will indeed make the 'right' inference" (p. 153). From this point of view, the concept of intertextuality is closely related to the ideal reader because "[i]n any given historical moment of verbal-ideological life, each social level has its own language; moreover, every age group has as a matter of fact its own language, its own vocabulary, its own accentual system that, in their turn, vary depending on social level, academic institution and other stratifying factors" (Bakhtin, 1981, p. 290). The emphasis placed on the ways in which commenters speak to their 'ideal readers' is thus an important aspect of investigation of the present study.

\subsubsection{Constructed dialogue}

The analysis of quotation of others within the comments, alternatively described as 'reported speech', or what Tannen (1989) terms 'constructed dialogue', is a common focus when examining intertextuality in discourse. Tannen (1989) argues that the term 'reported speech' is misleading because it suggests that speakers convey exactly what another has said when they quote him or her in conversation. In response, she introduced the term constructed dialogue to acknowledge that even apparent direct quotation is "primarily the creation of the speaker rather than the party quoted" (1989, p. 99). In other words, direct speech is by no means a truly 
verbatim rendition of such an original speech situation but always speech that has undergone some transformation in the process of storytelling:

What is called "reported speech", "direct discourse", or "direct quotation" (that is, a speaker framing an account of another's words as dialogue) should be understood not as report at all, but as constructed dialogue. It is constructed just as surely as is the dialogue in drama or fiction (Tannen, 1989, p. 10).

This theoretical orientation begs the question of the function of quoting particular words in different contexts. According to Tannen, constructed dialogue is "a discourse strategy for framing information in a way that communicates effectively and creates involvement" (p. 110). Put differently, Tannen understands that constructed dialogue is used by speakers to make a conversation come to life or to dramatize it and thereby to interest their interlocutors in what they have to say. Therefore, the main function of such discursive action is to achieve a speaker/writer's conversational goals in social interaction. In the same spirit, in the present study, I adopt the term to emphasize that "language can never be simply quoted or reported but is instead always creatively constructed by a current speaker in a current situation" (Tannen, 1989, p. 105).

While Tannen focuses more on the function of constructed dialogue, Clark and Gerring (1990) pay attention to its form and define two different types of quotation in constructed dialogue, i.e. direct and indirect quotation. ${ }^{21}$ They regard indirect quotations as "descriptions", whereas direct quotations are understood as "in fact demonstrations" (as cited in Seals, 2012, p. 236). They go on to argue that "the prototypical quotation is a demonstration of what a person did in saying something. So when Alice quotes George, she may depict the sentence he uttered...

Furthermore, she can depict nonlinguistic events by themselves" (Clark \& Gerring, 1990, p. 769). In other words, direct quotation assigns full responsibilities of the words to the person who is originally quoted. In terms of indirect quotation by contrast, the speaker/writer takes some

\footnotetext{
${ }^{21}$ See discussion provided in section 4.5.2 on the distinction between direct and indirect quotation.
} 
responsibility for the quoted words. This highlights the importance of distinguishing direct quotation from indirect quotation, as the choice of what to quote, how to quote, and from whom to quote shows the writer/speaker's particular ideological stance as well as allowing them to position the quoted person. In her examination of double-voicing through the use of constructed dialogue, Sclafani (2008) argued that the different use of quotations (e.g. the choice of who to quote, what and how it was quoted) impact readers' perception of the news story and its issues (cf. Tannen, 1989). This finding resonates with Bakhtin's (1981, pp. 293-294) argument that "the world in language is half someone else's... [1]t exists in other people's mouths, in other people's contexts, serving other people's intentions: it is from there that one must take the word, and make it one's own".

As for the present study, I examined the intertextual feature of constructed dialogue, separating direct and indirect quotation while analysing the data. In general, direct quotations are identified with the use of quotation marks, referring to the exact words taken from an original source and used in a second piece of writing. For example, William Moon states, "...our civilization is dying and unless we keep the focus it will get worse". In response to this, Un-commonsense directly quotes his words by saying “@ William Moon, 'our civilization is dying' where is this fact stated?” (collected from "Little men with soft backbones and no soul: Furious Peta Credlin unleashes on her former Liberal Party colleagues as gay marriage debate splits the government", Mail Online). In contrast to this, indirect quotation was used to categorise paraphrases of someone else's words, such as Alooa who writes, "Politicians (Pyne) says parliament should have a conscience vote" (collected from "Angela Merkel votes AGAINST legalising marriage", Mail Online). This form was not usually accompanied by quotation marks.

I offer a distributional description of constructed dialogue before continuing to the interactional examples of how commenters utilize intertextual resources in their interaction. 


\section{Distribution of constructed dialogue within SSM}

The results of Query 2 (i.e. how is constructed dialogue employed by commenters on different topics in the three different news websites), provides information about how constructed dialogue is distributed in the different news websites. Through the results of the query, I will identify the correlation between the employment of constructed dialogue and the nature of the topics under investigation.

Figure 5.1 demonstrates the participants' use of constructed dialogue, specifically how they use direct and indirect quotation in the three news websites when discussing same-sex marriage.

In this figure, the $\mathrm{X}$-axis shows the types of quotation, namely direct versus indirect quotation employed by commenters in the different sources, and the $\mathrm{Y}$-axis signals the number of quotations coded in this research data regarding the topic of same-sex marriage. 
Figure 5.1 Quotations used by participants in three news websites regarding the topic of SSM

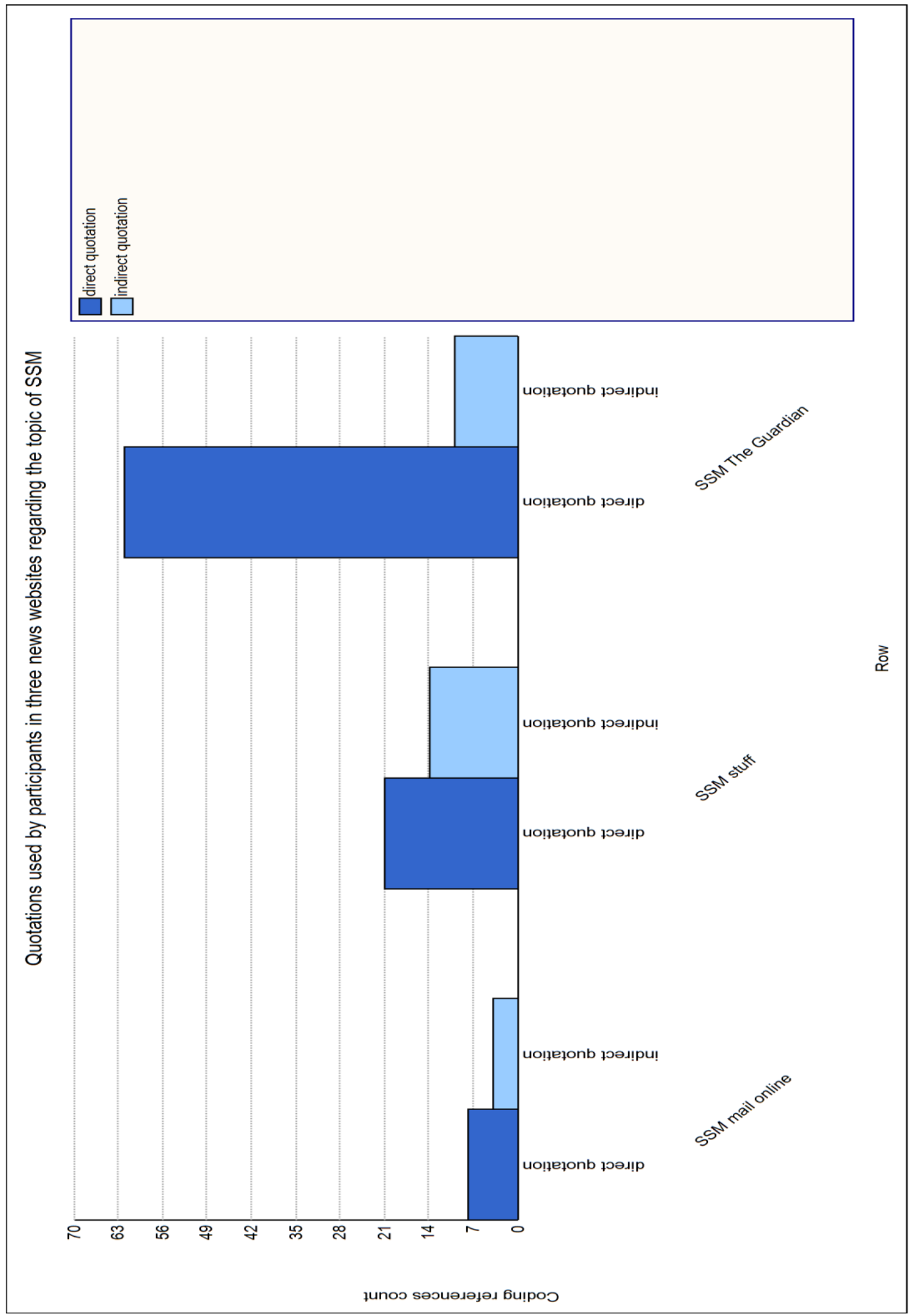


Under the category of constructed dialogue there were 168 references, including 131 instances

of direct quotation and 37 of indirect quotation. Across the two themes (same-sex marriage and travel), constructed dialogue occurs 119 times and 49 times, respectively (out of 168 references in total). (Detailed distribution of constructed dialogue regarding the topic of travel will be discussed in next chapter). As seen in the figure, quotation is heavily used by the commenters of The Guardian in comparison with the other two news sources. In addition relatively speaking, direct quotation is used more than indirect quotation in each news source. This is particularly noticeable in The Guardian, as the number of direct quotations harnessed by commenters is six times higher than the number of indirect quotations. The employment of quotation corresponds with what Mannheim and Tedlock (1995) claim, "any and all present discourse is already replete with echoes, allusions, paraphrases, and outright quotations of prior discourse" (p. 7). More details of the distribution of each type of quotation has been given in Table 5.3

Table 5.3 Distribution of quotation in three news websites on the topic of SSM

\begin{tabular}{lccc}
\hline Type of quotation & A: Direct quotation (\%) & $\begin{array}{c}\text { B: Indirect } \\
\text { quotation } \\
\text { (\%) }\end{array}$ & $\begin{array}{c}\text { Total number of } \\
\text { quotations coded } \\
\text { from each news } \\
\text { source (\%) }\end{array}$ \\
\hline Mail Online & $8 / 66.7 \%$ & $4 / 33.3 \%$ & $12 / 100 \%$ \\
\hline Stuff & $21 / 60.0 \%$ & $14 / 40.0 \%$ & $35 / 100 \%$ \\
\hline The Guardian & $62 / 86.1 \%$ & $10 / 13.9 \%$ & $72 / 100 \%$ \\
\hline Total No. of quotations coded in the data & 91 & 28 & \\
\hline
\end{tabular}

Table 5.3 provides the exact number of quotations coded within the topic of same-sex marriage in each news source. As shown, direct quotation has been employed by commenters far more than indirect quotation (direct quotation and indirect quotation were coded 91 and 28 times, respectively). In Mail Online, although the overall number of quotations employed by commenters is quite small (direct quotation only occurred 8 times, while indirect quotation occurred just 4 times), direct quotation still makes up $66.7 \%$ of the total 12 coded quotations. A similar pattern of distribution also occurs in the other two news sources. Specifically, direct quotation accounts for $60 \%$ (coded 21 times of total 35 comments) and $86.1 \%$ (coded 62 times of total 72 comments) in Stuff and The Guardian, respectively. The relatively high proportion of 
direct quotations in the three news sources shows that comments discourse is inherently intertextual in nature and also more likely to involve direct quotation, arguably due to the technological affordances of the discourse context. The preference of using more direct quotations than indirect ones explicitly connects the current commenter to the news item and in turn to other interlocutors, which suggests interest in launching or maintaining the dialogue in online comments. The discursive action thus helps commenters achieve their conversational goals.

I now turn to the examination of constructed dialogue from a qualitative perspective. In what follows, examples are used to demonstrate how commenters directly or indirectly quote other interactants' comments to convey their meanings, and how direct and indirect quotations impact identity construction in this online space.

\section{Direct quotation}

Analysing who gets quoted and what they are quoted for, offers insights into the kind of information the writer is aiming to convey to his/her readers (Seals, 2012). Here I provide examples to demonstrate how commenters use direct quotation to communicate with other interlocutors.

Excerpt 5.4 [Religious faith is no obstacle to support for marriage equality; The Guardian]

\section{CCoasty}

2

3

4

5

6

7

8
"The truth is we supported marriage equality not in spite of, but because of the values our faith raised each of us in"... "The old argument of gay versus God is bogus. It is not a choice of picking one or the other and the members of churches see that." This is what those who extol from the pulpit need to be telling their flocks, most members might see this but not all...its called good shepherding to teach tolerance, acceptance and 
9

10

11 Zackdog > CCoasty

12

13 InderbtedYouth > Zackdog

14

15

16

17

18

19

20 blueterrace $>$ InderbtedYouth

21

22

23

24

25

26

27

28

29 Sonneteer $>$ blueterrace

30

31

32

33

34

35 Crownstay3830 > Sonneteer

36 Lipsyl > Sonneteer

37 how to live in a cohesive society with respect for each

other.

These values do not contradict same-sex

marriage, rather they lead us to supporting it.

Agreed this: "These values do not contradict same-sex

marriage, rather they lead us to supporting it". Was

nowhere to be heard during the pre-referendum

debates. The referendum was largely passed by

younger, less religious or non-religious voters. I expect

we will see none of this "values" argument in upcoming

abortion debate either.

It was only a matter of time before religionists started

rewriting history to present themselves as, once again,

saviours of yet another down trodden minority. Where

were they when homosexuality was a crime

punishment by prison, gay bashing was a police sport

and brave protesters marched for basic human rights.

The big churches, congregations and leadership were

overwhelmingly in opposition to these changes, and

usually vigorously so.

It was the churches that were at the forefront of

decriminalisation of homosexuality in the fifties. The

churches have also often been the one place where

gays have found solace, sanctuary and counsel in a

hostile society. Blueterrace needs to learn some basic

history.

Bullshit. If anyone needs a history lesson its you.

you say, "It was the churches that were at the forefront

of decriminalisation of homosexuality in the fifties. The 
In this excerpt, commenters discuss the influence of religion on the legalisation of same-sex marriage. CCoasty fronts their statement by using two direct quotations (lines 1 through 5). Interestingly, these direct quotations are not quoted from other interlocutors, but rather quoted from the article itself ${ }^{22}$, pointing out that this specific opinion comes from the article writer. The location of the quotations serves two main functions. First, by using a direct quotation, the commenter highlights the specific point that they want to respond to. So, in this context, CCoasty is trying to convey a message to their readers that marriage equality should be promoted as same-sex marriage does not conflict with God (religious beliefs). In lines 6 through 10, this supportive attitude towards legalising same-sex marriage is subsequently emphasised by asking religious people and pastors to teach tolerance, acceptance and respect. Second, through the use of direct quotation here, their own opinion on the legalisation of same-sex marriage is implicitly understood as aligning with the lines repeated directly from the source which simultaneously shows their affiliation with the writer they are quoting. The employment of direct quotation positions them as advocates of marriage equality along with the author of the article. Zackdog joins the same campaign of promoting gay marriage rights by claiming that these values (i.e. tolerance, acceptance and respect, as mentioned by the article writer and CCoasty) lead people to support the legalisation of same-sex marriage (lines 11-12). In response to this positioning, in the following comment, InderbtedYouth also directly quotes what has been said earlier by Zackdog, commenting that "Agreed this: 'these values do not contradict same-sex marriage, rather they led us to supporting it'". Likewise, in this comment, the use of direct quotation reveals a specific positioning on the issue of same-sex marriage and thus contributes to constructing InderbtedYouth's social identity as a supporter of equal marriage.

\footnotetext{
22 In lines 1 through 5, two quotations are quoted directly from the source article, specifically from paragraph 2 and 3 of the article itself. See Appendix C: Data set.
} 
Having perceived the previous three commenters' negative feelings about hijacking religious beliefs as an excuse to stop the process of legalising same-sex marriage, in this continuing conversation blueterrace once again points the finger at churches. This criticism however triggers an alternative view from Sonneteer, who defends the churches. As they write, "It was the churches that were at the forefront of decriminalisation of homosexuality in the fifties. The churches have also often been the one place where gays have found solace, sanctuary and counsel in a hostile society" (lines 29 through 33). Through this description, they have put themselves on the same side as the churches. Responding to this positioning, Lipsyl then quotes Sonneteer's description in a direct way (line 36-40) and calls it 'horse shit' (line 40). The concept of 'horse shit' is a repetition borrowed from 'bullshit' (line 35). This kind of swearing harnessed by two commenters in a row is very explicit and direct, as a way of disagreeing strategy. Through the employment of this direct quotation, Lipsyl's diverse view has been introduced to the discussion while at the same time, they have successfully created involvement in this interaction and constructed their social identity as advocates of marriage equality along with other interlocutors of this interaction, such as CCoasty. So, in this extract, the employed direct quotation shows that it can be used to frame an opposing point of view just as much as to frame an expression of agreement.

Within this example, we can see that during the interaction, commenters not only quote words from the source articles but also from other interlocutors' comments. In fact, the phenomenon of quoting from the source article appears relatively often in this research data. In addition to Excerpt 5.4, another example is found in the article entitled "At long last, Germany's bells are ringing for same-sex marriage" (see Excerpt 5.5). While talking about Merkel's vote against the legalization of same-sex marriage, the commenter, The_Sentinel, quotes from the news article (as underlined) before adding their own comment: 
Excerpt 5.5 [At long last, Germany's bells are ringing for same-sex marriage"; The Guardian]

"Chancellor Angela Merkel said she was moved recently by visiting a lesbian couple in her rural constituency who had invited her into their home. Seeing that they had been trusted by social services with a succession of long-term foster children was apparently a life-changing experience for her..." but not so 'moved' that she'd consider voting for it herself. So, not that 'life-changing' then, as she didn't even change her opinion.

In this example, the direct quotation is used as a form of an echo in discourse, turning the article writer's words back on them and constructing a taunt as a strategy of identity construction through distancing. The commenter directly quotes from the article in a section that speaks to emotional aspects describing Merkel has been 'moved'. This idea of being 'moved' is strategic but not real because it contrasts the vote that Merkel cats. By using this intertextual idea, the use of direct quotation completely allocates the responsibility of what has been described about Merkel to the article writer and challenges the authenticity of what has been said, as the commenter him/herself does not think in the same way. Thus, the commenter not only frames their own view on Merkel's vote but also arguably adopts a sarcastic tone (as the quotation contradicts with the vote that Merkel offers in reality) (cf. Bamman \& Smith, 2015)) in order to refute what has been reported about Merkel, thus distancing themselves from her and coconstructing their personal identity as friendly to the LGBTQ community.

In addition to employing a direct quotation to show commenters' dis/agreement and thus convey their own positioning in identity construction, direct quotation is also used by commenters to invite further engagement, which connects the current commenter with the previous speaker in a conversation. This way of quoting addresses the point made by the previous speaker and asks the person who gets quoted to explain more, as seen in Excerpt 5.6. 
Excerpt 5.6 ["Little men with soft backbones and no soul": Furious Peta Credlin unleashes on her former Liberal Party colleagues as gay marriage debate splits the government; Mail Online]

1Tom79Tom: I can't be the only one who grits my teeth at such an irrelevant 2 issue getting so much govt time and discussion. Who cares who 3 marries who!

six replies to Tom79Tom

4 WilliamMoon> Tom79Tom The further we get from monogamous marriage between a 5 man and a woman being about creating a family the more the

6 birth rate will plummet, the more families become unstable, 7 the more confused people become and the more they will

8

9

10

$[\ldots]^{23}$

11 smudge

12

13

14

15 waste their precious fertile years, the more they will fail to commit. Our civilisation is dying and unless we keep the focus it will get worse.

@WilliamMoon, "our civilisation is dying", where is this fact stated? Last time I checked, our world population was at record numbers - to the point where it is becoming unmanageable. If you're going to make a completely bias comment like that, at least try to make it factual.

In lines 11 through 12, the commenter, smudge quotes WilliamMoon's words (which first appear in line 9) and uses an attribution symbol, i.e. @, to tell WilliamMoon that they are orienting to his comment in this interaction. They quote herein and put forward their opinion by asking "where is this fact stated?" (lines 11-12). In saying this, they are not only questioning WilliamMoon's comment as biased and non-factual (as they go on further to express), but also they invite him to make an explanation and anticipate answers from him. The use of direct

\footnotetext{
${ }^{23}$ As shown, Tom79Tom received six replies in total in this interaction. The others are omitted because they are not focusing on the use of direct quotation.
} 
quotation in this interaction arguably functions as a continuer aimed at maintaining the current dialogue between the interlocutors, through which the current speaker, smudge, creates involvement to use Tannen's $(1989,2007)$ terms.

In sum, as the above excerpts illustrated, we can see that the use of direct quotation allows the writer to perform dialogue in a way that positions the quoted writer as someone who is responsible for the words and subsequent ideologies (Seals, 2012). Specifically, when it comes to the use of direct quotation to express the current speaker's agreement, it "makes the quotation seem undeniable, as if it were fact" (Seals, 2012, p. 236), as the quoting reinforces the point made and therefore may enhance its authority. In this sense, direct quotations hold an extensive degree of power for the commenters; how they choose to assign positions to their interlocutors through the quoted content. By sharing mutual ideologies without formulating them anew themselves, the use of direct quotation enables the writer to speak to the ideal readers intertextually (Seals, 2012, p. 236; also see discussion in section 5.4).

\section{Indirect quotation}

Alongside directly quoting others is indirect quotations, referring to a paraphrase of someone else's words: these report on what a person has said/written without using the exact words of the speaker/writer (Bauman \& Briggs, 1990). The ways in which speech is reported (e.g. quoted from whom? What and how the speech is quoted?) all have an impact on readers' interpretation of issues being discussed (Tannen, 2007, 2010). Within the theme of same-sex marriage, the report of Chancellor of Germany (Merkel) voting against legalising same-sex marriage received extensive coverage in The Guardian, despite the fact that the gay marriage bill was passed by the German Parliament. This conflicting narrative led to a fierce discussion among commenters.

Excerpt 5.7 [At long last, Germany's bells are ringing for same-sex marriage; The Guardian]

1 LostInScience

2 Kate Fleming $>$ LostInScience
It's shameful that Merkel voted against.

It would be surely be more shameful if she held a 
3

4

5

6

7

8 lionfod > Kate Fleming

9

10

11

12

13

14

15

16

17

18

19

20

21

22

23

24 conscientious view (shared by billions throughout the world) that 'marriage' by definition is the union of biological opposites for the procreation and rearing of the next generation....and voted FOR same sex marriage?

it is a constitutional question. A tricky one. The German constitution says clearly that all people are equal and have equal rights. It also says that marriage and family is of high value and needs to be protected and to be together with their spouse family is a constitutional right. The constitutional does not define marriage as a union between a man and woman. So it was overdue to grant men the right to marry another man, and women the right to marry another woman. The common assumption, or the church laws, that marriage means only a union between a man and a woman is simply against the constitution. Equal rights mean equal rights. Church can warp their noisy bells up, and go back to wherever they came from. They have no more say. If we want to speak to God, we whatsApp it directly. And until it answers everyone should love and marry whoever he/she wants and enjoy that to the fullest.

Focusing on Merkel's vote on the gay marriage bill, LostInScience directly positions them in the opposite camp to Merkel by defining her behaviour as 'shameful' (line 1). Responding to this, Kate Fleming places emphasis on the constitutionality decision in her argument. As she writes, "it would be surely be more shameful" (line 2) if Merkel held the belief that "marriage only exists between biological opposites" while she still "voted FOR same-sex marriage" (lines 5 through 7). Within this comment, two points need to be further clarified. First, when LostInScience sees 
Merkel's vote (against gay marriage) as 'shameful', Kate Fleming responds to this specific opinion rather than the content, as she claims that it would have been hypocritical of Merkel, or, 'more shameful' (line 2) if she had voted for same-sex marriage, given that she holds the traditional view on marriage (i.e. "marriage is the union of biological opposites"; lines 4-5). Although Kate Fleming does not explicitly say Merkel holds the belief (marriage only exists between a man and a woman), she alludes to having this belief via the parenthesis (line 3). On the one hand, the lexical item 'more shameful' functions as an intertextual echo to the previous comment, acknowledging that they recognise politicians can vote shamefully. This shows some degree of affiliation with LostInScience. While on the other hand, speaks to an ideal reader: it is acceptable that Merkel made a free vote rather than paying lip service, such as holding the traditional marriage definition but voting for same-sex marriage, which is 'more shameful'. Kate Fleming here draws on an intertextual understanding of "the right to vote freely" with the ideal reader (intending, I contend, for the ideal reader to pick up on this meaning that Merkel should not be questioned about her free vote; see section 5.4), suggesting that Kate Fleming is defending Merkel in some way. She has thus sidestepped being explicit about her opposition to same-sex marriage.

Lionfod is not a cooperative audience for Kate Fleming. They contest her idea in arguing that, "The German constitution says clearly that all people are equal and have equal rights. It also says that marriage and family is of high value and needs to be protected and to be together with their spouse family is a constitutional right" (lines 8 through 13). In this indirect quotation, the commenter rephrases the German constitution. In so doing, they use the quotation as a strong argument to support their own opinions about the definition of marriage. This provides credence to their claimed stance as if the argument made here were others' opinions (Bangerter et al., 2011; Matoesian, 2000). The use of indirect quotation thereby reinforces the shar ed pro LGBTQ group ideology, that is, marriage equality matters. So, through their presupposition of shared ideologies, they are conveying a message to the reader that they are LGBTQ friendly. This is confirmed by the following comment when they write, "The constitution does not define marriage as a union between a man and a woman...The common assumption, or the church 
laws, that marriage means only a union between a man and a woman is simply against the constitution. Equal rights mean equal rights." (lines 13 through 19). After indirectly quoting the definition of marriage from the German constitution, they then explicitly express their own view on marriage, that is, it does not merely exist between a man and a woman. The employment of indirect quotation backs up their own view on same-sex marriage and positions themselves as an advocate of marriage equality.

Additionally, in response to the religious belief, which is one of the main reasons the opposing camp uses to reject the same-sex marriage proposal (recall the discussion around dominant subtopics discussed by commenters; see section 5.2 in this chapter), Lionfod makes a sarcastic reference by saying, "Church can warp [sic; 'wrap'] their noisy bells up, and go back to wherever they came from. They have no more say. If we want to speak to God, we WhatsApp it directly" (lines 20-22). By connecting these two things, i.e. the traditional religious belief and the ultramodern communication WhatsApp, they are making an intertextual reference. This seems to be alluding to the common expression, "He has a direct line to God", albeit with connection to modern technology and with an interesting contestive reflecting to God as 'it'. This phrase also refers to church reformation. Specifically, the Catholic Church used to say people have to go through Christ in order to talk to God. But after reformation (Beckham, 2005), people are understood as being able to talk to God directly. And so, this use of WhatsApp in this context, is a clever updating of the telephone metaphor. What this interesting juxtaposition arguably is achieving to referencing a view that same-sex marriage is none of the business of those advocating religious basis for their belief, and that the religious belief that used to oppose SSM is no longer suitable for modern society and should be changed. Through the use of indirect quotation as well as employing sarcasm (Ghosh et al., 2018) against those people who oppose the legalisation of SSM, Lionfod has constructed their identity as a promoter of equal marriage.

As the discussion has demonstrated, constructed dialogue is abundant in the data set, adding support to the widely agreed view that no one 'owns' the language. That is, as Seals (2012) argues, "in all discourse, no language is solely authored by the person speaking (or using) at the 
time" (p. 233; also see e.g. Bakhtin, 1986; Hodges, 2015; Fairclough, 1992). Rather, it is connected to other people and other interactions. This argument specifically underscores the significance of quotation in our daily interactions and indicates that it can also play a role in constructing identities and relationships (Hodges, 2015). So, again, the quotations enable the writer to communicate with their ideal reader intertextually using shared (prior) knowledge and ideologies without having to "possess" them (Seals, 2012, p. 236). Because of the implicit meanings and intended messages that each word contains, semantic presupposition becomes another key aspect in analysing intertextuality in discourse.

\subsubsection{Semantic presupposition}

Van Dijk (1998) argues that people always over-interpret the information of a text. This points out the relationship between semantics and ideologies embedded in discourse. Ideologies present what people know and think about a specific event and situation. Semantic presupposition is thus key in connecting the discourse to its readers, which includes the 'ideal reader' (recall Fairclough's (2001) discussion; see section 5.4). As a result, semantic presupposition is essential for connecting the discourse to its intended audience, including the ideal reader. Just as Fairclough (2001) points out and noted above in the work of Seals, the 'ideal reader' will comprehend the underlying meaning through intertextual links to ideologies given in the text. According to this understanding, presupposition seems to be an appropriate means to examine the relation between semantics and discourse in an intertextual analysis. However, in real interactions, we cannot expect actual readers to always draw upon the exact same inferences and conclusions as the ideal reader or to take up the positions assigned by the writer (Seals, 2012, p. 235).

Presupposition then contributes to solving this problem, as the writer believes that they share mutual intertextual indicators with the ideal reader. This allows the ideal reader to be aware of the positions that the writer is attempting to allocate to them (as well as to the potential interlocutors) and as a result, to understand the implicit meanings expressed by the writer. However, it is often the case that actual readers are not the so-called 'ideal', making it 
impossible to identify these propositions and thereby reject them (Fairclough, 2001, p. 154).

However, there are some circumstances in which these readers recognise the writer's proposition. As Oughton (2007) observes, they are then invited to negotiate their reaction to the text with the ideal reader and to take up a position (as cited in Seals, 2012, p. 235). In so doing, readers "will often feel that they should 'fall in' with the subject position of the ideal reader rather than oppose it" (Oughton, 2007, p. 266). As a result, the concept of ideal reader remains crucial in comments discourse analysis, especially in understanding the relationship between the commenter and their reader, as well as the socio-cultural context in which the text is produced. Additionally, by including an investigation of presupposition I aim to offer a better understanding of how commenters draw upon social ideologies to construct discourse through intertextuality, as well as how commenters use a particular type of quotation to speak to the ideal reader, thereby strengthening ideologies of specific social groups or communities (in line with Seals, 2012, pp. 237-238).

The following examples illustrate how commenters use specific presuppositions to convey the underlying meaning of their contribution to their ideal readers. These ideal readers are, for the writers, versions of themselves.

Excerpt 5.8 [Angela Merkel votes AGAINST legalizing gay marriage but is defeated as Germany passes new same-sex wedding law; Mail Online]

1 Kirsty1

2

3 user1448 > Kirsty1

4

5 julie

6

7 Huddersfieldlegend $>$ julie

$8 \mathrm{HAL}>$ Kirsty 1
Why would she vote against it given her supposedly open view on acceptance and tolerance.

Wow. One thing about Angela Merkel I can actually agree with.

which will be the first country in the Middle East to legalize gay marriage?

The sun will die before that happens.

It's the first time l've ever agreed with Merkel. 
Focusing on the recognition of same-sex marriage in Germany, Kirsty1 first expresses her surprise about Merkel's dissenting vote, as she writes, “...given her supposedly open view on acceptance and tolerance" (lines 1-2). The use of the lexical item 'supposedly' undermines a positive social identity of Merkel as an open-minded and tolerant politician, while at the same time, it also expresses astonishment regarding Merkel's negative attitude towards legislating gay marriage, presupposing that Merkel should not have voted against. As an actual reader of this specific text, user1448 does not seem to explicitly acknowledge the positioning made by Kirsty1. Their own position on the legislation of same-sex marriage, however, is quite ambiguous when they reply to Kirsty1, as they write, "Wow. One thing about Angela Merkel I can actually agree with" (lines 3 through 4). Specifically, when user1448 says "one thing" they actually agree with Merkel about, it could be either component of the previous comment that Kirsty1 made on Merkel, that is, her 'no' vote in her open view on acceptance and tolerance; or they may agree and be positioning themselves as advocates of the marriage equality, i.e. they show their affiliation with Merkel as opponents of same-sex marriage. This semantic ambiguity results in vague positioning appears to be a case where semantic presupposition has failed because the target of this specific semantic meaning is unknown.

By employing the strategy of semantic presupposition, both commenters are inviting their ideal readers to take the same position as them. The interlocutor who follows does not engage with these positions respond to their positionings. Rather, they compare other countries' with Germany. To be more specific, julie asks: "Wonder which will be the first country in the Middle East to legalize gay marriage" (lines 5 through 6). Importantly, this is a radical switch of topic that appears unrelated in this interaction. In essence, we can argue that this is not a random choice made by the commenter, but rather a deliberate strategy. First, in comparison with Germany or other countries across the world, countries in the Middle East are considered relatively conservative in many ways, including attention to legalising same-sex marriage. By using a rhetorical question here, she is not anticipating any answers from her readers (because Julie already knows the answer), but she is assuming a shared understanding of Discourses of the 
Middle East ${ }^{24}$ with her readers, thus adopting a sarcastic position on Middle East countries, presupposing their backwardness on the issue of marriage equality. Through this presupposition, she has positioned herself as a supporter of marriage equality implicitly. Furthermore, Julie is constructing her identity through the employment of a racist ideology, positioning Middle East countries as inferior.

The rhetorical question used by the writer is arguably functioning as an intertextual reference that speaks to the ideal reader. As an ideal reader, Huddersfieldlegend receives the implied meanings from Julie, since they answer: "The sun will die before that happens" (line 7). This answer not only presupposes that people should never ever expect legalization to occur, but also expresses solidarity with julie. So far, in this conversation, two commenters have successfully hijacked what was initially a discussion about Merkel's vote in order to construct a mutual identity built on racism (though of course strategies that are indirect allowing for plausible Discourses of racism). In this ongoing interaction, another commenter joins the discussion, responding to Merkel's vote in real-life. In line 8, HAL replies to Kirsty1 in saying that, "it's the first time I've ever agreed with Merkel". This directly affiliates themselves with Merkel and again, construct their identity as opponents of same-sex marriage. By emphasising it is the first time that they agree with Merkel (i.e. usually they do not agree with her), they are presupposing that people expect Merkel to support same-sex marriage. Through the use of this specific presupposition, their position on the issue of legalising gay marriage is clarified.

Within this example, the use of semantic presupposition shows that commenters do not always express their meaning directly during an interaction. Rather, they hope that their ideal rea ders know enough to interpret the underlying meanings. While readers can take a range of information from previous discourse, only the 'ideal reader' receives the message that the writers mean to display. By acknowledging the full message, the ideal readers can show their affiliation and further build solidarity within groups and communities in online interactions.

\footnotetext{
${ }^{24}$ That is, Western Discourse that involve an "essentialising and generalising cultural depiction" of the Middle East as a 'region of risk' (Bankoff, 2003, p. 414) where homosexuality (or the homosexual) is oppressed, passive, and even a crime (e.g. Kugle, 2010; Tolino, 2014).
} 
The attempted employment of presupposition sometimes fails interactionally, as the above excerpt has shown. Yet, a focus on presupposition can also offer insights where components of a message are missing. The following excerpt illustrates how semantic presupposition works in this context.

Excerpt 5.9 [Australia's referendum on gay marriage killed off by Senate; Stuff]

1 Onya Bike

2 sitting duck> Onya Bike

3

4 Positivepower

5 Thrace

6

7

8 EricChin2> Thrace

9

10

11 Draintheswamp:
Do they recognize marriage that are performed in NZ?

Yes and no. For some purposes such as immigration yes but same sex couples can't get a divorce in Australia.

Acknowledge your aboriginal people first!

Is it just me, or has an increasing number of news reports

recently tended to show our neighbors across the ditch up as a bunch of intolerant red-necks?

Maybe, or maybe there's an increasing number of incidents recently where they are behaving like a bunch of intolerant red-necks.

Gay marriage killed by Labor Party.

\section{one reply to Draintheswamp (This comment has been deleted ${ }^{25}$ )} one reply to the deleted comment

12 Djc92

13

14

15

16

17
That doesn't stop it being true. Australia could have had gay marriage by early next year. Thanks to Shorten, it isn't going to happen for at least three years - maybe never. But then that was his plan all along. He actually doesn't have any real policies, so he needs to keep this issue alive so that he thinks there is at least one reason to vote for him.

\footnotetext{
25 The comment has been deleted due to its content is against the regulations of the target online news website. Readers are referred to section 4.3.1. More detailed information is provided.
} 
In this excerpt, commenters discuss the rejection of a referendum on the legalisation of samesex marriage in Australia. Specifically, Onya Bike initiates the conversation by asking whether people in Australia recognise gay marriage performed in New Zealand (line 1). This question is a comparison of same-sex marriage between Australia and New Zealand, seeking answers from other interlocutors. Responding to this, in lines 5 through 7, Thrace calls Australia "our neighbours" (line 6). The use of first-person pronoun (i.e. 'our') serves as a certain form of identity cue (cf. Bazzanella, 2002, p. 249), indexing their national identity and specifically positioning them as New Zealanders. This positioning is later stressed by judging Australians as "a bunch of intolerant red-necks" (lines 6 through 7). In respond to this negative judgment on Australians, EricChin2 comments, "there's an increasing number of incidents recently where they are behaving like a bunch of intolerant red-necks" (lines 9 through 10). This is a form of an intertextual echo which serves two main functions. First, it aligns the commenter with Thrace by showing their total agreement (this has been argued earlier in the section on constructed dialogue regarding its function in interaction). Second, through this specific echo, a negative image of Australians accordingly has been emphasised. In addition, the employment of thirdperson pronoun they (line 9) serving as an outgroup marker also unpacks his national identity (although it is ambiguous) through distancing from Australians.

While commenting on Australians, in both comments, commenters are actually drawing upon the intertextual meaning of 'redneck'. This derogatory term, in fact, is closely associated with rural communities of the Southern United States and is originally applied to white Americans who are perceived to be crass and unsophisticated. Indexing rednecks in this intertextual way positions Australians as conservatives who are uneducated and have prejudiced beliefs towards the legalisation of same-sex marriage. In this way, a Discourse of national superiority is foregrounded, contributing to co-constructing the mutual Kiwi identity as accepting of the LGBTQ community.

Instead of targeting Australians, Draintheswamp attributes the rejection of same-sex marriage bill to the Labor Party (line 11). One of the commenters replies to this view, however, it is 
deleted by the commenter him/herself, or alternatively deleted by Stuff because the content violates its policy of online commenting. Djc92 responds to the deleted comment, as they write, "That doesn't stop it being true..." (line 12). In this comment, 'that' refers to the content of the deleted comment. Presumably, it not only connects with the earlier opinion that gay marriage was killed by the Labor Party, but also it has something to do with what is subsequently said by Djc92. By considering what Djc92 discusses (through lines 12 to 17), we can presuppose that the deleted comment brings forward proposition that contrasts with Draintheswamp's. That is, they proposed other reasons which contribute to the failure to support the legalization of same-sex marriage in Australia. This inferred message adds weight to the claim that intertextuality carries two voices during an interaction, transforming prior texts and restructuring existing discourse to generate new ones (Bakhtin, 1986; Seals, 2012). Rather than looking at speech events individually, intertextual analysis offers analysts additional information about how language is impacted by interaction, particularly when some of the 'links' and 'traces' are missing (Porter, 1986).

\subsection{Summary}

Focusing on the theme of same-sex marriage, this chapter investigated the representation and negotiation of commenters' identities, as well as the complex ways in which ideologies and Discourses are appropriated and resisted in online interaction. By and large the ideologies in the data were reasonably explicit while discussing the topic of same-sex marriage and operated as readily-accessible resources for the commenters in their identity construction and negotiations.

The attention to positionality demonstrated within identity construction includes relationships to "the dominant ideologies, widespread social practices and underlying structures drawn together as Discourses" (De Fina, Schiffrin \& Bamberg, 2006, p. 7), expanding a focus on positioning to include big-D Discourses (Gee, 1999) as central to the construction of identity. Within this chapter and the theme of same-sex marriage, while commenters' identity negotiations are different, they are all in varying ways influenced and constrained by ideologies of gender and sexuality. Negotiations involved aligning and disaligning with many Discourses nourished by 
ideological roots (Dawson, 2019), including Discourses of Homophobia, Minority, and The Middle East, to name those most prevalent in my data (e.g. Excerpt 5.1, 5.3, 5.8). We are always 'doing' our identities and negotiating our sexualities wherever we are, often without a conscious recognition of the structuring forces we are working with (Cameron, 2014). In other words, in negotiating one's sexual identities in an online interaction context, the dominant ideological framing stays the same, yet what changes is the shape and strength of the particular ideologies and Discourses one is exposed to and which we index.

Alongside the salient social construct of sexuality, commenters also foreground their national identities through interactional positioning. The most regular instantiations of national identities are through the strategic use of personal pronouns (e.g. Excerpt 5.2, 5.3 and 5.9). Performing national identity is also closely associated with a wide range of ideologies and Discourses (e.g. Discourses of national superiority, see Excerpt 5.9), emphasising again the importance of an intersectional approach. Whether commenters were interactionally drawing on, aligning with, or contesting (consciously or unconsciously) these Discourses and ideologies (e.g. heteronormativity, racism, national superiority, etc.), their identity negotiations cannot be disentangled from these structuring properties.

The data presented in this chapter also demonstrates how the use of intertextuality allows commenters to speak to different audiences, particularly to their ideal readers. This is shown in how an issue of interest is able to influence particular (imagined) communities. As the most mundane manifestation of intertextuality, I showed how constructed dialogue serves the construction of stances of agreement and disagreement with the articles discussed and other interlocutors involved in interaction (e.g. Excerpt 5.4, 5.5). I also explored how quotation can enhance authority of a particular positioning as well as how it can be used as a shorthand to express shared ideologies, relating it to the notion of symbolic capital (see e.g. Bourdieu, 1986; Meadows, 2009; Seals, 2011). In this sense, who is quoted and how, as well as the presuppositions in the discourse, create different meanings for different audiences. The focus on intertextuality then becomes a valid way of "activating and reinforcing particular ideologies 
through the expression of propositions as 'truth'” (Seals, 2012, p. 252). Thus, intertextuality enables us to understand how commenters speak to their ideal reader in order to access and reinforce ideological positionings when discussing specific issues. In this case, the intertextual analysis focuses on the long-standing LGBTQ issue of whether we should legalise marriage equality. This kind of intertextuality is also used for referencing social ideologies because it is the ideal reader who has access to the presupposition featured in the interaction (Seals, 2012).

To conclude, through the analyses of positionality and intertextuality, it becomes clear that ideologies are ever-present in discourse. By shifting my focus to the theme of travel in the following chapter, I will explore how covert ideologies are embodied in interaction. 


\section{Chapter 6}

\section{Analysis of theme 2: Travel}

\subsection{Introduction: Covert ideologies}

The previous chapter explored data that foregrounded ideological difference by focusing on the theme of same-sex marriage. I now turn my attention to the theme of travel. Commenters on travel stories may not be aware that their interactions (like all interactions) are imbued with ideological perspectives, i.e. the ideologies are generally more covert in comparison with the topic of same-sex marriage. When we talk about travel-related issues, interactions may reflect exploration, ideas of travel, the environmental implications of travel, ideologies of colonialism (e.g. ideologies of Whiteness; cf. Cogeanu, 2015) amongst other Discourses (see e.g. Cogeanu, 2015; Liashuk, 2019; Mills, 1991). In fact, there are a wide range of implicit ideologies presented and negotiated in discussion. In this analysis chapter I focus primarily on ideologies that are always present in discourse but often hidden. By connecting these ideologies with contextualization cues (whereas ideologies are invoked throughout the cues), I aim to achieve a better understanding of how commenters use ideologies (and sometimes the same ideologies) in different contexts to construct and negotiate their online identities.

In Chapter 5, in accessing to commenters' ideologies and identity construction, I made use of positionality and intertextuality. I also provided an overview of the sub-topics discussed by commenters, outlining the overall trends for how the theme of travel is discussed. This provides me with a means of seeing salience in the data and helps to narrow down my focus in the qualitative discourse analysis. 


\subsection{Prominent sub-topics under the topic of travel}

Issues of interest (i.e. sub-topics) discussed by commenters have an important impact on their position taking in online interaction. Bucholtz and Hall $(2005,2008)$ comment that positioning mediates between linguistic forms and general social categories and is thus fundamental to an understanding of identity. Bearing this in mind, an examination of sub-topics under the two themes was conducted in this study. The results have helped me sort the data for what I need to focus on later in qualitative analysis, because the sub-topics discussed by commenters index certain ideologies embedded in travel discourse.

Based on the coding report extracted from NVivo11, under the higher level topic of 'travel', the following top three sub-topics dominate the discussion. That is, 'comments about a place', 'sharing personal experiences', and 'comments about people' (as highlighted in red in the table). Table 6.1 indicates the relative frequency of the sub-topics. A numerical comparison across the three sites is further informed by a proportional analysis as provided in table 6.2. 
Table 6.1 Number of comments on each sub-topic (in the parent nodes) coded in three news websites regarding the topic of Travel

\begin{tabular}{|l|c|c|c|c|}
\hline sub topics & A: Stuff & B: Mail Online & C: The Guardian & Total \\
\hline 1: airlines & 31 & 18 & 25 & 74 \\
\hline 2: airport chaos & 0 & 21 & 0 & 21 \\
\hline 3: Brexit & 0 & 24 & 10 & 34 \\
\hline 4: comments about a place & 24 & 33 & 57 & 114 \\
\hline 5: comments about people & 45 & 21 & 29 & 95 \\
\hline 6: criticism on the factual-content & 0 & 42 & 0 & 42 \\
\hline 7: cultural differences & 6 & 0 & 0 & 6 \\
\hline 8: customer-related issues & 1 & 1 & 5 & 7 \\
\hline 9: entertainment & 8 & 16 & 0 & 24 \\
\hline 10: flight & 23 & 56 & 0 & 79 \\
\hline 11: insurance & 3 & 0 & 5 & 8 \\
\hline 12: over-developing issue & 5 & 0 & 0 & 5 \\
\hline 13: passengers' rights & 11 & 0 & 1 & 12 \\
\hline 14: religious values & 1 & 0 & 0 & 1 \\
\hline 15: safety concern & 5 & 43 & 0 & 48 \\
\hline 16: sharing personal experiences & 26 & 35 & 46 & 107 \\
\hline 17: showing sympathy & 0 & 21 & 0 & 21 \\
\hline 18: suggestions and tips on travelling & 7 & 7 & 26 & 40 \\
\hline 19: travelling items & 16 & 0 & 0 & 16 \\
\hline 20: visa issues & 26 & 0 & 9 & 35 \\
\hline
\end{tabular}

Table 6.2 Percentage of the top five sub-topics discussed in three news websites regarding the topic of Travel

\begin{tabular}{lcccccc}
\hline & \multicolumn{2}{c}{$\begin{array}{c}\text { Stuff } \\
\text { Total: } \mathbf{3 7 8}\end{array}$} & \multicolumn{2}{c}{$\begin{array}{c}\text { The Guardian } \\
\text { Total: } \mathbf{4 6 0}\end{array}$} & \multicolumn{2}{c}{$\begin{array}{c}\text { Mail Online } \\
\text { Total: } 500\end{array}$} \\
\cline { 2 - 7 } & $\begin{array}{c}\text { No. of } \\
\text { references } \\
\text { coded }\end{array}$ & $\begin{array}{c}\text { Percentage } \\
\%\end{array}$ & $\begin{array}{c}\text { No. of } \\
\text { references } \\
\text { coded }\end{array}$ & $\begin{array}{c}\text { Percentage } \\
\%\end{array}$ & $\begin{array}{c}\text { No. of } \\
\text { references } \\
\text { coded }\end{array}$ & $\begin{array}{c}\text { Percentage } \\
\%\end{array}$ \\
\hline $\begin{array}{l}\text { Comments about } \\
\text { a place }\end{array}$ & 24 & $6.3 \%$ & 57 & $12.4 \%$ & 33 & $6.6 \%$ \\
\hline $\begin{array}{l}\text { Comments about } \\
\text { people }\end{array}$ & 45 & $11.9 \%$ & 29 & $6.3 \%$ & 21 & $4.2 \%$ \\
\hline $\begin{array}{l}\text { Sharing personal } \\
\text { experience }\end{array}$ & 26 & $6.9 \%$ & 46 & $10.0 \%$ & 35 & $7.0 \%$ \\
\hline Flight & 23 & $6.1 \%$ & 74 & $16.1 \%$ & 56 & $11.2 \%$ \\
\hline Airlines & 31 & $8.2 \%$ & 79 & $17.2 \%$ & 18 & $3.6 \%$ \\
\hline Total & 149 & $39.4 \%$ & 285 & $62 \%$ & 163 & $32.6 \%$ \\
\hline
\end{tabular}


As shown in Table 6.1, in addition to commenting on places and people based on travel experiences (namely to express how they feel about the place and people; e.g. whether they like it or not), commenters are also keen to share personal experiences (e.g. telling others about their traveling stories; ranked as top 2 among other sub-topics) in the data. This ranking not only shows the willingness of participants across all sites to share their personal experiences, arguably to initiate or maintain an interaction in online communication (Kouper, 2012), but also demonstrate the specific functions served by the comment, such as building solidarity, closing distance and so forth (e.g. Chuang \& Yang, 2010; Kouper, 2010; Rhodes, 2019; Yuniawati, 2019). (This point will be explored further within the qualitative analysis of excerpts later in the chapter). The topics of 'flight' and 'airlines' also enjoy a relatively high proportion of the commenters' discussion (ranked as top 4 and 5, respectively).

On the face of it these two topics are interconnected but the coding reflects different focus. In this study, the topic of 'airlines' is coded when discussion relates to, such as policy of airlines, airlines' rules (e.g. how to earn points/buy miles), and the specific behaviour of airlines (e.g. over booking). The topic of 'flight' specifically deals with flight-related issues, for example, flight delay (e.g. the cause of flight delay), seat space, and alcohol prohibition (as these are discussed by commenters in this data).

As table 6.2 outlines, the trends vary slightly according to the news website. Specifically, in Stuff, the top three sub-topics discussed by commenters in order of frequency are: comments about people (coded 45 times), airline-related issues (coded 31 times), visa-related issues and personal experiences (both coded 26 times). With respect to The Guardian, the readerships of this newspaper mainly comment on a place (coded 57 times), followed by sharing personal experiences (coded 46 times) and comments on people (29 times). In contrast to the others, the top three sub-topics discussed by commenters of Mail Online are flight-related issues (56 times), safety concern (43 times), and criticism on the factual-content (42 times). This differences in the top three topics discussed by commenters seems to align with the experiences of the regions as well as the expectations of how fact-focused that particular newspaper is (Himma-Kadakas, 
2017). For example, within the New Zealand context, participants show great interest in talking about the process of visa application based on their experience of applying for a UK visa in particular, leading to the topic becoming one of the more frequent sub-topics discussed by commenters. This result, as I had assumed earlier, reflects the different readerships. Within the UK context, the readerships of Mail Online and The Guardian also differ by issue. Notably, in Mail Online, one of the frequent topics discussed by commenters is 'criticism on factual-content'. This topic does not occur even once in the other two news sources. This indicates a strong relationship between the readerships of newspapers and the topics discussed by them, and widely demonstrate the characteristics of Mail Online as a tabloid news source (cf. Atanasova \& Koteyko, 2017; Grant, 2016; also see section 4.2).

In addition, as table 6.2 illustrates, the total percentage of the top-five topics coded in The Guardian is much higher than the other two news sources (i.e. 62\% in The Guardian, and 39.4\% and $32.6 \%$ in the Stuff and Mail Online, respectively). On the one hand, this indicates the inclusiveness of topics discussed by commenters in The Guardian; on the other hand, it suggests that there are more topics being discussed in the other two news sources.

The results of prominent sub-topics discussed by commenters are influenced by the articles appearing in the papers as well as the intended audience and their engagement. The differences not only represent readerships' various interests at the time of data collection, but also gives early indications of potential ideological differences when commenters discuss travelling (cf. Dunn, 2006; Jaworski \& Thurlow, 2009). That is, diverse ideologies already appear to be influencing the construction and negotiations of online identities of the different readers.

\subsection{Analysis of positionality}

\subsubsection{In-groups and out-groups in identity construction}

The analysis in this chapter follows a similar method for accessing identity as Chapter 5 through the aspects of positionality and intertextuality. As discussed, Gumperz's Interactional Sociolinguistic approach to discourse analysis offers analysts a valid tool to explore micro-level discursive features in the interactional data, while at the same time, highlighting the importance 
of wider sociocultural contexts when interpreting the social meanings that people express in interaction. This approach to understanding communication posits that the way in which meaning is negotiated and interpretated is heavily dependent on the interactional context (Gumperz, 1982; Schiffrin, 1996). In other words, in order to better understand meaning, we need to contextualise the words and strategies used. As Gumperz (1982, p. 13) asserts, "what we perceive and retain in our mind is a function of our culturally determined predisposition to perceive and assimilate", suggesting that the ways people interpret situated inferences is influenced by society as well as the cultures in which we live (Greenbank, 2020). Within this approach, Gumperz's key concept of contextualisation cues is valuable in understanding meaning-making and accessing situated inferences. These cues provide clues (both verbal and nonverbal) to how audiences understand the current communication and further the writer's implied message (Greenbank, 2020; Gumperz, 2005; Rampton, 2017). According to Gumperz (1982, p. 131), a contextualisation cue can be "any feature of linguistic form that contributes to the signalling of contextual presuppositions." (See discussion in section 4.5.2). Meanings of contextualisation cues, therefore, cannot be talked about out of context (Gumperz, 1982, 2005). This stance draws our attention to how interactants understand semantic content and how this content relates to what comes before and after the encounter. As discussed in Chapter 2, social identifications, or group memberships, influence and reflect salient aspects of the interactional negotiation of identity. The context of online communication, understood here as an interactional process through which a social actor claims membership of a group (through the mediational means of the internet), provides a rich environment for this kind of negotiation as commenters engage in social activities.

The formation of in-groups and out-groups is an integral part of the interactional process involved in identity construction. By interacting with other commenters from different backgrounds (e.g. different ethnical, national, socioeconomic, etc. backgrounds), commenters divide the interactional participants into in-groups (those they identify with) and out-groups (those they do not) (see Tajfel's intergroup theory, 1974). This allows commenters to create and give sense to their social structures as they form meaningful alliances that construct their 
multiple selves. Turner $(1975$, p. 7) explores the relationship between identity and group membership construction when explaining that "an individual defines himself as well as others in terms of his location within a system of social categories - specifically social group memberships - and social identity may be understood as his definition of his own position within such a system." Therefore, the relevant social groups with which commenters identify contribute to the construction of their identities as these group preferences reflect their values, beliefs and attitudes (Apker \& Eggly, 2004; Beijaard et al., 2000; Beliaeva \& Seals, 2020). In this case, the focus of in-groups and out-groups is helpful for exploring how commenters take up or reject specific ideological positioning by showing their preference for specific group memberships in online interaction.

This section examines the discursive construction of in-groups and out-groups as a way that commenters build their identities according to the interactional norms of their community (see e.g. Baxter \& Wallace, 2009; Giles \& Giles, 2013; Holmes \& Marra, 2002; Lazzaro-Salazar, 2017). The extracts explored in this section were chosen for their ability to illustrate several points of the relationship between membership formation and identity construction observed throughout the data. This section explores the discursive strategies that are employed to this end, particularly focusing on the dynamic use of pronouns, which serve as contextualisation cues (Gumperz, 1982; Schiffrin, 1996) to illustrate the shifting and fluid nature of identity construction in addressing interrelated interactional purposes.

\subsubsection{Building the in-group}

Social actors claim and maintain membership of social groups when they identify with those groups. They build, for example, mutual expectations of their roles in particular groups. They also establish views about what group members should be, as well as what they are allowed or not allowed to do within that group (Hogg \& Terry, 2000). In-group members are expected to share their way of behaving and of speaking, their "intentions, attitudes and systems of beliefs" (Tajfel, 1974, p. 69). Discourse plays an important role in this process, as Excerpt 6.1 illustrates. 
Excerpt 6.1 ["Welcome to hell": Furious British tourists endure severe delays at Majorca airport as police warm of MORE chaos this weekend; Mail Online]

1 martin

2 drik panzer $>$ martin

3

4

5

6

7

8
Let us teach those damn Brits to dare want to leave our club. Yeah...what do we call a British tourist these days? A target :) Ho Ho....loads of moaning from the "great" British public who live to sneer and abuse their own police...now they realise that we regard them as little more than something they would find on their shoe... it's a good lesson for them to learn. Well done Spanish, let us give them a hard time for our club. See, hate and you get hated back

In this short conversation, commenters blame Brexit for the airport chaos which caused thousands of British tourists to be stuck at Spain's Majorca airport. The relevance of Brexit and the UK's vote to leave to the European Union (EU) is implicitly suggested in line 1, as martin says, 'leave our club'. In this short statement, martin is drawing on a shared understanding of the meaning of 'club' and hoping his ideal reader would be able to understand that the club is intertextually referencing the EU in this specific context. Martin positions himself in opposition to British tourists through the use of first-person pronoun us and our (line 1), thus building affiliation between himself and possibly Spaniards as well as other members of the EU. At this point in the interaction, I interpret this statement as meaning they belong to the same in-group. This process of in-group identification becomes more relevant when other members engage in the interaction in which they measure their own positioning in relation to this positioning. Beginning with yeah, drik panzer indicates their agreement with what has been said earlier by martin (Bower, 2018; Fuller, 2003; Thuy, 2019; Wang et al., 2010). They go one step further to call British tourists 'a target', followed by the use of semiotic resource (i.e. :)) and the representation of a sound (i.e. 'Ho Ho') (lines 2-3). This combination appears to be deliberately childish to add humour to the comments (see e.g., Holmes \& Marra, 2002; Marra \& Holmes, 2007) and it is in the conventional form of a taunt, arguably functioning as a distancing strategy. 
Furthermore, the positioning is accentuated by using the distancing tactic of scare quotes (i.e. "great", line 3) (Ask, 2018; Predelli, 2003). By distancing themselves from the British, they have created a sense of in-group membership. This is later reinforced through the statement, "see, hate and you get hated back" (lines 7-8), which also positions drik panzer in opposition to Discourses of privilege (e.g. Leonardo, 2004; Park, 2015). In the case of extract one above, they are drawing upon privileges of nationality; they are being sarcastic about British people, implying that they have to suffer the consequences of Brexit. The in-group constructed by the two interlocutors is only relevant in relation to its out-group in this specific context in which they are implicitly talking about 'Brexit', as 'us' and 'our' distinguish them as members of EU distinct from the UK.

Group membership is "a process ongoingly produced and oriented to by the parties and not necessarily an explicit naming or describing of oneself, or the other" (Psathas, 1999, p. 56). The provision of membership relevant information and appropriate membership orientation requires "no explicit naming of who I am [...] done by either party. Rather, who / am is accomplished in the doing of the action" (emphasis in original, Psathas, 1999, p. 148). In this sense, discursive choices are harnessed to claim specific stances as well as to construct belonging to particular groups through positioning (see Ochs, 1993; Bucholtz \& Hall, 2005). One of the questions that arises from these considerations is: if no explicit naming of the group membership invoked in the interaction is necessary, what are the linguistic resources the commenters in this study employ to make salient aspects of their memberships that are relevant to a given interactional context? In this regard, in addition to other more subtle discursive strategies used to position themselves as in-group members and others as out-group members, and as seen in Excerpt 6.1, commenters use personal pronouns in dynamic ways to build group and specific identities.

\subsubsection{Personal pronouns in group membership}

Scholars from various disciplines have explored the relationship between the use of personal pronouns and the construction of social identity. Previous studies have shown that they are highly relevant in different contexts of communication, notably in the investigations of political 
discourse as they are often employed for claiming a certain identity, such as nationality or political allegiance (e.g. Beliaeva \& Seals, 2020). Personal pronouns are frequently referred to as deictics because they are "linguistic forms which are dependent on context for their (referential) meaning" (Fasulo \& Zucchermaglio, 2002, p. 1121). In other words, personal pronouns can be described as "empty signs", loaded when placed in a context (Moberg \& Eriksson, 2013). In the example given earlier (Excerpt 6.1), "Well done Spanish, let us give them a hard time for our club" (lines 6 -7), the meaning of pronoun 'us' depends on contextual features of the interaction such as who utters the sentence, to and of whom, when and where. Considering the airport chaos took place after the British vote to leave the EU, 'us', in this context, could be the referent for the EU as a whole, or alternatively as Spaniards in particular. It is only through the contextual information that we are able to identify 'us' as referring to the commenter and his compatriots (i.e. other Spaniards and/or in the wider sense of the EU but not including the UK), as the employment of 'our club' (line 7) suggests their group membership of the European Union. That is, drik panzer is supporting their construction of a sense of belonging to the EU group and positioning themselves as another representative of the group. In positioning themselves in opposition to the British, commenters therefore make an identity (their social identity as members of the EU) claim through the strategic use of personal pronouns in this interaction.

The following extract from comments associated with the same article illustrates some of the discursive functions of pronouns related to group membership construction as well as the indexical value of certain identities.

Excerpt 6.2 ["Welcome to hell": Furious British tourists endure severe delays at Majorca airport as police warm of MORE chaos this weekend; Mail Online]

\section{[...]}

9 ElMejor94> martin

10

11
I work in Palma airport and it's really only the British affected, usually when they have German, Spanish and other nationalities they tend to have more staff on the when there is 
12

\section{$13 \mathrm{BJ}$ retd > EIMejor94}

14

15

16

17

18

19

20 foxy pete > ElMejor94

21

22 block of UK flights then it's a different story.

They did change how they handle UK passports on the way out. They used to just glance at us and wave you through (as they when you are inbound) but now they stop, look at it, look at you and put it through some sort of digital scanner they have on their desks at least that's what happened to me last month. Whether that's just tightening controls or 'let's teach them a lesson' I will let you decide.

whatever the reason is, so many of us in DM think we are against them...they even think Manchester bombs were planted by Spaniards.

The extract is a continuation of the conversation undertaken in extract one above. On the matter of why British tourists were stuck in the airport, EIMejor94 shared their personal experience of working in the airport to explain that the chaos is intentionally caused by airport staff in Spain (lines 9 through 12). EIMejor94's identity positioning in this interaction is not as straightforward as might be expected. Broadly speaking, the use of the pronoun / is expected to index their group membership of the airport as a work team. However, the explicit shift from the firstperson pronoun to the third-person (i.e. 'they') in the following lines (lines 10-11) suggests the commenter's intention of distancing themselves from that group. That is, ' $I$ ' and 'they' do not belong to the same group although 'we' (as airport staff) work in the same place. So, in this statement, the use of pronoun / directly reveals their professional identity as worker at the airport through their narration, while the use of 'they' draws a clear boundary between EIMejor94's in-group and other groups, positioning themselves as someone who is not deliberately making things difficult for others.

Similarly, the third-person pronoun 'they' is repeatedly used in BJ retd's response to EIMejor94 in lines 13 through 19. By contrast with the previous identification of group membership discussed earlier, this time, the third-person they assigns a different indexical value to which 
Spaniards are excluded, from BJ retd's in-group (as a British person). BJ retd positions themselves within the group of British tourists, claiming their national identity through a small story of past travel (see e.g. Bamberg, 2004; Bamberg \& Georgakopoulou, 2008). Their cursory attitude towards their travel experience to the implicature of this experience (i.e. how they were treated while passing Spanish customs) seems to indicate their sensing of being othered (although it seems to function to suggest that it is a retaliatory move). Further, this implicature is achieved skilfully with an open-ended rhetorical question. That is, "whether that's just tightening controls or let's teach them a lesson, I will let you decide." (lines 18-19). This statement is a form of intertextual echo (Hays, 1989; Moyise, 2002; Seals, 2012) in discourse, because it borrows from the previous comment made by drik panzer (line 6; in Excerpt 6.1). Interestingly, in this statement, BJ retd refers to the British as 'them' (although he explicitly indexes their own national identity as a British earlier), I would argue that this particular use of pronoun is a way of mitigating the degree of self-mockery and covering any potential embarrassment in being associated with their poorly behaving countrymen (cf. Attardo, 2001; Santa Ana, 2009). By using a linguistic strategy of self-mockery, BJ retd thus shows their recognition of being excluded from the in-group (the EU group as identified earlier in Excerpt 6.1).

Additionally, the second-person pronoun you (line 19) arguably refers to the interlocutors who are already engaged in this conversation as well as potential others. By acknowledging this, they show a sense of belonging to this potential online 'imagined community' of commenters (Anderson, 1983). Showing a sense of belonging could also be seen from the following reply made by foxy pete, who also uses a collective first-person pronoun us in line 20 (i.e. so many of us in the DM; DM is the abbreviation for Daily Mail), including other interlocutors from this particular affinity space (see section 3.3). They continue referring sarcastically to British, saying that, "they even think Manchester bombs were planted by Spaniards" (lines 21-22). In this sarcastic use, the pronouns 'we' and 'they' ('them' as well) reveal their national identity as a Spanish, while simultaneously distancing themselves from the British. This juxtaposition places foxy pete as Spanish in a more privileged position to the British tourists who become, by implication, their out-group. However, in this interaction, both BJ retd and foxy pete have made 
a 'claim to belonging' (Greenbank \& Marra, forthcoming; Holmes, 2018) to this specific interactional group, which although subtly enacted, comprises a great many of messages and identity positioning work: sharing personal experiences with others in public suggests that commenters prefer to display a sense of belonging rather than being Othered (cf. Kouper, 2010), and the strategic use of personal pronouns suggests a sense of membership in this specific interactional context.

The extracts provide a glance into the complexity of the use of pronouns and their relevance in the construction of identity, which plays an important part in online interaction. As the discussion has shown, different memberships of groups, for example, membership of the EU/Spanish context and membership of this affinity space have been enacted and negotiated by utilising particular personal pronouns. Through the use of different person deixis, various positionings have been claimed and assigned to the commenter him/herself as well as to other interlocutors involved in the interaction, thus further contributing to the identification of ingroups and out-groups in online identity construction. It becomes important then that the focus of strategic use of personal pronouns provides an extra perspective of positionality in investigating commenters' online identity construction. In fact, the phenomenon of strategically using personal pronouns is common in this data set, not only as shown in the selected excerpts but also in the rest of my research data. That is, the use of pronouns is related to the formation of imaginary 'in-groups' and 'out-groups' (Tajfel \& Turner, 1986), which is closely intertwined with identity negotiation. These in-group and out-groups reflect speakers' conceptualisations of imagined communities (Anderson, 1983; cf. Excerpt 6.2). Defining the features of these imagined communities and drawing their borders is often achieved through the strategic use of personal pronouns, i.e. by distinguishing the members of this imaginary group ('us') from members of other groups ('them'). Furthermore, understanding who the 'others' are and what they represent is essential for constructing one's own identity (Chebel d'Appollonia, 2011) in interaction. The concept of imagined communities (Anderson, 1983) is thus tied to the construction of identity, as it encompasses shared values as well as ideologies. Unpacking the omnipresence of ideologies in interaction also requires us to gain a better understanding of 
intertextual inferences. Thus, intertextual analysis provides a different aspect to explore commenters' identity construction online.

\subsection{Analysis of intertextuality}

The analysis of intertextuality in this chapter also focuses two discursive aspects (i.e. constructed dialogue and semantic presupposition) in line with the approach in the previous chapter.

\subsubsection{Constructed dialogue}

\section{Distribution of constructed dialogue within travel}

With respect to the topic of travel, Figure 6.1 and table 6.3 demonstrate the overall trend of how quotations are used by participants. Figure 6.1 shows the overall distribution of quotations in each news website, and Table 6.3 breaks this down further, showing the numbers of references coded in each news source.

Interestingly the use of quotation is similar for both the topic of travel and the topic of same-sex marriage. In other words, the use of direct quotation is higher than indirect quotation as well as in each news source. This distribution is particularly notable in The Guardian if we have a closer look at the employment of different quotation devices. (See Chapter 4 as well as section 5.4.1 for how I code direct and indirect quotation in the analysis). 
Figure 6.1 Quotations used by participants in three news websites regarding the topic of Travel

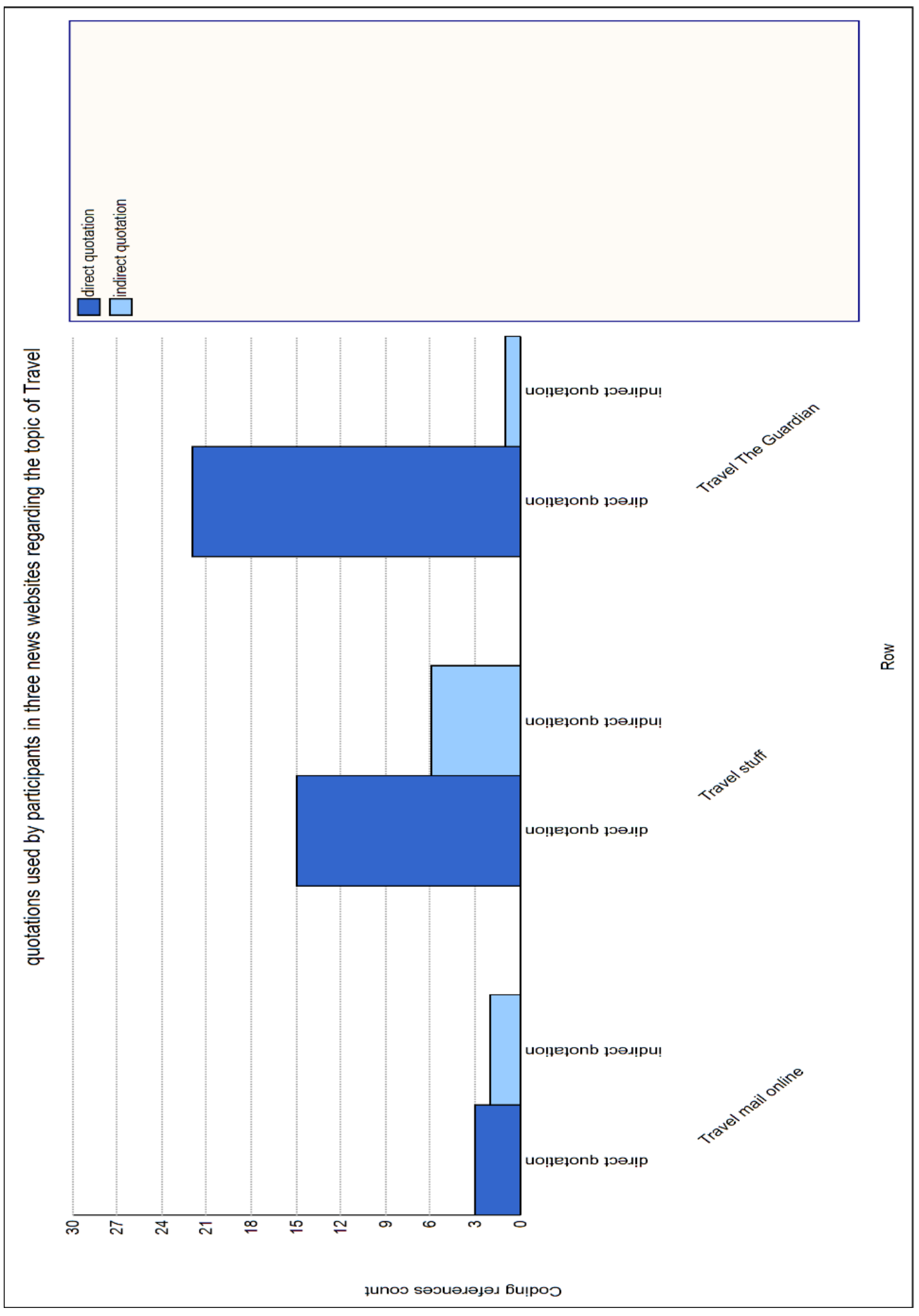


Table 6.3 Distribution of quotation in three news websites on the topic of Travel

\begin{tabular}{lccc}
\hline Type of quotation & A: Direct quotation (\%) & $\begin{array}{c}\text { B: Indirect } \\
\text { quotation } \\
\text { (\%) }\end{array}$ & $\begin{array}{c}\text { Total number } \\
\text { of quotations } \\
\text { coded from } \\
\text { each news } \\
\text { source (\%) }\end{array}$ \\
\hline Mail Online & $3 / 60.0 \%$ & $2 / 40.0 \%$ & $5 / 100 \%$ \\
\hline Stuff & $15 / 71.4 \%$ & $6 / 28.6 \%$ & $21 / 100 \%$ \\
\hline The Guardian & $22 / 95.7 \%$ & $1 / 4.30 \%$ & $23 / 100 \%$ \\
\hline Total No. of quotations coded in the data & 40 & 9 & \\
\hline
\end{tabular}

As shown in Table 6.3, commenters use more direct quotation than indirect quotation in each news source, most clearly in The Guardian (the proportion employing direct quotations totals 95.7\%). This tendency implies that commenters are more likely to reference others' opinions during the interaction, such as quoting other interlocutors' words in a direct way when they want to show their agreement with, or alternatively challenge, a point of view. In so doing, commenters are able to build connections with other interlocutors while simultaneously using the quotation as an index of initiating or maintaining the interaction with someone whose words are quoted (Tannen, 1998). This likely explains why direct quotation is more regularly found in each news source in comparison with indirect quotation, as commenters are engaged with exchanging and sharing opinions with people from this online space rather than simply voicing their own views. Notably, the total number of quotations coded within the topic of travel is relatively small in comparison with the topic of same-sex marriage (recall the results of distribution of quotation on the topic of SSM; i.e. the direct quotation and indirect quotation has been coded 91 and 28 times, respectively) (see section 5.4.1). This result shows to a certain extent that ideologies are more covert when discussing the topic of travel.

Overall, the occurrence of quotation in this research data shows that commenters as social actors are inevitably engaged with words that have come before them, and orient to anticipated responses (Hodges, 2015; Seals, 2012). In other words, the comments posted by them, in essence, are inherently intertextual and constituted by elements of other texts (HodsdonChampeon, 2010). 


\section{Direct quotation}

As the analyses suggested in the previous chapter, different types of quotation serve different linguistic function in commenters' identity construction. The use of direct or indirect quotation in an interaction largely depends on the interactional context and interlocutors' communicative purposes. See Excerpt 6.3 below.

Excerpt 6.3 [Chaos for thousands of British tourists as they face two-hour delays at Majorca airport caused by a shortage of Spanish police officers; Mail Online]

\section{CaliforniaDreaming}

2

3 Decimation

4

5 true or false $>$ CaliforniaDreaming

6

7

8

9 everything in Spain is complicated to solve. Just don't go to Spain!

It's a fact that if UK tourism/etc stops, the Spanish will have financial problems.

Quote of the year "everything in Spain is complicated to solve"...you'are not kidding! Do they have schools in Spain where you start them young to solve problems...???!!! never lived in a country where everything is a problem!!!

The event of airport chaos was selected as a recurring focus of attention in travel-related reports by Mail Online (during my period of data collection). In contrast to the previous two excerpts illustrated in this chapter, this excerpt shifts its focus towards the reason behind this chaos as a possible boycott of tourism development in Spain. CaliforniaDreaming initiates the interaction by arguing that "everything in Spain is complicated to solve" (line 1) and calls on other people not to travel to Spain, thus positioning themselves in opposition to Spain's tourism business. This specific positioning is perceived by what seems like a match with their ideal reader, true or false, who acknowledges that this statement is the quote of the year (lines 5 through 6). By drawing on notions of Spain being an excessively bureaucratic society (cf. Bahena, 2013; Chew, 2006) as well as the Discourses of Brexit, this direct quotation suggests their close alliance with 
CaliforniaDreaming, which is later supported further when they draw the conclusion that they "never lived in a country where everything is a problem" (lines 8 through 9). By choosing to use a direct quotation here, true or false distributes the responsibilities of the words to the person who gets quoted (i.e. CaliforniaDreaming), while simultaneously reinforcing the particular positioning that they take up during the interaction. In addition, true or false also works to keep the commenters united in their support for not going to Spain through this specific direct quotation.

\section{Indirect quotation}

In addition to adopting a direct quotation to show the current speaker's agreement and further to reinforce the specific positioning that they are trying to take up, in some cases, indirect quotation is also employed. It may function, however, to show their disagreement. Excerpt 6.4 illustrates this.

Excerpt 6.4 [Doctor dragged off United Airlines flight speaks for the first time; Stuff]

1 Kiwe

2

3 Floppy_disk> Kiwe

4

5

6 Lil4> Floppy_disk 7

8

9

10 Li14> Floppy_disk 11

12

13
Wrong the $\mathrm{AH}$ created the situation by not getting off when asked repeatedly

Kiwe, I agree. It is also because he does not speak English in English country, and also he did not buy a $1^{\text {st }}$ class ticket. The writing was on the wall for him.

He is working as a doctor in the US- you have to have good English for that. And just because someone doesn't speak English doesn't mean you're allowed to break their nose and front teeth while you are trying to illegally get them off a plane.

you are wrong - from a legal point of view the airline is allowed to deny boarding but once the passengers are boarded they are not legally allowed to kick them off the place. And even if the airline legally allowed -would you expect to get a broken nose, front 
teeth knocked our and possible brain damage for politely

15

16 Li14> Floppy_disk

17

18

19

20

21

22

23

24

25

26

27

28

29

30

31

32

33

34

35 disagreeing?

if you take the time to read the federal law cited by United Airlines

CFR 250.5-Amount of denied boarding compensation for passengers denied boarding involuntarily. It very clearly states that boarding can be denied to passengers but once a passenger has had their boarding pass processed and it seated on the plane it is not legal to deboard them. Please don't confuse federal law with you own opinion. Did you actually watch the video? $\underline{\text { He states }}$ politely that he does not wish to get off the plane and sit with his arms folded - the guards grab him and start to drag him for his seat and smashed out his two front teeth just for fun? The crew also have discretion to move on to a different passenger if the passenger then ask to deboard has a good reason for needing to fly - I think being a doctor and having to get to work on time to see patients is a pretty good reason to need to fly-l'm sure there were other passengers on that plane who needed to fly less urgently. The best option would have been to move onto another passenger who didn't need to fly urgently and was happy to deboard, the doctor would have been able to see his patients on time and the 4 crew members would have been able to reach their destination.

This conversation focuses on the legality of removing a boarded passenger by United Airlines.

Kiwe directly comes to the conclusion that it is the passenger who should be blamed, as "the AH created the situation by not getting off when asked repeatedly" (lines 1-2). Kiwe uses 'AH' (abbreviation for 'Asshole') to prevent his comments from being removed by the moderator (primarily because it is against the rules of the comment boards). Swearing, the use of taboo language (cf. Jay, 2009; Kwon \& Cho, 2017; Sapolsky et al., 2011) not only positions himself on 
the same side as the airlines, but also seemingly indexes that Dr. Dao (the passenger) deserves to be dragged off the plane. In response to this positioning, in lines 3 through 4, Floppy_disk explicitly shows their agreement with Kiwe in saying, "Kiwe, I agree." This alliance is further accentuated by claiming two potential reasons which leads to Dr. Dao being dragged off the airplane: "he can't speak English and didn't buy a first-class ticket" (line 3-4). The contempt for Dr Dao suggests ideologies of racial discrimination (e.g. Twine, 2000; van Dijk, 2019) based on the fact that Dr Dao comes from Vietnam (as the news article reveals). The dominant ideology of the racial inferiority of Asians accordingly drives them to assume that Dr Dao cannot speak English (line 3), resulting in the failure to follow the cabin crews' instruction. In addition to this, they present a second reason that leads to his removal, that is, he cannot afford the price of a first class ticket. This suggests that if Dr. Dao was seated in a first-class seat, then he would definitely not be dragged off, which sounds like the passengers of economy class are inferior to those of first-class and therefore Dr. Dao should be removed as expected. There are multiple layers of ideologies (closely connect to the negative stereotypes) embedded with each other in this interaction. Interestingly, Floppy_disk is assuming that because Dr. Dao is a Vietnamese, he thus cannot speak English and afford the first class. Drawing on the Discourses of Vietnam being a developing country and ideologies of poor Asians (and it is a different ideology of crazy rich Asians who are necessarily Chinese), he is presenting arguably interrelated ideologies of racism, ideologies of poor people and money talks ideologies (e.g. McMenamin, 2012) in this interaction, through which he constructs himself as a racist.

Responding to Floppy_disk's specific ideological positioning, Li14 posts three comments in a row. They directly and explicitly show their disalignment with Floppy_disk (as well as Kiwe) and further define United Airlines' behavior as illegal (line 9, 12, 21). In order to back up their opinion on this debated issue (i.e. they criticize UA's violent way of removing Dr. Dao) and to solidify this positioning, Li14 indirectly quotes from federal law when they defend Dr Dao (lines 18 through 21), thus enhancing the reliability and authority of their argument. Furthermore, in lines 22 through 23, they again use an indirect quotation. In contrast to the previous strategy, this quotation is what Dr. Dao said in response to the airline's decision to remove him off the 
airplane as reported. The use of quotation in this excerpt is drawing upon Bourdieu's (1986) notion of institutionalized and embodied symbolic capital (see e.g. Bourdieu, 1986; Meadows, 2009; Seals, 2011; also see discussion in section 5.3.3). As the discussion has shown, within this example, the particular positioning on the topic is constructed and reinforced through indirect quotation, which works to create distance. This can also be seen in another article in Stuff, where commenters talk about useless travel items. See Excerpt 6.5 below.

Excerpt 6.5 [Money belt, iron and zip-off pants: 10 useless travel items you don't need to pack; Stuff]
1 Barbara7
Unless you are wearing bulky clothes, everyone can see you
2
have a money belt on and if it is hot they are sweaty and
3 uncomfortable. Bought one and in 40 years of overseas travel
4 have never used it.
5 BenM
Money belts aren't just huge wads of cash around. You
6
mentioned that you need your passport and credit card-a
7 money belt can be used to store them.
8 Blue Pen> Barbara7 Just this week a report says someone having $\$ 4000$ 9 stolen from first class on Emirates, so no matter where you are 10 travelling to/from if you're carrying a large amount of cash, a money bag is the best way to go. You just never reveal it in public, carry a small amount in your pocket, and visit a toilet or changing room if you need to get some more out.

The above conversation is conducted based on the article writer's suggestion of not bringing a money belt while traveling. Barbara7 first shares their own travel experience (lines 3-4), aiming at showing their agreement with the writer's opinion as well as using their own experience to persuade other readers that a money belt is useless. This appeal to authority via experience (Goodwin et al., 2011), however, is challenged by BenM, as he indirectly quotes from the news 
article (lines 5 through 7) and suggests that travellers do need to bring a money belt. Similarly, Blue Pen quoted another news source indirectly when replies to Barbara7. In lines 8 through 9, they comment that a great amount of cash has been stolen from first-class on Emirates, emphasising the importance of bringing a money belt and positioning themselves on the opposite side of the news article writer. In this way, the use of indirect quotation allows the writer to express their own views instead of adopting the position assigned to them by the previous writer. In this excerpt, the commenters' discussion is a negotiation of what characterizes an experienced tourist (e.g. Pirolli, 2017; Rodríguez-Fernández et al., 2019) as they use quotation in an indirect way to emphasise their own positioning in response to the article writer's suggestion in order to construct their identity as a professional tourist. As discussed, indexicality enables access to these ideologies. Indexicalities of recognizable discourses are either picked up or ignored by the responders. Thus, the choice of who gets quoted and what to quote influences expert identity construction. In this sense, the formation of reported speech is driven by ideological stances. During this process, presuppositions are brought to bear on the speech; the writer "selectively introduces reported perspectives into their own voice" (Hodges, 2015, p. 51).

Constructed dialogue not only conveys information to the speakers but importantly also aims to persuade people to change their understandings of certain things. This kind of understanding largely depends on the writer's ideological stances (Seals, 2012; Theleta, 2001). Based on the analyses of constructed dialogue in both chapters 5 and 6 , I have shown that using constructed dialogue has three primary purposes based on different contexts: (a) to indicate that a quote is an incontrovertible fact (if they are using direct quote and agreeing with the point made) and further to (b) increase the authority and reliability of what the source said in order to support the writer's own opinions (if they are using direct quote and agreeing with the point made); or (c) to distance and disown the endorsement of what the source said (if they are using direct quotation and disagreeing with the point made) (cf. Bell, 1998; Thetela, 2001). These three functions are not mutually exclusive-a single quote may realize more than one function. 


\subsubsection{Semantic presupposition}

In chapter 5, I presented two different cases of using semantic presupposition through intertextuality. One illustrated how specific semantic meanings help interlocutors construct their identities, while the other case shows the failure of using semantic presupposition in an interaction. The following excerpt shows how interlocutors use indexicality to draw on semantic meaning and presupposition and further connect these to group ideologies to speak to their ideal reader.

Excerpt 6.6 [Smiling for the camera seconds before dream holiday ends in tragedy: Australian tourist, 70, plunges $100 \mathrm{ft}$ to his death while parasailing in Thailand; Mail Online]

\section{HughJass}

2 CACV> HughJass

3 Lornelover> CACV

$4 \mathrm{H}$ Lander> CACV

5

6

7

8

9

10

11

12

13

14
How awful his wife had to see that. Condolences to his family. I'd investigate the wife.

How long was he married and how big is his life insurance?

Death by unnatural causes should be properly investigated by a professional law enforcement officer and coroner -for which Thailand had dubious reputation. It would be interesting to know whether any person would financially gain from the demise of the deceased? It would not be inconceivable for an elderly gentleman to have a significantly younger South East Asian spouse; for 71 years of age he looked much younger in the photo, and considering the gung-ho spirit to an adventure sport I would suggest he was encouraged by someone younger. People do have bucket list at 71, but they are usually conservative or at least cautious. Appears suspicious?

In this example, commenters show different positionings regarding the man's death. In line 1, HughJass expresses sympathy to the man and his family directly, constructing himself as a compassionate person. However, CACV chooses to take a completely different positioning by 
asking the police to investigate the man's wife (line 2). The lexical item 'investigate' explicitly indexes suspicion on the man's wife, presupposing that the man's death is not an accident, but it is well-planned. CACV does not presuppose this casually, but rather his understanding of this accident embraces personal biases. This presupposition draws upon the Discourses of (new) racism in particular (see e.g. Araeen, 2000; Baker, 1981; Pantti et al., 2019; van Dijk, 2000), because they share an understanding of the background of the wife (as mentioned in the article) as well as the cultural difference (i.e. Western and Asian culture) without specifically mentioning race in this context. In comparison with explicitly race-based and biologically-based racism, new racism (Baker, 1981) is used to describe a newer form of racism that "wants to be democratic and respectable, and hence first off denies that it is racism" (van Dijk, 2000, p. 34). Augoustinos et al., (2005) argue that new racism is also understood as 'value-based racism', as it places emphasis on cultural differences instead of talking about the traditional identity category of race.

The use of 'investigate' is a deliberate choice in this context, through which CACV draws on the wider social ideologies of sexism (Mills, 2003, 2008) as well as racism, making attempts to speak to the ideal reader. Simultaneously, they are buying into overlapping cultural stereotypes about old men and young wives (Robinson, 1996). So, these stereotypes are powerful forms of presupposition by which their identities as sexist and racist are constructed and performed in this example.

The denial of seeing the man's death as an accident caused by unprotected safety measures is further evident in the following replies. As Lornerlover asks, "How long was he married and how big is his life insurance?" (line 3). Seemingly, Lornerlover is anticipating answers from their potential interlocutors by proposing this question. However, considering this question is a direct reply to CACV's statement, I argue that this is a rhetorical question. By referencing their potential readers to the Discourses of mammonism (i.e. money worship; e.g. Cao, 2014; Spira, 2018), the use of the rhetorical questions not only serves as a way of showing their agreement (Frank, 1990; Galitsky, 2017) with CACV's point of view, but also functions as a persuasion for other readers to take the same positioning as them (Blankenship \& Craig, 2006). This therefore 
reinforces their positioning in opposition to the young Thai wife, though they do not state this directly. Importantly, the username 'Lornerlover' is a word borrowed from Spanish, literally meaning that the person feels hopeless about love. In this context, this specific username, to some extent, suggests a cynicism which would support why they make this presupposition about the Thai wife and takes up this specific positioning in the interaction. As seen, the username plays a role in online interaction (Hassa, 2012; Hutchens et al., 2019), indexing their specific ideologies and wider societal understanding which are intertwined with identity construction. My analysis primarily focuses on the discourse features used by commenters, but this kind of investigation focusing on usernames could also draw attention from researchers in identity research, as this example has briefly shown.

The shared group ideologies represented in the comments are later accentuated by a potential ideal reader, $\mathrm{H}$ Lander, in their statement (lines 4 through 14). Within this long statement, they first define this accident as 'unnatural' (line 4) and then challenge the authority of the Thai government through the use of 'dubious' (line 6). Through the indexical value of the choice of these two particular lexical items, they highlight and again bring about the presupposed understanding that the Thai wife is suspicious in this case. Their collective positioning in opposition to this Thai wife becomes more obvious through the emphasis on the wife's ethnicity and age (i.e. 'significantly younger South East Asian spouse', lines 9-10). Therefore, they come to a conclusion that the death has been 'encouraged' (line 12) by someone younger, referring to the wife in an obvious but strategically implicit way. The use of specific lexical items allows the interlocutors to speak to their ideal reader through intertextuality by drawing on this larger societal Discourse, thus positioning the Thai wife in opposition. Importantly, these statements are necessarily casting the Thai woman as a sex worker or a "Bar girl" (Poltecha, 2017; StorbergWalker et al., 2010; Wilson, 2008) indexed by explicitly mentioning her nationality. Through this indexicality, a 'dogwhistle'26 (Drainville \& Saul, forthcoming; Henderson \& McCready, 2018) has been picked up by their readers, a signal that has plausible deniability. Broadly, a linguistic

\footnotetext{
${ }^{26}$ The term 'dogwhistle' originates in media and online discussions (originally of opinion polling). See detailed discussion in (Drainville \& Saul, forthcoming).
} 
dogwhistle is an utterance whose full meaning is only understood by -at most-a subset of audience members. According to (Drainville \& Saul, forthcoming), there are two sorts of things which are referred to as 'dogwhistle'. One sort of dog whistle functions very much like a code. It is a message meant to be understood by only a part of the audience, but that subgroup in the know is meant to be fully aware of what is going on, which is referred to as overt dogwhistle; another kind of dogwhistle is altogether stranger. It too has an intended audience, but that intended audience is meant to be affected without being aware of it. This is called a covert dogwhistle. ${ }^{27}$ In this context, although only describing her nationality, the idea reader would recognise the discourse that is being used, thus attracting their ideologies of racism as well as sexism and picking up these ideologies immediately.

Interestingly, within this interaction, the Thai wife is the only one that commenters target, suggesting a masculine style of interaction. At a societal level, it seems that the commenters are all drawing on the cultural stereotypes (i.e. young Asian wife and old White man as discussed earlier) and connecting this particular stereotype to the wider socio-cultural contexts, such as the phenomenon of sex tourism or girlfriend experience (i.e. Asian women who tricks a White man into paying for her and the White men in turn look for submissive Asian women) in Thailand (Bishop \& Robinson, 1999). Together this contributes to constructing a negative social identity of this woman as a gold digger and greedy wife, evidence of new racism at paly; race is not explicitly signalled, but understood by the readers through ideological connections.

As discussed, ideologies are still present in the travel dataset, but ideologies are not the explicit focus of the topic like they were in the topic of same-sex marriage (see Chapter 5 ). Nevertheless they contribute to invoking ideas in terms of identity construction. Ideologies are being drawn upon and indexed in all identity construction and negotiations.

\footnotetext{
27 In the everyday sense of the term, all dogwhistles are covert.
} 


\subsection{Summary}

Focusing on the theme of travel, this chapter investigates identity construction through the analyses of positionality and intertextuality. By unpacking a variety of covert ideologies (e.g. racism, sexism, etc.) embedded in interaction, I have shown how such hidden ideologies play a role in the commenters' process of understanding each other as well as the meaning that they try to convey in interactions.

Notably, during the process of identity construction, one important way in which various types of identities are enacted and further negotiated is through the use of personal pronouns.

Understood as indexical resources and contextualisation cues, pronominal choices play a crucial role in discursive identity positioning and construction. Most examples focusing on in-group and out-group construction presented in this chapter demonstrate that group memberships are commonly constructed using pronouns with ostensibly similar communicative purposes (see e.g. Lazzaro-Salazar, 2013, 2017; Tajfel, 1974).

The excerpts illustrated in the two analysis chapters highlight the role of personal pronouns in identity construction during online interaction, that is, indexing certain identities so as to construct in-group membership (e.g. Excerpt 6.1) or alternatively to construct an out-group by

distancing themselves from a specific positioning (e.g. Excerpt 5.2). This phenomenon shows that the norms that regulate commenters' online interactional activities are shared among the group's interactants. The selected excerpts in the two analysis chapters are representative of what was discovered across my data, suggesting that these linguistic strategies (e.g. strategic use of pronouns, quotations etc.) employed by interactants are core discursive practices of this online affinity space (cf. Lazzaro-Salazar, 2013).

Commenters frequently use pronouns without directly pointing out who they are referring to in the interaction. Arguably, this might lead to miscommunication. However, rather than asking for further clarification from the relevant interlocutors, (most) participants of this study are capable of identifying these referents in order to continue the conversation. This legitimises the claim 
that the use of pronominal choice is a well-established practice in the online space and represents widely shared ideologies and societal understanding. The distinctive use of pronouns seems to be part of this affinity space's shared repertoire of linguistic strategies, which serve to enact their preferred online identities. Thus, by using 'we', 'us', 'they', 'them', 'I' and 'you' at different times, commenters display their social positioning through their affiliations and disaffilations with certain groups as they see fit according to the interactional context of the conversation. In this research data, personal pronouns have been found to meaningfully highlight certain identities in interaction, while, at other times, they have taken on different indexical values to display different positionings between interlocutors.

Regarding the analysis of intertextuality, I have argued that intertextuality is often manifested in two analytical aspects: constructed dialogue and semantic presupposition. These two aspects provide commenters, especially the ideal reader, with tools to interpret the intended messages and thereby to reinforce particular shared ideologies about the issues being discussed (cf. Seals, 2012). The combined analyses of positionality and intertextuality provide useful insights in examining online identity construction.

These two analysis chapters focused on how various discourse strategies used in interaction contribute to commenters' identity construction at a micro level. The following chapter examines the macro concepts made salient in the past two chapters (e.g. many instances of national identity enactment and negotiation are pointed out in the analysis; othering in identity construction, etc.). Thus, findings from these two chapters will be discussed to bring together all my analysis, focusing on the pervasiveness of ideologies. 


\section{Chapter 7}

\section{Discussion}

\subsection{Introduction}

Throughout the micro-level analysis of identity navigation presented in the previous two chapters, I have demonstrated the ways in which commenters construct and negotiate their various identities in an online space. Focusing on (Gee's "little-d") discourse as "the basic research site" (Gumperz, 2005, p. 215), the interpretative approach of Interactional Sociolinguistics draws heavily on the analyst's "understanding of the socio-cultural context of the interaction under investigation" (Vine, Holmes, Marra, Pfeifer, \& Jackson, 2008, p. 345). In other words, IS emphasises that larger socio-cultural context and situational context are crucial in interpretating communication (Gumperz, 1982). Given the micro-level concepts that emerge as prominent in the analysis, in this chapter, I shift my focus from the micro level enactment of commenters' online identity construction towards the discussion of wider societal influences as implications of commenters' identity construction.

In Chapter 2, I explored the construct of ideology as part of my theoretical positioning, and here I bring that consideration to the fore. Van Dijk's definition is a useful starting point. He asserts that ideologies are "the fundamental beliefs of a group and its members" (2011, p. 7). MenardWarwick (2014, p. 2) adds an important critical element in defining ideologies as the "beliefs and perceptions linked to power relations between social-groups, which may or may not be expressed explicitly as discourses, but often become apparent in taken-for-granted practices". Discourses (capital-D Discourses) can be thus conceptualised as one of the important means through which ideologies gain voice. Data from this study shows evidence of various ideologies at play (whether explicit or implicit) in constructing and negotiating online identities, pointing to the ubiquity of ideology in discourse. Even though ideologies are at times seemingly invisible (e.g. travel related messages), they still contribute to understanding how specific identities are 
co-constructed and negotiated in interaction. Because ideologies are socially situated and "tied to questions of identity and power in societies" (Blackledge \& Pavlenko, 2001, p. 246), I therefore embrace Dawson's (2019) argument that ideologies can be considered as "powerful forms of social structure" (p. 192).

Specifically, I focus on the constructs of ideology and Discourses and the ways in which they impact upon commenters' identity negotiations. From this I then engage with the ongoing structure and agency debate in the social sciences. As discussed in Chapter 2, identity is understood as a process of co-construction and negotiation between interactants. Identity positioning practices, including both self-and other-positioning (i.e. reflective and interactive positioning; see discussion in section 4.5.2) are also a negotiation between interlocutors. Despite individuals having agency to contest or make use of disempowering Discourses, as Greenbank (2020, p. 212) argues, valid attempts to position oneself and assign positions to others in an interaction must be negotiated and further endorsed by interlocutors. Different backgrounds (e.g. cultural, educational, and religious, etc. or affiliation), as well as ideologies and Discourses they hold may conflict with one another. I thus argue that an understanding of how identities are constructed and negotiated during an interaction is enriched by close attention to these theoretical constructs, which are themselves illuminated by the interactions of commenters. In my data, ideologies of, for example, gender, sexuality, and nationality infiltrate and act as a resource in their identity negotiations. Because of the removal of firm geographical obstacles, the written online context creates different ideological constraints for commenters to negotiate their identities. This focus emphasises the social embeddedness of participants (referring to commenters in this context), which in turn has rich implications for our understandings of the relationship between the individual and the social.

This chapter draws together and discusses the findings presented in Chapters 5 and 6 . By focusing on commenters' online interaction in the previous two analysis chapters, I demonstrate that identity construction is a complex and dynamic process. In order to get access to that complexity, in this chapter, I draw on indexicality (Ochs, 1992; Silverstein, 1976, 2003), using the 
concept to frame my findings at the various levels of abstraction I have embraced: for example, agency, positionality (Bucholtz \& Hall, 2005), intertextuality (Bakhtin, 1981), and the ideal reader (Fairclough, 2001), all salient layers of identity construction in this study that are impacted through and impact on ideologies. Throughout the analysis, I have shown that indexicality works from the micro-level (e.g. strategic use of pronouns) to (wider) macro-level (e.g. numerous ideologies), illustrating that indexicality plays a leading role in exploring commenters' identity online.

To make these arguments, I first explain how indexicality works at multiple levels in online identity construction (section 7.2). I then call for greater focus on agency and structure in identity examination (section 7.2.1). This is followed by a discussion which synthesises and extends key findings emerging from the analysis (section 7.2.2). This enacts my further consideration about the value of the two analytic guides used in the analysis (i.e. positionality and intertextuality), illustrating the operationalisation of these approaches in the online context (section 7.3). This discussion reinforces the pivotal role that indexicality plays in the investigation of identity, here in the written online context. As a specific interactional environment, the online space offers unique affordances such as the ways in which technology allows commenters to use constructed dialogue through intertextual resources to embrace their preferred identities, presuppositions to speak to the ideal reader, strategic use of pronouns to construct membership in certain groups, etc. These considerations are brought together in section 7.4 , where I discuss the peculiarities of investigating online identity and recognise the significance of the ideal reader as well as ideologies in online interaction.

By embracing ideologies, we can access valuable and nuanced understandings of the complexity involved in this theoretically elusive, but influential aspect of identity co-construction. Despite its scholarly popularity, the concept of ideology remains one of the "vaguest and most 'contested' concepts of the social sciences" (van Dijk, 2011, p. 6). In investigating identity online, I argue for the need to pay attention to the wide range of ideologies and D/discourses embedded in interaction. 


\subsection{Indexicality in investigating online identity}

All language has the potential for indexicality. Individuals use various forms of linguistic features to index memberships of both local and broader identity categories (e.g. Bamberg, De Fina, \& Schiffrin, 2011). This indexicality draws on ideological structures to animate associations about what kind of speakers can or should produce what kind of language (Ochs, 1992; Silverstein, 1976, 2003). The use of shared socio-cultural knowledge and belief allows speakers to align with local communities through the construction of group membership. At the macro-level, this shared knowledge is harnessed to index particular identity categories such as gender, ethnicity and social class. This highlights the idea that indexicality can be examined at multiple levels of abstraction. As discussed in Chapter 2, Ochs (1990) distinguishes between two types of indexicality: direct and indirect. Direct indexicality often relies on referential lexical items, for example 'he' or 'Mrs', to overtly and explicitly align the speaker with a specific facet of social identity (in this case, male and married woman respectively). Indirect indexicality requires (a series of) links to create meaning. In indexing, a speaker takes up a specific positioning towards that component of identity, for example if a speaker mentions her child in the interaction, then, a 'mother' identity is spontaneously enacted and indexed in a direct way. In this sense, the analysis of positionality allows us to see how indexicality in action. However, how the audience/addressee interprets the indexicality relies on socio-cultural knowledge and their assessment of the situation (N. Wilson, 2011, p. 20), particularly in the case of indirect indexes. Arguably as Wilson notes, there is a wide range of indexicalities and these can be interpreted using both local and global context. For example, terms like mate, bro, dude are often used by address in interaction to index solidarity with the addressee (see Kiesling, 2004). However, in Excerpt 5.2, the term mate employed by the commenter serves an opposite function in that particular context. This example will be repeated here for convenience, see Excerpt 7.1.

Excerpt 7.1 (repetition of Excerpt 5.2 for convenience)

1 Chromelayer @all, legalising SSM is not something we should be

2 proud of. Get real people. I'm happy it's rejected.

3 Baranta $>$ Chromelayer Yeah! if gays and lesbians want to institutionalize their 
4

5

6

7

\section{JonnyCK > Baranta}

relationship, fine-but use a different word for that.

Oh you know, they can't even steal a trademark, a

figment in time and space in its significance, compared

to the persistence and common understanding of marriage.

Fucking weird reason to deny people rights mate.

$[\ldots]$

As seen, using mate as a term of address in this context does not index affiliation to the addressee but instead it indexes an ideology of 'Otherness', functioning as a condescending strategy (see discussion in Chapter 5). This context-based interpretation of indexicality simultaneously highlights the importance of the ideal reader in online interaction, as not every reader is able to pick up this meaning of indexicality.

Beyond the categories of direct and indirect indices, Silverstein (2003) divides indexicality into an ordered series. In sum this involves the "first order equating to direct indexicality and the subsequent indexicalities each indexing one previous, to the degree $n+1$ " (N. Wilson, 2011, p. 20; also see discussion in Chapter 2). The concept of an indexical order relates to the method by which the audience interprets the indexicality of an utterance, that is the steps they take (consciously or otherwise) to access the index. As there are many possible interpretations and understanding of one single index, indexicality is an intersubjective process (N. Wilson, 2011). Silverstein's (1992) ordered indexicality encourages a focus on the interpretation process for analysing the relationship between a linguistic feature and the ideology it triggers. That is, a particular linguistic feature indexes a positioning in response to the proposition being made. This, in turn, as Wilson (2011, p. 20) argues, "can index a membership, which can index an ideology, and so on." Taking the discussion of airport chaos as an example (see Chapter 6, Excerpt 6.1), by positioning themselves in opposition to British tourists, Spanish commenters explicitly index their membership of the EU; this positioning and membership indexes an ideology of anti-superiority (in this case it refers to national superiority) as well as othering. 
The concept of indexicality accounts for the complexity of identity construction in the online context. Indexicality is therefore a fundamental concept in understanding how identity formation comes to be associated with the pervasiveness of ideologies, allowing me to embrace the multiple levels of abstraction.

\subsubsection{Agency as tied to structure}

The capacity of individuals to act independently and to make choices (whether conscious or not) is related to our agency. In accessing various forms of indexicalities we are making agentive choices. Agency and indexicality however are all constrained within ideologies and social structures. In Chapter 2, I made the argument that social structures are constitutive of and constituted by individual agency (cf. Ortner, 1995; also see section 2.2.1), bound in a form of ongoing dialogue. This is in line with Desjarlais (1997, p. 204) who posits that one does not 'possess' agency as an ontologically prior and unchanging attribute with the ability to effect change on one's environment irrespective of context. It is instead a dynamic construct and will flow according to sociocultural contexts and one's ongoing experiences and exposure to Discourses.

Additionally, the call for paying more attention to social structure is reflected in a broad range of sociolinguistic work. For example, Natalie Schilling (2013, p. 342) reminds us that "we cannot create meaningful style out of nothing", drawing attention to the binding properties of structures and norms on the micro-level linguistic forms which impact identity work. Susan Ehrlich (2008) also urges more analytical attention to Butler's (1990) "rigid regulatory frame" in order to advance understandings of what and how agency is constrained and enabled in identity construction. Miller's (2014) conceptualisation of agency as performed (drawing upon Butler's 'performativity', 1990) and as socially mediated coheres with the overall social constructionist stance outlined in Chapter 2. Agency, like identity, is something we do to different levels in interactions in particular sociocultural contexts. 
These ideas resonate with Bakhtinian notions of dialogism and intertextuality (see MenardWarwick, 2009, 2014; Vitanova, 2010; also see discussion in Chapter 4 and section 7.3.2 in this chapter) offering a promising middle ground between structure and agency in identity coconstruction as well. As shown throughout Chapter 5 and 6, these considerations all bring to bear on commenters' identity negotiations in the dialogic nature of their interactions. In coconstructing identities in this hybrid sociocultural online context, commenters are not only speaking with other interlocutors, but speaking with (and through) various ideologies (see discussion in section 7.5 in this chapter). From this perspective, intertextuality as used in this study is thus valuable in understanding the "sociocultural mediation" to which Aheran (2001) refers in her definition of agency. As discussed, agency allows commenters to enact indexicalities which impact on their linguistic choices and further identity construction. Indexing is thus an agentive action (albeit within structural constraints). Here I turn to the ways in which the commenters in my data index framed identities and related ideologies, via positionality and intertextuality as my analytic foci.

\subsubsection{Positionality}

The way we position ourselves and others is constantly negotiated, re-negotiated, shifting, context dependent and dynamic (Seals, 2019). Throughout Chapters 5 and 6, I have shown how commenters position themselves as well as others during interaction. Hinging on different interactional purposes, self- and other-positionings are variously harnessed by commenters to achieve certain identity positions, thus further constructing myriad identities online. For example, in response to the airport chaos in Spain, commenters assigned specific identity positions to themselves and other interlocutors involved in the interaction (see Excerpt 6.1, 6.2 and 6.3). By indexing their membership of a particular social group (notably Spanish or British citizens), they co-construct and negotiate their group identities (in this case most obviously their national identity) during the interaction.

Particularly salient in this research data are the ways in which commenters strategically use personal pronouns to build a sense of belonging to a certain group; or, to discursively position relevant interlocutors as an Other. Revisiting the examples focusing on airport chaos (see 
Excerpt 6.1 and 6.2) as a consequence of Brexit, Spanish commenters show solidarity with the EU while simultaneously positioning British citizens as an Other. Discursive choices that the commenters make in discussions of this matter provide valuable insights into the nature of identity negotiation (Beliaeva \& Seals, 2020). The choice between the pronouns we/our/us and they/their/them, through which commenters index a sense of belonging and othering, thus negotiating identities with other interlocutors. Linguistic research related to othering highlights the drawing of ideological borders through discourse (Van Leeuwen \& Wodak, 1999; Wodak \& Boukala, 2015).

While discussing the airport chaos, the chosen excerpts (i.e. Excerpt 6.1 and 6.2) look at commenters' negotiation of in-groups and out-groups in relation to the changing social and political situation in the UK as well as in relation to their own ideological principles and attitudes towards Brexit. From this perspective, attention paid to the use of pronouns, particularly focusing on belonging and othering, provides additional insights into how commenters claim and/or reject specific identities (cf. Hatoss, 2012; Jaworski \& Coupland, 2005). However, sometimes pronouns are ambiguous. This requires wider Discourses for interpretation, that is, commenters index Discourses which are salient to (some of) their audience through these pronouns. The following section revisits some data to highlight the vital role that personal pronouns play in the process of identity negotiation during an interaction.

\section{Othering through strategic use of personal pronouns}

The strategic use of personal pronouns plays an important role in co-constructing and negotiating commenters' online identities, as every individual personal pronoun carries ideologies with it in a specific context. Previous research (e.g. Cramer, 2010; Moberg \& Eriksson, 2013; Timmis, 2015) shows that personal pronouns are often used for specific effects and work as a form of identity cue (cf. Bazzanella, 2002, p. 249). My data also supports these findings, emphasising that commenters harness pronouns in a strategic way in different interactional contexts in order to construct and negotiate their "ideal" online identities. For example, in Excerpt 5.1, the use of first-person pronoun us is employed by the commenter to directly claim a 
national identity during the interaction. This function is similarly found in other excerpts, such as Excerpt 5.3, 5.9, 6.1 and 6.2, in which personal pronouns index certain aspects of their identities (i.e. sexual and national identities). By strategically using pronouns, commenters appear to achieve communicative goals such as distancing themselves or others from a certain positioning or group, thus creating a sense of othering in the interaction (e.g. Excerpt 5.2, 5.3, 6.2); this idea resonates with Dervin's (2015, p. 45) argument that pronouns serve to "turn the other into an Other, thus creating a boundary between different and same, insiders and outsiders".

The strategic use of personal pronouns may similarly be employed to show commenters' alignment and solidarity with a particular point of view or an interlocutor so as to construct group membership (Beliaeva \& Seals, 2020; Bull \& Fetzer, 2006; Liebrecher et al., 2010) (see e.g. Excerpt 6.1 for how commenters construct group membership of the EU). It is important to recognise that the use of personal pronouns, even within a simple interaction, is dynamic. In Excerpt 6.1 (repeated below as Excerpt 7.2), the collective first-person pronoun we/us is used by the same commenter multiple times within the same utterance; however, each time the use of 'we'/'us' contains different meanings. For the convenience of reading, I repeat this specific example here.

\section{Excerpt 7.2 (repetition of excerpt 6.1)}

\section{$[\ldots]$}

\section{2 drik panzer $>$ martin}

3

4

5

6

7

8
Yeah....what do we call a British tourist these days? A target :) Ho Ho....loads of moaning from the "great" British public who live to sneer and abuse their own police...now they realise that we regard them as little more than something they would find on their shoe... it's a good lesson for them to learn. Well done Spanish, let us give them a hard time for our club. See, hate and you get hated back 
Specifically, in line 2, we intends to include every other potential interlocutor, and then we becomes members of the EU (in line 5); in line 7, the use of 'us' refers to Spaniards in particular. This shows the dynamic nature of identity negotiation in online interaction (see section 6.3.2 for discussion; also see section 5.3.2 for another example). Across the data, the third-person pronoun (e.g. 'he', 'his', 'she', 'hers' 'they', 'them', 'their') and second-person pronoun (e.g. 'you', 'your') feature frequently to exclude other interlocutors in the interaction. In so doing, a sense of othering has thus been articulated discursively. In addition to the use of third-person pronoun, the first-person pronoun (e.g. 'I', 'me', 'we', 'our', 'us') however is generally used to claim an identity of belonging, but sometimes it is also used to achieve the discursive 'othering' if the use of ' $w e^{\prime}$ excludes the hearer (i.e. ' $w e^{\prime}=$ ' $l$ ' +my group). This is evidenced in Excerpt 5.2, where the use of 'we' particularly refers to the commenter himself and his imagined 'in-group' of heterosexual people. It is through the creation of boundaries between in-groups and out-groups, insiders and outsiders, that commenters are able to convey a sense of belonging or othering to other interlocutors.

Othering has been explored by many others in a range of contexts. My findings in particular correspond to those of Dervin. Dervin $(2015$, p. 46) argues that "Othering can relate to definite and varied identity markers: nationality, race, language, religion, gender, and so on". Furthermore, Othering is frequently associated with the key idea that some groups are dehumanized or stigmatized as a result of their perceived inferiority (Dervin, 2015). This is seen in the use of the word 'red-necks' by New Zealander commenters in Excerpt 5.9, whereby Australians are positioned as inferior and othered in terms of legalising same-sex marriage (compare the use of concepts such as 'Oreos' and "Bananas' 28 which are regularly used for selfand other- othering; see e.g. Dervin, 2015; Moon, 2016; Perkins, 2008). Dervin (2015) also notes that amongst other possibilities, national identities are one of the most powerful Othering strategies. This is particularly notable in this data set. For example, within the topic of same-sex marriage, Australians (sometimes as well as other nations) are othered by commenters who

\footnotetext{
${ }^{28}$ Afro-Americans and Asians alike use the words 'Oreos' (also known as the black-on-the-outside, white-on-theinside sandwich cookie) and 'Bananas' (i.e. yellow on the outside, white inside), respectively, to refer to inconsistent identity issues (often for self-deprecating as noted)
} 
come from countries where same-sex marriage is legalised (see e.g. Excerpt 5.3, 5.8 and 5.9). While discussing the topic of travel, in Excerpt 6.5, British commenters' national identities are reinforced multiple times; by contrasting themselves with the poor economic situation of Spain, and thereby Othering Spain, they are able to implicitly enact their assumed superiority as British citizens.

In sum, personal pronouns are used by commenters in a strategic way to position themselves, to emphasise claimed identities, to resist stigmatisation and/or marginalisation in the course of interaction etc. The strategic use of personal pronouns can be seen as an indicator of how commenters position themselves and other interlocutors in interaction. Personal pronouns thus provide a practical perspective of examining 'othering' (as a contrast with 'belonging'; see discussion in Chapters 5 and 6; also see Kirilova \& Angouri, 2018) in identity construction, as they contribute to perceived social distance and proximity, inclusiveness or exclusiveness (Brown \& Gilman, 1960). In fact, attention to the use of pronouns is reflected in numerous studies focusing on political discourse (e.g. Beliaeva \& Seals, 2020; Bull \& Fetzer, 2006). My analysis not only aligns with these previous studies but also demonstrates the various affordances of examining pronouns in the online context in particular. Specifically, the construction of in-groups and outgroups through pronouns reflects speakers' conceptualisations of imagined communities (Anderson, 1983). Defining the features of these imagined communities and drawing their borders is often enacted by distinguishing the members of this imagined group ('us') from members of other groups ('them').

In this data set, the analysis confirms my decision to consider the comments section as an affinity space, recognising the ideal reader while simultaneously acknowledging a sense of belonging created by commenters during the interaction. That is, commenters make sense of seeing themselves as part of a community, but it does not necessarily meet the technical criteria of that community (recall the discussion of Chapter 3; also see analysis in Chapter 6; cf. King, 2019). Affinity spaces reflect the present-day Web 2.0 environment in which participants are 
both audience and producers of content, as evident in the news comments section in this study (see discussion in Chapter 3).

Next, I synthesise and extend the findings emerging from the intertextual analysis, highlighting the important role that intertextuality plays in negotiating identities.

\subsubsection{Intertextuality}

In terms of intertextuality, my analysis highlights two key concepts, constructed dialogue and semantic presupposition, when examining intertextual features embedded in commenters' online interactions. This choice of concepts was inspired by the work of Sclafani (2008), Seals (2012), and Thetela (2001) who each show the effectiveness of exploring intertextuality in their work. Bakhtin's (1981) notion that a text contains 'traces' of prior texts and inescapably carries potential future texts within it has resonance within various disciplines because of the promise of the articulation of multiple perspectives. Hence, intertextual analysis fits particularly well in the scope of the present study, which aims to find out which realm of sources the commenters rely on and how they do this.

As shown throughout Chapters 5 and 6, constructed dialogue, as one of the most explicit ways in which intertextuality is signaled in comments discourse, is frequently used by commenters, indicating that commenters as social actors are inevitably engaged with other texts. This finding echoes Fairclough (1992), who claims that texts are incorporated in other texts. Commenters continually "assimilate, rework, and re-accentuate" what has come before them (Bakhtin, 1986, p. 89) and anticipate what may come ahead of them in "subsequent links in the chain of speech communication" (p. 94). With respect to the types of constructed dialogue, commenters in the present data set use direct quotation more than indirect quotation (see Table 5.2 and 6.3) for both topics. This phenomenon triggers the question of why direct quotation is more common in this data set. 
First of all, we can assume that direct quotation is easier in a CMC context due to the copy-paste function provided by the technology (Severinson Eklundh, 2010); alternatively, this preference of using direct quotation is related to the audience-design factor (Bell, 1984) that is the commenter thinks that when a reader sees their own language being repeated, they are more likely to be persuaded by the commenter's point of view (cf. the role of institutional capital as discussed in Bourdieu, 1986; Meadows, 2009). These two potential reasons are highly likely to influence commenters' preference of whether to use direct or indirect quotations during the interaction. However, I would argue that this also depends on their communicative purposes (e.g. whether they intend to make a response to the specific point addressed by the previous interlocutor). As discussed earlier in Chapter 6, the use of constructed dialogue in this research data serves three main functions (see section 6.4.1) which are in line with Fairclough's (1992) claim that manifest intertextuality could be used both to distance oneself from other voices or to enhance one's claim.

The overall trend is that the percentage of direct quotation is much higher than indirect quotation. This is particularly the case for The Guardian, compared to the other two news sources. This finding is not surprising, as the readerships of The Guardian have been found generally to have a higher percentage of formal education (Anderson, 2018; Bastos, 2015; Duffy \& Rowden, 2005), and they may therefore expect to cite sources in ways that help them enhance their authority (Goodwin et al., 2011; Tannen, 2010). This illustrates the function of using direct quotation in online interaction. I would argue that online commenting is generally an opinion-oriented activity. By framing the arguments through constructed dialogue (Tannen, 2007), the commenters establish a relationship of identification with others in the discourse community or affinity space, arguably orienting to the ideal reader associated with the community. It is through the use of quotation that the current writer is able to show their ideologies and further introduce presuppositions, selectively capitalising on or suppressing certain voices, and variously internalising or externalising quoted perspectives into the writer's own voice (Hodges, 2015; Tannen, 2007). 
The use of semantic presupposition is strongly connected to the concept of ideology. As Van Dijk (1998) explains, "ideologies organize specific group attitudes; these attitudes may be used in the formation of personal opinions as represented in 'models' and these personal opinions may finally be expressed in text and talk...Because models represent what people know and think about an event or situation, they essentially control the 'content' or semantics of discourse" ( $p$. 27). The connection between ideology and discourse has been shown multiple times throughout the present research data. Ideologies such as racism, heterosexism, national superiority and so forth are frequently found within the two topics. For example, within the topic of same-sex marriage, the most salient type of ideology is related to Discourses of heterosexism. Drawing upon this, some of the commenters actively position gay people as a threat to the institution of traditional marriage as well as inferior (to heterosexual people). In terms of the travel topic, one of the most prominent categories is national identity, whereby Discourses of national superiority are regularly displayed by commenters (see discussion in Chapter 6; see e.g. Excerpt 6.2 regarding the topic of airport chaos; and Excerpt 6.3 regarding the topic of dragging the passenger off the aeroplane).

Additionally, the embodiment of ideologies is closely connected to (socio-cultural) stereotypes (see Amancio, 1993; Banchefsky \& Park, 2018; Koch, 2002). Taking Excerpt 6.6 as an example (the tragedy of the Australian man who died in a parasailing activity in Thailand; repeated as Excerpt 7.3 below), a great number of comments are imbued with racist and sexist ideology (notably in the form of new racism). In analysing this example, I discussed how presuppositions help interlocutors to convey ideologies and underlying meanings to their interlocutors and importantly, speak to their ideal readers. I will briefly revisit that key excerpt here.

\section{Excerpt 7.3 (repetition of excerpt 6.6)}

\section{[...]}

2 CACV> HughJass

3 Lornelover> CACV
I'd investigate the wife.

How long was he married and how big is his life insurance?

\section{$[\ldots]$}


It would be interesting to know whether any person would financially gain from the demise of the deceased? It would not be inconceivable for an elderly gentleman to have a

[...]

One kind of comment in particular deserves closer attention. As shown, commenters say "I'd investigate the wife" (line 2), "how long was he married and how big is his life insurance?" (line 3), "it would be interesting to know whether any person would financially gain from the demise of the deceased? It would not be inconceivable for an elderly gentleman to have a significantly younger South East Asian spouse..." (lines 6-9). These statements presuppose that the wife is responsible for her husband's death. This presupposition therefore positions these commenters (arguably as sexist and racist) as they bring to the fore cultural stereotypes of old men and young wives. However, the recognition of these ideologies is not that obvious and easy for every reader. This highlights the vital role that ideal reader plays in online interaction; when commenters draw upon semantic presuppositions, they are simultaneously presupposing that other readers, the ideal reader in particular, will be able to access the same intertextual references to recognise these embedded ideologies as well as to share this stereotype as a 'natural' fact. (Fairclough, 2001; Seals, 2012).

Having discussed how the core findings emerging from the analyses of positionality and intertextuality extends our understanding of identity construction online, in the next section I shift my focus to justify the relevance of these two specific analytical foci to show the benefit of their operationalisation in this online context.

\subsection{How can positionality and intertextuality inform each other?}

I argue that the combination of positionality and intertextuality analysis has great potential to be applied to different contexts of interaction while examining identity, because it enables analysts 
to track not just explicit positions but their relationships to each other, their relationship to ideologies and their cumulative significance in interaction.

Focusing on the meanings or implications of peoples' actions, an analysis of positionality explains intricacies of social interaction by primarily situated itself within a social constructionist framework (Whitsed \& Volet, 2013), claiming that the self is constituted through processes of social interaction. As a consequence, "who one is [must always be] always an open question with a shifting answer" (Davies \& Harré, 1990 p. 46). This view points to the relationship between language and identity, that is, as 'subjects' of discourse, interlocutors' identity construction is impacted by their discursive choices and always constrained by wider societal structures. 'Positioning' is thus a discursive process whereby identities or 'selves' are located in conversations. As mentioned earlier in Chapter 4, there are two types of positioning which are routinely employed: both reflexive and interactive positionings are found throughout the data. The term reflexive positioning is used for the claiming of identities by the individual speaker, and interactive positioning refers to cases when identities are assigned by others (Menard-Warwick, 2009, p. 38; see also discussion in Chapter 4). Through these two fundamental types of positioning, commenters index their (dis)affiliation to the interlocutors and/or to the specific topics of the interaction, which further enacts the identities they aim to construct online. In addition to this direct way of constructing identities, I have demonstrated how positioning leads to othering or being othered (rejecting the specific positioning in an interaction) in negotiating identities (see Chapters 5 and 6). Importantly, the analysis of positionality conducted in this study not only focuses on how actions and attributes are discursively created, but also draws on the sociocultural contexts (including ideologies) that influence participants' positioning. Drawing upon these, in Chapter 6, I go one step further to investigate how participants position themselves in alignment with other (potential) interlocutors and vice-versa, showing how they construct their in-group, as well as out-group, memberships (see section 6.3).

Positionality thus entails positioning oneself and/or others, and/or being positioned by others, which is influenced by their own or other interactants' intersecting identities such as gender, 
race, age, etc. (Bourke, 2014; Fisher, 2015; Hoskins, 2015). The concept of positionality highlights the dynamic and negotiated nature of identity. Whilst positioning is influenced by the wider categories of identity, it is also impacted by interlocutors' numerous ideologies, for instance, commenters position themselves as certain types of people (e.g. advocates of equal marriage, superior British tourists, etc.). How this particular positioning comes into being and how it further contributes to identity negotiations is enhanced by nuanced examination of the larger context, which draws upon our societal understandings and our exposure to ideologies and Discourses.

This instantiation underscores the importance of examining intertextuality in online interaction (see section 4.5.2). All texts and utterances are populated by intentions (Bakhtin, 1981). This Bakhtinian perspective keeps us aware that all utterances are ideologically informed. The intertextual analysis conducted in this present study investigates the ways in which multiple voices (multiple types of ideologies, multiple points of views, and multiple things to say) are transformed and reused to create something new. Taking Excerpt 5.5 as an example again, commenters discuss the legalisation of same-sex marriage in Germany, particularly focusing on Merkel's vote. In response to her vote, a commenter directly quotes a statement from the news article itself before adding their own extension:

\section{" 'Chancellor Angela Merkel said she was moved recently by visiting a lesbian couple in her rural} constituency who had invited her into their home. Seeing that they had been trusted by social services with a succession of long-term foster children was apparently a life-changing experience for her...' [italics are used to distinguish the direct quote from the news article] but not so 'moved' that she'd consider voting for it herself" (see section 5.4.1).

This direct quotation is seemingly used to show alignment in order to position themselves in the same camp as the news writer. Questions about, for example, why they quoted this statement instead of others, how it is quoted (direct or indirect) and how this quotation functions in this context, cannot be thoroughly answered by solely investigating the identity positions 
commenters take up or reject. Yet importantly, the answers to these questions play a pivotal role in a further attempt to claim identities. The examination of intertextuality in interaction hence helps to solve this problem, as explored below.

When we apply an intertextual analysis to the above excerpt, the employment of the direct quotation is arguably a sarcastic use which allocates the responsibility of what has been described about Merkel to the article writer, thereby co-constructing a taunt (by turning the words back on the writer) as a strategy of identity construction through distancing. The use of an intertextual echo is, again, in line with the central argument of Intertextuality theory, that is, all texts and utterances are "half-ours and half-someone else's" (Bakhtin, 1981, p. 345), showing that comments are intertextually related within an interaction. This emphasises the importance of considering prior as well as future texts in interaction, in order to understand how they impact on the current statement made by the commenter. This intertextuality is enacted via the means of constructed dialogue.

As well as focusing on constructed dialogue as I have demonstrated in Excerpt 5.5, the present thesis also pays attention to the semantic presuppositions used by commenters while examining intertextual relations in interaction. Now let us revisit Excerpt 5.8, which also focuses on Merkel's vote on same-sex marriage in Germany (see section 5.4.3). In response to Merkel's vote, commenter user1448 says "Wow. One thing about Angela Merkel I can actually agree with" (lines 3 through 4). For this comment, if we only focus on positioning to interpret its meaning, we would be more likely to position the commenter user1448 in opposition to equal marriage. However, this comment is a response to Kirsty1's statement, who initially writes: "why would she vote against it given her supposedly open view on acceptance and tolerance." (lines 1 through 2). Taking this prior text into consideration, we may feel confused about what kind of thing the commenter is actually agreeing with. Is it about the comment made by the previous commenter on Merkel, or is it about the vote that Merkel has given? So far, the positioning that user1448 takes is still ambiguous (due to the difficulty of identifying the subject of their statement, as I argued earlier in section 5.4.3 while discussing Excerpt 5.8); this ambiguity however stresses the 
importance of looking for 'traces' that are not explicitly "there" while examining intertextuality in the interaction (Allen, 2011; Hodges, 2015). In this case, the analysis of intertextuality provides two possible options of understanding the commenter's positioning: one is that they agree with Merkel's decision (voting against), thus positioning themselves as opponents of marriage equality; in contrast to this positioning, they might project themselves as advocates of equal marriage when they agree with Kirsty1's statement regarding Merkel (Merkel holds an open view on acceptance and tolerance). So, instead of looking at the texts individually, intertextual analysis offers us a new perspective for interpreting what is happening during the interaction.

This does not mean analysis of positionality is dispensable in the analysis. Rather, it adds important insights to the examination of online identity construction in addition to the examination of intertextuality. It is via the analysis of positionality that the embedded meanings and attitudes towards the debated issue are brought to the table; at the same time, intertextual analysis adds additional insights into those discursive strategies that have been drawn upon in the interaction, telling us more about what is happening in the linguistic interaction. The intertextual analysis thus answers the question of how the text comes into being. The analysis of intertextuality has demonstrated that "connections across contexts of situation create understandings, establish relations, construct identities, and generally 'yield social formations'(Agha, 2005, p. 4)" (Hodges, 2015, p. 53). Therefore, focusing on positionality and intertextuality together is particularly fruitful in examining how commenters discursively construct and negotiate their online identities. Identity construction is interwoven with many social forms and structures.

In summary, by focusing on both positionality and intertextuality, a comprehensive demonstration of how different discursive strategies are used by commenters to take up and/or reject particular identity positions, and how commenters draw on intertextual references to convey their meanings to the readers (as well as the ideal reader) have been provided throughout the course of the present thesis. These examinations illustrate the omnipresence of 
ideologies and recognise the important concept of the 'ideal reader' in online identity construction.

\subsection{The ideal reader, ideologies, and online identity construction}

In contrast to face-to-face communication, and as discussed earlier, traditional contextualisation cues such as eye contact, body gesture, tone of voice, etc are mostly absent in the context of online interaction. Even though this asynchronous, written context removes these traditional opportunities for identity investigation, commenters create alternative contextualisation cues in their interaction. They make use of, for example, capitalisation for emphasis, whether their feelings and opinions (Bell et al., 2004; Cho, 2010), or alternatively, to serve as a form of sarcasm (Ghosh et al., 2018; Muresan et al., 2016); specific usernames to index certain meanings or types of their identities (Aldrin, 2019; Hassa, 2012; Hutchens et al., 2019; Shafie et al., 2012; also see discussion 8.3.1); creative use of emoticons and punctuations (Crystal, 2001; Thurlow, 2001; Thurlow et al., 2004) and so forth. In other words, contextualisation cues still exist in online interaction, but in different and new forms, largely influenced by technological developments. These resources are an important consideration when exploring their contribution to commenters' identity construction.

In addition to recognising new forms of contextualisation cues in the online context, this study addresses some other unique affordances for constructing identity online: The technical ease allows commenters to use constructed dialogue in a much convenient way through the copypaste function, enabling them to embrace and/or distance themselves from particular positionings; strategic use of personal pronouns helps commenters construct memberships of certain groups; through shared knowledge and understanding, the use of semantic presuppositions offers opportunities for the current commenter to convey embedded meanings to their readers. Each of these affordances, however, requires the acknowledgment of the ideal reader (see Fairclough, 2001; Seals, 2012; also see discussion in section 5.4.2); an ideal reader is expected to make the 'right' inference during the interaction. The focus on presupposition as a form of indexicality is thus particularly important: The authors structure their arguments in a way 
that ideal readers will notice and then enable them to access to the proposition being made (Seals, 2012). Ideal readers are not limited geographically, and they are not limited through anything other than an internet connection; the writer must imagine who might be reading their comment. Through the lens of the ideal reader, I have demonstrated the omnipresence of ideologies in the online interaction, noting the contrast to face-to-face communication. Commenters do not have access to the 'regular' contextualisation cues of spoken interaction nor direct access to audience; the ideal reader thus plays a central role in the written context. The indexing of ideologies is necessarily enacted in different ways in this text-based online context and the ideal reader is the mechanism which allows us to see those ideologies.

In online commenting as in offline interaction, the process of identity construction is seen as an important means of negotiating discourse. Discourses signalling the embodiments of ideologies, (Capital-D) Discourses and stereotypes require shared socio-cultural knowledge for interpretation (Ochs, 1993). This kind of knowledge can then be used by interactants later in the interaction through indexing to contribute to the enactment of an identity. Similarly, ideologies existing at the macro-level beyond the online space can be re-negotiated and incorporated into online identity construction. For example, what does it mean to be a straight (white) male U.S. voter-citizen in the context of legalising same-sex marriage? (See discussion in section 5.3.1). Macro level identities such as sexuality and national superiority (categories that are the most salient within the analysis) are indexed through different discursive strategies during an interaction. Based on this discussion, we can see that both identity and the way it is constructed are multi-layered (N. Wilson, 2011, p. 141).

The analysis shows that identities are framed and constructed in various ways and inherently interconnected to ideologies. In performing these ideologies, commenters use various indexes (e.g. discourse styles, discourse markers, swearing, etc.) in the interaction. Some ideologies are explicit (as discussed in Chapter 5), while some remain implicit (see Chapter 6). It is through the indexing of these ideologies that commenters construct their identities. In negotiating one's identity in an online context, the presence of ideologies always exists; what changes is the 
particular norms and Discourses one may be exposed to. Specifically, during the process of identity construction and negotiations, ideologies are the roots of the belief system, they are not always visible yet provide strong support for circulating meanings in society. ${ }^{29}$

While ideologies are multiple, some gain a firmer foothold than others (e.g. national superiority) and thus have more penetration and influence in society. For example, within the theme of same-sex marriage, heteronormativity (representing the root) appears indexical to its societal dominance, whereas that representing an empowering LGBTQ ideology is feasibly still being embedded (see Dawson, 2019). This in turn feeds into Discourses, which are connected with and sustained by numerous ideologies through our society (recall Menard-Warwick's conceptualisation of Discourses giving voice to ideologies). These key concepts then inform the more micro levels through which interlocutors negotiate identities (e.g. through self-and otherpositioning) in interactions. The dynamic co-construction and indexical processes involved as interlocutors position themselves and are positioned by others in relation to these Discourses and ideologies, allow commenters to negotiate identities within the socially constructed categories available.

The connectedness and interrelatedness between all the concepts, as discussed above, have conceptual repercussions for the study of identity, which are always affecting one another. Ideologies and Discourses are in a constant state of (re)negotiation in discourse. Recognising that everything is connected and yet dynamic, we realise the complexities involved in the negotiation of social identities. This study thereby draws attention to the affordances of investigating ideologies when exploring identity. Finally, as a result of my analysis, I emphasise the importance of the ideal reader in written online interaction as a central factor in the enactment of these ideologies.

\footnotetext{
29 The conceptualisation of ideologies as "roots" is taken from the informative 'Tree Analogy' described in Dawson (2019); Dawson argues that the tree's branches are Discourses, the leaves are discourse, positioning and stance, and that the trunk is society and habitus. This analogy is intended to describe the interrelated and interdependent nature of discourse, ideology and agency.
} 


\subsection{Summary}

The ways in which we engage with ideology at a little-d discourse level is enacted through indexicalities, which themselves can be direct, indirect and layered. It is at all these indexical levels that ideology comes into play. This chapter is a reflection and theoretical extension of the previous chapters. By revisiting some core findings that have emerged across the data, I demonstrate the ways in which commenters construct and negotiate identities in this text-based online context. Discussion around the affordances of focusing on positionality and intertextuality addresses the complexity of identity construction in the online context. This not only highlights the importance of recognising the ideal reader in a written context (vs face-to-face interaction), but also leads to my theoretical claim that ideologies are omnipresent and play a part in commenters' identity construction and negotiations. The discussion points to the unique affordances of exploring identity in the context of online interaction.

In the next final chapter, I discuss the contributions and implications of the present study and elaborate on future studies which are needed in the area of language use and identity in CMC contexts. 


\section{Chapter 8}

\section{Conclusion}

\subsection{Introduction}

Identity construction is a complex interactional process. This is especially true when it comes to online commenting where features used in face-to-face interactions, including paralinguistic features and demographic information, are usually absent. This thesis has explored ways of constructing and negotiating online identities by commenters using three online news websites, namely, Stuff in New Zealand, and The Guardian and Mail Online in the UK. By employing positionality (Bucholtz \& Hall, 2005) and intertextuality (Bakhtin, 1981) as the discourse analytical foci, this study has answered the overarching research question: How is identity discursively constructed and negotiated through comments discourse in an online communication setting? To answer this research question, I collected and analysed a total of 2,874 comments posted in response to the topics of same-sex marriage and travel. Throughout the course of this research, commenters' strategies for constructing and negotiating identities have been investigated. This investigation has thereby aimed to broaden the scope of language and identity research as well as CMC studies.

Locating identities as emergent and as discursively co-constructed draws our attention to the very fabric of social life, to what has been constructed as 'reality' and how established largescale identity categories are held together by robust (though not unbreakable) ideological threads (Dawson, 2019). I have shown how negotiating identities inherently involves negotiating ideologies. Exploring these ideological parameters through interaction (and the micro linguistic features this comprises) enriches understandings of identity processes, and provides valuable entry into the wider structure and agency relationship. In sum, identity construction and negotiations in online interaction contexts are a key site for practice and theory to come 
together, offering crucial insights into the relationship between language, ideology, identity and society as experienced in today's increasingly online world.

I first revisit the research questions. This is followed by a discussion about contributions this study has made. Looking forward to the remainder of this chapter, I outline the implications of the study, and consider future research directions.

\subsection{Answering the research questions}

In this study, I attempted to methodically address my overarching research question (see Chapters 1 and 2) surrounding identity negotiation in online comments discourse. This research question was broken down into three sub-questions to better understand the complex process of identity construction and negotiation in this online context.

RQ1: How does context impact on commenters' identity construction?

RQ2: How do commenters make use of discursive strategies to negotiate their identities online? RQ3: How do commenters draw upon wider societal ideologies to shape their interactions and identity negotiations?

In what follows, I answer the individual research questions (RQ1-3), building towards a response to the overarching research question.

\subsubsection{Research question 1}

How does context impact on commenters' identity construction?

To operationalise the three refined sub-questions, as mentioned in Chapter 4, I narrowed down my focus of each for analytical purposes. As well as exploring the online context more widely, in this first research question, I aimed to investigate how different topics influence readers' comments. In order to answer this question, it is first important to recall the rationale for choosing these two selected topics (see section 4.2.2). In this research data, the first topic is the discussion of same-sex marriage, an area where ideologies are foregrounded and commenters 
were explicit about their positions. In other words, when commenters discuss same-sex marriage, the ideologies being discussed and negotiated are quite obvious and explicit (e.g. sexism, heteronormativity). The second topic is travel; interestingly, my initially somewhat naive thoughts were that when commenters discuss travel-related issues, they would be more inclined to share factual knowledge which would not include ideologies; it became clear for me in the analysis that ideologies are still highly influential but more covert or hidden (e.g. national superiority) in the interaction. The data needed to be further unpacked in order to better understand how identity construction is driven by the specific ideologies. This analysis emphasised the role of ideologies in all identity construction.

I argue that the ideologies presented in the interactional data are partly influenced by the topics of news articles selected by the newspaper. Furthermore, the chosen topics depend on the (national) contexts amongst a range of possible contextual constraints, including the type of paper (e.g. broadsheet or tabloid). For example, in the UK context, both The Guardian and Mail online reported the legalisation of same-sex marriage in Germany; however, Mail Online particularly drew readers' attention to Merkel's dissenting vote (see section 4.4). This resulted in a different focus for the commenters' discussions and accordingly, diverse ideologies were enacted and negotiated. In contrast to the UK context, Stuff did not focus on the status quo of equal marriage in Germany. Rather, it paid great attention to the rejection of the same-sex marriage bill in Australia. This difference is largely a result of the different assumed interests of the readerships of two different news media contexts (see Chapter 4, e.g. replies from the editors regarding why they choose to focus on these specific topics; cf. Riffe et al., 2018), which in turn reflects the ideological stance of the newspaper itself (Islentyeva, 2019; Jonsson, 2014; Maydell, 2010). The recognition of readership is also evident in the selection of news articles under the theme of travel. Again, taking the event of airport chaos in Spain as an example (reported by Mail Online many times; see Excerpt 6.1, 6.2 and 6.3) and considering that this event happened after the proposal of Brexit, the selection had great potential to trigger a large amount of participation from commenters as numerous ideologies (e.g. national superiority) 
were enacted and further negotiated during the construction of the identities in the related comments.

This is evidence that the context influences readers' comments and their online interaction (thus further influencing their identity construction online). It is thus important to remember that different interactional contexts might support the negotiation of different identities. The specific topic in the context shapes the particular identity that is being negotiated, highlighting the importance of contextual constraints in identity construction.

\subsubsection{Research question 2}

How do commenters make use of discursive strategies to negotiate their identities online? To operationalise this research question, I focused on how the analyses of positionality and intertextuality can complement each other in the examination of online identity construction (see Chapter 7, section 7.3). In this section, I provide a summary of this discussion rather than rehearsing the details in order to avoid repetition.

Online interactions, as the present study has shown, are a fruitful research site for exploring identity. In the interaction that we engage with, we not only discursively locate ourselves but also are located by others. During the interaction, we establish 'relationships' with specific topics being discussed and relevant interlocutors and attempt to take up specific positions in relation to our identity construction. As a fundamental example of self-and other-positioning in interaction, Excerpt 5.1 which involves comments on a news article in The Guardian about legalising samesex marriage in Germany illustrates how commenters assign different positions to themselves as well as others in order to embrace their preferred identities (i.e. sexual identities) in response to the topic of same-sex marriage. Nonetheless, in taking up these particular identities, commenters also navigate various Discourses of LGBTQ (e.g. Discourses of minority) which are pervasive in the interaction. These Discourses, however, sometimes contradict their 'beliefs'; this contributes to mismatches when adopting particular identity positions in the process of identity negotiation. In other words, in the moment-to-moment interaction, people are constantly 
balancing these ideological positions. Following the social constructionist view that identity emerges dynamically, people are not always consistent in interaction and they find ways of moving between position to balance these various identity claims (Bamberg et al., 2011; Bucholtz \& Hall, 2005; De Fina, 2003; Holmes \& Marra, 2017).

By assigning particular positions to themselves and the other interlocutors, commenters build a conceptual boundary between themselves and an imagined community (Anderson, 1991) of others (also see discussion in Chapter 3, section 3.3). In this data set, it is notable that the construction of these imagined communities is largely achieved by strategically using personal pronouns. For example, in both themes (i.e. in Chapters 5 and 6), various forms of 'us' and 'them' are frequently employed by commenters as useful discursive strategies to create distinct but imaginary boundaries between in groups and out-groups (cf. Beliaeva \& Seals, 2020; Fasulo \& Zucchermaglio, 2002; Grice et al., 2006; Tajfel, 1974; Tajfel \& Turner, 1986). It is through these indexicalities that social actors (commenters) display their memberships of certain groups. For example, under the topic of travel, Spanish commenters repeatedly show solidarity with the EU to emphasise their membership in contrast to British commenters/presumed readers (see discussion in Excerpt 6.2 and 6.3 in response to the airport chaos). By means of contrast, they seem to index an imagined community (either in an explicit or implicit way) to strength their ideologies that allow them to construct particular identities online. This finding is in line with many other previous studies focusing on political discourse (e.g. Thetela, 2001) which point out the close relationship between the use of personal pronominal references and ideologies embedded in discourse.

Intertextual analysis in this study highlights the close connections between a current statement, and both prior and future texts, providing additional insights into how the identity that the commenter is trying to claim or reject comes into being (Allen, 2011; Hodges, 2015; HodsdonChampeon, 2010). By using particular direct and indirect quotations, commenters frame information in a way that communicates effectively and creates involvement with potential interlocutors (cf. Tannen, 1989). For instance, in Chapter 5 (see section 5.4.1), one commenter 
directly quotes from the news article to contrast with the vote offered by Merkel in terms of legalising same-sex marriage in Germany. By using direct quotation in this specific context, the commenter allocates the responsibility of what has been described about Merkel to the article writer and positioned him/herself in opposition to Merkel as well. The choice of what to quote, how to quote, and from whom to quote shows the commenter's particular ideological stance, which simultaneously puts themselves and the quoted person in a specific positioning.

In addition, semantic presupposition points to the close relationship between ideology and discourse. Van Dijk $(1998,2003)$ argues that ideologies "organise" specific attitudes and these attitudes may in turn be used in the formation of personal opinions. Crucially, these opinions may be expressed in the text and impact on the negotiations of commenters' identities. Therefore, the exploration of semantics presupposition allows us to gain a better understanding of how discourse is able to draw on ideologies through intertextuality and then use the intertextual links to connect this to its ideal readers (Fairclough, 2001). Through shared knowledge, both the commenter and their ideal reader understand much more of the text than it expresses on the surface (van Dijk, 1998).

Such discursive actions are harnessed by commenters to help them achieve communicative goals in social interaction, so as to further perform their desired identities online. In other words, it is the combination of positionality and intertextuality in this study that works to investigate commenters' online identity construction and negotiation. Commenters draw on various linguistic and sociocultural resources, and the shared 'knowledge' at their disposal, to stake claims to particular identities and to position themselves (and their interlocutors) as certain types of people in a particular time and context, all within the identity categories available to them.

\subsubsection{Research question 3}

RQ3: How do commenters draw upon wider societal ideologies to shape their interactions and identity negotiations? 
Over the course of the analysis, I have shown that ideologies are pervasive in interaction and they play a central role in exploring commenters' identity. To understand how the numerous ideologies are discursively constructed and negotiated in the interaction, however, requires a closer analysis of, for instance, what was said, how it was said, what could have been said instead, and how what was said was responded to by other interlocutors, among other considerations (see Chapter 4 for a full discussion of Interactional Sociolinguistics). This kind of understanding supports access to meanings, which are conveyed and understood on the basis of different interactional contexts.

During online interaction, commenters often engage with interlocutors who come from different backgrounds. This means commenters are highly likely to expose themselves to an environment where various forms of (new) Discourses and societal ideologies are enacted. In order to fully convey meanings to others and express themselves in interaction, these Discourses and ideologies need to be negotiated through diverse discursive strategies (as discussed in section 8.2.2). Importantly, these negotiations of ideologies are sometimes closely related to cultural stereotypes. For instance, when commenters discuss the example of dragging a Vietnamese passenger off an aeroplane (see Excerpt 6.4), they make use of cultural stereotypes of Vietnam being a poor, developing country. This particular ideology (and related cultural stereotypes) thus leads the readers in a direction that pulling the Vietnamese passenger off the plane is the right thing to do, thus enacting an identity of national superiority. Another salient example can be found in Excerpt 6.6, where commenters discuss a tragedy that had happened in Thailand. In this context, in addition to the stereotype of Thailand being a third world country (as mentioned by the commenters), they are also introducing the negative cultural stereotype of a young Asian wife and an old white man into the interaction.

By unpacking these ideologies embedded in the discourse, we are able to get a better understanding of why the commenter takes up and/or rejects the specific positionings (assigned by others) in interaction so as to perform their preferred identities online. The analyses of the data show that commenters have their own ideological positions while discussing either of these 
two topics, even if in some cases the ideologies are left less explicit (see analysis in Chapter 5 and $6)$.

In sum, the analysis conducted in this study involved careful attention to the interpretations of meaning from the commenter's perspective as well as to the wider social forces at play, as I have shown through attention to Discourses (recall Menard-Warwick's conceptualisation of Discourses giving voice to ideologies) and ideologies. This analytical focus on the how of identity construction is a good starting point from which to investigate the role of ideologies in commenters' identity negotiations, a focus which I believe has the potential to be theoretically generative, as discussed further below.

\subsection{Contributions}

This section is devoted to discussing the contributions that the present study has made, including methodological, theoretical, and analytical contributions. Each of these will be discussed below.

\subsubsection{Methodological contributions (and overcoming challenges)}

The methodology I adopted in this research actively aimed to overcome a number of methodological challenges inherent in operating in the online space. Many of the issues stem from a lack of direct comparison with face-to-face sites which represent the traditional context for investigations of identity. In order to fully embrace the dynamism and complexity of identity as a construct, the online space needs to be acknowledged as a non-material and highly changeable environment (Darvin, 2016; Miller \& Arnold, 2009; Prantl, 2016). Taking the present study as an example, I investigate how anonymous commenters discursively construct and negotiate their diverse identities. This anonymity provides commenters with the potential to construct different identities that they may not have access to perform off-line, while simultaneously creates difficulties for researchers in terms of controlling the data size. In this study, my rough estimation was that 4,000 comments would be collected equating to 100 comments for 40 articles; in reality, because I am reliant on the commenters (who are mostly 
likely to be self-selecting) and their natural setting, I could not control the actual number of comments. As a result, for the data set, I collected and analysed 2,874 comments in total (as discussed earlier in Chapter 4; see section 4.3). Rather than viewing this methodological difficulty as a limitation that must be resolved, I instead argue that our datasets should reflect the realities of working with naturally occurring data, and that we should embrace the diversities and complexities of the research site.

In addition to this, participants' demographic information is usually absent in these comment sections. On one hand, this kind of absence allows participants to perform identities in ways that they prefer to; on the other hand, it excludes the potential for other approaches (e.g. interviewing participants), which may provide researchers with a rich collection of data and add additional insights to the analysis of identity construction. As argued by Schneider \& Kirsten (2004, p. 118), "the emergence of the Internet, and especially the web, has challenged scholars conducting research to both adapt familiar methods and develop innovative approaches that account for the unique aspects of the web." The unpredictable character of the Internet generates considerable challenges. And to be sure there are many more methodological difficulties than those described in this present thesis. The expectation of this thesis is that by sharing my research experience, it might be possible to broaden the methodological approaches used to examine identity construction in different contexts of online communication.

The traditional contextualisation cues such as body gesture, eye contact, tone of voice, etc., which play an important part in face-to-face communication, lose their place in adding additional insights into the examination of online identity in the text-based online commenting context. Although this particular online context removes traditional opportunities for exploring identity, commenters create other ways to replace these traditional contextualisation cues in online interaction. They make use of different fonts, capitalisation, usernames and punctuation marks and so forth to make their identity claims (see the analysis chapters, e.g. Excerpt 5.1, 6.1, 6.2 and 6.6). For example, in response to the airport chaos, in Excerpt 6.1, the commenter calls British tourists "a target" (line 2) and makes use of punctuation marks (i.e. :)=(:), arguably functioning 
as a form of taunt which adds humour to the comments (cf. Holmes \& Marra, 2002; Marra \& Holmes, 2007). In addition to this, the username used by commenters also deserves our attention, as we can see in Excerpt 6.6. In this specific context, commenters are discussing the death of an old Australian man who married a young Thai wife; the username 'Lornerlover' suggests a sense of hopelessness about love. This contextualisation cue therefore is interpreted as a way of indexing a specific positioning in opposition to the Thai wife whose 'love' is challenged as inauthentic and mercenary (see discussion in section 6.4.2).

I took the above mentioned resources into consideration while analysing the data. As analysts, we should be aware of that online users draw upon different resources as new contextualisation cues and it is through these resources that they are explicitly doing identities. Therefore, the methods of data collection and analysis adopted in this study emphasise the use of language in text-based online interaction, particularly highlighting the role of new contextualisation cues in exploring identity in this asynchronous, written context.

\subsubsection{Analytical contributions}

The overall, interdisciplinary approach used in this thesis has made room for interpretive depth. And, on a more specific level, a discursive approach to capturing identities offers enriched understandings of how online users actually do identities. Interactional Sociolinguistics suited the complexity of my data well, allowing for attention to micro linguistic elements combined with macro wider sociocultural factors. Throughout this study, I have shown the validity of applying IS to a non-face-to-face communication environment, in line with the arguments of others (e.g. Bullingham \& Vasconcelos, 2013; Cetina, 2009; Seals, 2021). In this regard, IS provides researchers with a potential analytical approach (as well as a theoretical framework) to investigate online identity construction and negotiation, because IS regards cultural as well as situational context as being crucially important for the analysis of interaction. This focus provides particular affordances in the analysis of Excerpt 6.6; by connecting the analysis to the sociocultural context of sex tourism or the 'girlfriend experience' in Thailand, I emphasise this 
significant influence on the commenters' interaction and the enactment of specific identities (see discussion in section 6.4.2).

A further analytical contribution is insight into the employment of positionality and intertextuality in the data analysis. Throughout Chapters 5 and 6 , analysis of positionality provided insight into ways in which commenters position themselves as well as other relevant interlocutors involved in the specific interaction, in either a direct or indirect way. An important aspect of displaying their various identities that surfaced clearly in the data is that of indexing group memberships through taking up or rejecting certain positions. This feature is salient in Excerpts 6.1 and 6.2, where commenters claiming Spanish citizenship regularly claim their membership of the EU by taking up opposite positions to British commenters in the interaction (see discussion in Chapter 6). In particular, this thesis has shown that the commenters' group memberships play an important role in the linguistic choices available to them. In this online interactional context, language then is used as a vehicle through which commenters index their (dis)affiliations to appropriate groups drawing on their shared knowledge and societal understandings, and their repertoire of linguistic resources for fulfilling their relevant activities (see Lazzaro-Salazar, 2017). Although a commenter may at times index their group affiliations in different ways, at other times they seem to use the same discursive strategies for similar sociopragmatic purposes. For example, the use of personal pronouns indexes multiple group memberships, or alternatively may be used to distance themselves from certain groups in similar ways. It is through positioning that commenters embrace a preferred image of their various selves (Bamberg, 2005; Kayı-Aydar, 2019). By illustrating with concrete examples the dynamism of the negotiation process involved and the resulting display of a given positioning (see Chapters 5 and 6 for how commenters discursively take up and/or reject positionings in interaction), this thesis contributes to advancing our understanding of the construction of identity online.

In addition to this, through the examination of constructed dialogue and semantic presupposition, intertextual features embedded in comments discourse also become salient in examining online identity construction. Specifically, the examination of constructed dialogue 
addresses questions around what is quoted, how it is quoted, and from whom, which reveals particular ideologies and thus reinforces the specific positioning that a commenter may be attempting to take up or reject. Drawing on the concept of indexicality, semantic presupposition then sets up a strong link between the discourse and its reader, the ideal reader in particular. The examination of presupposition then becomes a core method to examine the relationships between semantics and discourse (Porter, 1986; Seals, 2012), exposing the numerous ideologies embedded in interaction. Going beyond presupposition to look at intertextual analysis provided me with more information about what exactly is happening during the interaction and how it happens. This information connects closely to the results of analysing positionality, which together contribute to the navigation of how commenters construct and negotiate their online identities (see discussion in Chapter 7 around how positionality and intertextuality complement each other in the analysis).

\subsubsection{Theoretical contributions}

A major part of the theoretical contribution recognises the role of societal ideologies as an integral component of identity negotiations around, for example, nationality, gender and sexual identities (see Chapter 5 and 6). Identities are not constructed in a vacuum. I argue that while dominant ideologies related to these social categories are increasingly penetrative (Dawson, 2019), the Discourses and norms which give them voice can sometimes change shape in the online communication context. This is particularly apparent in Chapter 5 (on the theme of samesex marriage), where heteronormativity is given voice through Discourses of LGBTQ empowerment and disempowerment, and these Discourses in turn are themselves embodied by different norms (e.g. the 'freedom' for gay couples to get married, or, overt sexual discrimination).

In Chapter 6 (on the theme of travel), Discourses of Britishness and national superiority too were clearly ideological in their connections to nationhood and belonging (i.e. the ethnicised 'othering' that occurred for and by Spanish commenters in the interaction). By unpacking identity construction, I have shown how commenters draw on ideologies and I recognise that 
ideologies are always present in their interaction, even if the commenters themselves are not being explicit about their expression of ideologies. While ideologies often remain hidden, they nevertheless play a central role in identity construction online. In the online discourse literature which investigates identities, ideologies have been underestimated. Analysts sometimes seem to overlook ideology in the analysis, though there is room for deeper exploration of how ideology connects to various Discourses and further contributes to our understanding of what is going on during the interaction. Because ideologies are not always readily accessible as we speak or reflect on interactions, this study further calls for considering the vital role that ideology plays in the process of (online) identity construction and negotiation.

The ideology focus that I have foregrounded throughout the thesis is relatively unexplored in identity-focused studies of online interaction (e.g. Durante, 2011; also see discussion in Chapter 3), and sheds valuable light on the role of structural constraints within which online users operate (Al Zidjaly, 2009). By engaging with this macro-level concept, we gain an important appreciation of categories as socially and historically constructed. This ideology focus therefore provided a valuable lens through which to interpret contestation of identity categories by commenters, who had differential access to societally-sanctioned resources. In future work there is a need to investigate disparities in accessing and usage of new technology, with a focus on how ideologies influence identity construction. I therefore argue that ideological foundations are always sites of potential (re)construction.

In Chapter 7 I synthesised my analysis by applying Ochs's (1993) concept of indexicality to online interaction to identify how commenters construct and negotiate their identities, actively drawing connections between the core concepts used for analysis, from ideologies to the ideal reader, from intertextuality to positionality. In terms of indexicality, Ochs (1993) prioritises direct and indirect indexicalities. My analysis identified both types of indexicality in the process of commenters' identity construction, acknowledging their use as an important tool for communicative purposes through associations with various forms of ideologies and Discourses. Through the lens of indexicality, different forms of ideologies, whether overt or embedded in 
discourse, are recognised by the ideal reader. This impacts upon commenters' position taking, construction and negotiation of preferred online identities. In this sense, indexicality enables commenters to speak to their ideal readers, facilitating the expression of meaning among the discourse community or members of the affinity space. The interpretation of the indexical meaning is dependent on the interactional context (Bucholtz \& Hall, 2010), highlighting the importance of taking account of both previous and future texts in online interaction. Various forms of indexicalities (including distinct contextualisation cues for the online environment) allow commenters to draw on intertextual features to present themselves via shared associations. The focus on indexicality thus offers a fruitful tool for contributing to analysis in online discourse research, and the examination of online identity construction as resulting from the complex interplay of many factors in particular.

\subsection{Future research}

This study provides the starting point for many more possible future directions for research. First, the methodology (including methods of data collection and analysis) presented in this study allowed for a comprehensive examination of identity construction in online communication. As such, it would be fascinating to see future studies done using the same methodology, especially longitudinally, given the narrow selection of timescale and the limited size of the dataset. A multimodal approach which pays close attention to other aspects of communication (including but not limited to non-verbal features) such as semiotics, particular usernames, and profile pictures used by online users (e.g. King, 2019; Shafie et al., 2012) and imaged text (e.g. Yadlin-Segal, 2017) and so forth, would also be well suited to exploration of online identity. This might provide additional insights into how people employ language and other emerging online features as efficient tools to interact with other interlocutors in the cyber world so as to construct and negotiate their desired identities.

In addition, focusing on emerging linguistic practices in affinity spaces and communities and their locally situated character (Leppänen et al., 2015), future research could contribute to the methodological advancement of Affinity Spaces (Lammers et al., 2012), developing 'affinity space 
ethnography', a method derived from discourse-centred online ethnography (Androutsopoulos, 2008). In other words, researchers are encouraged to go beyond simple 'digital language data collection' (i.e. collecting online data without observing or contacting participants) and instead engage in systematic ethnographic observation of participants' sites, practices and trajectories (Androutsopoulos \& Stæhr, 2018).

Furthermore, it would be interesting to return to the same interactional online spaces and follow some participants who actively contribute to online commenting on different topics. Put differently, rather than only focusing on two topics like I have in this study, researchers could conduct case studies to find out how these individual participants negotiate their identities over time and across topics. Additionally, as some studies have already focused on the distinction between the online and offline self (cf. Georgalou, 2016), in a similar way, future research could also examine commenters' online and offline identity construction. Findings from such studies may be valuable for understanding participants' online communication behavior and their identity construction, an area in which the literature is limited.

Finally, as this study only focuses on comment sections, future researchers could also consider conducting studies focused on different online platforms. For example, it would be interesting to see whether forms of identity construction vary according to platform, such as microblogs, and social networking sites (e.g. Facebook, Twitter and YouTube), which require identity identification, compared with comment boards that allow for a certain degree of anonymity. By mapping the trajectory of the different online platforms, interesting findings could be extracted to contribute to an in-depth understanding of identity construction in the context of CMC.

\subsection{Concluding remarks}

In this study, I have illustrated how identities are emergent and negotiated in the asynchronous, written context of online interaction. It provides me with affordances to incorporate disciplines include, for instance, computer-mediated communication (CMC), applied sociolinguistics, discourse analysis, and sociocultural theory to explore identity construction online. In this study, 
I accomplished my overarching goal of examining how commenters discursively construct and negotiate their online identities. By getting access to the comment sections of three online news websites in New Zealand and the UK, I was able to draw a clear picture of what is happening in these online commenting space, thus gaining a better understanding of commenters' linguistic behaviour in online interaction.

The many findings from this study show that identity is a dynamic process rather than an "essentialized fixed product" (Block, 2007b, p. 866). This idea feeds into the important notion of seeing identity as co-constructed, performed and negotiated, thus underscoring the significant role that language plays in interactions. And, depending on the interactional goals, diverse linguistic strategies play a part in enacting and performing commenters' preferred identities online, as the analysis has shown. I have seen commenters' opinions fluctuate and change, and positioning take different forms during an interaction, all of which, of course, is evidence of identities as dynamic and in flux. This is why the discursive approach to identity with a focus on ideology is so valuable; it does not seek to position commenters within this study as a particular type of person. Rather, I gain intriguing insights into how they navigate identities and ideologies with different interlocutors in particular contexts and at particular times. This dynamic perspective is better suited to capturing the social complexity and contradictions that surround us.

I hope that this study speaks to many groups of people, including academics, media professionals, and not least, online users who will continue to experience the convenience that the online commenting function affords. I hope, too, that the exploration of identity in this particular online interaction setting is one that inspires discussion on both practical and academic levels, which contributes to studies of language and identity as well as to CMC studies in general. 


\section{References}

Abizadeh, A. (2005). Does collective identity presuppose an Other? On the alleged incoherence of global solidarity. American Political Science Review, 99(1), 45-60.

Agha, A. (2005). Introduction: Semiosis across encounters. Journal of Linguistic Anthropology, 15(1), 1-5.

Agheyisi, R. N., \& Fishman, J. A. (1970). Language attitude studies: A brief survey of methodological approaches. Anthropological Linguistics, 12(5), 137-157.

Ahearn, L. (2001). Language and agency. Annual Review of Anthropology, 30, 109-137.

Al Zidjaly, N. (2009). Agency as an interactive achievement. Language in Society, 38(2), 177-200.

Aker, A., Kurtic, E., Balamurali, A. R., Paramita, M., Barker, E., Hepple, M., \& Gaiza uskas, R. (2016). A Graph-Based Approach to Topic Clustering for Online Comments to News. In N. Ferro, F. Crestani, M.-F. Moens, J. Mothe, F. Silvestri, G. M. Di Nunzio, C. Hauff, \& G. Silvello (Eds.), Advances in Information Retrieval (Vol. 9626, pp. 15-29). Springer International Publishing.

Aldrin, E. (2019). Naming, Identity, and Social Positioning in Teenagers' Everyday Mobile Phone Interaction. Names, 67(1), 30-39.

Allen, G. (2011). Intertextuality (2nd ed.). Routledge.

Amancio, L. (1993). Stereotypes as Ideologies. The case of Gender Categories. Revista de Psicología Social, 8(2), 163-170.

Anderson, B. (1983). Imagined communities: Reflections on the origin and spread of nationalism. Verso.

Anderson, B. (2018). Influence of Education, Income and Age on Newspaper Use and Platform Preference. Elon Journal of Undergraduate Research in Communications, 9(1), 108-114.

Androutsopoulos, J. (2006). Introduction: Sociolinguistics and computer-mediated communication. Journal of Sociolinguistics, 10(4), 419-438.

Androutsopoulos, J. (2008). Potentials and Limitations of Discourse-Centred Online Ethnography. Language@Internet, 5, article8. 
Androutsopoulos, J., \& Stæhr, A. (2018). Moving Methods Online: Researching Digital Language Practices. In A. Creese \& A. Blackledge (Eds.), The Routledge Handbook of Language and Superdiversity (pp. 118-132). Routledge.

Angouri, Jo. (2016). Online Communities and Communities of Practice. In A. Georgakopoulou \& T. Spilioti (Eds.), The Routledge Handbook of Language and Digital Communication (pp. 323-338). Routledge.

Apker, J., \& Eggly, S. (2004). Communicating professional identity in medical socialization: Considering the ideological discourse of morning report. Qualitative Health Research, 14(3), 411-429.

Appadurai, A. (1996). Modernity at Large. Cultural Dimensions of Globalization. University of Minnesota Press.

Araeen, R. (2000). The art of benevolent racism. Third Text, 51, 57-64.

Armour, W. S. (2004). Becoming a Japanese language learner, user, and teacher: Revelations from life history research. Journal of Language, Identity, and Education, 3, 101-125.

Arundale, R. (2010). Face as emergent in interpersonal communication: An alternative to Goffman. In F. Bargiela-Chiappini \& M. Haugh (Eds.), Face, communication and social interaction (pp. 33-54). Equinox.

Ask, S. (2018). 'She had it coming?': An experimental study of text interpretation in a police classroom setting. Nordic Journal of Linguistics, 41(2), 133-153.

Atanasova, D., \& Koteyko, N. (2017). Metaphors in Guardian Online and Mail Online Opinionpage Content on Climate Change: War, Religion, and Politics. Environmental Communication, 11(4), 452-469.

Attardo, S. (2001). Humor and irony in interaction: From mode adoption to failure of detection. In L. Anolli, R. Ciceri, \& G. Riva (Eds.), Say not to say: New perspectives on miscommunication (pp. 166-186). IOS Press.

Augoustinos, M., Tuffin, K., \& Every, D. (2005). New racism, meritocracy and individualism: Constraining affirmative action in education. Discourse \& Society, 16(3), 315-340.

Authier-Révuz, J. (1982). Hétéreogenéité montrée ethétérogenéité constitutive: Éléments pour une approach de l'autre dans le discourse. DRLAV, 32, 91-151. 
Azariah, D. R. (2016). Tourism, Travel, and Blogging: A discursive analysis of online travel narratives (1st ed.). Routledge.

Bahena, F. L. (2013). The promotion of Tourism in Spain from Stereotype to brand image. Tourism and Tourist Promotion around the World: A Linguistic and Socio-Cultiral Perspective.

Bailey, B. (2008). Interactional Sociolinguistics. In W. Donsbach (Ed.), International Encyclopedia of Communication (pp. 2314-2318). Blackwell.

Baker, M. (1981). The new racism: Conservatives and the ideology of the tribes. Junction Books.

Baker, P. (2010). Sociolinguistics and Corpus Linguistics. Edinburgh University Press.

Baker, P., \& Levon, E. (2015). Picking the right cherries? A comparison of corpus-based and qualitative analyses of news articles about masculinity. Discourse and Communication, 9(2), 1-16.

Bakhtin, M. (1986). The problem of speech genres. In C. Emerson \& M. Holquist (Eds.), Speech genres and other late essays (pp. 60-102). University of Texas Press.

Bakhtin, M. (1992). The dialogic imagination: Four essays. University of Texas Press.

Bakhtin, M. (1981). Discourse in the novel. In M. Holquist (Ed.), The dialogic imagination: Four essays (pp. 259-422). University of Texas Press.

Bakhtin, M. (1984). Problems of dostoevsky's poetics. University of Minnesota Press.

Bamberg, M. (2004). Talk, small stories, and adolescent identities. Human Development, 47(6), 366-369.

Bamberg, M. (2005). Encyclopedia entries on "agency", "Master Narratives", and "Positioning". In M. Herman, M. Jahn, \& M. L. Ryan (Eds.), The Routledge encyclopedia of narrative theory. Routledge.

Bamberg, M. (2014). Invited commentary: Narrative practices versus Capital-D Discourses: Ways of investigating family. Journal of Family Theory \& Review, 6, 132-136.

Bamberg, M. (2011a). Narrative practice and identity navigation. In J. A. Holstein \& J. F. Gubrium (Eds.), Varieties of narrative analysis (pp. 99-124). Sage.

Bamberg, M. (2011b). Who am I? Narration and its contribution to self and identity. Theory \& Psychology, 21(1), 3-24. 
Bamberg, M., De Fina, A., \& Schiffrin, D. (2007). Introduction to the Volume. In M. Bamberg, A. De Fina, \& D. Schiffrin (Eds.), Selves and Identities in Narrative and Discourse (pp. 1-8). John Benjamins.

Bamberg, M., De Fina, A., \& Schiffrin, D. (2011). Discourse and identity construction. In S. J. Schwartz, K. Luyckx, \& V. L. Vignoles (Eds.), Handbook of identity theory and research (pp. 177-199). Springer.

Bamberg, M., \& Georgakopoulou, A. (2008). Small stories as a new perspective in narrative and identity analysis. Text \& Talk-An Interdisciplinary Journal of Language, Discourse Communication Studies, 28(3), 377-396.

Bamman, D., \& Smith, N. (2015). Contextualized Sarcasm Detection on Twitter [conference presentation]. Ninth International AAAI Conference on Web and Social Media, Oxford, UK.

Banchefsky, S., \& Park, B. (2018). Negative gender ideologies and gender-science stereotypes are more pervasive in male-dominated academic disciplines. Social Sciences, 7(27). https://doi.org/10.3390/socsci7020027

Bandyopadhyay, S. (Ed.). (2010). India in New Zealand: Local identities, global relations. Otago University Press.

Bankoff, G. (2003). Regions of Risk: Western Discourses on Terrorism and the Significance of Islam. Studies in Conflict \& Terrorism, 26(6), 413-428.

Barber, B. R., Mattson, K., \& Peterson, J. (1997). The State of "electronically enhanced democracy": A survey of the Internet. Walt Whitman Center for the Culture and Politics of Democracy.

Barton, D., \& Lee, C. (2013). Language online: Investigating digital texts and practices. Routledge.

Bastos, M. T. (2015). Shares, Pins, and Tweets: News readership from daily papers to social media. Journalism Studies, 16(3), 305-325.

Bauman, R. (2005). Commentary: Indirect indexicality, identity, performance: Dialogic observations. Journal of Linguistic Anthropology, 15(1), 145-150.

Bauman, R., \& Briggs, C. (1990). Poetics and performance as critical perspectives on language and social life. Annual Review of Anthropology, 19, 59-88. 
Baxter, J., \& Wallace, K. (2009). Outside in-group and out-group identities? Constructing male solidarity and female exclusion in UK builders' talk. Discourse \& Society, 20(4), 411-429.

Baym, N. K. (1998). The emergence of online community. In Steven Jones (Ed.), Cybersociety 2.0: Revisiting Computer-mediated Communication and Community (pp. 35-68). Sage.

Baym, N. K. (2000). Tune In, Log On: Soaps, Fandom, and Online Community. Sage.

Baym, N. K. (2010). Personal Connections in the Digital Age. Polity.

Bazeley, P. (2007). Qualitative data analysis with NVivo. Sage.

Bazzanella, C. (2002). The Significance of Context in Comprehension: The "We Case." Foundations of Science, 7(3), 239-254.

Beckham, W. A. (2005). The second reformation: Reshaping the church for the twenty-first century. TOUCH Publications.

Beijaard, D., Verloop, N., \& Vermunt, J. D. (2000). Teachers' perceptions of professional identity: An exploratory study from a personal knowledge perspective. Teaching and Teacher Education, 16(7), 749-764.

Beliaeva, N., \& Seals, C. A. (2020). Who are "they" for Ukrainians in Ukraine and in the diaspora? Othering in ploitical discourse. In N. Knoblock (Ed.), Language of Conflict: Discourses of the Ukrainian Crisis (pp. 137-156). Bloomsbury.

Bell, A. (1984). Language style as audience design. Language in Society, 13(2), 145-204.

Bell, A. (2000). Maori and Pakeha English: A case study. In New Zealand English (pp. 221-248). Victoria University Press.

Bell, A. (1998). The discourse structure of news stories. In G. Peter \& A. Bell (Eds.), Approaches to Media Discourse (pp. 64-104). Blackwell.

Bell, D., Loader, B., Pleace, N., \& Schuler, D. (Eds.). (2004). Cyberculture: The key concepts. Routledge.

Bengtsson, M. (2016). How to plan and perform a qualitative study using content analysis. NursingPlus Open, 2, 8-14.

Berger, P. L., \& Luckmann, T. (1967). The social construction of reality. A treatise in the sociology of knowledge. The Penguin Press. 
Binderkrantz, A. S., Bonafont, L. C., \& Halpin, D. R. (2017). Diversity in the News? A Study of Interest Groups in the Media in the UK, Spain and Denmark. British Journal of Political Science, 47(2), 313-328.

Bishop, R., \& Robinson, L. S. (1999). In the Night Market: Tourism, Sex, and Commerce in Contemporary Thailand. Women's Studies Quartely, 27(1/2), 32-46.

Blackledge, A., \& Pavlenko, A. (2001). Negotiation of identities in multilingual contexts. International Journal of Bilingualism, 5(3), 243-257.

Blankenship, K. L., \& Craig, T. Y. (2006). Rhetorical Question Use and Resistance to Persuasion: An Attotude Strength Analysis. Journal of Language and Social Psychology, 25(2), 111-128.

Blitvich, P. G.-C. (2018). Globalization, transnational identities, and conflict talk: The superdiversity and complexity of the Latino identity. Journal of Pragmatics, 134, 120-133.

Block, D. (2006). Multilingual identities in a global city: London stories. Palgrave.

Block, D. (2007a). Second language identities. Continuum.

Block, D. (2007b). The Rise of Identity in SLA Research, Post Firth and Wanger (1997). The Modern Language Journal, 91(s1), 863-876.

Blommaert, J. (1999). Language ideological debates. Mouton de Gruyter.

Blyth, C., Recktenwald, S., \& Wang, J. (1990). 'I’m Like, "Say What?!": A New Quotative in American Oral Narrative. American Speech, 65(3), 215-227.

Bolander, B., \& Locher, M. (2010). Constructing Identity on Facebook: Report on a Pilot Study. SPELL: Swiss Papers in English Language and Literature, 24, 165-187.

Bolander, B., \& Locher, M. A. (2013). Doing sociolinguistic research on computer-mediated data: A review of four methodological issues. Discourse, Context \& Media.

Bolander, B., \& Locher, M. A. (2015). "Peter Is a Dumb Nut": Status Updates and Reactions to Them as "Acts of Positioning" in Facebook. Pragmatics, 25(1), 99-122.

Bolander, B., \& Locher, M. A. (2020). Beyond the online offline distinction: Entry points to digital discourse. Discourse, Context \& Media, 35, 100383. https://doi.org/10.1016/j.dcm.2020.100383

Bond, B. J. (2020). Media Use, Sexual identity, and Gender Identity. In J. Bulck (Ed.), The International encyclopedia of Media Psychology. Wiley. 
Borah, P. (2014). Does it matter where you read the news story? Interaction of incivility and news frames in the political blogosphere. Communication Research, 41(6), 809-827.

Bourdieu, P. (1986). The forms of capital. In J. Richardson (Ed.), Handbook of Theory and Research for the Sociology of Education (pp. 241-258). Greenwood.

Bourke, B. (2014). Positionality: Reflecting on Research Process. The Qualitative Report, 19, 1-9.

Bowen, G. A. (2008). Naturalistic inquiry and the saturation concept: A research note. Qualitative Research, 8(1), 137-152.

Bower, A. M. (2018). Yeah, No and No, Yeah: An anlaysis of Two Discourse Markers [Open Access Senior Honors Thesis]. Eastern Michigan University.

boyd, D. (2008). Taken out of context: American Teen Sociality in Networked Publics. UC Berkeley Dissertation.

boyd, D. (2012). Participating in the always-on lifestyle. In M. Mandiberg (Ed.), The social media reader (pp. 71-76). New York University Press.

boyd, D. (2014). It's complictaed: The social lives of networked teens. Yale University Press.

boyd, D., Chang, M., \& Goodman, E. (2004). Representations of Digital Identity. Conference on Computer Supported Cooperative Work, Chicago.

Boyd, M. (2018). Critical Discourse Analysis and the Editorial 2.0: News Reception and Usergenerated Comments in Discourses about (Im)migration. Altre Modernità, 2018: NUMERO SPECIALE: Language and Discourse in Social Media: New Challenges, 1-22.

Boyne, R. (1990). Foucault and Derrida: The other side of reason. Unwin Hyman.

Brown, R., \& Gilman, A. (1960). The Pronouns of Power and Solidarity. In T. A. Sebeok (Ed.), Style in Language (pp. 253-276). MIT Press.

Bucholtz, M. (2003). Sociolinguistic nostalgia and the authentication of identity. 7(3), 398-416.

Bucholtz, M., \& Hall, K. (2004). Theorizing Identity in Language and Sexuality Research. Language in Society, 33(4), 501-547.

Bucholtz, M., \& Hall, K. (2005). Identity and interaction: A sociocultural linguistic approach. Discourse Studies, 7(4-5), 585-614.

Bucholtz, M., \& Hall, K. (2008). Finding identity: Theory and data. Multilingua, 27(1), 151-163. 
Bucholtz, M., \& Hall, K. (2010). Locating identity in Language. In C. Llamas \& D. Watt (Eds.), Language and identities (pp. 18-28). Edinburgh University Press.

Bucholtz, M., \& Hall, K. (2016). Embodied sociolinguistics. In N. Coupland (Ed.), Sociolinguistics (pp. 173-198). Cambridge University Press.

Bull, P., \& Fetzer, A. (2006). "Who are we and who are you?" The strategic use of forms of address in political interviews. Text \& Talk, 26(1), 3-37.

Bullingham, L., \& Vasconcelos, A. C. (2013). The presentation of self in the online world: Goffman and the study of online identities. Journal of Information Science, 39(1), 101-112.

Bulter, J. (1990). Gender trouble: Feminism and the subversion of identity. Routledge.

Burke, P. (2009). Identity theory. Oxford University Press.

Burr, V. (2003). Social Constructionism (2 ${ }^{\text {nd }}$ ed.). Routledge.

Burton-Roberts, N. (1989). The limits to debate: A revised theory of semantic presupposition. Cambridge University Press.

Butler, J. (1990). Gender Trouble. Routledge.

Calvert, S. L. (1999). Identity on the Internet. Annenberg public policy center conference on the internet and the family, Washington, D.C.

Cameron, D. (2014). Gender and language ideologies. In S. Ehrlich, J. Holmes, \& M. Meyerhoff (Eds.), Handbook of language, gender, and sexuality ( $2^{\text {nd }}$ ed., pp. 281-352). John Wiley \& Sons.

Cameron, D. (1997). Theoretical debates in feminist linguistics: Questions of sex and gender. In R. Wodak (Ed.), Gender and discourse (pp. 21-36). Sage.

Cameron, D. (2001). Working with Spoken Discourse. Sage.

Cameron, D. (2006). Performing gender identity: Young men's talk and the construction of heterosexual masculinity (1997). In On Language and Sexual Politics (pp. 47-64). Routledge.

Cao, X. (2014). Discourses on urbanism: "Reality televisions" by jiangsu Satellite Television sicne 2010 [Master Thesis]. Hong Kong Baptist University.

Castells, M. (2000). The Rise of Network Society ( $2^{\text {nd }}$ ed.). Oxford. 
Cervantes, C. A., \& Callanan, M. A. (1998). Labels and explanations in mother-child emotion talk: Age and gender differentiation. Developmental Psychology, 34(1), 88-98.

Cetina, K. (2009). The synthetic situation: Interactionism for a global world. Symbolic Interaction, 32(1), 61-87.

Chandler, M. J. (2000). Surviving time: The persistence of identity in this culture and that. Culture and Psychology, 6(2), 209-231.

Charmaz, K. (2006). Constructing grounded theory: A practical guide through qualitative analysis. SAGE.

Chebel d'Appollonia, A. (2011). Les frontières du racisme [Frontiers of Racism]. Presses de Sciences Po.

Chen, G. M., \& Pain, P. (2017). Normalizing Online Comments. Journalism Practice, 11(7), 876892.

Chew, W. L. (2006). What's in a National Stereotype? An Introduction to Imagology at the Threshold of the 21st Century. Language and Intercultural Communication, 6(3-4), 179187.

Cho, T. (2010). Linguistic Features of Electronic Mail in the Workplace: A Comparison with Memoranda. Language@Internet, 7, article 3.

Chuang, K. Y., \& Yang, C. C. (2010). Helping you to help me: Exploring supportive interaction in online health community. Proceedings of the American Society for Information Science and Technology, 47(1), 1-10.

Chung, D. (2008). Interactive features of online newspapers: Identifying patterns and predicting use of engaged readers. Journal of Computer-Mediated Communication, 13, 658-679.

Cinnirella, M., \& Green, B. (2007). Does "cyber-conformity" vary cross-culturally? Exploring the effect of culture and communication medium on social conformity. Computers in Human Behavior, 23(4), 2011-2025.

Clark, H. H., \& Gerrig, R. J. (1990). Quotations as demonstrations. Language, 66(4), 764-805.

Clark, L. S. (1998). Dating on the net: Teens and the rise of "pure relationships." In S. G. Jones (Ed.), Cyberspace2.0: Revisiting computer-mediated communication and community (pp. 159-183). Sage. 
Coe, K., Kenski, K., \& Rains, S. A. (2014). Online and Uncivil? Patterns and Determinants of incivility in Newspape Website Comments. Journal of Communication, 64(4), 658-679.

Cogeanu, O. (2015). Travelling Ideologies: A Story of Whiteness. Linguaculture, 2015(2), 15-32.

Cook, H. M. (2008). Socializing identities through speech style: Learners of Japanese as a foreign language. Multilingual Matters.

Cote, J. E., \& Levine, C. G. (2014). Identity, formation, agency, and culture: A social psychological synthesis. Lawrence Erlbaum Associates.

Coupland, N. (1980). Style-shifting in a Cardiff work-setting. Language in Society, 9(1), 1-12.

Coupland, N., Coupland, J., Giles, H., \& Henwood, K. (1988). Accommodating the elderly: Invoking and extending a theory. Language in Society, 17(1), 1-41.

Cramer, J. (2010). Do We Really Want to be Like Them? Indexing Europeaness through Pronominal Use. Discourse \& Society, 21(6), 619-637.

Crenshaw, K. (1989). Demarginalizing the intersection of race and sex: A black feminist critique of antidiscrimination doctrine, feminist theory and antiracist politics. University of Chicago Legal Forum, 14, 538-554.

Crystal, D. (2001). Language and the Internet. Cambridge University Press.

Cushion, S., Kilby, A., Thomas, R., Morani, M., \& Sambrook, R. (2018). Newspapers, Impartiality and Television News: Intermedia agenda-setting during the 2015 UK General Election campaign. Journalism Studies, 19(2), 162-181.

Dailey-O'Cain, J. (2000). The Sociolinguistic Distribution of and Attitudes toward Focuser Like and Quotative Like. Journal of Sociolinguistics, 4(1), 60-80.

Danet, B. (1998). "Text as mask: Gender, play and performance on the internet." In S. Jones (Ed.), Revisiting Computer-Mediated Communication and Community (pp. 129-158). Sage.

Darvin, R. (2016). Language and identity in the digital age. In S. Preece (Ed.), The Routledge Handbook of Language and Identity (pp. 523-540). Routledge.

Darvin, R., \& Norton, B. (2015). Identity and a model of investment in Applied Linguistics. Annual Review of Applied Linguistics, 35, 36-56. 
Das, D., \& Clark, A. J. (2018). Sarcasm detection on Facebook: A supervised learning approach. Proceedings of the International Conference on Multimodal Interaction Adjunct - ICMI '18, 1-5. https://doi.org/10.1145/3281151.3281154

Davies, B., \& Harré, R. (1990). Positioning: The discursive production of selves. Journal for the Theory of Social Behavior, 20(1), 43-63.

Davis, K. (2008). Intersectionality as buzzword: A sociology of science perspective on what makes a feminist theory successful. Feminist Theory, 9(1), 67-85.

Dawson, S. V. (2019). Identities and Ideologies in Study Abroad Contexts: Negotiating Nationality, Gender, and Sexuality [Ph.D Dissertation]. Victoria University of Wellington.

De Costa, P. I. (2010). Language ideologies and standard English language policy in Singapore: Responses of a "designer immigrant" student. Language Policy, 9(3), 217-239.

De Fina, A. (2003). Identity in Narrative. John Benjamins.

De Fina, A. (2007). Code-switching and the construction of ethnic identity in a community of practice. Language in Society, 36(3), 371-392.

De Fina, A. (2011). Discourse and identity. In Discourse studies: A multidisciplinary introduction (2 $2^{\text {nd }}$ ed., pp. 263-282). SAGE Publications Ltd.

De Fina, A. (2012). Discourse and Identity. In The Encyclopedia of Applied Linguistics. Blackwell.

De Fina, A. (2015). Narrative and identities. In A. De Fina \& A. Georgakopoulou (Eds.), The handbook of narrative analysis (pp. 351-368). Wiley-Blackwell.

De Fina, A., Schiffrin, D., \& Bamberg, M. (2006). Discourse and Identity. Cambridge University Press.

De Fina, A., \& Tseng, A. (2017). Narrative in the study of immigration. In S. Canagarajah (Ed.), The Routledge handbook of migration and language (pp. 381-396). Routledge.

De Ruyter, D., \& Conroy, J. (2002). The Formation of Identity: The importance of ideals. Oxford Review of Education, 28(4), 509-522.

Dervin, F. (2015). Discourses of Othering. In Karen Tracy, T. Sandel, \& C. Ilie (Eds.), The International Encyclopedia of Language and Social Interaction. John Wiley \& Sons Ltd. https://doi.org/10.1002/9781118611463.wbielsi027 
Desjarlais, R. R. (1997). Shelter blues: Sanity and selfhood among the homeless. University of Pennsylvania Press.

Diakopoulos, N. A., \& Naaman, M. (2011). Towards quality discourse in online news comments. In CsCW' 11 Proceedings of the ACM 2011 conference on computer supported cooperative work (pp. 133-142). NY: ACM.

Dobrowsky, D. (2012). Constructing identity on social networks: An analysis of competences of communication constituted on Facebook.com. Central European Journal of Communication, 1(8), 91-102.

Domingo, D., \& Heinonen, A. (2008). Weblogs and journalism: A typology to explore the blurring boundaries. Nordicom Review, 29(1), 3-15.

Domingo, D., Quandt, T., Heinonen, A., Paulussen, S., Singer, J., \& Vunjnovic, M. (2008).

Participatory journalism practices in the media and beyond. Journalism Practice, 2(3), $326-342$.

Douai, A., \& Nofal, H. K. (2012). Commenting in the online Arab public sphere: Debating the Swiss Minaret Ban and the "Ground Zero Mosque" online. Journal of Computer-Mediated Communication, 17(3), 266-282.

Drainville, R., \& Saul, J. (forthcoming). Visual and Linguistic Dogwhistles. In L. Anderson \& E. Lepore (Eds.), Oxford Handbook of Applied Philosophy of Language.

Duderija, A. (2007). Literature Review: Identity Construction in the Context of Being a Minority Immigrant Religion: The Case of Western-born Muslims. Immigrants \& Minorities, 25(2), $141-162$.

Duff, P. (2015). Transnationalism, multilingualism, and identity. Annual Review of Applied Linguistics, 35, 57-80.

Duffy, B., \& Rowden, L. (2005). You Are What You Read? How Newspaper Readership is Related to Views. MORI.

Dunn, D. (2006). Mediating the Tourist destination in British Television Holiday Programmes. Tourist Studies, 6, 37-58.

Durante, M. (2011). The Online Construction of Personal Identity Through Trust and Privacy. Information, 2(4), 594-620. 
Duranti, A. (2004). Agency in language. In A. Duranti (Ed.), A companion of linguistic anthropology. Blackwell.

Dynel, M., \& Poppi, F. I. M. (2018). In tragoedia risus: Analysis of dark humour in post-terrorist attack discourse. Discourse \& Communication, 12(4), 382-400.

Eckert, P. (2008). Variation and the indexical field. Journal of Sociolinguistics, 12(4), 453-476.

Eckert, P., \& McConnell-Ginet, S. (2013). Language and gender (2 ${ }^{\text {nd }}$ ed.). Cambridge University Press.

Ehrlich, S. (2008). Sexual assault trials, discursive identities and institutional change. In R. Dolon \& J. Todoli (Eds.), Analysing identities in discourse. John Benjamins Publishing Company.

Ellison, N. B., \& Vitak, J. (2015). Social network site affordances and their relationship to social capital processes. In S. S. Sundar (Ed.), The Handbook of the Psychology of Communication Technology (pp. 205-227). Wiley-Blackwell.

Ellison, N., Steinfield, C., \& Lampe, C. (2007). The Benefits of Facebook "Friends": Social Capital and College Students' Use of Online Social Network Sites. Journal of Computer-Mediated Communication, 12(4), 1143.

Eranti, V., \& Lonkila, M. (2015). The social significance of the Facebook Like button. First Monday, 20(6). https://doi.org/10.5210/fm.v20i6.5505

Facer, K. (2011). Learning futures: Education, technology and social change. Routledge.

Fairclough, N. (1992). Discourse and social change. Polity Press.

Fairclough, N. (2001). Language and Power (2 ${ }^{\text {nd }}$ ed.). Pearson Education Ltd.

Fasulo, A., \& Zucchermaglio, C. (2002). My selves and I: Identity markers in work meeting talk. Journal of Pragmatics, 34(9), 1119-1144.

Fisher, K. T. (2015). Positionality, Subjectivity, and Race in Transnational and Transcultural Geographical Research. Gender, Place, and Culture, 22(4), 456-473.

Fishman, J. A. (Ed.). (1968). Readings in the Sociology of Language. Mouton.

Flanagan, O. (1991). Varieties of Moral Personality. Harvard University Press.

Frank, J. (1990). You call that a rhetorical question? Journal of Pragmatics, 14(5), 723-738. 
Frischlich, L., Boberg, S., \& Quandt, T. (2019). Comment Sections as Targets of Dark Participation? Journalists' Evaluation and Moderation of Deviant User Comments. Journalism Studies, 20(14), 2014-2033.

Fuller, J. M. (2003). The influence of speaker roles on discourse marker use. Journal of Pragmatics, 35(1), 23-45.

Galbin, A. (2014). An introduction to social constructionism. Social Research Reports, 26, 82-92.

Galitsky, B. (2017). Discovering Rhetoric Agreement between a Request and Response. Dialogue \& Discourse, 8(2), 167-205.

Garfinkel, H. (1963). A conception of, and experiments with, "trust" as a condition of stable concerted actions. In O. J. Harvey (Ed.), Motivation and social interaction. Ronald Press.

Gavin, N. T. (2018). Media definitely do matter: Brexit, immigration, climate change and beyond. The British Journal of Politics and International Relations, 20(4), 827-845.

Gazdar, G. (1979). Pragmatics. Academic Press.

Gee, J. P. (1990). Social linguistics and literacies: Ideology in discourses. Taylor \& Francis.

Gee, J. P. (2015). Social linguistics and literacies: Ideology in discourses (Fifth edition). Routledge, Taylor \& Francis Group.

Gee, J. P. (2005c). An Introduction to Discourse Analysis: Theory and Method. Routledge.

Gee, J. P. (2005a). Meaning Making, Communities of Practice, and Analytical Toolkits. Journal of Sociolinguistics, 9(4), 590-594.

Gee, J. P. (2005b). Semiotic Social Spaces and Affinity Spaces: From "The Age of Mythology" to Today's Schools. In D. Barton \& K. Tusting (Eds.), Beyond Communities of Practice (pp. 214-232). Cambridge University Press.

Georgalou, M. (2016). 'I make the rules on my Wall': Privacy and identity management practices on Facebook. Discourse \& Communication, 10(1), 40-64.

Ghosh, D., Fabbri, A. R., \& Muresan, S. (2018). Sarcasm Analysis Using Conversation Context. Computational Linguistics, 44(4), 755-792.

Gibbons, M. (2014). Newspaper quality, content and competition in New Zealand. Pacific Journalism Review, 20(1), 181-199. 
Gibson, R. (2018). Same-Sex Marriage and Social Media: How Online Networks Accelerated the Marriage Equality Movement (1st ed.). Routledge.

Giddens, A. (1991). Modernity and self-identity: Self and society in the late modern age. Polity Press.

Giles, H., Coupland, N., \& Coupland, J. (1991). Accommodation theory: Communication, context, and consequence. In H. Giles, N. Coupland, \& J. Coupland (Eds.), Contexts of accommodation: Developments in applied sociolinguistics (pp. 1-68). Cambridge University Press.

Giles, H., \& Giles, J. (2013). Ingroups and Outgroups. In A. Kurylo (Ed.), Inter/Cultural Communication: Representation and Construction of Culture (pp. 141-162). SAGE Publications, Inc.

Gilpin, D. R. (2011). Working the twittersphere: Microblogging as professional identity construction. In Z. Papacharissi (Ed.), A Networked Self (pp. 232-251). Routledge.

Given, L. M. (Ed.). (2008). The Sage encyclopedia of qualitative research methods. Sage Publications.

Goffman, E. (1955). On face-work: An analysis of ritual elements in social interaction. Psychiatry: Journal for Teh Study of Interpersonal Processes, 18, 213-231.

Goffman, E. (1964). The neglected situation. American Anthropologist, 66, 133-136.

Goffman, E. (1967). Interaction Ritual: Essays on Face-to-Face Behavior. Anchor Books.

Goffman, E. (1971). Relations in public: Microstudies of the public order. Penguin.

Goffman, E. (1972). On Face-Work: An analysis of ritual elements in Social Interaction. In J. Laver \& S. Hutcheson (Eds.), Communication in Face-to-Face Interaction (pp. 319-346). Penguin.

Goffman, E. (1981). Forms of Talk. University of Pennsylvania Press.

Goffman, E. (1983). The interaction order: American Sociological Association, 1982 presidential address. American Sociological Review, 48, 1-17.

Goffman, E. (1989). The Interaction Order. American Sociological Review, 48, 1-17.

Goffman, E. (1990). The presentation of self in everyday life. Penguin. 
Golash-Boza, T. (2010). Does Whitening Happen? Distinguishing between Race and Color Labels in an African-Descended Community in Peru. Social Problems, 57(1), 138-156.

Goodwin, J., Zemplén, G., \& Kutrovátz, G. (2011). Accounting for the Appeal to Authority of Experts. Argumentation, 25(3), 285-296.

Gordon, C. (2011). Gumperz and interactional sociolinguistics. In R. Wodak, B. Johnstone, \& P. Kerswill (Eds.), The SAGE handbook of sociolinguistics (pp. 67-84). Sage Publications.

Gordon, C. (2003). Aligning as a team: Forms of conjoined participation in (stepfamily) interactions. Research on Language and Social Interaction, 36(4), 395-431.

Gramsci, A. (1971). Selections from the Prison Notebooks of Antonio Gramsci. International Publisher.

Grant, A. (2016). "I...don't want to see you flashing your bits around": Exhibitionism, othering and good motherhood in perceptions of public breastfeeding. Geoforum, 71, 52-61.

Greenbank, E. (2020). Discursive navigation of employable identities in the narratives of former refugees. John Benjamins Publishing Company.

Greenbank, E., \& Marra, M. (forthcoming). Narrating belonging: Realising the impact of self and other positioning in former refugees' stories of flight. Language and Intercultural Communication Special Issue on Translational Research: Language, Intercultural Communication and Social Action.

Greenfield, P. M., Gross, E. F., Subrahmanyam, K., Suzuki, L. K., Tynes, B. M., \& Kraut, R. (2006). Teens on the Internet: Interpersonal connection, identity, and information. In R. Kraut, M. Brynin, \& S. Kiesler (Eds.), Computers, phones, and the Internet: Domesticating information technology (pp. 185-200). Oxford University Press.

Grice, T. A., Jones, E., Paulsen, N., \& Callan, V. J. (2006). "We Do It, but They Don't": Multiple Categorizations and Work Team Communication. Journal of Applied Communication Research, 34(4), 331-348.

Grosz, E. (1994). Volatile bodies: Toward a corporeal feminism. Indiana University Press.

Guest, G., Bunce, A., \& Johnson, L. (2006). How Many Interviews Are Enough?: An Experiment with Data Saturation and Variability. Field Methods, 18(1), 59-82. 
Gumperz, J. J. (1964). Linguistic and Social Interaction in Two Communities. American Anthropologist, 66(6), 137-153.

Gumperz, J. J. (1982). Discourse Strategies. Cambridge University Press.

Gumperz, J. J. (2001). Contextualization and ideology in intercultural communication. Pragmatics and beyond New Series, 35-54.

Gumperz, J. J. (2005). Interactional Sociolinguistics: A Personal Perspective. In D. Schiffrin, D. Tannen, \& H. E. Hamilton (Eds.), The Handbook of Discourse Analysis (pp. 215-228). Blackwell Publishing Ltd.

Gumperz, J. J., \& Cook-Gumperz, J. (2008). Studying language, culture, and society: Sociolinguistics or linguistic anthropology? Journal of Sociolinguistics, 12(4), 523-545.

Gumperz, J. J., \& Hymes, D. (1972). Directions in sociolinguistics: The ethnography of speaking. Rinehart and Winston.

Harmash, L., Khalanska, N., Melnyk, S., Nevelska-Hordieieva, O., \& Razumenko, I. (2020). Semantic and Pragmatic Presuppositions in Postmodern Text. Journal of History Culture and Art Research, 9(3), 168.

Hassa, S. (2012). Projecting, Exposing, Revealing Self in the Digital World: Usernames as a Social Practice in a Moroccan Chatroom. Names, 60(4), 201-209.

Hatoss, A. (2012). Where are you from? Identity construction and experiences of "othering" in the narratives of Sudanese refugee-background Australians. Discourse \& Society, 23(1), 47-68.

Hays, R. B. (1989). Echos of scripture in the letters of Paul. Yale University Press.

Heller, M. (2013). Gumperz and social justice. Journal of Linguistic Anthropology, 23(3), 192-198.

Hemmatian, B., Sloman, S. J., Cohen Priva, U., \& Sloman, S. A. (2019). Think of the consequences: A decade of discourse about same-sex marriage. Behavior Research Methods, 51(4), 1565-1585.

Henderson, R., \& McCready, E. (2018). How Dogwhistles Work. In S. Arai, K. Kojima, K. Mineshima, D. Bekki, K. Satoh, \& Y. Ohta (Eds.), New Frontiers in Artificial Intelligence (Vol. 10838, pp. 231-240). Springer International Publishing. 
Hercheui, M. D. (2011). A LITERATURE REVIEW OF VIRTUAL COMMUNITIES: The relevance of understanding the influence of institutions on online collectives. Information, Communication \& Society, 14(1), 1-23.

Herring, S. C. (2001). Computer-mediated discourse. In D. Schiffrin, D. Tannen, \& H. E. Hamilton (Eds.), The Handbook of Discourse Analysis (pp. 612-634). Malden.

Herring, S. C. (2004). Computer-mediated discourse analysis: An approach to researching online behaviour. In S. A. Barab, R. Kling, \& J. H. Gray (Eds.), Designing for Virtual Communities in the Service of Learning (pp. 338-376). Cambridge University Press.

Herring, S. C. (2008). Virtual community. In Encyclopedia of Qualitative Research Methods (pp. 920-921). Sage.

Herring, S. C. (2013). Discourse in Web 2.0: Familiar, Reconfigured, and Emergent. In D. Tannen \& A. M. Trester (Eds.), Discourse 2.0: Language and New Media (pp. 1-25). Georgetown University Press.

Herring, S. C. (2005). Computer-mediated communication on the internet. Annual Review of Information Science and Technology, 36(1), 109-168.

Himma-Kadakas, M. (2017). Alternative facts and fake news entering journalistic content production cycle. Cosmopolitan Civil Societies: An Interdisciplinary Journal, 9(2), 25-40.

Hodges, A. (2015). Intertextuality in Discourse. In D. Tannen, H. E. Hamilton, \& D. Schiffrin (Eds.), The Handbook of Discourse Analysis (2 ${ }^{\text {nd }}$ ed., pp. 42-60). Wiley-Blackwell.

Hodkinson, P., \& Lincoln, S. (2008). Online journal as virtual bedrooms? Young: Nordic Journal of Youth Research, 16, 27-46.

Hodsdon-Champeon, C. (2010). Conversations within Conversations: Intertextuality in Racially Antagonistic Online Discourse. Language@Internet, 7, article 10.

Höflich, J. R. (1997). "Electronic communities" as social worlds: Toward a sociosemiotic analysis of computer mediated interpersonal communication. In W. Nöth (Ed.), Semiotics of the Media (pp. 507-518). Mouton de Gruyter.

Hogg, M. A., \& Terry, D. J. (2000). Social Identity and Self-Categorization Processes in Organizational Contexts. Academy of Management Review, 25(1), 121-140. 
Holmes, J. (2006). Gendered talk at work: Constructing social identity through workplace interaction. Blackwell.

Holmes, J. (2007). Social constructionism, postmodernism and feminist sociolinguistics. Gender \& Language, 1(1), 51-65.

Holmes, J. (2008). Gendered talk at work: Constructing gender identity through workplace discourse (Vol. 3). Blackwell Publishing.

Holmes, J. (2013). An introduction to sociolinguistics (4th ed.). Routledge.

Holmes, J. (2018). Negotiating the culture order in New Zealand workplaces. Language in Society, 47(1), 33-56.

Holmes, J., \& Marra, M. (2002). Over the edge? Subversive humor between colleagues and friends. Humor, 15(1), 65-87.

Holmes, J., \& Marra, M. (2004). Leadership and managing conflict in meetings. Pragmatics. Quarterly Publication of the International Pragmatics Association (IPrA), 14(4), 439-462.

Holmes, J., \& Marra, M. (2011). Leadership discourse in a Māori workplace: Negotiating gender, ethnicity and leadership at work. Gender \& Language, 5(2), 317-342.

Holmes, J., \& Marra, M. (2017). You're a proper tradesman: Identity struggles and workplace transitions in New Zealand. In D. van de Mieroop \& S. Schnurr (Eds.), Identity Struggles: Evidence from workplacs around the world (pp. 127-146). John Benjamins.

Holmes, J., Marra, M., \& Lazzaro-Salazar, M. (2016). Negotiating the tall poppy syndrome in New Zealand workplaces: Women leaders managing the challenge. Gender and Language, 11(1), 1-29.

Holmes, J., Marra, M., \& Vine, B. (2011). Leadership, discourse, and ethnicity. Oxford University Press.

Holmes, J., \& Meyerhoff, M. (1999). The community of practice: Theories and methodologies in language and gender research. Language in Society, 28(2), 173-183.

Holmes, J., \& Stubbe, M. (2015). Power and politeness in the workplace: A sociolinguistic analysis of talk at work ( $2^{\text {nd }}$ ed.). Routledge.

Hoskins, K. (2015). Researching Female Professors: The Difficulties of Representation, Positionality and Power in Feminist Research. Gender and Education, 27, 393-411. 
Howie, D., \& Peters, M. (1996). Positioning Theory: Vygotsky, Wittgenstein and Social Constructionist Psychology. Journal for the Theory of Social Behaviour, 26(1), 51-64.

Hua, Z. (2017). New orientations to identities in mobility. In S. Canagarajah (Ed.), The Routledge handbook of migration and language (pp. 117-132). Routledge.

Hutchens, M. J., Silva, D. E., Hmielowski, J. D., \& Cicchirillo, V. J. (2019). What's in a username? Civility, group identification, and norms. Journal of Information Technology \& Politics, 16(3), 203-218.

Hymes, D. (1974). Foundations in Sociolinguistics: An Ethnographic Approach. University of Pennsylvania Press.

Ínigo-Mora, I. (2004). On the use of the personal pronoun we in communities. Journal of Language and Politics, 3(1), 27-52.

Islentyeva, A. (2019). The Europe of Scary Metaphors: The Voices of the British Right-Wing Press. Zeitschrift Für Anglistik Und Amerikanistik, 67(3), 209-229.

Jakobson, R. (1953). “Discussion in Claude Lévi-Strauss, Roman Jakobson, Carl F. Voegelin, and Thomas A. Sebeok," Results of the Conference of Anthropologists and Linguistics. International Journal of American Linguistics Memoir, 8, 11-21.

Janks, H. (1997). Critical Discourse Analysis as a Research Tool. Stuides in the Cultural Politics of Education, 18(3), 329-342.

Jaspers, J. (2011). Interactional sociolinguistics and discourse analysis. In J. P. Gee \& M. Handford (Eds.), The Routledge Handbook of Discourse Analysis (pp. 135-146). Routledge.

Jaworski, A., \& Coupland, J. (2005). Othering in gossip: "you go out you have a laugh and you can pull yeah okay but like..." Language in Society, 34, 667-694.

Jaworski, A., \& Thurlow, C. (2009). Taking an Elitist Stance: Ideology and the Discursive Production of Social Distinction. In A. Jaffe (Ed.), Stance: Sociolinguistic Perspective (pp. 195-226). Oxford University Press.

Jay, T. (2009). The utility and ubiquity of taboo words. Perspectives on Psychnological Science, 4, 153-161.

Jenkins, R. (2010). The 21st century interaction order. In M. Hviid Jacobsen (Ed.), The contemporary Goffman (pp. 257-274). Routledge. 
Jones, S. (1995). Understanding community in the information age. In S. Jones (Ed.), Cybersociety: Computer-mediated Communication and Community (pp. 10-35). Sage. Jones, S. (1998). Cybersociety 2.0: Revisiting Computer Mediated Communication and Community. Sage.

Jonsson, T. (2014). White Feminist Stories: Locating race in representations of feminism in The Guardian. Feminist Media Studies, 14(6), 1012-1027.

Jucker, A. H., \& Smith, S. W. (1998). And people just you know like "wow": Discourse markers as negotiatinig strategies. In A. H. Jucker \& Y. Ziv (Eds.), Discourse markers: Descriptions and theory (pp. 171-201). Benjamins.

Kammer, A. (2020). Audience Participation in the Production of Online News: Towards a Typology. Nordicom Review, 34(s1), 113-126. https://doi.org/10.2478/nor-2013-0108 Kangasharju, H. (1996). Aligning as a team in multiparty conversation. Journal of Pragmatics, 26(3), 291-319.

Kaposi, D. (2019). Hope and dread in representing Palestine-Israel: A case study of editorials in the British broadsheets. Critical Discourse Studies, 16(1), 40-55.

Karim, K. H. (Ed.). (2003). The Media of Diaspora. Mapping the Globe. Routledge.

Kasperiuniene, J., \& Zydziunaite, V. (2019). A Systematic Literature Review on Professional Identity Construction in Social Media. SAGE Open, 9(1), 1-11.

Kayı-Aydar, H. (2019). Positioning Theory and Discourse Analysis. In H. Kayı-Aydar, Positioning Theory in Applied Linguistics (pp. 27-40). Springer International Publishing.

Kempson, R. (1975). Presupposition and the delimitation of semantics. Cambridge University Press.

Kerry, V. J. (2019). Stance, Same-Sex Marriage and Space: An Analysis of Self-Referencing on YouTube [Ph.D Dissertation]. Massey University.

Kersten, S., \& Lotze, N. (2020). Creating a Self-Image: Face-Work and Identity Construction Online. Journal Für Medienlinguistik, 2(2), 123-156.

Khoja-Moolji, S. (2014). Poststructuralist approaches to teaching about Gender, Islam, and Muslim societies. Feminist Teacher, 24(3), 169-183. 
Kidner, K. (2015). Beyond Greenwash: Environmental Discourses of Appropriation and Resistance [Ph.D Dissertation]. Victoria University of Wellington.

Kiesling, S. F. (2004). DUDE. American Speech, 79(3), 281-305.

Kiesling, S. F. (2006). Hegemonic identity-making in narrative. In A. De Fina, D. Schiffrin, \& M. Bamberg (Eds.), Discourse and identity (pp. 261-287). Cambridge University Press.

Kiesling, S. F. (2013). Constructing identity. In J. Chambers \& N. Schilling (Eds.), The Handbook of Language Variation and Change ( $2^{\text {nd }}$ ed., pp. 448-467). John Wiley \& Sons.

King, B. W. (2011). Linguistic negotiations of sexual agency in sexuality education [Ph.D Dissertation]. Victoria University of Wellington.

King, B. W. (2019). Communities of practice in applied language research: A critical introduction. Routledge/Taylor \& Francis Group.

Kirilova, M., \& Angouri, J. (2018). You are now one of us - Negotiating "fitting in" in the workplace. In Angela Creese \& A. Blackledge (Eds.), The Routledge Handbook of Language and Superdiversity. Routledge.

Koch, J. W. (2002). Gender Stereotypes and Citizens' Impressions of House Candidates' Ideological Orientations. American Journal of Political Science, 46(2), 453-462.

Korsgaard, C. M. (2009). Self-constitution: Agency, identity, and integrity. Oxford University Press. Kouper, I. (2010). The Pragmatics of Peer advice in a LiveJournal Community. Language@Internet, 7, article 1.

Kristeva, J. (1980). Desire in language: A semiotic approach to literature and art. Columbia University Press.

Kristeva, J. (1986). The Kristeva Reader (T. Moi, Ed.). Blackwell.

Kroskrity, P. V. (2000a). Language Ideologies in the Expressions and Representation of Arizona Tewa Ethnic Identity. In P. V. Kroskrity (Ed.), Regimes of Language: Ideologies, Politics, and Identities (pp. 329-359). School of American Research Press.

Kroskrity, P. V. (2000b). Regimes of language: Ideologies, Politics, and Identities. School of American Research Press.

Kugle, S. A. (2010). Homosexuality in Islam: Critical reflection on gay, lesbian and transgender Muslims. Oneworld. 
Kunneman, F., Liebrecht, C., van Mulken, M., \& van den Bosch, A. (2015). Signaling sarcasm: From hyperbole to hashtag. Information Processing \& Management, 51(4), 500-509. Kwon, K. H., \& Cho, D. (2017). Swearing Effects on Citizen-to-Citizen Commenting Online: A Large-Scale Exploration of Political Versus Nonpolitical Online News Sites. Social Science Computer Review, 35(1), 84-102.

Kytölä, S. (2013). Multilingual Language Use and Metapragmatic Reflexivity in Finnish Internet Football Forums: A Study in the Sociolinguistics of Globalization [Ph.D Dissertation]. University of Jyväskylä.

Kytölä, S. (2014). Negotiating Multilingual Discourse in a Finland-Based Online Football Forum: Metapragmatic Reflexivity on Intelligibility, Expertise and "Nativeness." Copenhagen Studies in Bilingualism, 70(1), 81-122.

Kytölä, S. (2017). "Are they singing the National Anthem?": Football followers' responses to the ethnic diversification of Finland Men's National Football Team. In S. Leppänen, E. Westinen, \& S. Kytölä (Eds.), Social Media Discourse, (Dis)Identifications and Diversities (pp. 62-93). Routledge.

Kytölä, S., \& Westinen, E. (2015). “I Be Da Reel Gansta” - A Finnish Footballer's Twitter Writing and Metapragmatic Evaluations of Authenticity. Discourse, Context \& Media, 8(1), 6-19.

Labov, W. (1966). The Social Stratification of English in New York City. Center for Applied Linguistics.

Labov, W. (1972). Sociolinguistic Patterns. Blackwell.

Lammers, J. C., Curwood, J. S., \& Magnifico, A. M. (2012). Toward an Affinity Space Methodology: Considerations for Literacy Research. English Teaching: Practice and Critique, 11(2), 4458.

Landert, D., \& Jucker, A. H. (2011). Private and public in mass media communication: From letters to the editor to online commentaries. Journal of Pragmatics, 43(5), 1422-1434.

Larsson, A. O. (2018). Thumbs up, thumbs down? Likes and dislikes as popularity drivers of political YouTube videos. First Monday.

Laughey, D. (2007). Key themes in media theory. Open University Press. 
Lave, J., \& Wenger, E. (1991). Situated learning: Legitimate peripheral participation. Cambridge University Press.

Lazzaro-Salazar, M. V. (2013). Investigating nurses' professional identity construction in two health settings in New Zealand [Ph.D Dissertation]. Victoria University of Wellington.

Lazzaro-Salazar, M. V. (2017). Ingroups and Outgroups in Complaints: Exploring Politic Behaviour in Nurses' Discourse. Logos: Revista de Lingüística, Filosofía y Literatura, 27(2), 319-333.

Lee, E.-J., \& Jang, Y. J. (2010). What Do Others' Reactions to News on Internet Portal Sites Tell Us? Effects of Presentation Format and Readers' Need for Cognition on Reality Perception. Communication Research, 37(6), 825-846.

Lee, R. C., \& Wong, S. C. (Eds.). (2003). Asian America.Net: Ethnicity, Nationalism, and Cyberculture. Routledge.

Lehtonen, S. (2017). "I just don't know what went wrong" - Neo-sincerity and doing gender and age otherwise in a discussion forum for Finnish fans of My Little Pony. In S. Leppänen, E. Westinen, \& S. Kytölä (Eds.), Social media discourse, (Dis)identifications and diversities (pp. 287-309). Routledge.

Leonardo, Z. (2004). The Color of Supremacy: Beyond the discourse of 'white privilege.' Educational Philosophy and Theory, 36(2), 137-152.

Leppänen, S., Kytölä, S., Jousmäki, S. P., \& Westinen, E. (2012). Entextualization and Resemiotization as Resources for Identification in Social Media. In P. Seargeant \& C. Tagg (Eds.), The Language of Social Media (pp. 112-138). Palgrave Macmillan.

Leppänen, S., Møller, J. S., Nørreby, T. R., \& Stæhr, A. (2015). Authenticity, Normativity and Social Media. Discourse, Context \& Media, 8(1), 1-5.

Lerner, G. H. (1993). Collectivities in action: Establishing the relevance of conjoined participation in conversation. Text, 13(2), 213-245.

Lester, D. (2010). A multiple self theory of personality. Nova Science.

Liashuk, X. (2019). Reflection of Ideology and Politics in Travel Writing: America and Russia in Each Other's Mirror, 1930s-1940s. In Ö. Çakırtaş (Ed.), Language, Power, and Ideology in Political Writing: Emerging Research and Opportunities (pp. 80-104). IGI Global. 
Liebrecher, G., Dailey-O’Cain, J., Müller, M., \& Reichert, T. (2010). Negotiating identities through pronouns of address in an immigrant community. Pragmatics, 20(3), 375-400.

Liu, Chengbo. (2019). Book review: Ruth Page, Narratives Online: Shared Stories in Social Media. Discourse Studies, 21(3), 368-370.

Liu, G. Z. (1999). Virtual community presence in Internet Relay Chatting. Journal of ComputerMediated Communication, 5(1).

Liu, H. (2007). Social Network Profiles as Taste Performances. Journal of Computer-Mediated Communication, 13(2), art.13.

Locher, M. A., \& Mondada, L. (2014). Linguistics and the new media. Dichtung Digital- Journal Für Kunst Und Kultur Digitaler Medien, 44. http://www.dichtung-digital.de/journal/aktuellenummer/?postID=2538

Lønsmann, D. (2016). Negotiating Positionality in Ethnographic Investigations of Workplace Settings: Student, Consultant or Confidante? In G. M. Alessi \& G. Jacobs (Eds.), The Ins and Outs of Business and Professional Discourse Research: Reflections on Interacting with the Workplace (pp. 13-36). Palgrave Macmillan.

Lucius-Hoene, G., \& Deppermann, A. (2000). Narrative identity empiricized: A dialogical and positioning approach to autobiographical research interviews. Narrative Inquiry, 10(1), 199-222.

MacNaughton, G., Davis, K., \& Smith, K. (2009). Exploring “Race-Identities" with young children: Making politics visible. In G. MacNaughton \& K. Davis (Eds.), Race and early childhood education: An international approach to identity, politics, and pedagogy (pp. 31-47). Palgrave Macmillan.

Madden, A., Ruthven, I., \& McMenemy, D. (2013). A classification scheme for content analyses of YouTube video comments. Journal of Documentation, 69(5), 693-714.

Maingueneau, D. (1987). Nouvelles tendances en analyse du discourse. Hachette.

Manosevitch, E., \& Walker, D. (2009). Readers comments to online opinion journalism: A space of public deliberation. 10th International Symposium on online Journalism. Texas.

Marotta, V. (2011). New Online Ethnicities and the Politics of Representation. Journal of Intercultural Studies, 32(5), 539-553. 
Marra, M., \& Angouri, J. (2011). Investigating the Negotiation of Identity: A view from the Field of Workplace Discourse. In J. Angouri \& M. Marra (Eds.), Constructing Identities at Work (pp. 1-14). Palgrave Macmillan UK.

Marra, M. (2012a). Disagreeing without being disagreeable: Negotiating workplace communities as an outsider. Journal of Pragmatics, 44(12), 1580-1590.

Marra, M. (2012b). Discourse analysis and conversation analysis. In C. A. Chapelle (Ed.), The Encyclopedia of Applied Languages. Wiley-Blackwell.

Marra, M., \& Holmes, J. (2007). Humor across cultures: Joking in the multicultiral workplace. In H. Kotthoff \& H. Spencer-Oatey (Eds.), Handbook of Intercultural Communication (pp. 153-172). de Gruyter.

Marra, M., \& Holmes, J. (2008). Constructing ethnicity in New Zealand workplace stories. Text \& Talk, 28(3), 397-419.

Martin, J. N., Krizek, R. L., Nakayama, T. K., \& Bradford, L. (1996). Exploring whiteness: A study of self labels for white Americans. Communication Quarterly, 44(2), 125-144.

Marwick, A. E. (2013). Online Identity. In J. Hartley, J. Burgess, \& A. Bruns (Eds.), A Companion to New Media Dynamics (pp. 355-364). Blackwell Publishing Ltd.

Maydell, E. (2010). The making of cosmopolitan selves: The construction of identity of Russianspeaking immigrants in New Zealand [Ph.D Dissertation]. Victoria University of Wellington.

McCluskey, M., \& Hmielowski, J. (2011). Opinion expression during social conflict: Comparing online reader comments and letters to the editor. Journalism, 13(3), 303-319.

McConnell, A. R. (2011). The Multiple Self-aspects Framework: Self-concept Representation and Its Implications. Personality and Social Psychology Review, 15(1), 3-27.

McDowell, J., Lazzaro-Salazar, M., \& Marra, M. (2020). A discourse of caring a case study of male nurses' discourse and identity construction in the United Kingdom and New Zealand. In J. McDowell (Ed.), De-Gendering Gendered Occupations: Analysing Professional Discourse (pp. 62-83). Routledge.

McElhinny, B. (1996). Strategic Essentialism in Sociolinguistic Studies of Gender. In N. Warner, J. Ahlers, L. Bilmes, M. Oliver, S. Wertheim, \& M. Chen (Eds.), Gender and Belief Systems: 
Proceedings of the Fourth Berkeley Women and Language Conference (pp. 469-480). Berkeley Women and Language Group.

Mckee, H. A., \& Porter, J. E. (2012). The ethics of conducting writing research on the Internet: How heuristics help. In L. Nickoson \& M. P. Sheridan (Eds.), Writing studies research in practice: Methods and musings (pp. 245-260). Southern Illinois University Press.

McMenamin, I. (2012). If Money Talks, What Does It Say? Varieties of Capitalism and Business Financing of Parties. World Politics, 64(1), 1-38.

Meadows, B. (2009). Capital negotiation and identity practices: Investigating symbolic capital from the "ground up". Critical Discourse Studies, 6(1), 15-30.

Menard-Warwick, J. (2005). Both a fiction and an existential fact: Theorizing identity in second language acquisition and literacy studies. Linguistics and Education, 16(3), 253-274.

Menard-Warwick, J. (2009). Gendered identities and immigrant language learning. Multilingual Matters.

Menard-Warwick, J. (2014). English language teachers on the discursive faultlines: Identities, ideologies and pedagogies. Multilingual Matters.

Meyerhoff, M. (2013). Place and purpose: Indexicality in ecological perspective. In W. Vandenbussche, E. H. Jahr, \& P. Trudgill (Eds.), Language ecology for the 21st century: Linguistic conflict and social environments (pp. 267-291). Novus Press.

Millen, D. R., \& Patterson, J. F. (2003a). Identity disclosure and the creation of social capital. $\mathrm{CHI}$ 'O3 Extended Abstracts on Human Factors in Computing Systems - CHI '03, 720. https://doi.org/10.1145/765891.765950

Millen, D. R., \& Patterson, J. F. (2003b). Identity disclosure and the creation of social capital. CHI '03 Extended Abstracts on Human Factors in Computing Systems - CHI '03, 720-721. https://doi.org/10.1145/765891.765950

Miller, E. R. (2014). The language of adult immigrants: Agency in the making. Multilingual Matters.

Miller, H. (1995). The presentation of self in electronic life: Goffman on the Internet. Proceedings of the Embodied Knowledge and Virtual Space Conference. Proceedings of the embodied 
knowledge and virtual space conference, London.

https://doi.org/10.1177/0165551512470051

Miller, H., \& Arnold, J. (2003). Self in Web Home Pages: Gender, Identity and Power in Cyberspace. In G. Riva \& C. Galimberti (Eds.), Towards cyberpsychology: Mind, cognitions and society in the Internet age (pp. 73-94). IOS Press.

Miller, H., \& Arnold, J. (2009). Identity in cyberspace. In S. Wheeler (Ed.), Connected minds, emerging cultures: Cybercultures in online learning (pp. 53-64). IAP.

Mills, S. (1991). Discourses of difference: An analysis of women's travel writing and colonialism. Routledge.

Mills, S. (2003). Gender and Politeness. Cambridge University Press.

Mills, S. (2008). Language and sexism. Cambridge University Press.

Moberg, U., \& Eriksson, G. (2013). Managing ideological differences in joint political press conferences: A study of the strategic use of the personal pronoun "we." Journal of Language and Politics, 12(3), 315-334.

Moon, L. (2016). Counselling Ideologies: Queer Challenges To Heteronormativity. Taylor \& Francis Ltd.

Moyise, S. (2002). Intertextuality and Biblical Studies: A Review. Verbum et Ecclesia, 23(2), 418431.

Muresan, S., Gonzalez-Ibanez, R., Ghosh, D., \& Wacholder, N. (2016). Identification of nonliteral language in social media: A case study on sarcasm. Journal of the Association for Information Science and Technology, 67(11), 2725-2737.

Newon, L. (2011). Multimodal Creativity and Identities of Expertise in the Digital Ecology of a World of Warcraft Guild. In C. Thurlow \& K. Mroczek (Eds.), Digital Discourse: Language in the New Media. Oxford University Press.

Newon, L. (2016). Online Multiplayer Games. In A. Georgakopoulou \& T. Spilioti (Eds.), The Routledge Handbook of Language and Digital Communication (pp. 289-304). Routledge.

Nielsen, C. (2012). Newspaper journalists support online comments. Newspaper Research Journal, 33(1), 86-100. 
Nofal, M. Y. (2020). Multilingual Practices and Identity Negotiation among Multilingual Heritage Language Learners in New Zealand [Ph.D Dissertation]. Victoria University of Wellington.

Norton, B. (2000). Identity and language learning: Gender, ethnicity, and educational change. Longman.

Norton, B. (2001). Non-participation, imagined communities and the language classroom. In M. Breen (Ed.), Learner contributions to language learning: New directions in research (pp. 159-171). Pearson Education.

Norton, B. (2010). Language and identity. In N. Hornberger \& S. McKay (Eds.), Sociolinguistics and language education (pp. 349-369). Multilingual Matters.

Norton, B. (2013). Identity and language learning: Extending the conversation. Multilingual Matters.

Norton, B., \& Morgan, B. (2013). Poststructuralism. In C. Chapelle (Ed.), The Encyclopedia of Applied Linguistics. Wiley-Blackwell.

Ochs, E. (1990). Indexicality and socialization. In J. W. Stigler \& R. A. Shweder (Eds.), Cultural psychology: Essays on comparative human development (pp. 287-308). Cambridge University Press.

Ochs, E. (1992). Indexing gender. In A. Duranti \& C. Goodwin (Eds.), Rethinking context (pp. 335358). Cambridge University Press.

Ochs, E. (1993). Constructing social identity: A language socialization perspective. Research on Language and Social Interaction, 26(3), 287-306.

Ortner, S. (1995). Resistance and the problem of ethnographic refusal. Comparative Studies in Society and History, 37(1), 173-193.

Östman, J.-O. (1981). You Know: A discourse-functional approach: Vol. II:7. John Benjamins Publishing Company.

Oteiza, T. (2003). How contemporary history is presented in Chilean middle school textbooks. Discourse \& Society, 14(5), 639-660.

Oualif, M. (2017). Presupposition: A Semantic or Pragmatic Phenomenon? Arab World English Journal, 8(3), 46-59. 
Oughton, H. M. (2007). Constructing the "ideal reader": A critical discourse analysis of the adult numeracy core curriculum. Research in Post-Compulsory Education, 12(2), 259-275.

Oulasvirta, A., Lehtonen, E., Kurvinen, E., \& Raento, M. (2010). Making the ordinary visible in microblogs. Personal and Ubiquitous Computing, 14(3), 237-249.

Page, R. E. (2018). Narratives online: Shared stories in social media. Cambridge University Press.

Page, R. E. (2013). Stories and social media: Identities and interaction. Routledge.

Pantti, M., Nelimarkka, M., Nikunen, K., \& Titley, G. (2019). The meanings of racism: Public discourses about racism in Finnish news media and online discussion forums. European Journal of Communication, 34(5), 503-519. https://doi.org/10.1177/0267323119874253

Papacharissi, Z. (2009). The virtual geographies of social networks: A comparative analysis of Facebook, Linkedln and ASmallWorld. New Media \& Society, 11(1 \& 2), 199-220.

Park, G. (2015). Situating the discourses of privilege and marginalization in the lives of two East Asian women teachers of English. Race Ethnicity and Education, 18(1), 108-133.

Parker, D., \& Song, M. (2009). New ethnicities and the Internet: Belonging and the negotiation of difference in multicultural Britian. Cultural Studies, 23(4), 583-604.

Paterson, L. L., \& Coffey-Glover, L. (2018). Discourses of marriage in same-sex marriage debates in the UK press 2011-2014. Journal of Language and Sexuality, 7(2), 175-204.

Patrick, P. (2001). The speech community. In J. K. Chambers, P. Trudgill, \& N. Schilling-Estes (Eds.), The Handbook of Language Variation and Change (pp. 573-597). Blackwell.

Pavlenko, A., \& Blackledge, A. (2003). Negotiation of identities in multilingual contexts. Multilingual Matters.

Pavlik, J. V. (2013). INNOVATION AND THE FUTURE OF JOURNALISM. Digital Journalism, 1(2), 181-193.

Pears, D. (1985). The goals and strategies of self-deception. In J. Elster (Ed.), The multiple self (pp. 59-77). Cambridge University Press.

Pennycook, A. (2004). Global Englishes, rip slyme, and performativity. Journal of Sociolinguistics, 7, 523-533.

Perkel, D. (2008). Copy and Paste Literacy? Literacy Practices in the Production of a MySpace profile". In K. Drotner, H. S. Jensen, \& K. Schroeder (Eds.), Informal Learning and Digital 
Media: Constructions, Contexts, Consequences (pp. 203-224). Cambridge Scholars Publishing.

Perkins, R. (2008). An Oreo Ain't Nothing But A Cookie: An Analysis of Identity Struggles of African Americans in Desegregated Public Schools from 1950 to 1968. Journal of Interdisciplinary Research, 2(1), 111-126.

Pickering, B., Thompson, D., \& Filik, R. (2018). Examining the emotional impact of sarcasm using a virtual environment. Metaphor and Symbol, 33(3), 185-197.

Pirolli, B. (2017). Travel Journalists and Professional Identity: Ideology and evolution in an online era. Journalism Practice, 11(6), 740-759.

Poltecha, S. (2017). Stereotypical depiction of Thai women in Hollywood films [Master Thesis]. Thammasat University.

Porter, J. E. (1986). Intertextuality and the discourse community. Rhetoric Review, 5, 34-47.

Prantl, A. (2016). Identity construction in the comments section of TomandLorenzo.com [Master Thesis]. University of Jyväskylä.

Predelli, S. (2003). Scare Quotes and Their Relation to Other Semantic Issues. Linguistics and Philosophy, 26, 1-28.

Preece, J., \& Maloney-Krichmar, D. (2005). Online Communities: Design, Theory, and Practice. Journal of Computer-Mediated Communication, 10(4), 00-00.

Preece, J., Maloney-Krichmar, D., \& Abras, C. (2003). History of Online Communities. In K. Christensen \& D. Levinson (Eds.), Encyclopedia of Community: From Village to Virtual World (pp. 1023-1027). Sage Publications.

Psathas, G. (1999). Studying the organization in action: Membership categorization and interaction analysis. Human Studies, 22(2), 139-162.

Rafeeq, A., \& Jiang, S. (2020). Breaking news of disasters: How Stuff.co.nz and NZHerald.co.nz used Facebook and Twitter in the 2016 Kaikoura earthquake coverage in New Zealand. Cogent Social Sciences, 6(1), 1731121. https://doi.org/10.1080/23311886.2020.1731121

Rampton, B. (1998). Speech community. In J. Verschueren, J.-O. Östman, J. Blommaert, \& C. Bulcaen (Eds.), Handbook of Pragmatics (pp. 1-30). Benjamins.

Rampton, B. (2001). Critique in interaction. Critique of Anthropology, 21(1), 83-107. 
Rampton, B. (2017). Interactional sociolinguistics. Tilburg Papers in Cultural Studies, 175, 1-15.

Redeker, G. (1984). On differences between spoken and written language. Discourse Processes, $7(1), 43-55$.

Reich, Z. (2011). User comments: The transformation of participatory space. In Participatory journalism: Guarding open gates at online newspapers (pp. 96-117). Wiley-Blackwell.

Reisigl, M. (2017). The Discourse-Historical Approach. In J. Flowerdew, \& J. E. Richardson (Eds.), The Routledge Handbook of Critical Discourse Studies (pp. 44-59). Routledge.

Reisigl, M., \& Wodak, R. (2016). The discourse-historical approach. In R. Wodak, \& M. Meyer (Eds.), The Routledge Handbook of Critical Discourse Studies (3rd ed., pp. 23-61). Sage.

Rendle-Short, J. (2009). The Address Term Mate in Australian English: Is it Still a Masculine Term? Australian Journal of Linguistics, 29(2), 245-268.

Rheingold, H. (1993). The Virtual Community: Homesteading on the Electronic Frontier. AddisonWesley.

Rhodes, R. J. (2019). Personal Story Sharing as an Engagement Strategy to Promote Student Learning. GSE Perspective on Urban Education, 16(1), 1-2.

Riffe, D., Kim, S., \& Sobel, M. R. (2018). News Borrowing Revisited: A 50-Year Perspective. Journalism \& Mass Communication Quarterly, 95(4), 909-929.

Robinson, K. (1996). Of Mail-Order Brides and 'Boys' Own' Tales: Representations of AsianAustralian Marriages. Feminist Review, 52(1), 53-68.

Rodríguez-Fernández, M.-M., Sánchez-Amboage, E., \& Juanatey-Boga, O. (2019). Virtual Tourist Communities and Online Travel Communities. In M. Túñez-López, V.-A. MartínezFernández, X. López-García, X. Rúas-Araújo, \& F. Campos-Freire (Eds.), Communication: Innovation \& Quality (Vol. 154, pp. 435-446). Springer International Publishing.

Rohling, N., \& Rucinski, V. R. D. (2017). Teacher identity in the discourse of online comments: Reenunciation and resistance discourses. Calidoscópio, 15(3), 516-528.

Rosenberry, J. (2011). User support online anonymity despite increasing negativity. Newspaper Research Journal, 32(2), 6-18.

Rosenmann, A., \& Safir, M. P. (2006). Push factors of Internet sexuality: A preliminary study of online paraphilic empowerment. Journal of Homosexuality, 51(2), 71-92. 
Rosino, M. L., \& Hughey, M. W. (2017). Speaking through Silence: Racial Discourse and Identity Construction in Mass-mediated Debates on the "War on Drugs." Social Currents, 4(3), $246-264$.

Rucker, J. M., Murphy, M. C., \& Quintanilla, V. D. (2019). The immigrant labeling effect: The role of immigrant group labels in prejudice against noncitizens. Group Processes \& Intergroup Relations, 22(8), 1139-1160.

Rueda, A. M. (2012). Impoliteness in Spanish digital mass media. In L. Fernández Amaya, M. Padilla Cruz, M. Mejias Borrero, \& M. Relinque Barranca (Eds.), New perspectives on (im)politeness and interpersonal communication (pp. 91-113). Cambridge Scholars Publishing.

Ruiz, C., Domingo, D., Mico, J. L., Diaz-Noci, J., Masip, P., \& Meso, K. (2011). Public sphere 2.0? The democratic qualities of citizen debates in online newspapers. The International Journal of Press/Politics, 16(4), 463-487.

Salahshour, N. (2017). Representation of Immigration in New Zealand Print Media: A Critical Discourse Analysis [Ph.D Dissertation]. Victoria University of Wellington.

Santa Ana, O. (2009). Did you call in Mexican? The racial politics of Jay Leno immigrant jokes. Language in Society, 38(1), 23-45.

Santana, A. D. (2011). Online readers' comments represent new opinion pipeline. Newspaper Research Journal, 32(3), 66-80.

Santana, A. D. (2014). Virtuous or vitriolic: The effect of anonymity on civility in online newspaper reader comment boards. Journalism Practice, 8(1), 18-33.

Santana, A. D. (2015). Incivility dominates online comments on immigration. Newspaper Research Journal, 36(1), 92-107.

Sapolsky, B., Shafer, D., \& Kaye, B. (2011). Rating offensive words in three television program contexts. Mass Communication and Society, 14, 45-70.

Satchell, C., Shanks, G., Howard, S., \& Murphy, J. (2006). Knowing me, knowing you: End user perceptions of identity management systems. ECIS 2006 Proceedings, Göteborg, Sweden.

Schieffelin, B., Woolard, K. A., \& Kroskrity, P. V. (Eds.). (1998). Language ideologies: Practice and theory. Oxford University Press. 
Schiffrin, D. (1987). Discourse markers. Cambridge University Press.

Schiffrin, D. (1993). "Speaking for another" in sociolinguistic interviews: Alignments identities, and frames. In D. Tannen (Ed.), Framing in Discourse (pp. 231-263). Oxford University Press.

Schiffrin, D. (1996). Interactional Sociolinguistics. In S. L. McKay \& N. H. Hornberger (Eds.), Sociolinguistics and Language Teaching (pp. 307-328). Cambridge University Press.

Schiffrin, D., Tannen, D., \& Hamilton, H. (2001). Handbook of Discourse Analysis. Blackwell.

Schilling, N. (2013). Sociolinguistic fieldwork. Cambridge University Press.

Schneider, S., \& Kirsten, A. (2004). The Web as an object of study. New Media \& Society, 6(1), $114-122$.

Sclafani, J. (2008). The intertextual origins of public opinion: Constructing Ebonics in the New York Times. Discourse \& Society, 19(4), 507-527.

Seals, C. A. (2012). When a "non-issue" becomes an issue in discourse surrounding LGBT communities. Journal of Language and Sexuality, 1(2), 230-255.

Seals, C. A. (2013). Multingual identity development and negotiation amongst heritage language learners: A study of East European-American school children in the United States [Ph.D Dissertation]. Georgetown University.

Seals, C. A. (2017a). Dynamic family language policy: Heritage language socialization and strategic accommodation in the home. In J. Macalister \& S. H. Mirvahedi (Eds.), Family language policies in a multilingual world: Opportunities, challenges, and consequences (pp. 175-194). Routledge.

Seals, C. A. (2011). Gender and Memory: How Symbolic Capital and External Evaluation Affect Who Receives the Credit in Discourse. 346-366.

Seals, C. A. (2021). Interactional Sociolinguistics in Language and Sexuality Research: Benefits and Challenges. In J. Baxter \& J. Angouri (Eds.), Routledge Handbook of Language, Gender, and Sexuality (pp. 226-240). Routledge.

Seals, C. A. (2019). Choosing a Mother Tongue: Sociolinguistic identity politics in contemporary Ukrainian discourse. Multilingual Matters. https://doi.org/10.21832/SEALS4993 
Seals, C. A. (2017b). Positive and negative identity practices in heritage language education. International Journal of Multilingualism, 15(4), 329-348.

Seib, P. (2001). Going live: Getting the news right in a real-time, online world. Rowman \& Littlefield Publishers.

Severinson Eklundh, K. (2010). To quote or not to quote: Setting the context for computermediated dialogues. Language@Internet, 7, article 5.

Shafie, L. A., Nayan, S., \& Osman, N. (2012). Constructing Identity through Facebook Profiles: Online Identity and Visual Impression Management of University Students in Malaysia. Procedia - Social and Behavioral Sciences, 65, 134-140.

Silverstein, M. (1976). Shifters, linguistic categories, and cultural description. In K. Basso \& H. Selby (Eds.), Meaning in anthropology (pp. 11-55). University of New Mexico.

Silverstein, M. (2003). Indexical ordr and the dialectics of sociolinguistic life. Language and Communication, 23(3), 193-229.

Sindoni, M. G. (2013). Spoken and written discourse in online interactions: A multimodal approach. Routledge.

Singer, J. B. (2009). Separate Spaces: Discourse About the 2007 Scottish Elections on a National Newspaper Web Site. The International Journal of Press/Politics, 14(4), 477-496.

Smith, M., \& Kollock, P. (1999). Communities in Cyberspace. Cambridge University Press.

Spira, I. (2018). Chinese isms: The modernization of ideological discourse in China. Journal of Political Ideologies, 23(3), 283-298.

Stalnaker, R. (1974). Pragmatic Presupposition. In M. Munitz \& D. Unger (Eds.), Semantics and Philosophy (pp. 197-213). New York University Press.

Stommel, W. (2008). Chinese isms: Conversation Analysis and Community of Practice as Approaches to Studying Online Community. Language@internet, 5, article 5.

Stone, S. (1996). The War of Desire and Technology at the Close of the Mechanical Age. MIT Press.

Storberg-Walker, J., Johnson-Bailey, J., Bierema, L., \& Chapman, D. D. (2010). Five HRD Women Professor Discuss Wilson's Thai Bar Girls. 3693-3708. 
Stubbe, M., \& Holmes, J. (1995). You know, eh, and other "exasperating expressions": An analysis of social and stylistic variation in the use of pragmatic devices in a sample of New Zealand English. Language and Communication, 15(1), 63-88.

Szulc, L., \& Dhoest, A. (2013). The internet and sexual identity formation: Comparing Internet use before and after coming out. Communications, 38(4).

Tajfel, H. (1974). Social identity and intergroup behaviour. Social Science Information, 13(2), 6593.

Tajfel, H., \& Turner, J. C. (1986). "The Social Identity Theory of Intergroup Behaviour." In S. Worchel \& W. G. Austin (Eds.), Psychology of Intergroup Relations (pp. 7-24). Nelson-Hall.

Tannen, D. (1989). Talking Voices: Repetition, Dialogue, and Imagery in Conversational Discourse. Cambridge University Press.

Tannen, D. (1992). Interactional sociolinguistics. In W. Bright (Ed.), Oxford International Encyclopediaof Linguistics (Vol. 4, pp. 9-12). Oxford University Press.

Tannen, D. (2007). Talking Voices: Repetition, Dialogue, and Imagery in Conversational Discourse $\left(2^{\text {nd }}\right.$ ed.). Cambridge University Press.

Tannen, D. (2010). Abduction, dialogicality, and prior text: The taking on of voices in conversation discourse. Plenary Address, Linguistic Society of America Annual Meeting, Baltimore, Maryland.

Tannen, D., \& Trester, A. M. (Eds.). (2013). Discourse 2.0: Language and new media. Georgetown University Press.

Taylor, C. (1989). Sources of the self: The making of the modern identity. Harvard University Press.

Tedlock, D. (1995). The Dialogic Emergence of Culture. Illinois University Press.

Thetela, P. (2001). Critique discourses and ideology in newspaper reports: A discourse analysis of the South African press reports on the 1998 SADC's military intervention in Lesotho. Discourse \& Society, 12, 347-370.

Thompson, J. (1984). Studies in the Theory of Ideology. University of California Press.

Thompson, J. (1995). The media and modernity: A social theory of the media. Polity Press. 
Thurlow, C. (2001). Naming the "outsider within": Homophobic pejoratives and the verbal abuse of lesbian, gay and bisexual high-school pupils. Journal of Adolescence, 24, 25-38.

Thurlow, C., \& Jaworski, A. (2006). The Alchemy of the Upwardly Mobile: Symbolic Capital and the Stylization of Elites in Frequent-Flyer Programs. Discourse \& Society, 17, 131-167.

Thurlow, C., \& Jaworski, A. (2011). Tourism discourse: Language and banal globalization. Review of Applied Linguistics, 2, 285-312.

Thurlow, C., Lengel, L. B., \& Tomic, A. (2004). Computer-mediated communication: Social interaction and the internet. Sage Publications.

Thurlow, C., \& Mroczek, K. (2011). Fresh perspectives on new media sociolinguistics. In C. Thurlow \& K. Mroczek (Eds.), Digital discourse - Language in the new media (pp. XIXXLIV). OUP.

Thurlow, Crispin, \& Mroczek, K. R. (Eds.). (2011). Digital discourse: Language in the new media. Oxford University Press.

Thuy, D. H. (2019). A RELEVANCE-THEORETIC ANALYSIS OF YEAH AS A DISCOURSE MARKER. VNU Journal of Foreign Studies, 35(3).

Timmis, I. (2015). Pronouns and identity: A case study from a 1930s working-class community. ICAME Journal, 39(1), 111-134. https://doi.org/10.1515/icame-2015-0005

Tolino, S. (2014). Homsexuality in the Middle East, an analysis of dominant and competitive discourse. DEP, 25, 72-91.

Tracy, K., \& Robles, J. (2013). Everyday talk: Building and reflecting identities ( $2^{\text {nd }}$ ed.). The Guilford Press.

Trester, A. M. (2009). Discourse marker 'oh' as a means for realizing the identity potential of constructed dialogue in interaction. Journal of Sociolinguistics, 13(2), 147-168.

Triandafyllidou, A., \& Wodak, R. (2003). Conceptual and methodological questions in the study of collective identities. Journal of Language and Politics, 2(2), 205-223.

Trudgill, P. (2003). A glossary of sociolinguistics. Oxford University Press.

Turkle, S. (2011). Life on the screen: Identity in the age of the internet. Simon \& Schuster.

Turner, J. C. (1975). Social comparisaon and social identity: Some prospects for inintergroup behaviour. European Journal of Social Psychology, 5, 5-34. 
Twine, F. W. (2000). Racial Ideologies and Racial Methodologies. In F. W. Twine \& J. W. Warren (Eds.), Racing Research, Researching Race: Methodological Dilemmas in Critical Race Studies (pp. 1-34). New York University Press.

VanderStouwe, C. (2016). "Straight-ish": Constrained agency and the linguistic constructions of sexual identities, desires, and practices among men seeking men [Ph.D Dissertation]. University of California.

van Dijk, T. A. (2003). Ideology and discourse: A multidisciplinary introduction. http://www.discourses.org/UnpublishedArticles/Ideology\%20and\%20discourse.pdf van Dijk, T. A. (2011). Discourse studies: A multidisciplinary introduction (2 ${ }^{\text {nd }}$ ed.). SAGE Publications Ltd.

van Dijk, T. A. (2000). New(s) racism: A discourse analytical approach. In S. Cottle (Ed.), Ethnic minorities and the media (pp. 33-49). Open University Press.

van Dijk, T. A. (2019). Ideologies, Racism, Discourse. Debates on Immigration and Ethnic Issues. In J. T. Wal \& M. Verkuyten (Eds.), Comparative Perspectives on Racism ( $2^{\text {nd }}$ ed., pp. 91116). Routledge.

van Dijk, T. A. (1998). Opinions and ideologies in the press. In P. Garrett \& A. Bell (Eds.), Approaches to Media Discourse (pp. 21-63). Blackwell.

Van Leeuwen, T., \& Wodak, R. (1999). Legitimizing Immigration Control: A Discourse-Historical Analysis. Discourse Studies, 1(1), 83-118.

Vasalou, A., Joinson, A. N., \& Pitt, J. (2007). Constructing my online self: Avatars that increase self-focused attention. Proceedings of the SIGCHI Conference on Human Factors in Computing Systems - CHI '07, 445. https://doi.org/10.1145/1240624.1240696

Vásquez, C. (2019). Language, creativity and humour online. Routledge, Taylor \& Francis Group. Vine, B., Holmes, J., Marra, M., Pfeifer, D., \& Jackson, B. (2008). Exploring co-leadership talk through interactional sociolinguistics. Leadership, 4(3), 339-360.

Vitanova, G. (2010). Authoring the dialogic self: Gender, agency and language practices. John Benjamins Publishing Company.

Waksler, R. (2001). A New All in Conversation. American Speech, 76(2), 128-138. 
Walker, K. (2000). "It's difficult to hide it": The presentation of self on Internet home pages. Qualitative Sociology, 23(1), 99-120.

Wallsten, K., \& Tarsi, M. (2016). Persuasion from below? An experimental assessment of the impact of anonymous comments sections. Journalism Practice, 10(8), 1019-1040.

Wang, Y. F., Tsai, P. H., Goodman, D., \& Lin, M. Y. (2010). Agreement, acknowledgment, and alignment: The discourse-pragmatic functions of hao and dui in Taiwan Mandarin conversation. Discourse Studies, 12(2), 241-267.

Weber, P. (2014). Discussions in the comments section: Factors influencing participation and interactivity in online newspapers' reader comments. New Media \& Society, 16(6), 941957.

Weber, S., \& Mitchell, C. (2008). Imagining, Keyboarding, and Posting Identities: Young People and New Media Technologies. In D. Buckingham (Ed.), Youth, Identity, and Digital Media (pp. 25-48). The MIT Press.

Weedon, C. (1997). Feminist practice and poststructuralist theory (2nd ed.). Blackwell.

Weizman, E., \& Dori-Hacohen, G. (2017). On-line commenting on opinion editorials: A crosscultural examination of face work in the Washington Post (USA) and NRG (Israel). Discourse, Context \& Media, 19, 39-48.

Wenger, E. (1998). Communities of Practice: Learning, Meaning and Identity. Cambridge University Press.

Wertsch, J. V. (1993). Voices of the mind: A sociocultural approach to mediated action. Harvard University Press.

West, L., \& Trester, A. M. (2013). Facework on Facebook: Conversations on Social Media. In Discourse 2.0: Language and New Media (pp. 133-153). Georgetown University Press.

West, L. (2013). Facebook sharing: A sociolinguistic analysis of computer-mediated storytelling. 2(1), 1-13.

Whitsed, C., \& Volet, S. (2013). Positioning foreign English language teachers in the Japanese university context. Teachers and Teaching: Theory and Practice, 19(6), 717-735.

Wilkes, G. A. (1993). Exploring Australian English. ABC Books. 
Wilson, J. (2008). Thai bar girls and farang: A customized inter-cultural professional services market. Human Resource Development International, 11(4), 401-415.

Wilson, N. A. (2011). Leadership as Communicative Practice: The discursive construction of leadership and team identity in a New Zealand rugby team [Ph.D Dissertation]. Victoria University of Wellington.

Wodak, R., \& Boukala, S. (2015). (Supra)national Identity and Language: Rethinking National and European Migration Policies and the Linguistic Integration of Migrants. Annual Review of Applied Linguistics, 35, 253-273.

Woodhams, J. M. (2015). A CRITICAL REALIST STUDY OF POLITICAL IDENTITY IN AOTEAROA NEW ZEALAND: Materiality, Discourse and Context [Ph.D Dissertation]. Victoria University of Wellington.

Woodhams, J. M. (2019). Political Identity in Discourse: The Voices of New Zealand Voters. Springer International Publishing.

Woolard, K. A. (1998). Introduction: Language ideology as a field of inquiry. In B. B. Schieffelin, K. A. Woolard, \& P. V. Kroskrity (Eds.), Language ideologies: Practices and theory (pp. 3-47). Oxford University Press.

Yadlin-Segal, A. (2017). Constructing National Identity Online: The Case Study of \#Iranjeans on Twitter. International Journal of Communication, 11, 2760-2783.

Yang, H. S. (2008). The effects of the opinion and quality of user postings on Internet news readers' attitude toward the news issue. Korean Journal of Journalism \& Communication Studies, 52(2), 254-281.

Yoder, M. M., \& Johnstone, B. (2018). Unpacking a political icon: 'Bike lanes' and orders of indexicality. Discourse \& Communication, 12(2), 192-208.

Yuan, Zhou-min. (2018). Exploring Chinese college students' construction of online identity on the Sina Microblog. Discourse, Context \& Media, 26, 43-51.

Yuniawati, Y. (2019). Sharing Travel Experience Online: Motivation and Engagement. The 2nd Bali International Tourism Conference, Bali, Indonesia.

Zappavigna, M. (2011). Ambient affiliation: A linguistic perspective on Twitter. New Media \& Society, 13(5), 788-806. 
Zappavigna, M. (2012). The discourse of Twitter and social media: How we use language to create affiliation on the web. Continuum International Pub. Group.

Zappavigna, M. (2014). Enacting identity in microblogging through ambient affiliation. Discourse \& Communication, 8, 209-228.

Zhao, S. Y., Grasmuch, S., \& Martin, J. (2008). Identity Construction on Facebook: Digital empowerment in anchored relationships. Computers in Human Behavior, 24, 1816-1836.

Ziegele, M., Breiner, T., \& Quiring, O. (2014). What creates interactivity in online news discussions? An exploratory analysis of discussion factors in user comments on news items. Journal of Communication, 64, 1111-1138.

Zimman, L. (2014). The discursive construction of sex: Remaking and reclaiming the gendered body in talk about genitals among trans men. In J. Davis \& J. Raclaw (Eds.), Queer Excursions: Retheorizing Binaries in Language, Gender, and Sexuality (pp. 13-34). Oxford University Press. 


\section{Appendix A: Ethics Approval}

TE Whare wãnanga o te opoko o te iKa a MÃuI

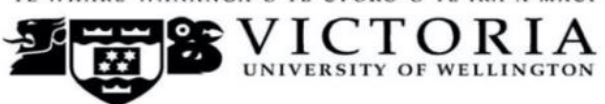

\section{MEMORANDUM}

Phone $0-4-4635480$

Email susan.corbett@vuw.ac.nz

\begin{tabular}{l|l}
\hline TO & Kai Liu \\
\hline COPY TO & Corinne Seals \\
\hline FROM & AProf Susan Corbett, Convener, Human Ethics Committee \\
\hline
\end{tabular}

\begin{tabular}{|c|c|}
\hline DATE & 9 May 2017 \\
\hline PAGES & 1 \\
\hline SUBJECT & $\begin{array}{l}\text { Ethics Approval: } \mathbf{2 4 5 6 3} \\
\text { Ideologies and identity construction in online reader comments: A } \\
\text { poststructuralist perspective }\end{array}$ \\
\hline
\end{tabular}

Thank you for your application for ethical approval, which has now been considered by the Standing Committee of the Human Ethics Committee.

Your application has been approved from the above date and this approval continues until 1 August 2019. If your data collection is not completed by this date you should apply to the Human Ethics Committee for an extension to this approval.

Best wishes with the research.

Kind regards

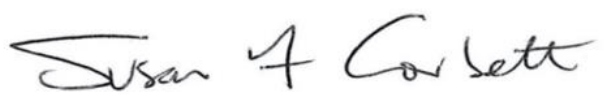

Susan Corbett

Convener, Victoria University Human Ethics Committee 


\section{Appendix B: Nodes Classification}

\section{Nodes classification}

\begin{tabular}{|c|c|c|c|}
\hline \multicolumn{4}{|c|}{ Topic of same-sex marriage } \\
\hline No. & parent node & child node & sub-child-node \\
\hline \multirow{3}{*}{1} & \multirow{3}{*}{$\begin{array}{l}\text { the legalisation of gay } \\
\text { marriage }\end{array}$} & & $\begin{array}{c}\text { marriage in } \\
\text { Germany }\end{array}$ \\
\hline & & $\begin{array}{l}\text { status of gay marriage across the } \\
\text { world }\end{array}$ & $\begin{array}{c}\text { marriage in New } \\
\text { Zealand \& } \\
\text { Australia }\end{array}$ \\
\hline & & $\begin{array}{c}\text { influence of the legalisation gay } \\
\text { marriage }\end{array}$ & step back \\
\hline \multirow{4}{*}{2} & \multirow{4}{*}{ politics-related issues } & comments about politicians & \\
\hline & & conscience vote & \\
\hline & & plebiscite & \\
\hline & & democracy & \\
\hline \multirow{4}{*}{3} & \multirow{4}{*}{ rights } & human rights & \\
\hline & & marriage rights & $\begin{array}{c}\text { marriage rights' } \\
\text { availability }\end{array}$ \\
\hline & & civil rights & \\
\hline & & constitutional rights & \\
\hline 4 & Mind your own business & & \\
\hline 5 & religion & & \\
\hline 6 & marriage equality & & \\
\hline 7 & morality & & \\
\hline \multirow{10}{*}{8} & \multirow{10}{*}{$\begin{array}{l}\text { attitudes toward gay \& same- } \\
\text { sex marriage }\end{array}$} & discrimination & \\
\hline & & hypocrisy & \\
\hline & & bigotry & homophobic \\
\hline & & \multirow{5}{*}{$\begin{array}{l}\text { reasons against same-sex } \\
\text { marriage }\end{array}$} & $\begin{array}{c}\text { protection of } \\
\text { children }\end{array}$ \\
\hline & & & $\begin{array}{c}\text { procreation } \\
\text { concern }\end{array}$ \\
\hline & & & $\begin{array}{c}\text { definition of } \\
\text { marriage }\end{array}$ \\
\hline & & & $\begin{array}{l}\text { marriage } \\
\text { institution }\end{array}$ \\
\hline & & & $\begin{array}{l}\text { sanctity of } \\
\text { marriage }\end{array}$ \\
\hline & & \multirow[t]{2}{*}{ freedom of speech } & $\begin{array}{l}\text { smoke and } \\
\text { mirrors }\end{array}$ \\
\hline & & & hate campaign \\
\hline 9 & culture & & \\
\hline 10 & gay wedding tourism & & \\
\hline
\end{tabular}




\section{Topic of travel}

\begin{tabular}{|c|c|c|c|}
\hline No. & Parent node & Child node & Sub-child-node \\
\hline 1 & insurance & travel insurance & \\
\hline 2 & Brexit & influence of Brexit & \\
\hline \multirow[t]{2}{*}{3} & safety concern & safety protection & \\
\hline & & electrical safety & \\
\hline \multirow[t]{2}{*}{4} & over-developing & against over-developing in New Plymouth & \\
\hline & & consequences of over-developing & \\
\hline 5 & showing sympathy & & \\
\hline 6 & religious values & & \\
\hline 7 & personal experiences & & \\
\hline \multirow{4}{*}{8} & \multirow{4}{*}{ airport chaos } & solution of airport chaos & \\
\hline & & passport control & \\
\hline & & world population & \\
\hline & & airport police & \\
\hline \multirow{9}{*}{9} & \multirow{9}{*}{ airlines } & comments on airlines & $\begin{array}{l}\text { comments on } \\
\text { United Airlines }\end{array}$ \\
\hline & & over-booking & \\
\hline & & polices of airlines & \\
\hline & & paying by weight & \\
\hline & & profit of airlines & $\begin{array}{l}\text { the way of doing } \\
\text { business }\end{array}$ \\
\hline & & playing by airlines' rules & buying miles \\
\hline & & & earning points \\
\hline & & & hidden city ticketing \\
\hline & & & miss flights \\
\hline \multirow[t]{3}{*}{10} & passenger rights & drag passenger off the airplane & $\begin{array}{c}\text { influence of } \\
\text { dragging passenger } \\
\text { off airplane }\end{array}$ \\
\hline & & & legality \\
\hline & & & law suit \\
\hline \multirow[t]{2}{*}{11} & entertainment & animal attractions & \\
\hline & & warning tourists avoid dangerous activities & \\
\hline \multirow[t]{2}{*}{12} & $\begin{array}{l}\text { customer-related } \\
\text { issues }\end{array}$ & customer assault & \\
\hline & & customer service & $\begin{array}{c}\text { terrible UK } \\
\text { customer service }\end{array}$ \\
\hline \multirow[t]{4}{*}{13} & travelling items & zip off pants & \\
\hline & & books & \\
\hline & & tripod & \\
\hline & & money belt & \\
\hline \multirow[t]{4}{*}{14} & visa issue & procedure of applying a visa & \\
\hline & & comments about the UK visa & \\
\hline & & comments about France & camp in France \\
\hline & & comments about Spain & $\begin{array}{l}\text { comments about } \\
\text { Majorca island }\end{array}$ \\
\hline
\end{tabular}




\begin{tabular}{|c|c|c|c|}
\hline \multirow[t]{13}{*}{15} & \multirow[t]{13}{*}{$\begin{array}{c}\text { comments about a } \\
\text { place }\end{array}$} & & $\begin{array}{c}\text { comments about } \\
\text { Spain's Maresue } \\
\text { beach }\end{array}$ \\
\hline & & & $\begin{array}{l}\text { comments about } \\
\text { cities of Spain }\end{array}$ \\
\hline & & & $\begin{array}{c}\text { importance of } \\
\text { tourism in Spain's } \\
\text { finance }\end{array}$ \\
\hline & & comments about Thailand & \\
\hline & & & $\begin{array}{c}\text { complains about the } \\
\text { UK }\end{array}$ \\
\hline & & & $\begin{array}{c}\text { comments about food } \\
\text { at Whitby }\end{array}$ \\
\hline & & comments about the UK & $\begin{array}{c}\text { accommodation in } \\
\text { Whitby }\end{array}$ \\
\hline & & & $\begin{array}{c}\text { comments about } \\
\text { Whitby }\end{array}$ \\
\hline & & comments about India & expressing love to India \\
\hline & & & complains about India \\
\hline & & & $\begin{array}{l}\text { good things about } \\
\text { New Plymouth }\end{array}$ \\
\hline & & comments about New Zealand & $\begin{array}{c}\text { real-estate ruins New } \\
\text { Plymouth }\end{array}$ \\
\hline & & & $\begin{array}{l}\text { poor infrastructure } \\
\text { of New Plymouth }\end{array}$ \\
\hline \multirow{10}{*}{16} & \multirow{10}{*}{$\begin{array}{l}\text { comments about } \\
\text { people }\end{array}$} & comments about British & \\
\hline & & comments about Spanish & \\
\hline & & comments about German & \\
\hline & & $\begin{array}{l}\text { comments about tourists who are } \\
\text { interested in animal attractions }\end{array}$ & \\
\hline & & $\begin{array}{l}\text { refugees } \\
\end{array}$ & \\
\hline & & sexism on women & \\
\hline & & generosity of strangers & \\
\hline & & taking advantage of others' hospitality & \\
\hline & & charity & \\
\hline & & complains about obese people & $\begin{array}{l}\text { paying for extra } \\
\text { seats }\end{array}$ \\
\hline \multirow{5}{*}{17} & \multirow{5}{*}{ flight } & flight delay & influence of fog \\
\hline & & The alcohol prohibition & $\begin{array}{c}\text { disagreement with } \\
\text { the alcohol } \\
\text { prohibition }\end{array}$ \\
\hline & & & $\begin{array}{c}\mathrm{n} \text { favour of the } \\
\text { alcohol prohibition }\end{array}$ \\
\hline & & & $\begin{array}{c}\text { influences of } \\
\text { providing alcohol in } \\
\text { the airplane }\end{array}$ \\
\hline & & & $\begin{array}{l}\text { suggestion about } \\
\text { dealing with } \\
\text { alcoholic }\end{array}$ \\
\hline
\end{tabular}




\begin{tabular}{|c|c|c|c|}
\hline & & seat space of airplanes & $\begin{array}{l}\text { change flight seat } \\
\text { space }\end{array}$ \\
\hline & & & $\begin{array}{l}\text { secret button that } \\
\text { helps to give more } \\
\text { space }\end{array}$ \\
\hline \multicolumn{4}{|c|}{ jet-service } \\
\hline \multirow[t]{6}{*}{18} & \multirow[t]{6}{*}{$\begin{array}{l}\text { suggestions and tips } \\
\text { on travelling }\end{array}$} & suggestion of holiday destinations & $\begin{array}{l}\text { suggest not going to } \\
\text { UK }\end{array}$ \\
\hline & & $\begin{array}{l}\text { suggestion of getting cheaper seats of } \\
\text { airlines }\end{array}$ & \\
\hline & & suggestion of travelling alone & \\
\hline & & showing appreciation of others' suggestions & \\
\hline & & tips of travelling around Spain & \\
\hline & & tips of travelling in Whitby & \\
\hline \multirow{3}{*}{19} & \multirow{3}{*}{$\begin{array}{l}\text { Criticisms on the } \\
\text { article structure }\end{array}$} & doubting the accuracy of the article & \\
\hline & & \multirow{2}{*}{$\begin{array}{l}\text { responses to the shared tricks of } \\
\text { upgrading class }\end{array}$} & $\begin{array}{c}\text { agreement with the } \\
\text { tricks of upgrading } \\
\text { class }\end{array}$ \\
\hline & & & $\begin{array}{c}\text { disagreement with } \\
\text { the tricks of } \\
\text { upgrading class }\end{array}$ \\
\hline 20 & cultural differences & & \\
\hline
\end{tabular}




\section{Appendix C: Data Set}

Note: For access to the full qualitative data set, including all the news articles and comments collected from the target online news websites, see the CD attached. 